MÁRIO LUIZ DE OLIVEIRA MEDRANO

\title{
Avaliação de métodos dinâmicos baseados em nega e repique elástico: estudo de caso
}

Orientador: Profa. Dra. Cristina de Hollanda Cavalcanti Tsuha 



\section{Avaliação de métodos dinâmicos baseados em nega e repique elástico: estudo de caso}

Dissertação apresentada à Escola de Engenharia de São Carlos da Universidade de São Paulo, como parte dos requisitos para obtenção do Título de Mestre em Ciências, Programa de Pós-Graduação em Geotecnia.

Orientador: Profa. Dra. Cristina de Hollanda Cavalcanti Tsuha

\section{VERSÃO CORRIGIDA}

ORIGINAL SE ENCONTRA DISPONIVEL NA UNIDADE QUE ALOJA O PROGRAMA 
AUTORIZO A REPRODUÇÃO TOTAL OU PARCIAL DESTE TRABALHO POR QUALQUER MEIO CONVENCIONAL OU ELETRONICO, PARA FINS DE ESTUDO DE PESQUISA, DESDE QUE CITADA A FONTE.

$\mathrm{Da}$

de Oliveira Medrano, Mário Luiz

Avaliação de métodos dinâmicos baseados em nega e repique elástico: estudo de caso / Mário Luiz de Oliveira Medrano; orientadora Cristina de Hollada Cavalcanti Tsuha. São Carlos, 2014.

Dissertação (Mestrado) - Programa de Pós-Graduação e Área de Concentração em Geotecnia -- Escola de Engenharia de São Carlos da Universidade de São Paulo, 2014 .

1. Repique Elástico. 2. Ensaio de Carregamento Dinâmico. 3. Fórmulas Dinâmicas. I. Título. 


\section{FOLHA DE JULGAMENTO}

Candidato: Engenheiro MÁRIO LUIZ DE OLIVEIRA MEDRANO.

Título da dissertação: "Avaliação de métodos dinâmicos baseados em nega e repique elástico: estudo de caso".

Data da defesa: 21/02/2014

\section{Comissão Julgadora:}

Profa. Dra. Cristina de Hollanda Cavalcanti Tsuha (Orientador) (Escola de Engenharia de São Carlos/EESC)

Prof. Titular Faiçal Massad

(Escola Politécnica/USP)

Prof. Dr. Alexandre José Soares Miná

(Universidade Federal da Paraíba/UFPB)

\section{Resultado:}

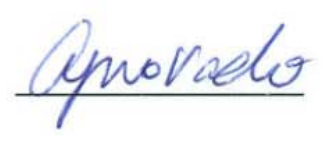

$$
\text { Aprovado }
$$

Aprovado

Coordenador do Programa de Pós-Graduação em Geotecnia:

Prof. Titular Osni José Pejon

Presidente da Comissão de Pós-Graduação:

Prof. Titular Denis Vinicius Coury 

Aos meus pais, Eliziara e José Luiz. Ao meu irmão, Leonardo. 



\section{AGRADECIMENTOS}

Agradeço a Deus, pelo dom da vida e por ter me sustentando durante todo o período do desenvolvimento do trabalho. Glória e honra seja dada ao seu nome.

A minha mãe Eliziara pelo apoio incondicional. Aos meus pais pela minha formação, caráter e princípios que permitiram chegar até aqui. Ao meu irmão Leonardo pelo apoio e estímulo.

A Professora Cristina Tsuha por ter acreditado, incentivado e estimulado. Muito obrigado pela sua confiança e paciência.

Ao Professor Nelson Aoki pela orientação nos primeiros passos na Engenharia de Fundações.

A Professora Teresinha Bonuccelli por despertar o meu interesse pela área de geotecnia, e por me incentivar sempre. Agradeço pela amizade.

Ao Professor Jasson Figueiredo Filho, a amizade e por me ensinar os primeiros passos na carreira acadêmica.

Ao Professor Jose Carlos Cintra pelos constantes conversas e inquietações na área, bem como pela amizade.

Aos amigos Alexandre Miná e Heraldo Pitanga por abrir importantes portas no início da carreira.

A empresa SCAC Fundações e Estruturas Ltda. por abrir as primeiras portas de trabalho, pelo incentivo, pela concessão de dados. Aos amigos Henrique Grahovec, Alexandre Nápoli, Diogo Rezende, Jose Antonio Becaleti, Rosangela Perez e Edvaldo Fernandez Cassundé.

A Themag Engenharia e Gerenciamento Ltda. pelo apoio na fase final dos estudos, em especial a Tarcísio Celestino e Luiz Ferreira Vaz. Aos amigos que sempre incentivam: Alba, Marcos Vita, João Pimenta, Agnaldo Oliveira, Rodrigo Augusto Alves e Fernando Akira.

A Primeira Igreja Batista em São Carlos pelas orações, e ao PG de Osasco pelo companheirismo e orações durante essa fase. A família do Carlos Ficher pelo incentivo.

Aos amigos da pós-graduação pelo constante apoio e ajuda em muitas vezes: Francisco Avesani, Jorge Silva e Marcos Vinicius.

Aos funcionários e professores do Departamento de Geotecnia da EESC/USP, agradeço pelos ensinamentos e apoio. 

"O SENHOR é o meu pastor e nada me faltará." Salmos 23:1 



\section{RESUMO}

MEDRANO, M. L. O. Avaliação de métodos dinâmicos baseados em nega e repique elástico: estudo de caso. 2014. 236f. Dissertação - Escola de Engenharia de São Carlos, Universidade de São Paulo, São Carlos, 2014.

Em obras de fundações por estacas cravadas, os diferentes comprimentos finais das estacas refletem a variabilidade natural do terreno, e variam de acordo com o critério de paralização da cravação, normalmente baseado em medidas de nega e repique elástico. Pouco se tem aproveitado desses registros para o controle da resistência mobilizada na fundação ao final da cravação, devido à limitação da aplicação das fórmulas dinâmicas e ao desconhecimento de alguns parâmetros. Em muitos casos de controle de capacidade de carga, apenas é realizada a aferição de um fator de segurança pontual, obtido via prova de carga. Neste trabalho, é apresentado um procedimento de controle de capacidade de carga de fundações por estacas cravadas, baseado em registros de nega e repique elástico, a partir de fórmulas dinâmicas, que possibilitam a estimativa da resistência mobilizada ao final da cravação em todo o universo de estacas de uma obra. Este procedimento proposto foi aplicado em um estudo de caso de uma obra em um porto em Santa Catarina. Nesta obra foram cravadas 2506 estacas pré-moldadas de concreto, controladas por nega e repique elástico, registrados em todas as estacas no final da cravação. Neste conjunto de estacas foram executadas 74 provas de carga dinâmica, com energia crescente, e quatro provas de carga estática. Neste caso de obra controlada, os resultados mostraram que o procedimento adotado, baseado na utilização de fórmulas dinâmicas, com parâmetros calibrados a partir dos resultados das provas de carga dinâmica, permitiu estimar valores de resistência mobilizada ao final da cravação das 2506 estacas da obra, que apresentaram um valor médio próximo ao valor médio encontrado nas 74 estacas ensaiadas. Além disso, o coeficiente de variação dos valores de resistência mobilizada de todas as estacas da obra foi da ordem de $16,0 \%$, similar ao coeficiente de variação de $14,7 \%$, obtido nos resultados das provas de carga dinâmica.

Palavras chaves: repique elástico, ensaio de carregamento dinâmico e fórmulas dinâmicas. 



\begin{abstract}
MEDRANO, M. L. O. Evaluation of dynamic methods based on set and rebound elastic: a case study. 2014. $236 \mathrm{f}$. Dissertation - School of Engineering at Sao Carlos, University of Sao Paulo, Sao Carlos, 2014.

The different final lengths of driven piles reflect the natural variability of the soil, and are dependent of the driving controls based in the measurements of the final set and elastic rebound. Normally these measurements are not used to predict the ultimate capacity of pile foundations, at the end of driving, due to the limitation of the dynamic formulas and the lack of some parameters. In many cases, the pile capacity control is based on a determination of a single safety factor, obtained from pile load tests. In this work, it is proposed a procedure to control the ultimate capacity of driven piles, based on the results of the final set and the elastic rebound, and dynamic formulas, which allow the estimation of the mobilized resistance at the end of driving of all piles driven in a particular project. This procedure was applied in a case study of a port in Santa Catarina. In this case, 2506 precast concrete piles were driven, and controlled by the elastic rebound, recorded at the end of driving. Also, dynamic load tests, with increasing energy, were performed on 74 piles, and static load tests were carried out on four piles. The results showed that this procedure adopted, based on the use of dynamic formulas calibrated using the results of dynamic load tests, is capable to estimate the values of mobilized resistance along all piles at the end of driving. The average result of the mobilized resistance of the 2506 piles was close to the average value found by the results of the 74 pile dynamic load tests. Also, the coefficient of variation of the mobilized resistance of all piles was around $16.0 \%$, similar to the coefficient of variation of $14.7 \%$, obtained by the dynamic load tests.
\end{abstract}

Keywords: pile elastic rebound, dynamic load testing and dynamic formula. 



\section{LISTA DE FIGURAS}

Figura 2.1- Geometria da superfície resistente na Formação Barreiras (Aoki, 2002).

Figura 2.2 - Analise estatística dos comprimentos cravados e da resistência do estaqueamento (Aoki, 2002). 38

Figura 2.3 - Superfície resistente no projeto de Salvador/BA (Foá, 2001). 38

Figura 2.4- a) Marcações definidas no fuste da estaca para elaboração do diagrama de cravação e b) exemplo de diagrama de campo.

Figura 2.5 - Arranjo da montagem de uma prova de carga estática. 43

Figura 2.6 - Interpretação dos resultados das PCE (Velloso e Lopes, 2010). 45

Figura 2.7 - Gráfico de controle de capacidade de carga de campo, para o martelo Delmag D30 (Wang, 1992).

Figura 2.8 - Gráfico da resistência versus deslocamento para um golpe (Whitaker, 1976).... 49

Figura 2.9 - Diagrama de distribuição de resistência genérico (Velloso, 1987). .....................53

Figura 2.10 - Transformação da curva de resistência total em estática (Cintra et al., 2013)...55

Figura 2.11: Comparação entre os resultados de PC e valores de resistência mobilizada baseado no Energy Approach (Paikowsky e Chernauskas, 1992)..... .59

Figura 2.12 - Registro de nega e repique (Chellis, 1951 apud Rosa, 2000). 62

Figura 2.13- Obtenção de nega e repique através do método de Chellis (Miná, 2005). 63

Figura 2.14 - Medidas de deslocamento do topo da estaca e martelo (Machado, 1995 apud Cummings, 1940).

Figura 2.15 - Esquema da medição com o Electro-Optical Displacement Meter(Machado, 1995 apud Sakimoto et al., 1985). 64

Figura 2.16 - O sistema Dynamic Piling Analyser - DPA (Uto et al. 1989)..........................64

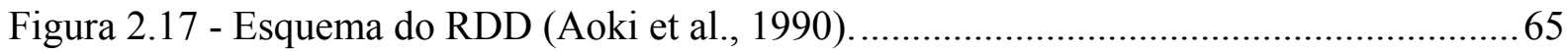

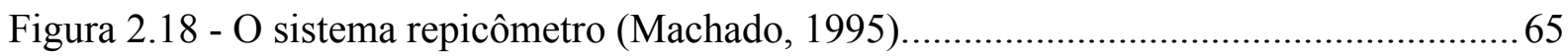

Figura2.19 - O equipamento optical rebound analyzer - PDR (Oliveira et al., 2010). ..........66

Figura2.20 - Pile Driving Monitoring - Foundation QA (2010).........................................66

Figura 2.21 - Dispositivo interno à estaca para medição do quake - C3 (Souza Filho e Abreu, 1990 apud Rosa, 2000). .68

Figura 2.22 - Relação entre a resistência da estaca e quake da ponta $\left(\mathrm{Q}_{\mathrm{p}}\right)$ e lateral $\left(Q_{L}\right)$ (Danziger, 1990).

Figura 2.23 - Instalação de deflectômetro e acelerômetro em estaca do tipo hélice continua 
(Rosa, 2013). 70

Figura 2.24 - Equipamento de aquisição de dados na PCD (Rosa, 2013)............................. 72

Figura 2.25 - Execução com martelo hidráulico em camisa metálica (Rosa, 2013).............. 72

Figura 2.26 - Curva resistência mobilizada por deslocamento para PCD com energia

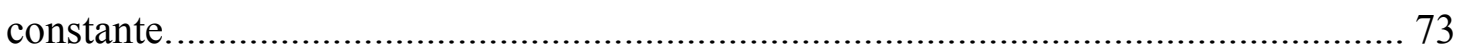

Figura 2.27 - Curva resistência mobilizada por deslocamento para PCD com energia crescente. 75

Figura 2.28 - Controle de altura na execução da PCD com energia crescente (Miná, 2005). 76

Figura 2.29: Obtenção de nega e repique para diferentes níveis de energia aplicado (Miná,

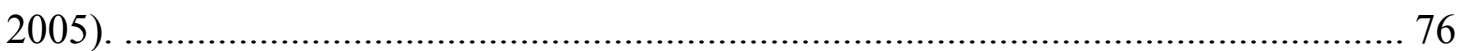

Figura 2.30 - Formação da Onda de Impacto (Niyama, 1991).............................................. 78

Figura 2.31: Registro das curvas de força e velocidade medido em campo (Soares, 2002)... 80

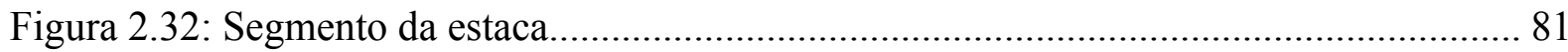

Figura 2.33 - Idealização de Smith para resolução da equação da onda para estacas (Smith, 1960). 84

Figura 2.34 - Representação da parcela estática da reação do solo a cravação. 85

Figura 2.35 - Representação da parcela não estática da reação do solo a cravação. 86

Figura 2.36 - Fatores de amortecimento dinâmico em função do tipo de solo na ponta da estaca (Pereira, 2003 apud Rausche et al., 1985, Goble et al., 1975). 89

Figura 2.37 - Diagrama da relação $S$ em função do tempo (Paraíso e Costa, 2010). 92

Figura 2.38 - Curvas de $Q(t) / Q_{0}$ em função do tempo (Paraíso e Costa, 2010). 94

Figura 2.39 - Comparação das curvas de carga-deslocamento entre Ensaios de Carregamento Dinâmico com Energia Crescente e Prova de Carga Estática (Aoki e Niyama, 1991).95 Figura 2.40 - Resultados dos estudos de comparação entre resultados de provas de carga dinâmica e estática (Likins e Rausche, 2004).............................................................. 95

Figura 2.41 - Método de extrapolação proposto por Chin-Kondner (1971). ........................... 96

Figura 2.42 - Definição da carga de ruptura convencionada................................................. 97

Figura 2.43 - Método gráfico de Van der Veen (1953) ........................................................... 98

Figura 2.44 - Método gráfico de Mazurkiewicz (1972). ....................................................... 99

Figura 2.45 - Representação do limite inferior e superior do atrito lateral. .......................... 100

Figura 2.46 - Funções existentes entre atrito lateral e ponta em função do recalque $-1^{\circ}$. e $2^{\circ}$. Relação de Cambefort (1964). 100 
Figura 2.47 - Curva carga-recalque teórica a partir da instrumentação de topo (Massad e Lazo, 1998).

Figura 2.46 - Curvas adimensionalizadas - comportamento da estaca sendo comandada pela resistência do elemento estrutural. 107

Figura 2.47 - Curvas adimensionalizadas - comportamento da estaca sendo comandada pela resistência do solo (Aoki e Cintra, 1997).

Figura 3.1 - Implantação da obra e dos módulos. 109

Figura 3.2 - Seção geológico-geotécnica do depósito sedimentar (Marques e Lacerda, 2004).

Figura 3.3 - Perfil de sondagem SP32 (Marques e Lacerda, 2004).

Figura 3.4 - Projeto de fundações do porto (módulo típico)......

Figura 3.5 - Vista aérea da execução do projeto (SCAC, 2012). 115

Figura 3.6 - Diagrama de cravação em comparação com o perfil de sondagem mais próximo módulo 18.

Figura 3.7 - Modelo da ficha de cravação registrado na obra. 116

Figura 3.8 - Registro dos sinais de nega e repique elástico durante a execução da PCD com energia crescente. 117

Figura 3.9 - Esquema (planta e perfil) da prova de carga estática. 121

Figura 3.10 - Curva carga aplicada $\mathrm{x}$ deslocamento para 4 PCE. 122

Figura4.1 - Comparação entre os valores de $N_{S P T}$ e previsão pelos métodos semi-empíricos para a sondagem mais próxima (SP-02) e próximas (SM-01, SP-03, SP-17 e SP-24) para a estaca E114M02. 128

Figura4.2 - Comparação entre os valores de $N_{S P T}$ e previsão pelos métodos semi-empíricos para a sondagem mais próxima (SP-25) e próximas (SP-03, SP-04, SP-17 e SP-18) para a estaca teste E018M04.

Figura4.3 - Comparação entre os valores de $N_{S P T}$ e previsão pelos métodos semi-empíricos para a sondagem mais próxima (SP-08) e próximas (SP-07, SP-09, SM-20 e SP-27) para a estaca teste E125M09.

Figura4.4 - Comparação entre os valores de $N_{S P T}$ e previsão pelos métodos semi-empíricos para a sondagem mais próxima (SP-30) e próximas (SP-13, SP-14, SP-22 e SP-23) para a estaca teste E113M15..... 
Figura 4.5 - Resultados da prova de carga dinâmica em três estacas testes.

Figura 4.6 - Gráfico de quake do solo ( $C 3$ ) versus $E M X / E_{P O T}$ a partir da retro analise da fórmula de Chellis -estaca n ${ }^{\circ}$. E114 M02 136

Figura 4.7 - Comparação entre as resistências mobilizadas obtidas pelos ECD e fórmulas dinâmicas - estaca nº. E114M02. 136

Figura 4.8 - Gráfico de quake do solo ( $C 3$ ) versus $E M X / E_{P O T}$ a partir da retroanálise da fórmula de Chellis -estaca n ${ }^{\circ}$ E018 M04. 138

Figura4.9 -Comparação entre as resistências mobilizadas obtidas pelos ECD e fórmulas dinâmicas - estaca n ${ }^{\circ}$. E018 M04. 138

Figura4.10 - Gráfico de quake do solo (C3) versus $E M X, E_{P O T}$ a partir da retroanálise da fórmula de Chellis - estaca ${ }^{\circ}$. E125M09. 140

Figura 4.11 - Comparação entre as resistências mobilizadas obtidas pelos ECD e fórmulas dinâmicas - estaca $n^{\circ}$. E125 M09.

Figura 4.12 - Curvas carga $\mathrm{x}$ deslocamento das provas de carga. 142

Figura 4.13 - Curvas de aplicação do método da rigidez para as estacas n . E114 M02, E018 M04, E125 M09 e E113 M15 - PCE. 144

Figura4.14 - Aplicação dos métodos da NBR 6122 (2010) e Davisson (1972) para as estacas testes. 150

Figura 4.15 - Aplicação do método de Van der Veen (1953) modificado por Aoki (1979) para as PC (E114 M02, E018 M04, E125 M09 e E113 M15).

Figura 4.16 - Aplicação do método de Mazurkiewicz (1972) as PC das estacas n ${ }^{\circ}$ E114 M02 e E125 M09. 152

Figura 4.17: Aplicação do método de Chin (1970) para as PC. 152

Figura 4.18 - Comparação de capacidade de carga em função das previsões ( $N_{S P T}$ e $N_{E Q U I V}$ ), dos resultados da PCE, PCD, registros de nega e repique- estaca ${ }^{\circ}$. E114M02...... 155 Figura4.19 - Comparação das parcelas de resistência lateral e ponta em função das previsões ( $N_{S P T}$ e $\left.N_{E Q U I V}\right)$, dos resultados da PCE, PCD, registros de nega e repique- estaca $\mathrm{n}^{\circ}$. E114M02. 156

Figura 4.20 - Comparação da carga de ruptura ( $R T$ ) obtida pelo PCD e PCE em relação as previsões dos métodos semi-empírico - estaca $\mathrm{n}^{\circ}$. E114M02. 157 
Figura4.21 - Comparação de capacidade de carga em função das previsões ( ${ }^{N_{S P T}} \mathrm{e}^{N_{E Q U I V}}$ ), dos resultados da PCE, PCD, registros de nega e repique- Estaca $n^{\circ}$. E018 M04..... 158 Figura 4.22 - Comparação das parcelas de resistência lateral e ponta em função das previsões ( $N_{S P T}$ e $\left.N_{E Q U I V}\right)$, dos resultados da PCE, PCD, registros de nega e repique - estaca $n^{\circ}$. E018 M04. 158

Figura 4.23 - Comparação da carga de ruptura (RT) obtida pelo PCD e PCE em relação as previsões por métodos semi-empírico - Estaca nº. E018 M04.

Figura4.24 - Comparação de capacidade de carga em função das previsões ( $N_{S P T} \mathrm{e}^{N_{E Q U I V}}$ ), dos resultados da PCE, PCD, registros de nega e repique - estaca ${ }^{\circ}$. E125 M09... 160 Figura4.25 - Comparação das parcelas de resistência lateral e ponta em função das previsões ( $\left.N_{S P T} \mathrm{e}^{N_{E Q U I V}}\right)$, dos resultados da PCE, PCD, registros de nega e repique - estaca $n^{\circ}$. E125 M09. 160

Figura4.26 - Comparação da carga de ruptura (RT) obtida pelo PCD e PCE em relação as previsões por métodos semi-empírico - Estaca n. E125 M09. 161

Figura 4.27 - Comparação de capacidade de carga em função das previsões ( $N_{S P T} \mathrm{e}^{N_{E Q U I V}}$ ), dos resultados da PCE, PCD, registros de nega e repique - Estaca ${ }^{\circ}$. E113 M15.... 162 Figura4.28 - Comparação das parcelas de resistência lateral e ponta em função das previsões ( $\left.N_{S P T} \mathrm{e}^{N_{E Q U I V}}\right)$, dos resultados da PCE, PCD, registros de nega e repique - Estaca $\mathrm{n}^{\circ}$. E113 M15. 162

Figura 4.29 -Comparação da carga de ruptura (RT) obtida pelo PCD e PCE em relação as previsões por métodos semi-empírico - Estaca $n^{\circ}$. E113 M15.

Figura 4.30 - Histograma da quantidade de ensaios realizados em função da idade relativa ao momento final da cravação. 164

Figura4.31 - Valores médios, mínimos e máximos de RMX em função do setup de cravação das estacas $-\mathrm{n}=74 \mathrm{ECD}$. 165

Figura4.32 - Valores médios da $R M X, P R_{R M X}, R S$ e $R T$ em função da idade. 165

Figura4.33 - Curva de tensões de compressão ( $C S X$ ) pela energia liquida ( $E M X$ ) para os ECD para os diferentes materiais na ponta da estaca. 167

Figura 4.34 - Curvas adimensionalizada de $R M X / R E$ pelo $D M X / \Phi$ para a região doM01 ao M08, M09/M10 e do M11 ao M18. 
Figura4.35 - Curva de eficiência para diferentes níveis de energia potencial aplicado equipamento BE-02 e BE-06.

Figura4.36 - Curva de quake do solo ( $C 3$ ) em função dos diferentes níveis de energia liquida aplicado, com ajuste médio - equipamento BE-02.

Figura4.37 - Comparativo entre as curvas médias de C3 por EMX para os equipamentos. 172

Figura 4.38 - Relação entre $E M X / E R E$ em função de $R M X$ para estacas verticais (n $=50$ estacas) e inclinadas $(\mathrm{n}=24$ estacas $)$.

Figura 4.39 - Comparação entre $R M X$ e $P R_{R M X}$ em função da profundidade para estacas verticais e inclinadas.

Figura 4.40 - Correlação entre o fator de amortecimento em função da energia líquida...... 175

Figura 4.41 - Comparação entre os valores de $P R_{R M X}$ obtidos pelos PCD em relação a previsão pelos métodos semi-empírico $-\mathrm{n}=74$ estacas. 176

Figura 4.42 - Comparação entre a parcela de atrito lateral (RL) obtida na análise CAPWAP do PCD pelo previsto a partir dos métodos semi-empírico $-\mathrm{n}=74$ estacas.

Figura4.43 - Comparação da parcela de ponta (RP) prevista com os resultados obtidos na análise CAPWAP nos $\mathrm{PCD}-\mathrm{n}=74$ estacas. 178

Figura4.44 - Retro análise dos valores de $N_{R P}$ a partir da $R P$ avaliada pelas analises CAPWAP em comparação com os $N_{S P T}$ na ponta das estacas. 179

Figura 4.45- Critério de embuchamento de estacas sob areia compacta (Jardine e Chow, 1996). 180

Figura 4.46- Comparação dos valores medidos da resistência de ponta com as previsões considerando-se ponta aberta e fechada.

Figura 4.47- Influências da espessura e do diâmetro da estaca na altura da bucha (Niyama, 1992).

Figura 4.48- Comparação dos valores medidos da resistência de ponta com as previsões considerando-se:1 - ponta aberta (sem o efeito do embuchamento), 2 - ponta igual à seção do anel mais atrito interno na bucha e 3 - ponta fechada.

Figura4.49 - Restituição da curva resistência mobilizada por deslocamento a partir dos registros de nega e repique elástico (estacas E132 M18, E124 M15, E122 M07 e E126 M03) 
Figura4.50 - Comparação entre o fator $f$ pelos resultados das previsões e analises CAPWAP

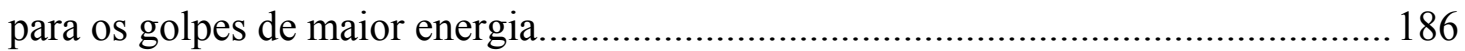

Figura4.51 - Correlação entre o fator $f_{\mathrm{e}} C 3$ em função do comprimento cravado.............. 186

Figura4.52 - Retroanálise a partir dos PCD de $C 3_{C H}$ em função de $E M X$ - estacas E132 M18,

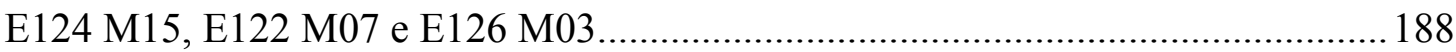

Figura4.53 - Comparação entre os valores de $C 3_{C P W}$ por $C 3_{C H}, C 3_{C H, R}$ obtidos por retro

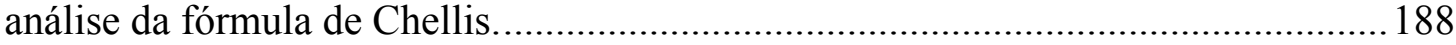

Figura4.54 - Relação entre $E M X$ em função de $C 3_{C P W}$ e retroanalisado $C 3_{C H, R} \ldots \ldots \ldots \ldots \ldots \ldots . . . . . . .189$

Figura4.55 - Valores de $C 3_{C H, R}$ para energia de cravação $\left(e \cdot E_{P O T}\right)$, no final de cravação. .. 190

Figura 4.56 - Comparação entre a resistência mobilizada por quake do solo com a observação

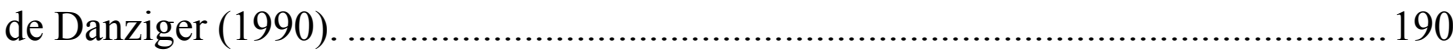

Figura4.57: Adimensionalização entre $R P_{U L T} / P R_{R M X}$ pelos valores de $C 3_{C H, U} / D_{K+S} \ldots \ldots \ldots . . . .191$

Figura4.58: Comparação entre os resultados entre $R M_{C H}$ e $R M X$................................... 192

Figura4.59: Comparação entre as resistências mobilizadas obtidas pelo ECD e repique elástico interpretados por Chellis - todos os golpes.

Figura4.60 - Distribuição de frequências para os valores de resistência mobilizada obtida pela fórmula de Chellis.

Figura4.61 - Relação entre os registros dinâmicos $(S+D)$ e a energia líquida. 195

Figura4.62 - Medidas de nega e repique elástico coletados nos diversos níveis de energia aplicados. 196

Figura4.63 - Calibração do parâmetro $\xi$ a partir dos golpes aplicados em diversos níveis de energia. 196

Figura4.64: Comparação entre os resultados entre $R M_{S M M}$ e $R M X$ 197

Figura4.65 - Comparação entre os valores de resistência mobilizada pela fórmula dinâmica de Smith com o ECD - análise CASE 197

Figura4.66: Variação dos valores de $\xi$ em função do setup 198

Figura4.67 - Distribuição de frequências para os valores de resistência mobilizada obtida pela fórmula de Smith modificada. 198

Figura 4.68 - Distribuição de frequências para os valores de $R M X$ obtidos nas PCD. 199 
Figura4.69 - Comparação entre a resistência mobiliza obtida pela expressão da Energy Approach com a capacidade estática obtida pela analise CAPWAP/CASE. 200

Figura4.70 - Coeficiente de capacidade estática $\left(K_{S P}\right)$ pela da nega obtida pelo ECD em

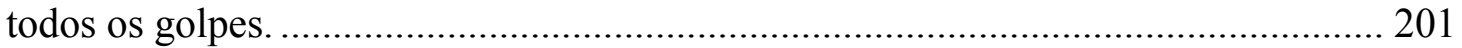

Figura4.71 - Coeficiente de capacidade estática $\left(K_{S P}\right)$ pela nega obtida pelo ECD para os golpes de maior energia em função do setup. 202

Figura4.72 - Influência do nível de energia aplicado no fator $K_{S P}$. 203

Figura4.73 - Comparação entre a obtenção do coeficiente de capacidade estática $\left(K_{S P}\right)$ através da análise CAPWAP e fórmula de Smith modificada por Aoki. 204

Figura4.74 - Distribuição de frequências para os valores de resistência mobilizada obtida pela fórmula do Energy Approach. 204

Figura4.75 - Distribuição de frequências e curva de Gauss para os comprimentos cravados (n $=2506$ estacas). 205

Figura4.76 - Registros de nega e repique elástico em função do comprimento cravado...... 207

Figura4.77 - Variação da relação de repique elástico/comprimento cravado em função da profundidade em comparação com os resultados de Rosa (2000). 208

Figura4.78 - Distribuição de frequências e estatística para a resistência mobilizada obtida pela fórmula de Chellis. 209

Figura4.79 - Distribuição de frequências e estatística para a resistência mobilizada obtida pela fórmula de Smith Modificada por Aoki (2011). 209

Figura4.80 - Distribuição de frequências e estatística para a resistência mobilizada obtida pela fórmula de Energy Approach. 210

Figura4.81 - Comparação entre as curvas de distribuição de frequências entre as fórmulas dinâmicas e o ECD. 210 


\section{LISTA DE TABELAS}

Tabela 2.1 - Correlação entre execução e tipologia de estacas (Velloso e Lopes, 2010).........34

Tabela 2.2- Valores de C3 para solos do Distrito Federal (Souza Filho e Abreu, 1990)........67

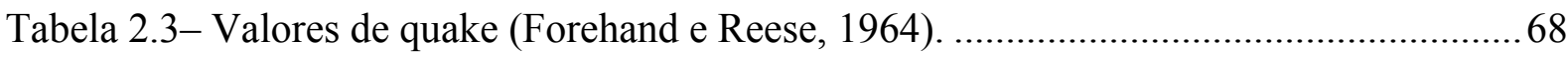

Tabela 2.4 -Valores de $\mathrm{J}_{\mathrm{CASE}}$ (Goble et al., 1996 e Rausche, 1985)...................................... 88

Tabela 2.5 - Fator A de Denver e Skov (1998) em função do tipo de material na ponta das

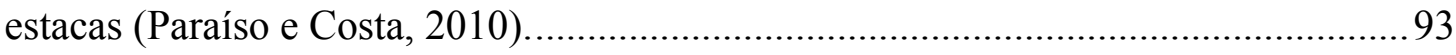

Tabela 3.1 - Parâmetros geotécnicos das camadas de argila de Santa Catarina (Marques e

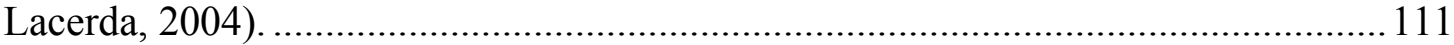

Tabela 3.2 - Parâmetros geotécnicos das argilas da Baixada Santista (Massad, 1994)......... 111

Tabela 3.3 - Resultados das provas de carga dinâmica amostradas em campo..................... 118

Tabela 3.4 - Características das estacas selecionadas para execução das provas de carga

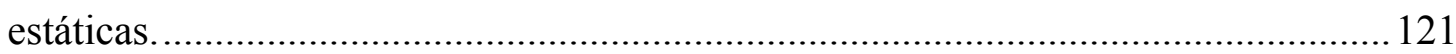

Tabela 4.1 - Previsões a partir dos métodos semi-empíricos para as estacas testes............... 126

Tabela 4.2 - Resultados obtidos pelo método CASE - estaca n ${ }^{\circ}$. E114M02 .......................... 133

Tabela 4.3- Resultados obtidos pelo método CASE - estaca n ${ }^{\circ}$ E018M04.......................... 133

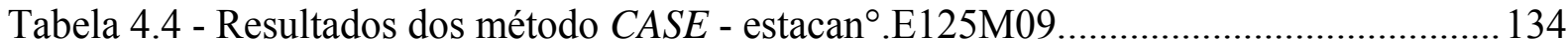

Tabela 4.5 - Interpretação dos registros da estaca $n^{\circ}$. E114M02 ....................................... 135

Tabela 4.6 - Registros de nega e repique elástico - estaca ${ }^{\circ}$. E018M04............................. 137

Tabela 4.7- Registros de nega e repique elástico- estaca ${ }^{\circ}$. E125M09.............................. 139

Tabela 4.8 - Interpretação da carga de ruptura para os resultados dos PCD......................... 141

Tabela 4.9 - Características das estacas ensaiadas e resultados da PCE.............................. 142

Tabela 4.10 - Características geométricas das estacas analisadas. ..................................... 145

Tabela 4.11 - Resultados do método da parábola. ............................................................... 146

Tabela 4.12 - Aplicação do método das duas retas............................................................ 147

Tabela 4.13 - Obtenção do fator de majoração do atrito lateral $(\mu)$.................................. 147

Tabela 4.14 - Resultados das parcelas de atrito e ponta. ................................................... 148

Tabela 4.15 - Valores das cargas de ruptura e deslocamentos na ruptura............................. 149

Tabela 4.16 - Resultados obtidos pelo método de Van der Veen modificado por Aoki com as

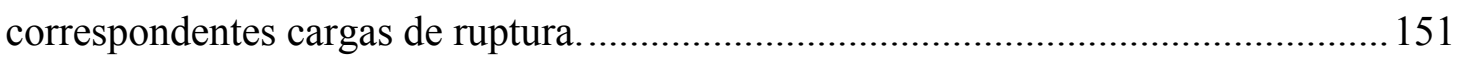

Tabela 4.17 - Resultados da carga de ruptura obtidos pelo método de Chin (1970).............. 153 
Tabela 4.18 - Resumo das interpretações da carga de ruptura das PC.

Tabela 4.19 - Resultado da interpretação das cargas de rupturas das PC.

Tabela 4.20 - Distribuição de ensaios e parâmetros de eficiência por equipamento.

Tabela 4.21 - Valores de resistência mobilizada em função do fator de amortecimento $(J$ ). 174

Tabela 4.22- Valores da contribuição do plug na resistência da ponta 182

Tabela 4.23- Comparação estatística entre os diferentes métodos de avaliação da resistência mobilizada. 


\section{LISTA DE ABREVIATURAS}

$\begin{array}{ll}\text { ABNT } & \text { Associação Brasileira de Normas Técnicas. } \\ \text { CASE } & \text { Case Institute of Technology } \\ \text { CAPWAP } & \text { Case Pile Wave Analysis Program. } \\ \text { CPR } & \text { Constant rate of penetration. } \\ \text { CPTU } & \text { Cone Penetration Test. } \\ \text { DPA } & \text { Dynamic Piling Analyser. } \\ \text { ECD } & \text { Ensaio de Carregamento Dinâmico. } \\ \text { EDD } & \text { Electro-Optical Displacement. } \\ \text { ELU } & \text { Estado Limite Ultimo. } \\ \text { ELS } & \text { Estado Limite de Serviço. } \\ \text { NBR } & \text { Norma Brasileira. } \\ \text { PCD } & \text { Prova de Carga Dinâmica. } \\ \text { PCE } & \text { Prova de Carga Estática. } \\ \text { PDA } & \text { Pile Driving Analyser. } \\ \text { PDR } & \text { Processador Digital de Repique. } \\ \text { PDM } & \text { Pile Driving Monitor. } \\ \text { QML } & \text { Quickmaintainde load test. } \\ \text { RDD } & \text { Registrador de Deslocamento Dinâmico. } \\ \text { setup } & \text { Tempo entre a cravação da estaca e a idade de execução do ensaio. } \\ \text { SML } & \text { Slow maintainde load test. } \\ \text { SPT } & \text { Standart Penetration Test. } \\ \text { SR } & \text { Superfície resistente. } \\ \end{array}$





\section{LISTA DE SÍMBOLOS}

A

A

a

B

c

C1

C2

C3

C3 $3_{\text {ajuste }}$

$C 3_{C H, R}$

$C 3_{C P W}$

$C 3_{F C}$

$C 3_{R M X}$

CSX

$d$

D

D

$D_{C, D A V}$

$D_{C, N B R}$

$D_{\text {final }}$

$D_{K+S}$

$D M X$

$D_{R}$

E

$E_{C S}$

$e$

Área da seção transversal.

Coeficiente adimensional empírico em função do tipo de solo.

Aceleração.

Diâmetro externo da estaca.

Velocidade de propagação da onda de tensão.

Compressão elástica de amortecimento do capacete e sistemas.

Compressão elástica devido à estaca.

Encurtamento elástico do solo na ponta da estaca ou quake.

Quake do solo obtido do ajuste de curva dos resultados das provas de carga dinâmica

Quake do solo retroanalisado pela fórmula de Chellis.

Quake do solo obtido na interpretação pelo método CAPWAP da PCD.

Quake do solo no final de cravação.

Quake do solo ajustado após calibração com resultados das provas de carga dinâmica.

Tensão de compressão na seção instrumentada.

Diâmetro interno da seção transversal.

Diâmetro da seção transversal.

Deslocamento total.

Deslocamento resultante da carga de ruptura caraterizada pelo método de Davisson.

Deslocamento resultante da carga de ruptura caraterizada pelo método da norma.

Deslocamento final.

Deslocamento total composto pelo somatório de nega e repique elástico.

Deslocamento máximo na seção instrumentada.

Compacidade relativa.

Módulo de elasticidade do material.

Módulo de elasticidade secante do material.

Eficiência do sistema. 


\begin{tabular}{|c|c|}
\hline$e_{M}$ & Eficiência média do sistema. \\
\hline$E_{e f}$ & Energia efetiva. \\
\hline$E M X$ & Energia máxima aplicada na seção instrumentada. \\
\hline$E_{\text {máx }}$ & Energia máxima aplicada no sistema. \\
\hline$E_{P O T, F C}$ & Energia potencial no final de cravação. \\
\hline ERE & Energia máxima teórica. \\
\hline$\Delta r$ & Recalque de ruptura convencionada. \\
\hline$\Delta t$ & Variação de tempo. \\
\hline$\Delta u$ & Variação de deslocamento. \\
\hline$f$ & $\begin{array}{l}\text { Fator de correção do comprimento cravado a partir do diagrama de } \\
\text { transferência de carga }\end{array}$ \\
\hline fmáx,$A l r_{1}$ & $\begin{array}{l}\text { Atrito lateral unitário para o esgotamento do atrito lateral na primeira } \\
\text { camada de solo. }\end{array}$ \\
\hline$F 1, F 2$ & Força aplicada para os tempos $t_{1}$ e $t_{2}$. \\
\hline$F(t)$ & Função força medida em campo. \\
\hline$f_{c k}$ & Resistência característica a compressão. \\
\hline$f_{t k}$ & Resistencia característica a tração. \\
\hline FS & Fator de Segurança. \\
\hline$G_{0}$ & Módulo de cisalhamento inicial. \\
\hline$h_{1}$ & Comprimento cravado em relação a primeira camada de solo. \\
\hline$H$ & Altura de queda do sistema de cravação. \\
\hline K & Repique elástico ou deformação elástica do sistema estaca-solo. \\
\hline$k$ & Coeficiente de rigidez estaca-solo considerando toda estaca. \\
\hline$k 1$ & Coeficiente de rigidez estaca-solo para a primeira camada de solo. \\
\hline$K r$ & Rigidez do sistema estaca-solo. \\
\hline$K r_{1}$ & Rigidez do sistema estaca-solo para a primeira camada de solo. \\
\hline$K_{\min }$ & Repique elástico mínimo. \\
\hline$K_{S P}$ & Coeficiente de capacidade estática. \\
\hline$J_{C}=J_{C A S E}$ & Fator de amortecimento dinâmico. \\
\hline$J_{\text {Smith }}$ & Fator de amortecimento dinâmico de Smith. \\
\hline
\end{tabular}


$N_{\text {EQUIV }}$

$N_{h}$

$N_{R P}$

$N_{S P T}$

$\eta$

Pou $P_{r}$

$P_{C, D A V}$

$P_{C, N B R}$

$P E$

PI

$P R_{R M X}$

p

$Q_{\text {máx }}$

Qreg

$Q_{s l}$

$Q_{\text {su }}$

$\left(Q_{u}\right)_{0}$

Qult

$R$

$R A(x)$

$r_{b}$

$R_{d}$

$R E$

$R L$

$R_{m}$

$R M_{C H}$

$R M_{S M M}$
Comprimento cravado da estaca.

Comprimento virtual - proporção do comprimento cravado.

Índice de resistência a penetração no ensaio SPT homogeneizado com as sondagens vizinhas.

Quantidade de golpes necessários para a cravação de 1,0 metro de estaca. Índice de resistência a penetração retroanalisado pelos resultados da PCD. Índice de resistência a penetração.

Coeficiente de restituição.

Carga de ruptura convencionada.

Carga de ruptura obtido pelo método de Davisson.

Carga de ruptura obtida pelo método da norma.

Penetração externa.

Penetração interna.

Carga de ruptura extrapolada a partir dos resultados da PCD.

Altura da bucha.

Carga máxima aplicada na PCE.

Ponto de regressão - interpretação do método de rigidez infinita.

Atrito lateral limite inferior.

Atrito lateral limite superior.

Carga de ruptura convencionada.

Carga ultima.

Resistência.

Parcela da resistência de atrito lateral na posição x.

Raio de base.

Parcela de resistência dinâmica.

Resistência estrutural.

Resistência lateral.

Resistência mobilizada.

Resistência mobilizada a partir da fórmula dinâmica.

Resistência mobilizada a partir da fórmula de Smith modificado por Aoki 


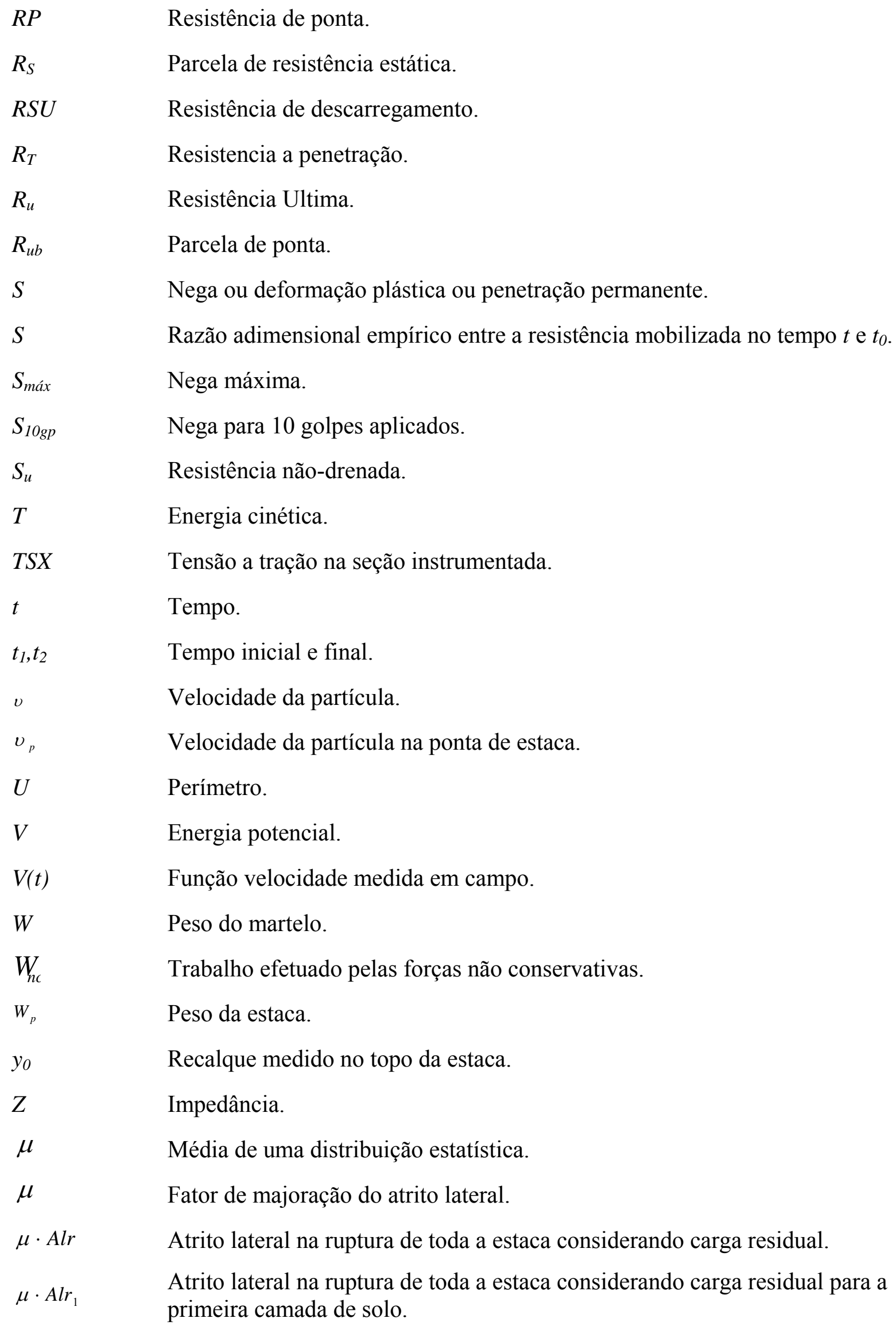




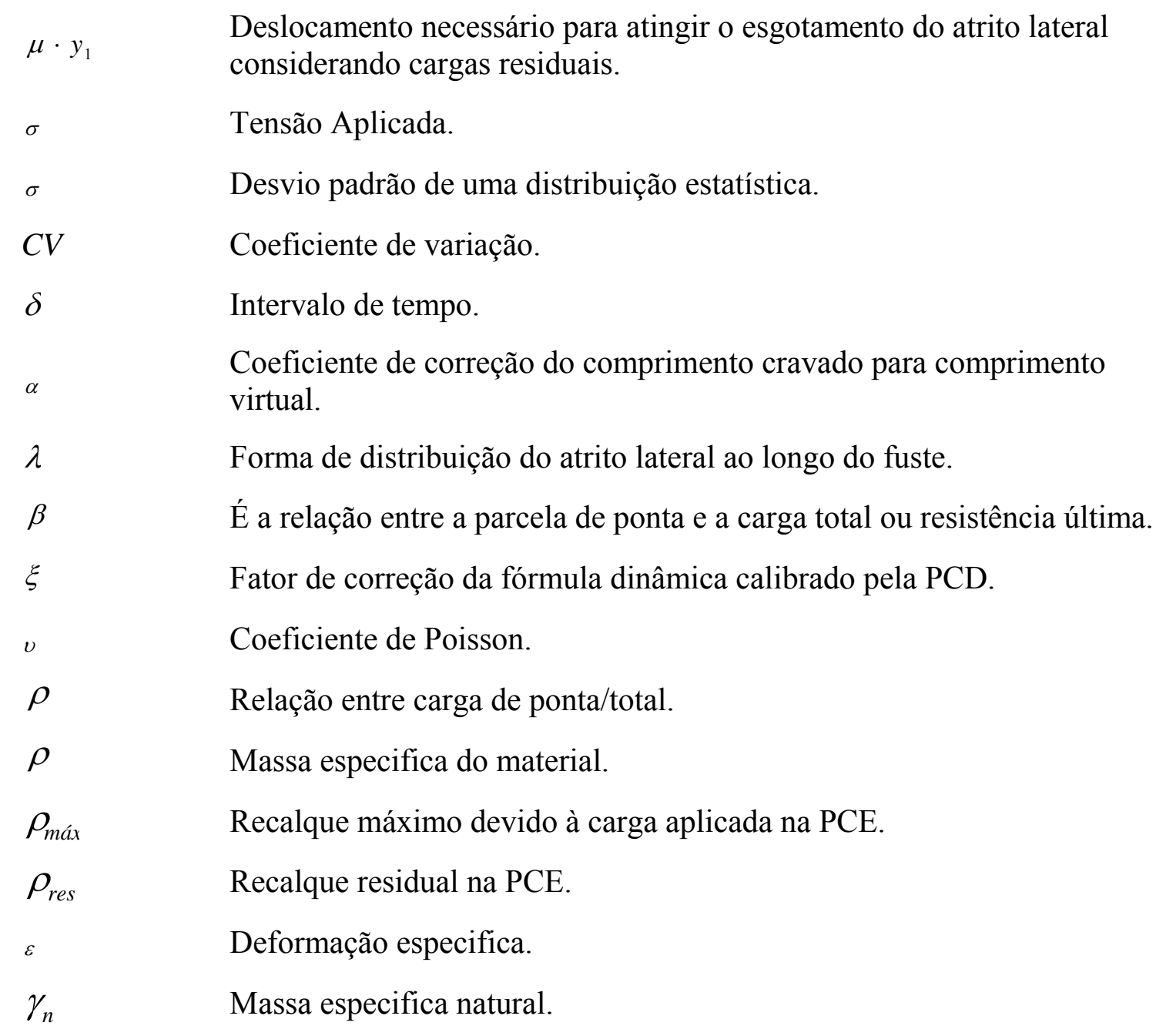





\section{SUMÁRIO}

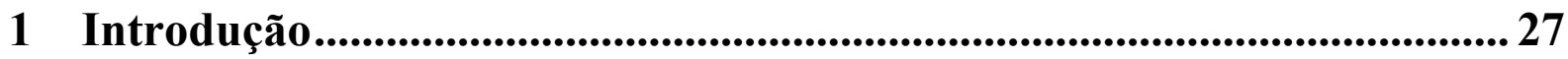

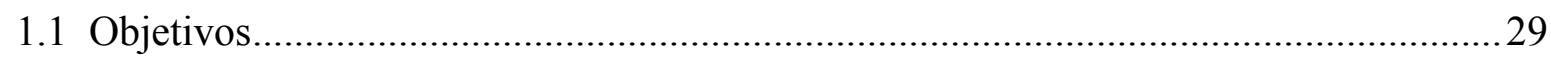

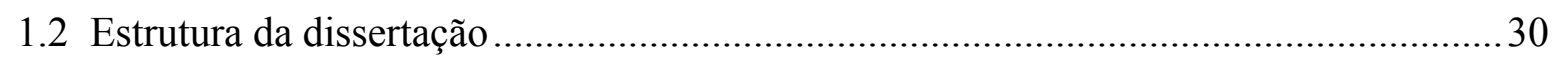

2 Revisão Bibliográfica ............................................................................................. 33

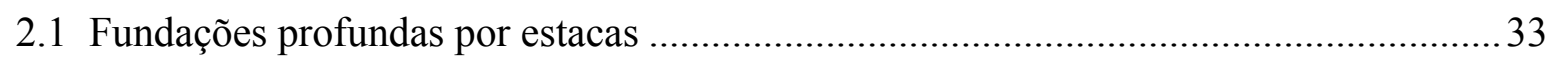

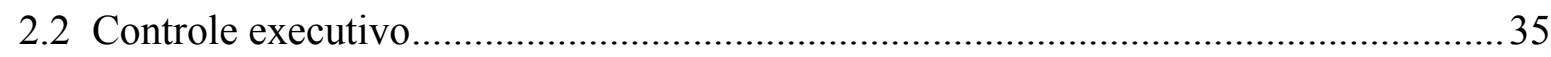

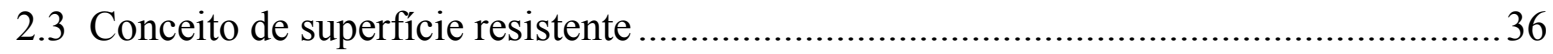

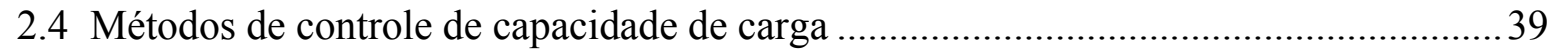

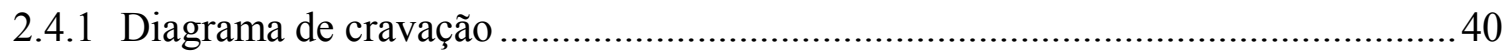

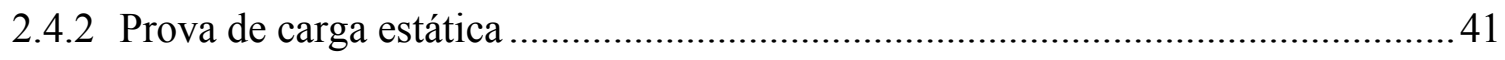

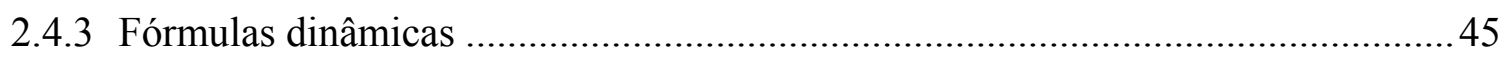

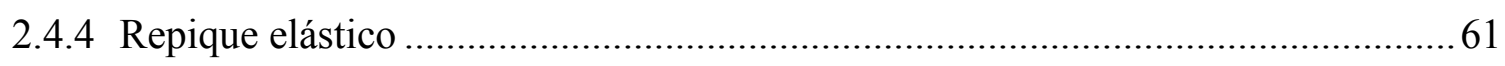

2.4.5 Ensaio de Carregamento Dinâmico................................................................ 70

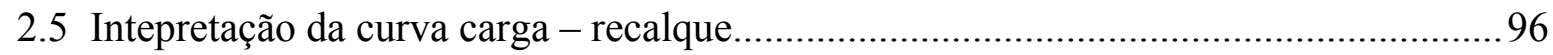

2.5.1 Métodos de extrapolação....................................................................................96

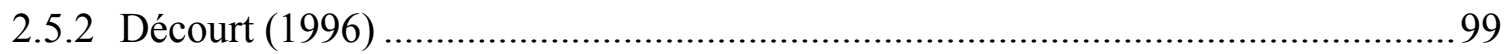

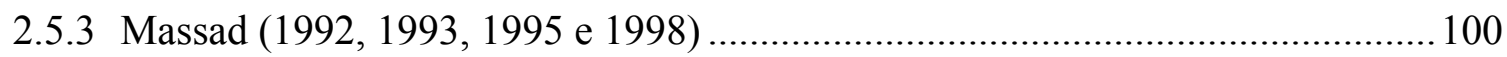

2.5.4 Adimensionalização de curvas de prova de carga dinâmica ............................... 105

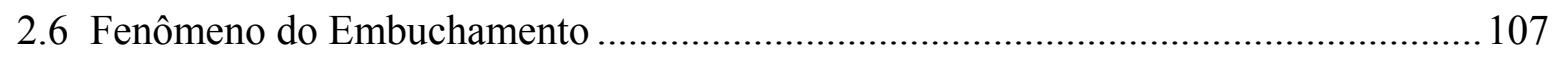

3 Materiais e Métodos ...........................................................................109

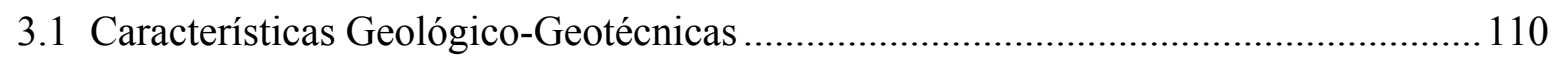

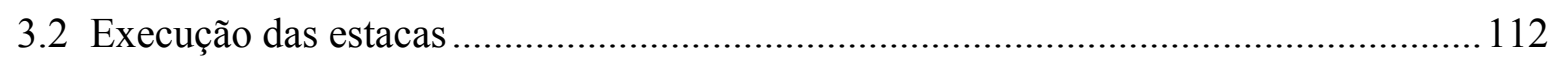

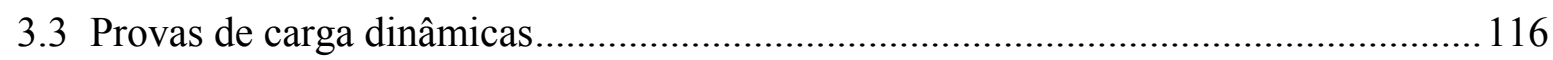

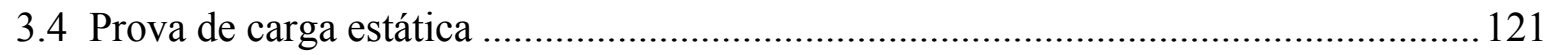

4 Resultados e Discussões ............................................................................. 123

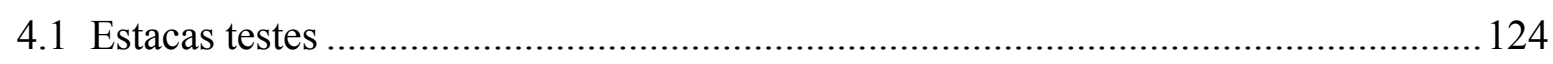

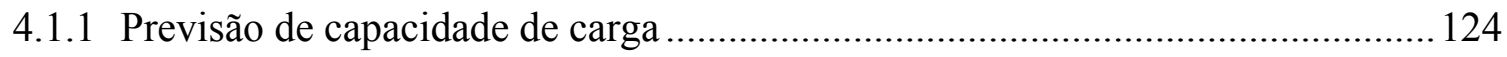

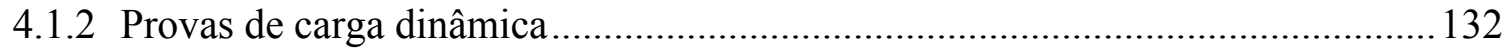

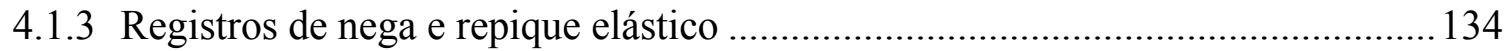

4.1.4 Interpretação da PCD em termos de carga de ruptura........................................ 140 


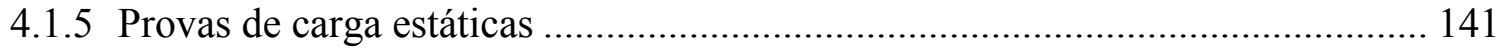

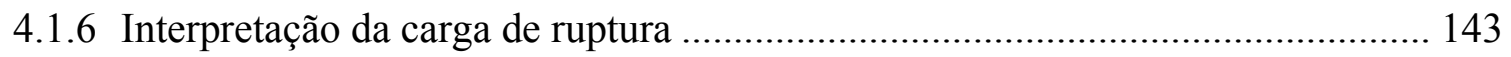

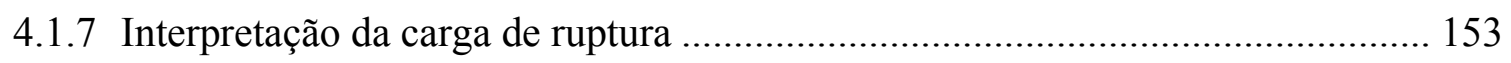

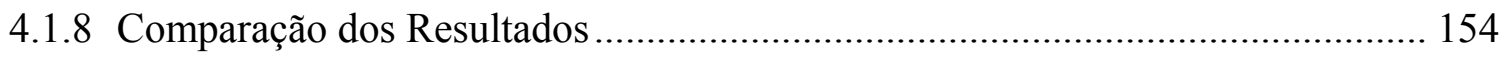

4.2 Controle do estaqueamento por prova de carga dinâmica ......................................... 163

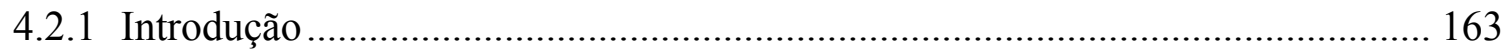

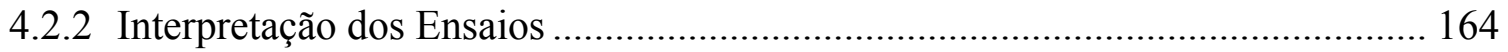

4.2.3 Considerações sobre a interpretação dos ensaios ................................................ 166

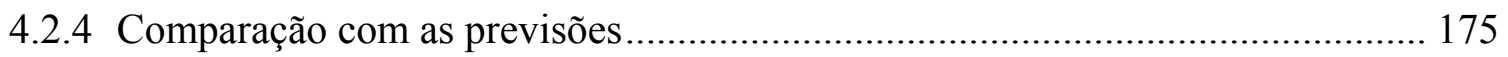

4.3 Avaliação da resistência de ponta - Efeito do Embuchamento .................................. 179

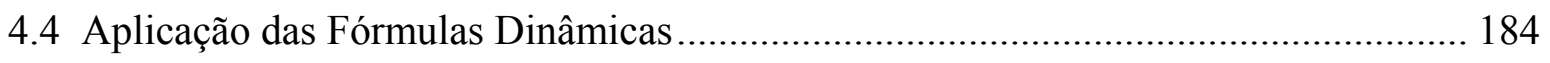

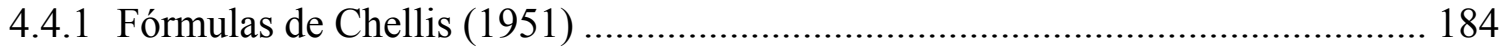

4.4.2 Fórmula de Smith Modificada por Aoki (2011) ................................................. 193

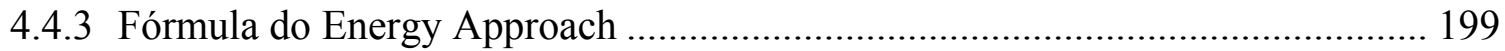

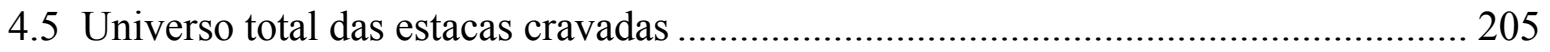

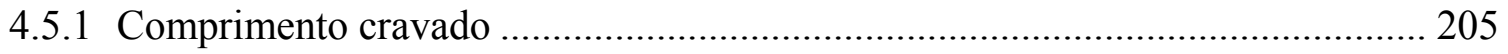

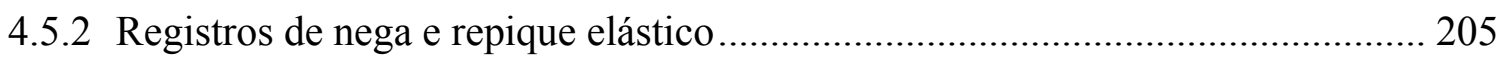

4.5.3 Resistência mobilizada no final de cravação ...................................................... 208

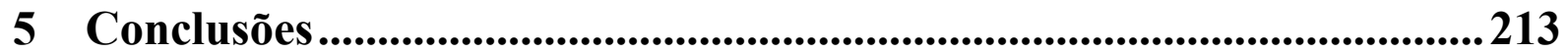

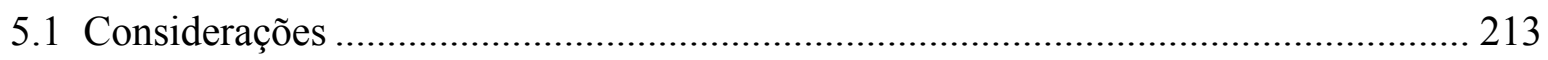

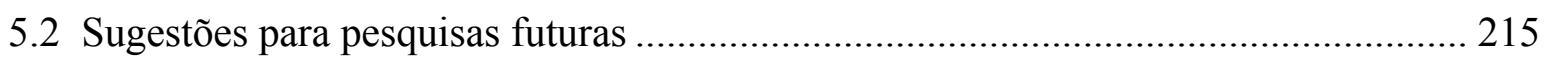

6 Referências ............................................................................. 217

ANEXO 


\section{Introdução}

Com o advento dos recursos de informática e a popularização da internet, hoje, durante a realização das fundações de obras civis, é possível acompanhar em tempo real a leitura de registros da execução, como por exemplo, resultados de ensaios de carregamento dinâmico em estacas, e simultaneamente propor alterações no projeto.

$\mathrm{Na}$ Engenharia de Fundações, os ensaios de carregamento dinâmico se popularizaram no Brasil de tal maneira, que inicialmente eram recomendados apenas para estacas pré-fabricadas (metálicas ou de concreto), e atualmente é comum a prática destes ensaios para avaliar o comportamento de estacas do tipo hélice contínua, escavada, e Franki. Muito dessa evolução ocorreu pela necessidade de se verificar os valores de capacidade de carga de um maior conjunto de estacas da fundação de uma obra civil.

Geralmente, as incertezas nas fundações são tratadas com a adoção de elevados fatores de segurança. Mais recentemente com a conscientização do risco existente em obras civis, considera-se que o fator de segurança está associado a uma probabilidade de ruína (ou de falha) da fundação.

Um modo de avaliar a probabilidade de ruína do estaqueamento de uma obra é a execução de provas de carga estáticas em algumas estacas (ensaio que exprime o comportamento carga aplicada $\mathrm{x}$ recalque de uma estaca).

Geralmente as provas de carga estáticas são realizadas em uma pequena parcela do universo total de estacas executadas em uma obra. Deste modo, em muitos casos não são possíveis de caracterizar as variabilidades das resistências das estacas advindas da variabilidade do terreno.

Os ensaios de carregamento dinâmico (ou provas de carga dinâmica) permitem, de forma rápida e econômica, amostrar os resultados de capacidade de carga de uma maior quantidade de estacas de uma obra. Estes resultados podem ser correlacionados com os resultados obtidos nas provas de carga estática.

Uma das vantagens mais interessantes do ensaio de carregamento dinâmico é a possibilidade de durante a sua execução em uma estaca da obra, um técnico acompanhar os resultados em tempo real no escritório, distante do canteiro de obra. Deste modo, é possível 
até mesmo executar uma análise mais sofisticada (análise CAPWAP) durante a aplicação dos golpes no ensaio.

Mesmo com a evolução dos métodos semi-empíricos de estimativa da capacidade de carga das fundações, existem ainda conflitos na interpretação dos resultados e na correlação entre os diferentes métodos de avaliação. Parte disso deve-se ao fato de normalmente ser avaliado o resultado apenas de uma ou de poucas estacas da obra, aferindose assim uma espécie de um fator de segurança pontual, e não se considerando o comportamento do grupo de estacas que formam a fundação como um todo, excluindo-se a variabilidade das resistências das estacas.

No caso de fundações por estacas cravadas, tem se a possibilidade de registrar no final de cravação as medidas de nega e repique elástico de todo o universo de estacas de uma obra. Dessa forma, é possível correlacionar estas medidas com os resultados de outros métodos de estimativa, permitindo-se estimar a resistência mobilizada para cada estaca da obra no momento final da cravação.

Apesar de várias críticas quanto à segurança do operário durante a coleta destes registros, existem equipamentos que permitem obter registros digitais como o PDR (Oliveira et al., 2010) e PDM (SCAC, 2012 - Seidel, 2011).

Nos Estados Unidos e países da Europa têm se utilizado fórmulas dinâmicas que permitem avaliar a resistência mobilizada da estaca a partir do registro de nega, e num segundo momento complementando-se com o registro do repique elástico. Essas expressões na grande maioria são baseadas na equação da $2^{\circ}$. Lei de Newton, no princípio da conservação de energia e na lei de Hooke para corpos perfeitamente elásticos.

O controle na maioria desses casos é baseado na dificuldade da cravação da estaca, ou seja, quanto menor for à medida da nega, maior será a capacidade de carga da estaca. Nesse contexto, os fabricantes de martelos ou cravadores elaboravam ábacos que correlacionam a dificuldade de penetração da fundação com a resistência última.

As fórmulas dinâmicas avaliam a capacidade de carga de estacas cravadas por meio da medição de parâmetros de cravação, correlacionados com a resistência estática da fundação como reação oferecida pelo conjunto solo-estaca.

Nos Estados Unidos a partir da década de 80, surgiram os ensaios de 
carregamento dinâmico, que utilizam como modelo para interpretação da resistência da estaca a equação da onda proposta por Saint Venant (1865), e a solução numérica proposta por Smith (1960). Forehand e Resse (1964) também contribuíram no desenvolvimento de uma solução numérica para este fim.

Alguns estudos questionam a aplicação dessas soluções quanto à confiabilidade dos resultados quando comparados aos obtidos em provas de carga estática, em que as dispersões são elevadas, sendo discutidos em Sorensen e Hansen (1957), Poulos (1980) e Liang (1997). Entretanto, segundo de Mello e Sobral (1997) diante do elevado número de críticas na aplicação das fórmulas dinâmicas, as velhas rotinas de obra continuam sendo executadas, e multiplicam-se os estudos sem a criação de novas fórmulas/ajustes.

Esse trabalho apresenta um caso de uma obra de fundações em estacas de concreto pré-fabricado, considerando-se um critério de controle de execução definido a priori, baseado no registro de nega e repique elástico, para a instalação da ponta das estacas em uma camada de areia compacta e intermediária (solo com sobreposição dos sedimentos flúvio-marinhos e flúvio-lacustres) e que garantisse a mesma capacidade de carga. Para a avaliação da resistência das estacas foram utilizados provas de carga estática e dinâmica de energia crescente, sendo coletados em cada golpe os registros de nega e repique elástico.

Neste estudo, foram interpretados os resultados para cada método de avaliação de capacidade de carga das estacas, e posteriormente analisados alguns parâmetros considerandose as influências da variabilidade do terreno e equipamento.

Adicionalmente, os resultados foram discutidos, verificando-se as cargas de ruptura interpretadas e as influências dos equipamentos de cravação e dos registros de campo. Deste modo, foi possível caracterizar para cada fórmula dinâmica avaliada, os valores médios e dispersões obtidos, comparando-se com os demais métodos.

\subsection{Objetivos}

O presente estudo tem como objetivo avaliar o uso de um método de controle in situ, para estimar a resistência mobilizada de estacas ao final da cravação, por meio das medidas de nega e repique elástico, interpretados com fórmulas dinâmicas, calibradas com os 
resultados de provas de carga dinâmica, retroanalisado-se as premissas de projeto.

Como objetivos secundários:

a) Verificar a correlação entre os resultados obtidos ao final de cravação com os obtidos em provas de carga dinâmicas, calibrando-se parâmetros para aplicação nas fórmulas dinâmicas.

b) Interpretação dos resultados das provas de carga dinâmica e estática, e comparação destes com as previsões obtidas por métodos semi-empíricos, com base em resultados de ensaios de SPT.

c) Avaliar as influências do efeito set-up (aumento da capacidade de carga ao longo do tempo, causado pela "cicatrização" da estaca), dos equipamentos de cravação, e dos condicionantes geológico-geotécnicos nos valores da resistência mobilizada das estacas, para um conjunto de ensaios executados em diferentes intervalos de tempo após o final da cravação.

d) Por meio das fórmulas dinâmicas, conhecer a variabilidade dos parâmetros após serem calibrados, e avaliar a resistência mobilizada de todas as estacas da obra pela interpretação do registro de nega e repique elástico, usando-se curvas de distribuição de frequências dos valores estimados de resistência das estacas da obra para cada caso.

\subsection{Estrutura da dissertação}

A dissertação foi dividida em seis capítulos. O capítulo 1 apresenta uma introdução ao tema abordado e trata dos objetivos do trabalho e a organização da dissertação.

No capítulo 2 é mostrada a revisão bibliográfica de assuntos relacionados ao tema desse trabalho. Neste capítulo apresenta-se: um breve histórico de fundações profundas por estacas, formas de controle de execução, provas de carga dinâmica, registros de nega e repique elástico, fórmulas dinâmicas, métodos de interpretação e correlação dos resultados. Também é apresentada uma comparação de resultados entre as diferentes metodologias de controle de execução de estacas e suas influências.

O capítulo 3 apresenta os materiais e métodos utilizados nessa pesquisa, baseados no estudo de caso de um projeto de um porto em Santa Catarina. Apresentam-se os 
condicionantes geológico-geotécnicos do terreno da obra, as principais unidades de solo, o critério de parada das estacas em campo, a metodologia de execução dos ensaios (provas de carga estática e dinâmica), e demais características do projeto. Os dados foram organizados em planilhas que incluem todos os parâmetros medidos neste estudo.

Os resultados e as interpretações dos dados estão contidos no capitulo 4, sendo apresentados por meio de gráficos e tabelas. Parte-se dos resultados das provas de carga estática (PCE), em seguida são analisados os resultados das provas de carga dinâmica (PCD), à luz das diferentes idades, correlacionados com as medidas de nega e repique elástico para os diferentes golpes do ensaio com energia crescente. Deste modo, foi possível calibrar as fórmulas dinâmicas - Chellis (1961), Energy Approach - Paikowsky e Chernauskas (1992) e Smith modificado por Aoki (2011).

Após aferidos alguns parâmetros por meio dos resultados das provas de carga dinâmicas (PCD), foram interpretados os registros obtidos no final de cravação de todas as estacas da obra. Obteve-se para cada método de estimativa das resistências das estacas uma curva de distribuição das resistências mobilizadas.

No capítulo 5 apresentam-se as conclusões sobre os resultados obtidos em relação aos objetivos pretendidos, e sugestões para o desenvolvimento de estudos futuros relacionados ao tema abordado. 
$-32-$ 


\section{Revisão Bibliográfica}

Este capítulo apresenta um contexto geral sobre o comportamento de estacas cravadas e métodos adotados para o controle da resistência por meio de ensaios de campo. Tais esclarecimentos são necessários para o entendimento dos pontos abordados ao longo deste trabalho.

\subsection{Fundações profundas por estacas}

A NBR 6122 (2010) define como fundação profunda o elemento de fundação que transmite a carga ao terreno ou pela base (resistência de ponta) ou por sua superfície lateral (resistência do fuste) ou por uma combinação das duas, devendo sua ponta ou base estar assente em profundidade superior ao dobro de sua menor dimensão em planta, e no mínimo 3,0 metros. Nesse tipo de fundação incluem-se as estacas e tubulões.

Para o caso de estaca a mesma norma define como elemento de fundação profundo executado inteiramente por equipamentos ou ferramentas, sem que, em qualquer fase de sua execução, haja descida de pessoas. Os materiais empregados podem ser madeira, aço, concreto pré-fabricado, concreto moldado in loco ou pela combinação das anteriores.

Velloso e Lopes (2010) apresentam outros critérios de classificação para estacas, baseando-se em diferentes materiais do elemento estrutural, tipo de instalação em campo até a combinação de ambos.

Em termos de material do elemento estrutural que compõe à estaca, esta pode ser classificada como: de concreto (seções maciças ou vazadas, ou quanto a geometrias circulares, quadradas, hexagonais ou em formatos especiais como estrela ou W), de aço (seções I, H, W, trilhos ferroviários ou tubos), de madeira (postes ou seções quadradas) ou com a combinação de mais de um elemento (por exemplo, estacas de concreto com ponteira em perfil metálico).

Quanto à forma de instalação as estacas podem ser classificadas em função do efeito no solo envolvente causado pelo processo executivo, sendo classificadas como:

a) de deslocamento - durante o processo de cravação ou prensagem o elemento 
estrutural da estaca provoca o deslocamento horizontal do terreno adjacente de modo a alterar o estado das tensões no solo em torno do fuste.

b) de substituição - na execução das estacas escavadas, o solo é removido primeiramente, dando origem a um espaço vazio, que é preenchido posteriormente. Deste modo ocorre o alívio nas tensões do maciço em torno do furo.

Um resumo geral da classificação dos tipos de execução é apresentado naTabela 2.1, onde são correlacionados os tipos de execução com as tipologias de estacas.

Tabela 2.1 - Correlação entre execução e tipologia de estacas (Velloso e Lopes, 2010).

\begin{tabular}{|c|c|c|}
\hline Tipo de Ex & cução & Estacas \\
\hline \multirow{8}{*}{$\begin{array}{c}\text { De } \\
\text { deslocamento }\end{array}$} & \multirow{5}{*}{ Grande } & madeira \\
\hline & & pré-moldada de concreto \\
\hline & & tubos de aço de ponta fechada \\
\hline & & tipo Franki \\
\hline & & microestacas injetadas \\
\hline & \multirow{3}{*}{ Pequeno } & perfis de aço \\
\hline & & $\begin{array}{l}\text { tubos de aço de ponta aberta (desde que } \\
\text { não haja embuchamento na cravação) }\end{array}$ \\
\hline & & $\begin{array}{c}\text { estacas hélice especiais (estacas hélice de } \\
\text { deslocamento) }\end{array}$ \\
\hline \multirow{2}{*}{\multicolumn{2}{|c|}{ Sem deslocamento }} & $\begin{array}{l}\text { escavadas com revestimento metálico } \\
\text { perdido que avança a frente da escavação }\end{array}$ \\
\hline & & estaca raiz \\
\hline \multirow{3}{*}{\multicolumn{2}{|c|}{ De substituição }} & $\begin{array}{l}\text { escavadas sem revestimento ou com o uso } \\
\text { de lama }\end{array}$ \\
\hline & & tipo Strauss \\
\hline & & estacas hélice continua em geral \\
\hline
\end{tabular}

Terzaghi e Peck (1967) apresentam uma classificação de estacas em função do tipo de transferência de carga pelo elemento estrutural de acordo com o tipo de solo, sendo agrupado em três tipos:

a) Estacas de atrito (solos granulares) - o processo de cravação de estacas muito próximas entre si, normalmente ocorre em grupos e/ou grandes blocos de estacas, reduzem 
especialmente a porosidade e compressibilidade do solo dentro e em torno do grupo. Esse comportamento é muito pronunciado em areias ou solos com características granulares, e que devido à alta permeabilidade tem um ganho na parcela de transferência por atrito lateral disponível, e de acordo com os autores essa categoria é denominada de estacas de compactação.

b) Estacas de atrito (solos finos) - também transferem as cargas ao solo preponderantemente por atrito lateral, visto que durante o processo de cravação não produzem a compactação do solo que cause grandes alterações no comportamento mecânico. Essa categoria de estacas é denominada de estacas flutuantes.

c) Estacas de ponta - pelas características e composição das camadas de solo, à estaca é instalada em uma cota muito profunda para encontrar uma camada resistente, permitindo assim a transferência de carga.

As estacas cravadas podem ser classificadas pelo processo de cravação: de percussão com a utilização de martelos de queda livre, a diesel ou hidráulico, por prensagem com o uso de macacos hidráulicos ou vibração através de martelos de vibro compressão.

No caso das estacas pré-moldadas elas podem ser formadas por um único elemento estrutural, ou constituída pela combinação de diferentes tipos de elementos, sendo denominada de estaca mista. A definição da combinação dos elementos irá depender dos tipos de camadas ou perfis estratigráficos que a estaca terá que atravessar até alcançar a cota de projeto.

\subsection{Controle executivo}

No caso de uma obra apoiada em fundações profundas, o principal condicionante é a definição do comprimento da estaca que atenda a duas condições de projeto: ao estadolimite último (ELU) e ao estado-limite de serviço (ELS).

Para otimizar os comprimentos das estacas, e simultaneamente garantir o atendimento aos estados-limites, é necessário estabelecer um controle durante a execução do estaqueamento. Este controle é baseado em uma série de procedimentos que padronizam a instalação das estacas, bem como na obtenção de registros das diversas etapas executivas, de modo a controlar e monitorar as variáveis de interesse durante a instalação que possam 
comprometer o desempenho da fundação.

No controle executivo de estacas cravadas, é muito comum o monitoramento da composição de elementos estruturais utilizados, a contagem de golpes aplicados para a cravação de um metro de estaca - elaboração do diagrama de cravação, os tempos de cravação de elementos, as interfaces entre trechos de cravação resistente ou de fácil penetração, o comprimento final e os registros de nega e repique elástico.

A partir do momento que se estabelece uma rotina de controle, é possível intervir em qualquer momento da instalação, e verificar se as premissas previstas em projeto são atendidas, e imediatamente modificar ou paralisar a execução se necessário.

\subsection{Conceito de superfície resistente}

Em Fundações, um aspecto fundamental é o mecanismo de transferência de carga entre o elemento estrutural e o maciço que o rodeia e suas particularidades. Aoki (2002) afirma que no estudo da carga admissível de um sistema de fundações por estacas, o objetivo do estudo é a definição da superfície resistente, sendo definida como a superfície formada pela ponta das estacas, em que nessas condições a fundação será:

a) Segura, de modo a proporcionar os fatores de segurança necessários para o atendimento dos estados limite últimos e de utilização.

b) Confiável, se a probabilidade de sucesso ou de falha de uma estaca for aceitável. Esse nível de aceitação é definido como um risco assumido pelos participantes do processo de decisão.

Para cada obra, a superfície resistente (SR) executada terá uma geometria única, e dependente do sistema de cravação, tipo de estaca, característica do maciço, e de parâmetros dos critérios de controle executivo.

Aoki (2002) apresenta o caso de um galpão industrial no Espirito Santo, apoiado em maciço de solo laterizado da formação Barreiras, composto por 95 estacas de concreto pré-fabricado, de diâmetro $70 \mathrm{~cm}$ e carga admissível de $2100 \mathrm{kN}$. A instalação das estacas foi controlada por registro de nega e repique elástico, e pela execução de provas de carga dinâmica a fim de definir o comprimento das estacas. A superfície resultante dos diversos comprimentos cravados em função da geometria do empreendimento está apresentada na 
Figura 2.1.

Pela geometria da SR (Figura 2.1), um dos cantos do galpão apresentou uma grande variação dos comprimentos cravados. Essa variabilidade é explicada pelas características da formação do maciço, que é um solo formado por sedimentos areno-argilosos não consolidados, de origem continental, e que apresentam forte cimentação entre os grãos. Nessa região a variação dos comprimentos é atribuída a uma diferença do grau de cimentação dos grãos. Pois, durante a execução da estaca, o processo de percussão ocasionou a quebra dessa cimentação e consequentemente o terreno ofereceu resistência numa profundidade maior.

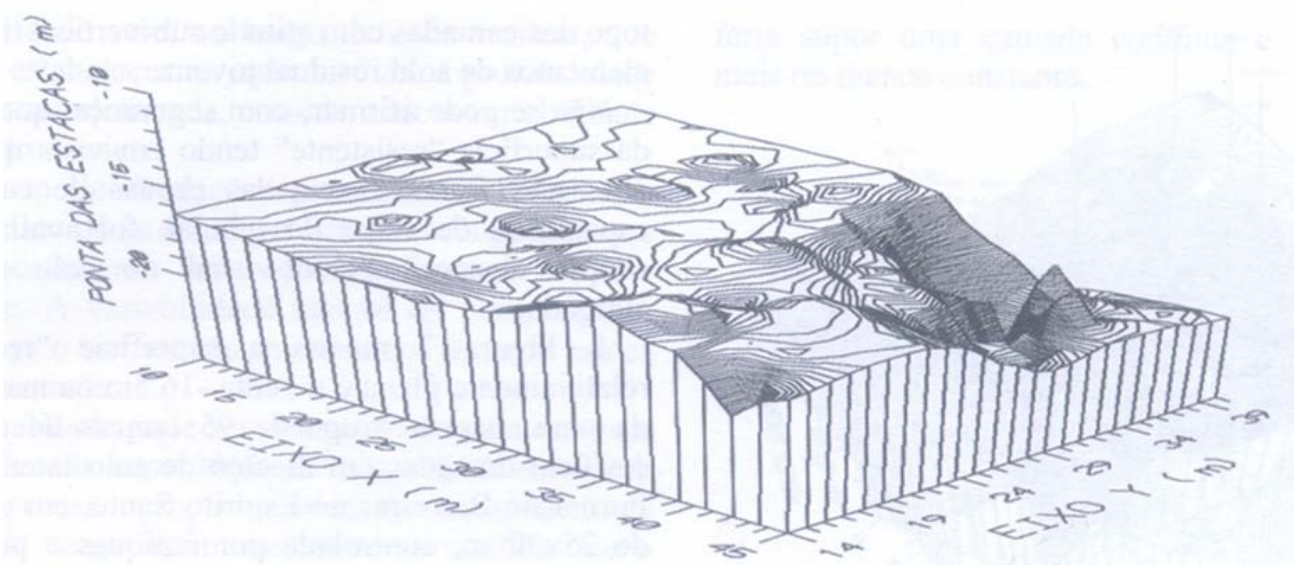

Figura 2.1- Geometria da superfície resistente na Formação Barreiras (Aoki, 2002).

Pela análise estatística dos comprimentos cravados (Figura 2.2.a), obteve como valor médio $(\mu) 17,2 \mathrm{~m}$, com desvio padrão $(\sigma)$ de $1,7 \mathrm{~m}$, resultando num coeficiente de variação ( $C V$ ) de 9,9\%. Para a resistência mobilizada nas estacas, a análise estatística (Figura 2.2.b) apresentou valor médio de $5953 \mathrm{kN}$, com desvio padrão de $1112 \mathrm{kN}$, resultando num $C V$ de $19 \%$. 
MACIÇO COM ELEMENTO DE SOLO LATERÍTICO ESTATÍSTICA DE COMPRIMENTOS

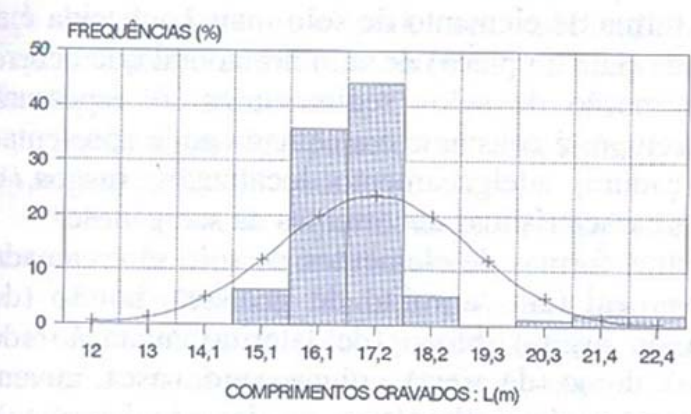

$\mathrm{N}=95$ ESTACAS; MÉDIA $=17.2 \mathrm{~m} ;$ DESVO PADRÃO $=1.7 \mathrm{~m} ;$ COEF. VARIAÇĀOO $=10 \%$
MACIÇO COM ELEMENTO DE SOLO LATERÍTICO

ESTATISTICA DE RESISTÊNCAAS

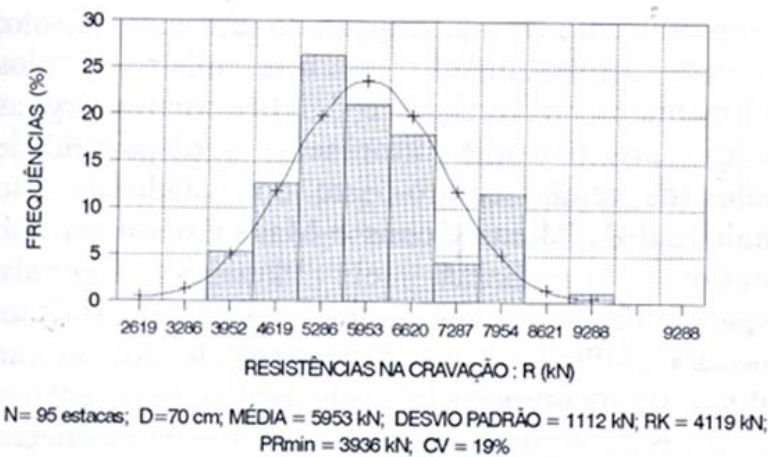

Figura 2.2 - Analise estatística dos comprimentos cravados e da resistência do estaqueamento (Aoki, 2002).

Foá (2001) apresenta um exemplo do projeto de um edifício executado na cidade de Salvador/BA, próxima à região da orla marítima constituída por areia de dunas, de origem eólica, sedimentos argilosos e areno-argilosos resultantes de processos erosivos e alterações de escudos cristalinos.

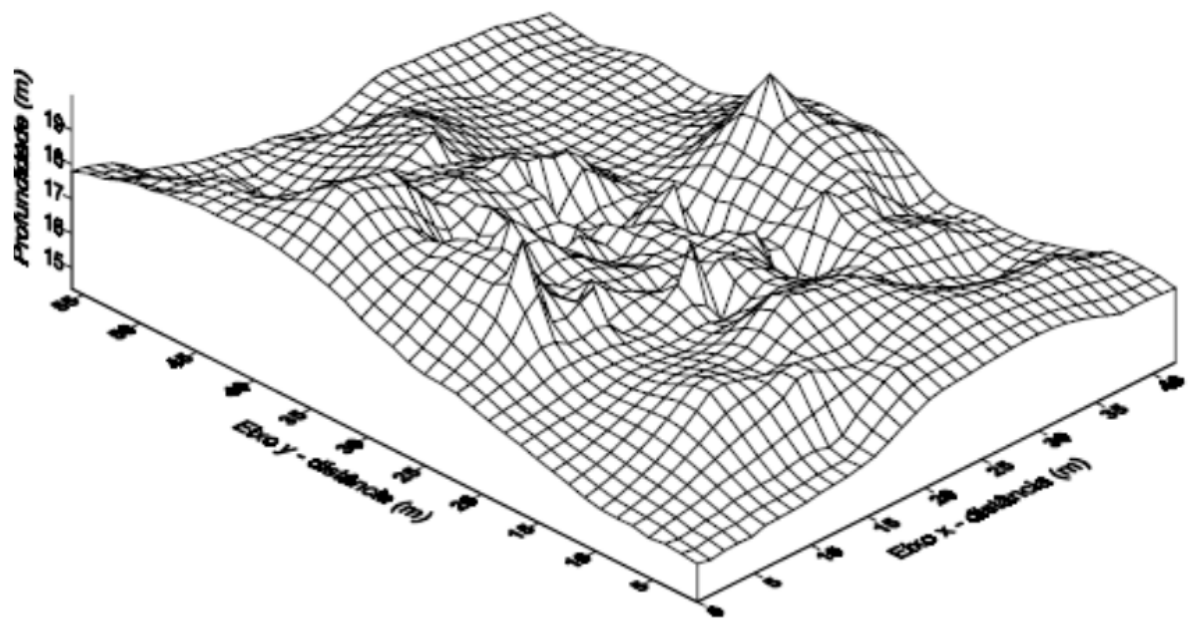

Figura 2.3 - Superfície resistente no projeto de Salvador/BA (Foá, 2001).

O projeto era composto por 25 pilares da torre e 78 pilares de periferia, sendo as fundações definidas em trilhos metálicos com perfil do tipo TR57, TR68 (simples e duplo), formando blocos de estacas para cada pilar. A carga admissível da estaca no projeto era 600 $\mathrm{kN}$. O controle executivo foi baseado na medida de nega ( $S \leq 15 \mathrm{~mm} / 10$ golpes $)$ e de provas 
de carga dinâmica e estática, resultando numa variação dos comprimentos cravados na faixa de 15,0 a 19,0 metros. A Figura 2.3 apresenta a superfície resistente do projeto.

Uma das características de fundações por estacas pré-moldadas é a possibilidade de controlar a sua execução, por meio da aplicação de golpes do martelo no topo da estaca e obter uma resposta do conjunto estaca-solo.

Essas repostas podem ser obtidas por medições de: nega (medida de penetração e/ou deslocamento permanente do topo da estaca em relação ao solo), repique elástico (resposta dinâmica à cravação - encurtamento elástico da estaca em relação ao solo) e por meio de instrumentação (Velloso e Lopes, 2002).

Com a obtenção dessas medidas, usando-se fórmulas dinâmicas de cravação, estabelecidas teoricamente ou empiricamente, é possível estimar a resistência mobilizada na estaca durante o golpe, e assim comparar com o valor previsto.

Habitualmente, a instrumentação do topo da estaca, necessária para a prova de carga dinâmica, não é possível de ser executada em todo o universo de estacas de uma obra, devido principalmente ao tempo gasto e a custos. Entretanto, a coleta dos registros de nega e repique permite amostrar valores de resistência mobilizada de todas as estacas de uma obra.

\subsection{Métodos de controle de capacidade de carga}

No controle executivo de estacas cravadas os dois principais objetivos são: garantir um comprimento mínimo para que a capacidade de carga da estaca seja igual ou maior que o valor calculado em projeto, e garantir a homogeneidade das resistências de todo estaqueamento.

De acordo com de Melo (1997), o controle executivo é orientado por critérios rudimentares de cravação, orientados por índices convencionais dos registros de nega e repique elástico, fórmulas dinâmicas, controle de energia e outros.

A seguir são apresentados os diferentes tipos de controle empregados durante a execução de estacas cravadas, e as medidas que podem ser coletadas durante o processo de cravação de uma estaca. 


\subsubsection{Diagrama de cravação}

Uma das formas mais simples de se acompanhar a execução de uma estaca é através da contagem de golpes necessários para a estaca penetrar no solo em função da profundidade, e compará-las com os índices de resistência a penetração de um ensaio SPT, esse registro é definido como diagrama de cravação.

O diagrama consiste em registrar o número de golpes aplicados pelo sistema de cravação, para um determinado nível de energia aplicado no topo da estaca, para a cravação de um comprimento pré-definido (normalmente se adota $0,5 \mathrm{~m}$ ou $1,0 \mathrm{~m}$ ). Nos Estados Unidos é usual se referenciar a 1 pé $(0,33 \mathrm{~m})$, e é designado por blows per foot. A NBR 6122 (2010) estabelece que se deve elaborar o diagrama de cravação em $100 \%$ das estacas.

Velloso e Lopes (2010) recomendam a elaboração do diagrama de cravação em pelo menos uma de cada 10 estacas, ou em uma estaca de cada grupo ou pilar, ou ainda, sempre que uma estaca for cravada perto de uma sondagem.

O procedimento consiste em fazer marcas com giz (Figura 2.4.a) na estaca nos intervalos de comprimento predefinido $(0,3 \mathrm{~m}, 0,5 \mathrm{~m}$ ou $1,0 \mathrm{~m})$, antes da estaca ser levantada, e, durante o processo de cravação, contar os golpes necessários para cravar um trecho entre marcas.

É importante verificar durante a cravação se não houve alteração na energia aplicada pelo sistema de cravação, o que pode influenciar em uma maior ou menor penetração da estaca, e depois dificultar a interpretação do diagrama pela mudança de critério.

Habitualmente, os resultados (Figura 2.4.b) são apresentados comparando-se o número de golpes para a penetração de uma parte da estaca com o índice de resistência a penetração ( $N_{S P T}$ ) ao longo da profundidade, permitindo-se assim, verificar a estratigrafia do terreno e as transições de camadas.

Vieira (2006) apresenta uma metodologia para avaliação da resistência mobilizada via fórmulas dinâmicas através do registro do diagrama de cravação. 

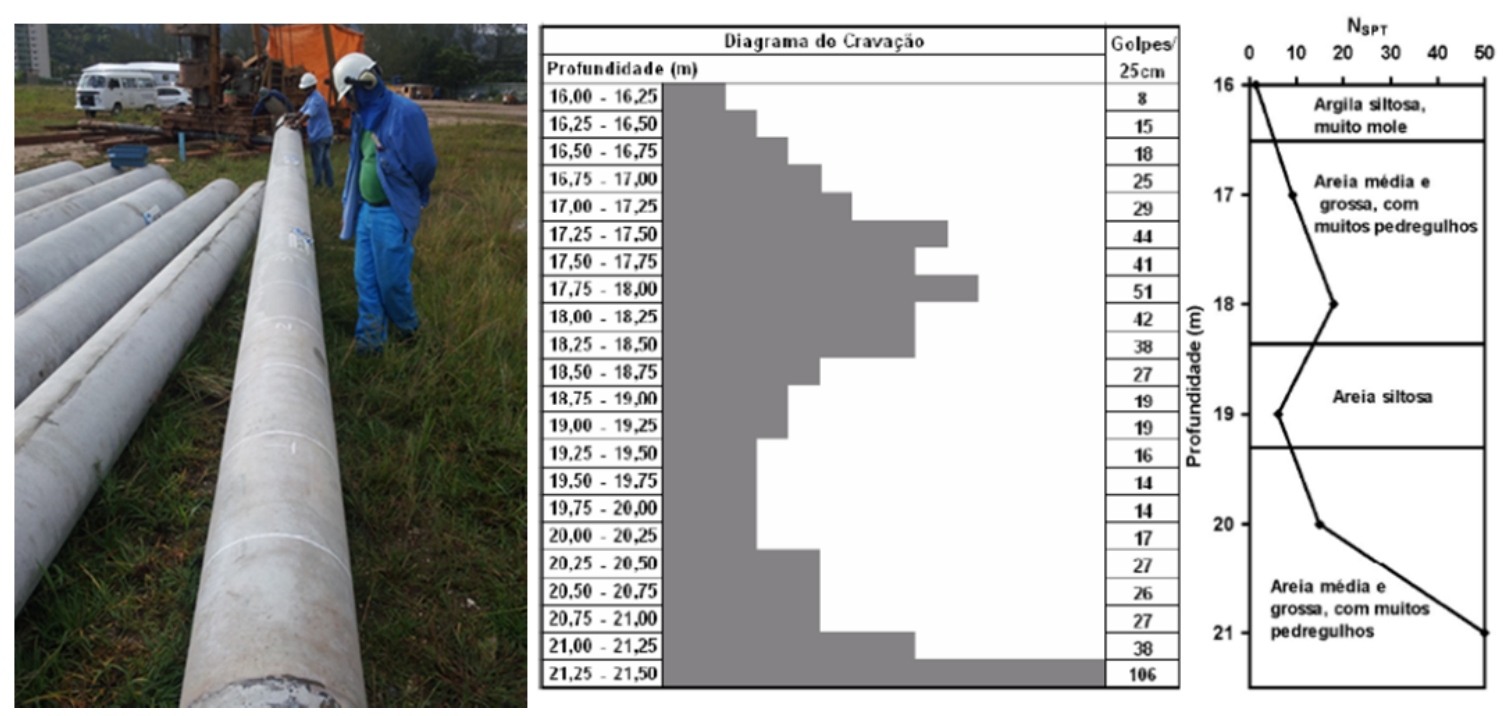

Figura 2.4- a) Marcações definidas no fuste da estaca para elaboração do diagrama de cravação e b) exemplo de diagrama de campo.

\subsubsection{Prova de carga estática}

As provas de carga estáticas (PCE) são realizadas nos elementos de fundação com o objetivo de verificar o comportamento previsto em projeto e retroanalisar as premissas adotadas no modelo de previsão, em termos de capacidade de carga e deslocamentos e definir a carga de trabalho em casos que não se tem nenhum conhecimento prévio da área e/ou consiga prever o comportamento (Velloso e Lopes, 2010).

Nesse ensaio pretende-se reproduzir o carregamento real que será aplicado à fundação, provocado através de incrementos de carga (em estágios), e medindo-se os deslocamentos correspondentes. Para níveis de carga crescentes busca-se caracterizar a carga de ruptura do sistema estaca-solo, em que ocorre o deslocamento contínuo da estaca sem novos acréscimos de carga.

Niyama et al. (1996) apresenta que uma das grandes vantagens da PCE é de representar o complexo comportamento do conjunto estaca-solo, influenciado pelas modificações causadas no solo pela instalação da estaca, e pelas incertezas decorrentes das dificuldades executivas.

A NBR 6122 (2010) define a obrigatoriedade de execução de provas de carga 
estática em obras, e especifica a quantidade em função do tipo de estaca. Para o caso de estacas pré-moldadas, a partir de 100 estacas é obrigatório à execução da PCE, e quando o número de estacas for superior a esse limite, deve-se executar o valor de no mínimo $1 \%$ da quantidade total, sempre se arredondando para um número inteiro.

A norma estabelece que para a determinação da carga admissível da estaca a partir de provas de carga é necessário que a prova de carga seja estática, e que tenham sido especificadas na fase de projeto, e executadas no início da obra, de modo que haja tempo para adequar o projeto, e a prova de carga sejam levados até um mínimo de duas vezes a carga admissível prevista em projeto.

As PCE são normatizadas pela NBR 12131 (2003), queestabelece diferentes procedimentos de carregamento se dividindo nas seguintes modalidades:

a) Carga controlada: carga incremental lenta (SML - slow maintainde load test), carga incremental rápida (QML - quick maintaned load test) ou carga cíclica (CRP - constant rate of penetration).

b) Deformação (deslocamento) controlada.

c) Método do equilíbrio.

Os ensaios mais comuns são os de carga incremental, com a aplicação de incrementos de carga mantidos até que ocorra a estabilização (ensaio lento) independentemente do tempo necessário, e os ensaios que a carga aplicada é mantida por um tempo pré-estabelecido, normalmente 15 minutos (ensaio rápido).

A velocidade de carregamento da PCE influencia os resultados do ensaio, entretanto em termos de caracterização da carga de ruptura os valores são compatíveis.

Milititsky (1991) comenta que a resistência ao cisalhamento do solo é afetada diretamente pela velocidade de carregamento, especialmente em argilas, no caso de fundações o comportamento também é alterado, pelo incremento da capacidade de carga e rigidez do sistema estaca-solo.

Devido questões de cronograma de implementação de uma obra em algumas situações, é comum a aplicação de um método misto entre os dois, sendo que até a carga máxima do ensaio se aplicam o ensaio rápido e na carga máxima do ensaio se estabiliza como um ensaio lento. 


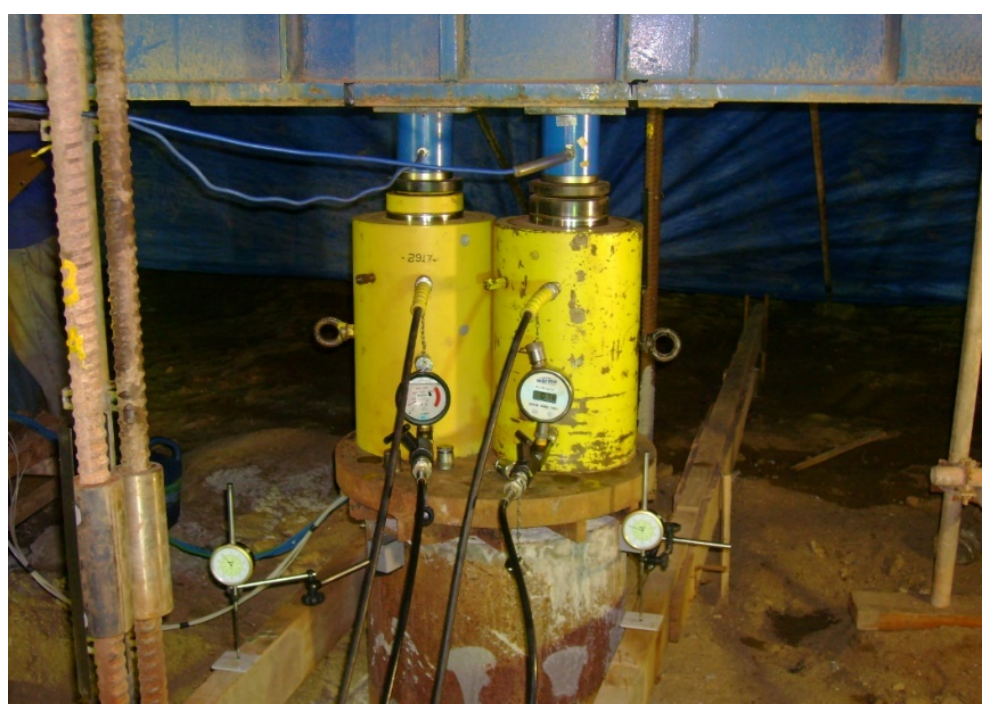

Figura 2.5 - Arranjo da montagem de uma prova de carga estática.

Um possível arranjo da montagem de uma prova de carga é apresentado na Figura 2.5, com o uso de macacos hidráulicos, e para a instrumentação células de carga e extensômetros para registras as leituras de força aplicada e deslocamento respectivamente.

Quando na execução da PCE o ensaio não permite caracterizar a carga de ruptura do sistema, pode-se tentar a extrapolação da curva carga aplicada x deslocamento, adotandose um modelo matemático que proporcione o melhor ajuste com os dados medidos na prova de carga. As principais funções utilizadas neste caso são:

a) Função exponencial proposta por Van der Veen (1953) e o método gráfico de Mazurquiewicz (1972).

b) Função parabólica proposta por Hansen (1963).

c) Função hiperbólica proposta por Chin (1970) e o método da rigidez infinita de Décourt (1996).

d) Função polinomial proposta por Massad (1986).

Mesmo definida a carga de ruptura através de um modelo matemático a curva carga aplicada por deslocamento precisa ser interpretada para a definição da carga admissível da estaca. Apenas um exame visual na curva e sua extrapolação podem ser insuficientes mesmo que nos casos em que se caracterizou uma assíntota vertical, a simples alteração da 
escala do gráfico pode afetar a interpretação.

Nesse sentido pode se estabelecer um critério, como o apresentado pela NBR 6122 (2010), em que é convencionada a carga de ruptura como aquela que corresponde na curva carga aplicada por deslocamento ao recalque obtido pela expressão [2.1]. Um critério bastante similar é apresentado por Davisson (1972) definido na expressão [2.2].

$$
\Delta r=\frac{P \cdot L}{A \cdot E}+\frac{D}{30}
$$

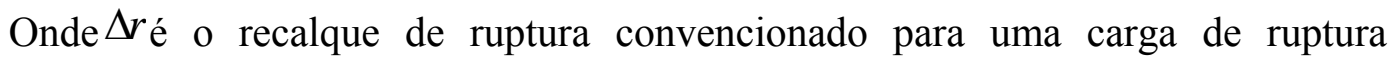
convencionada ( $P$ ), para o comprimento da estaca $(L)$, o diâmetro do círculo circunscrito ( $D)$ à estaca, $A$ e $E$ a área da seção transversal e o modulo de elasticidade do material respectivamente.

$$
\Delta r=\frac{P \cdot L}{A \cdot E}+\frac{D}{120}+3,8 m m
$$

Velloso e Lopes (2010) apresentam um resumo dos principais critérios empregados, que são agrupados em quatro categorias:

a) Critérios baseados num valor absoluto do recalque sejam total, plástico ou residual.

b) Critérios baseados na aplicação de uma montagem ou regra geométrica à curva.

c) Critérios que buscam definir uma assíntota vertical.

d) Critérios que caracterizam uma carga de ruptura convencionada a partir de uma parcela do encurtamento elástico somado a um percentual do diâmetro da base.

A Figura 2.6 apresenta esquematicamente os critérios de interpretação da curva carga aplicada por deslocamento. 

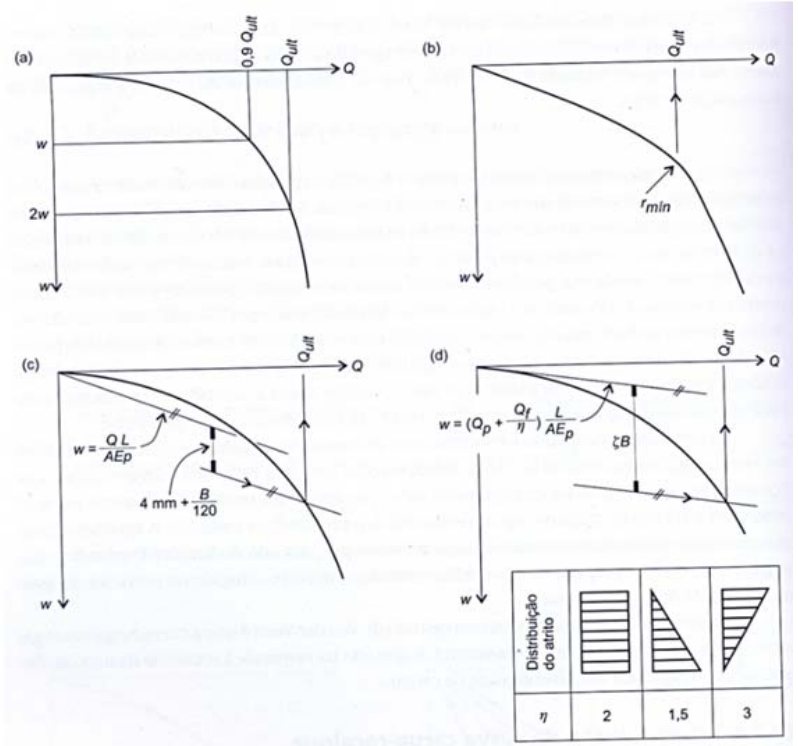

Figura 2.6 - Interpretação dos resultados das PCE (Velloso e Lopes, 2010).

\subsubsection{Fórmulas dinâmicas}

As fórmulas dinâmicas são expressões matemáticas que tentam correlacionar medidas de deslocamento da estaca (nega e repique elástico) registradas durante a aplicação do golpe pelo sistema de cravação com um valor de resistência mobilizada, que a princípio não é a capacidade de carga estática da estaca.

O processo de cravação de uma estaca pode ser entendido como um fenômeno de impacto, que pode ser interpretado pela: teoria do choque de corpos rígidos (ou de Newton), lei de Hooke (corpo deformável), lei de conservação de energia, ou como um fenômeno de propagação de ondas de tensão em barras, que é descrito pela teoria da equação da onda.

Apesar de intenso uso dessas fórmulas, principalmente as que tratam do fenômeno do impacto, observa-se que os resultados ainda são insatisfatórios em aplicações generalizadas (Rosa, 2000), pois envolvem uma série de incertezas tanto com relação a: validade das teorias empregadas, condições que foram desenvolvidas (condições de contorno relacionadas à variabilidade do solo), e com a confiança dos resultados obtidos (Poulos, 1980 e Liang, 1997).

Para a NBR 6122 (2010) as fórmulas dinâmicas baseadas na nega e repique elástico visam principalmente assegurar a homogeneidade das estacas cravadas. 
Mello e Sobral (1997) comentam que as fórmulas dinâmicas têm sido tratadas com bastante confiança pelos empreiteiros, a despeito de uma série de publicações que as questionam, e que apesar disso há décadas não se ousou formular novas expressões, e as antigas continuam a orientar as rotinas de controle de campo, motivando reformulações das normas de fundação.

Mesmo que as fórmulas dinâmicas estejam sujeitas a várias restrições, não deixam de ser uma medida para auxiliar o engenheiro de campo na tomada de decisões, e oferecer uma razoável segurança e uniformidade ao estaqueamento (Machado, 1995).

Na década de 80 , para a definição do controle das medidas de nega com o uso de martelos de queda livre e a diesel, existiam gráficos formulados por fabricantes de equipamentos que correlacionavam a dificuldade de cravação da estaca com a resistência mobilizada, e serviam para controle de campo - Figura 2.7.

Atualmente no Brasil ocorre um crescimento no parque de equipamentos, principalmente a evolução em martelos hidráulicos. Esse sistema incorpora diversos sistemas de monitoramento contínuo do equipamento permitindo controlar a energia aplicada em cada golpe, a eficiência do sistema, a contagem de golpes, o comprimento cravado, e existem módulos auxiliares que permitem registrar o repique elástico durante a cravação.

Entretanto, as formulações de controle para esses equipamentos dependem de novas ferramentas de controle, como sistemas de monitoramento contínuo (Zhang, 2005), com a reformulação de expressões baseadas no trabalho do sistema.

Aoki (1997) apresenta uma abordagem de interpretação com a aplicação do princípio de Hamilton, em que a variação da energia cinética $(T)$ e potencial $(V)$, mais a variação do trabalho $\left(W_{n c}\right)$ efetuado pelas forças não conservativas durante o intervalo de tempo $(\delta)$, dentro do sistema, é zero - expressão [2.3]. 


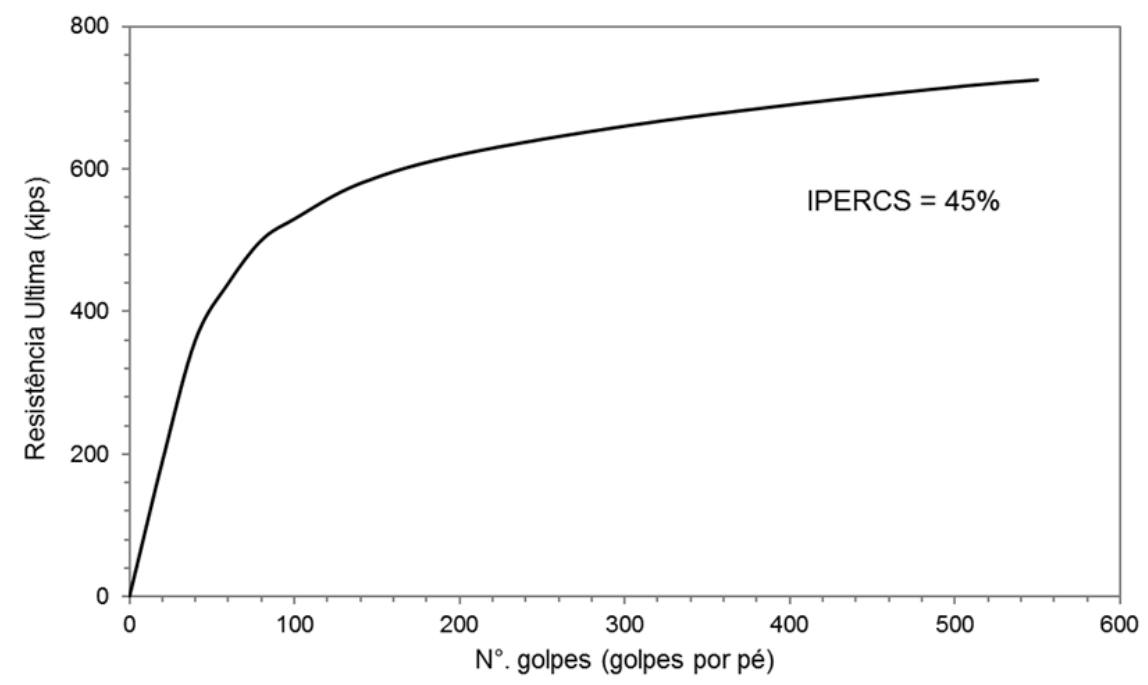

Figura 2.7 - Gráfico de controle de capacidade de carga de campo, para o martelo Delmag D30 (Wang, 1992).

$$
\int_{t 1}^{t 2} \delta \cdot(T-V) d t+\int_{t 1}^{t 2} \delta \cdot\left(W_{n c}\right) d t=0
$$

Velloso e Lopes (2010) citam que os fatores de segurança aplicados às fórmulas dinâmicas variam de 2 a 10, e tendo em vista essas incertezas seu melhor uso está no controle da homogeneidade do estaqueamento, nesse caso os autores recomendam:

a) Cravar uma estaca de referência próxima a um perfil de sondagem, baseando-se no comprimento definido nas previsões obtidas dos métodos semi-empíricos, e observar os valores de nega e repique obtidos no final da cravação.

b) Executar na mesma estaca uma PCD e/ou PCE a fim de calibrar um fator de correção para as fórmulas dinâmicas escolhidas.

c) Empregar a expressão aferida no controle das demais estacas cravadas.

\subsubsection{Expressões derivadas da lei do impacto}

A lei do impacto de Newton (teoria de choque dos corpos rígidos), também conhecida como método da conservação da energia, compara a energia potencial disponível (U) aplicado no golpe do martelo com o trabalho (Wnc) necessário para romper o solo 
realizado pelas forças não conservativas, acrescido de uma parcela referente as perdas do sistema (devido ao sistema de cravação, atrito dos cabos, amortecimento e outros). Matematicamente é expressa por [2.4].

$$
V=W_{n c}+\text { perdas }
$$

A energia potencial disponível (V), devida ao peso do martelo (W) suspenso a uma altura (H), por um coeficiente "e" que é a eficiência do sistema, e o trabalho das forças não conservativas (Wnc), corresponde à resistência última multiplicada pela penetração permanente (S). Reescrevendo a equação para obter a resistência mobilizada pelo golpe:

$$
R_{m}=\frac{e \cdot W \cdot H-\text { perdas }}{S}
$$

A expressão [2.5] expressa o equilíbrio entre os esforços atuantes (energia potencial - V) e resistentes (resistência última do sistema estaca-solo) desenvolvidos em um impacto newtoniano. Essa expressão é a base para diversas formulações, onde diferem entre si pela consideração da parcela das "perdas de energia" do sistema, em que cada autor as considera de diferentes maneiras.

Como exemplos de fórmulas dinâmicas baseadas na lei do impacto Newtoniano há: equação de Janbu (1957), Engineering News, Michigan Engineering News, Navy-McKay, Terzaghi, Redtenbacher, Canadian Building Code, Gates e outros. (Lowery Jr. et al., 1968)

Janbu (1957) modificou a expressão de Weisbach (1850) considerando que a única perda do sistema, seja devido à compressão elástica da estaca $(C 2$ ) relacionando a um percentual da energia disponível $(1,5+0,3 \cdot W)$ devido ao impacto, resultando na expressão [2.6]. O fator de segurança recomendado é igual a 3,0.

A fórmula da Engineering New Records, proposta por Wellington (1888), ainda hoje é muito utilizada nos Estados Unidos. Esta fórmula foi originalmente desenvolvida para estacas de madeira cravadas com martelo de queda livre. A energia potencial disponível no sistema (W.H) é representada pela área do trapézio OABD (Figura 2.8), e a energia dissipada pela triângulo BCD. 


$$
\frac{e \cdot W \cdot H}{(1,5+0,3 W)}=R \cdot S+\frac{R^{2} \cdot L}{2 \cdot E \cdot A}
$$

Onde $L$ é o comprimento da estaca, $A$ a área da seção transversal e $E$ o módulo de elasticidade da estaca.

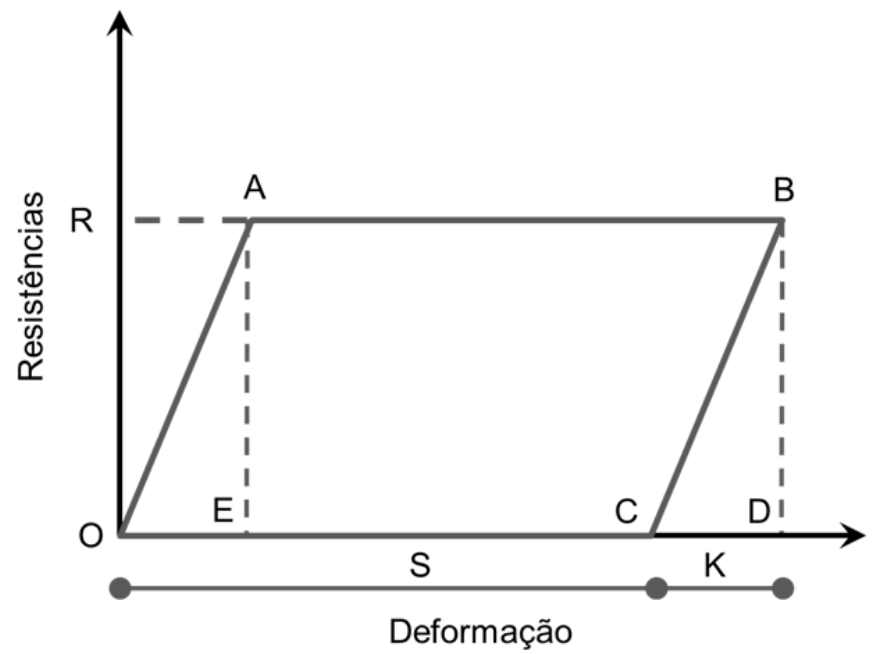

Figura 2.8 - Gráfico da resistência versus deslocamento para um golpe (Whitaker, 1976).

A partir das áreas:

$$
\begin{aligned}
& W \cdot H=\operatorname{Area}(O A B D) \\
& W \cdot H=\operatorname{Area}(O A B C)+\operatorname{Area}(B C D) \\
& W \cdot H=R \cdot S+R \cdot\left(\frac{K}{2}\right) \Rightarrow W \cdot H=R \cdot\left(S+\frac{K}{2}\right)
\end{aligned}
$$

Finalmente:

$$
R=\frac{W \cdot H}{\left(S+\frac{K}{2}\right)}[2.7]
$$

Onde K representa a deformação elástica do sistema estaca-solo (repique elástico), sendo sugerido por Wellington (1888) adotar empiricamente os valores de $K / 2=1$ " para martelos de queda livre e $K / 2=0,1 "$ para martelos a vapor.

Nessa expressão são desprezadas as perdas referentes ao encurtamento elástico do 
solo ( $C 3$ ), do capacete e sistema de amortecimento $(C 1)$, recomendando a utilização de um fator de segurança ( $F S$ ) igual a 6,0 .

Zhang et al. (2003) consideram que essa formulação conduz a resultados com grandes dispersões, propondo a aplicação de um fator de correção que leve em consideração as perdas devido ao impacto. Hiley (1925) considera que a energia disponível do sistema é consumida em parcelas de deformação elástica, e que por sua vez as perdas devido às deformações elásticas do solo $\left(C 3\right.$ ) e do capacete $\left({ }^{C 1}\right)$, resultando na expressão [2.8].

$$
R_{m}=\frac{e \cdot W \cdot H}{S+\left(\frac{K}{2}\right)} \times \frac{W+\eta^{2} \cdot W_{P}}{W+W_{P}}
$$

Onde é feita uma separação entre peso do martelo $(W)$ e da estaca ( $\left.{ }^{W p}\right), S_{\text {é a }}$ nega e $K$ o repique elástico composto pelo encurtamento elástico da estaca ( $C 2$ ), $C 3$ a deformação plástica do solo e $\eta_{0}$ coeficiente de restituição. É proposto um fator de segurança igual a 2,8 .

Outras fórmulas baseadas nas considerações de Hiley (1925) são: a dos Holandeses (1812), de Sanders (1851) e de Eytelwein (1820). Na maioria dessas expressões a grande diferença conforme dito está na adoção da parcela de perdas de energia. Os autores propõem a aplicação de um fator de segurança variando de 2 a 8 .

Velloso e Lopes (2002) apontam que as principais perdas no sistema de cravação são causadas por:
a) Atrito do martelo nas guias.
b) Atrito no cabo das roldanas.
c) Repique do martelo (levantamento após o choque).
d) Deformação elástica do cepo e coxim (C1) e da estaca (C2).
e) Deformação elástica do solo (quake ou C3).

A confiabilidade no uso dessas expressões está vinculada à aferição contínua na 
execução, pela verificação dos modelos que melhor se ajustem aos dados, correlacionando-se com PCD, PCE e com a previsão, calibrando-se fatores para os casos e condições locais específicos, ajustando-se aos condicionantes geológico-geotécnicos, aos diferentes tipos de estaca, equipamento de cravação, níveis de energia aplicados e outros. Ignorando-se essas condições, as fórmulas dinâmicas se tornam ferramentas perigosas na tomada de decisões.

\subsubsection{Expressões derivadas da Lei de Hooke}

Considerando-se a estaca com comportamento perfeitamente elástico, existe proporcionalidade entre tensão aplicada e deformação, sendo expresso pela Lei de Hooke. A rigor essa hipótese só é válida para carregamentos estáticos por não considerar os efeitos das ondas geradas por um carregamento e descarregamento dinâmico, mas apesar disso ela tem fornecido bons resultados (Rosa, 2000).

Chellis (1951) propõe que para a fórmula dinâmica de Hiley (1925) a resistência última de uma estaca cravada é expressa por [2.9].

$$
R u=\frac{e \cdot W \cdot H}{S+0,5 \cdot(C 1+C 2+C 3)} \cdot \frac{W+n^{2} \cdot W p}{(W+W p)}
$$

A energia correspondente à deformação elástica (C2) do fuste da estaca é definida por Chellis (1951) através da expressão [2.10].

$$
E e=\frac{R^{2} \cdot l}{2 \cdot E \cdot A}=\frac{R \cdot C 2}{2} \Rightarrow C 2=\frac{R_{u} \cdot l}{A \cdot E}
$$

Onde Ru é a resistência mobilizada, C2 a deformação ou encurtamento elástico do fuste da estaca, E o módulo de elasticidade do material, A é a área da seção transversal e 1 profundidade do centro de compressão (comprimento virtual).

A consideração do parâmetro 1 na expressão permite considerar a existência de uma parcela de atrito lateral, ao invés de simplificar considerando apenas que a resistência esteja toda concentrada na ponta da estaca caso considerássemos o comprimento total cravado 
(Machado, 1995).

Nos estudos desenvolvidos por Aoki (1986), é concluído que Ru é diretamente proporcional ao valor de $\mathrm{C} 2$, e que para a determinação da resistência mobilizada última é necessário medir em campo o valor de C2 durante a cravação e aplicar na expressão [2.11] reescrita a partir de [2.10].

$$
R u=\frac{C 2 \cdot A \cdot E}{l}
$$

Como se pretende determinar a reação do solo faz-se o cálculo a partir da deformação da estaca $(\mathrm{C} 2)$, obtido entre a diferença do repique elástico (K) medido em campo e o valor estimado de deformação elástica do solo (denominado quake- C3).

Aoki (1986) ressalta que a simplificação da expressão [2.11] não é válida para solos resilientes (ou borrachudos), devido a uma distorção na consideração da parcela do quake do solo. Como o valor do quake do solo não é medido em campo pode se adotar a princípio os valores de 1" (2,54 mm) ou a nega do golpe (Uto, 1985).

Para Casagrande (1942) a energia despendida na compressão elástica (C2) do sistema estaca-solo não pode ser considerado como perda, mas sim como uma energia temporariamente armazenada na forma de compressão elástica, a qual está testando à resistência oferecida (reação) do solo a penetração dinâmica da estaca.

Velloso (1987) propôs adotar o comprimento virtual como um percentual (aplicando um coeficiente $\alpha$ ) ao comprimento real cravado $(L)$ em função do diagrama de transferência de carga, em que para a ${ }^{\alpha=0,5}$ para a estaca que resiste apenas por atrito e $\alpha=1,0$ para a estaca que resiste pela ponta.

O coeficiente $\alpha$ exprime o diagrama de transferência de carga na estaca entre as parcelas de atrito e ponta, com base em um diagrama genérico de distribuição das parcelas de resistência (Figura 2.9) e integrando a área obtida no gráfico obtém-se a expressão [2.12]. 


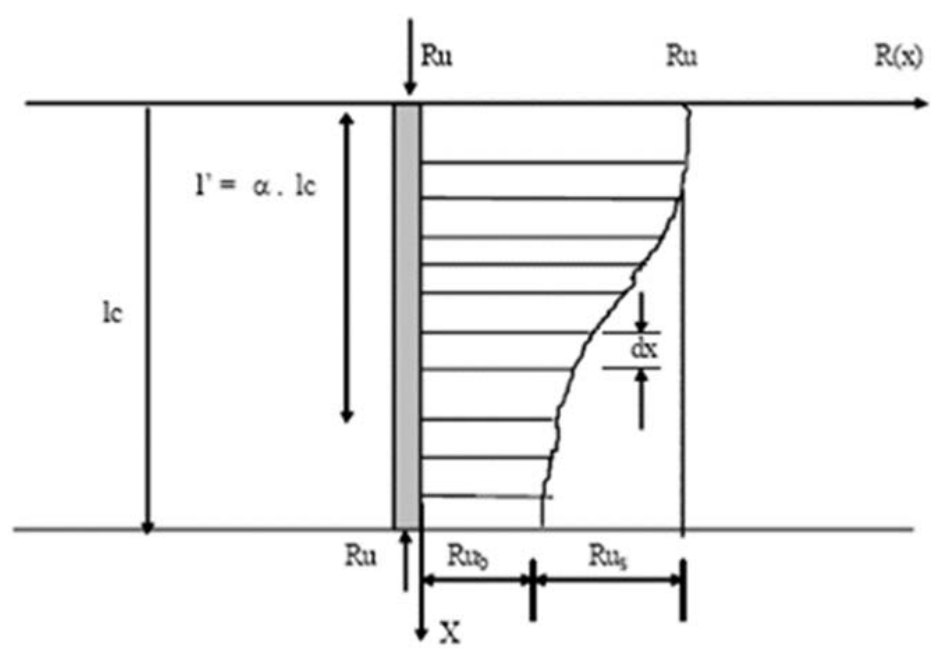

Figura 2.9 - Diagrama de distribuição de resistência genérico (Velloso, 1987).

$$
\alpha=\int_{0}^{L} \frac{R(z)}{L \cdot R_{u}} \cdot d z
$$

Pela demonstração de Aoki (1989), o termo $\alpha \cdot l$ seria igual ao valor do parâmetro d, sendo que esse termo procura levar em consideração o diagrama de transferência no cálculo da resistência mobilizada em função do valor de $\mathrm{C} 2$. O coeficiente pode ser obtido pela expressão aproximada [2.14].

$$
\begin{gathered}
\alpha=\beta+\lambda \cdot(1-\beta) \\
\beta \approx \frac{R_{u b}}{R_{u}} \quad
\end{gathered}
$$

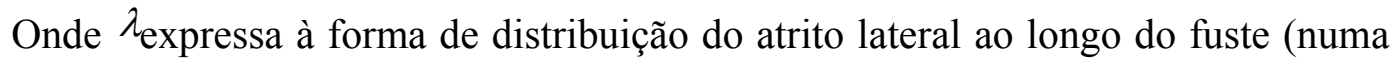
distribuição uniforme $=0,5)$ e ${ }^{\beta}$ expressa à relação entre a parcela de ponta da estaca $\left(R_{u b}\right)$ e a carga total $\left(R_{u}\right)$. Por uma questão de nomenclatura para o fator $\alpha$ será denominado por $f$.

Reescrevendo-se a expressão [2.11] em função da medida de repique e da proposta de Velloso (1987) resulta em [2.15]. 


$$
R_{u}=\frac{C 2 \cdot E \cdot A}{f \cdot L} \Rightarrow R_{u}=\frac{(K-C 3) \cdot E \cdot A}{f \cdot L}
$$

Velloso considera que, na ausência de dados, uma primeira estimativa pode se $\operatorname{adotar} f=0,7$. Rosa (2000), pela retroanálise de uma série de dados de provas de carga dinâmica, correlacionados com fórmulas dinâmicas, recomenda-se $f=0,8$ na ausência de dados.

\subsubsection{Smith modificado por Aoki (2011)}

Pela curva da prova de carga dinâmica obtida pelos diferentes níveis de energia aplicados, tem-se a princípio a resistência total $\left({ }^{R_{t}}\right)$ que de acordo com o modelo de Smith é comporto por duas parcelas - dinâmica e estática $\left({ }^{R_{u}}\right)$. A resistência dinâmica corresponde a uma parcela da resistência total, que multiplicando essa pelo fator de amortecimento dinâmico $\left({ }^{{ }^{c}}\right)$ encontra-se a resistência estática $\left({ }^{R_{u}}\right)$. Essa rotina de cálculo é muito similar ao que é desenvolvido pelo método CASE.

A Figura 2.10 apresenta graficamente a transformação da curva de resistência total obtida na prova de carga dinâmica ( $O A$ ) em estática $(O B)$, descontando-se a parcela de resistência dinâmica $\left(R_{u} \cdot J \cdot v\right)$, e a área $E F D$ representa o modelo elastoplástico idealizado por Smith (1960).

Aoki (1996) analisando a curva de resistência estática, o modelo de Smith e analisando a chamada fórmula de energia, a energia de deformação do sistema que corresponde à área da curva $O B$, pode ser aproximadamente a área $E F D$. A partir dessa consideração:

$$
\text { AreaEFD }=\frac{(S+D) \cdot R_{u}}{2} \Rightarrow R_{u}=\frac{2 \cdot \text { AreaEFD }}{(S+D)}
$$


A partir de Aoki e Cintra (1997), o valor da área EFD é um percentual da energia líquida aplicada no topo da estaca pelo sistema de cravação ( $E M X)$, em que Aoki (1996) propõe uma modificação nessa expressão aplicando um fator, denominado de ZETA $(\xi)$ para corrigir esse efeito, variando entre 1 a 2. A expressão resulta em:

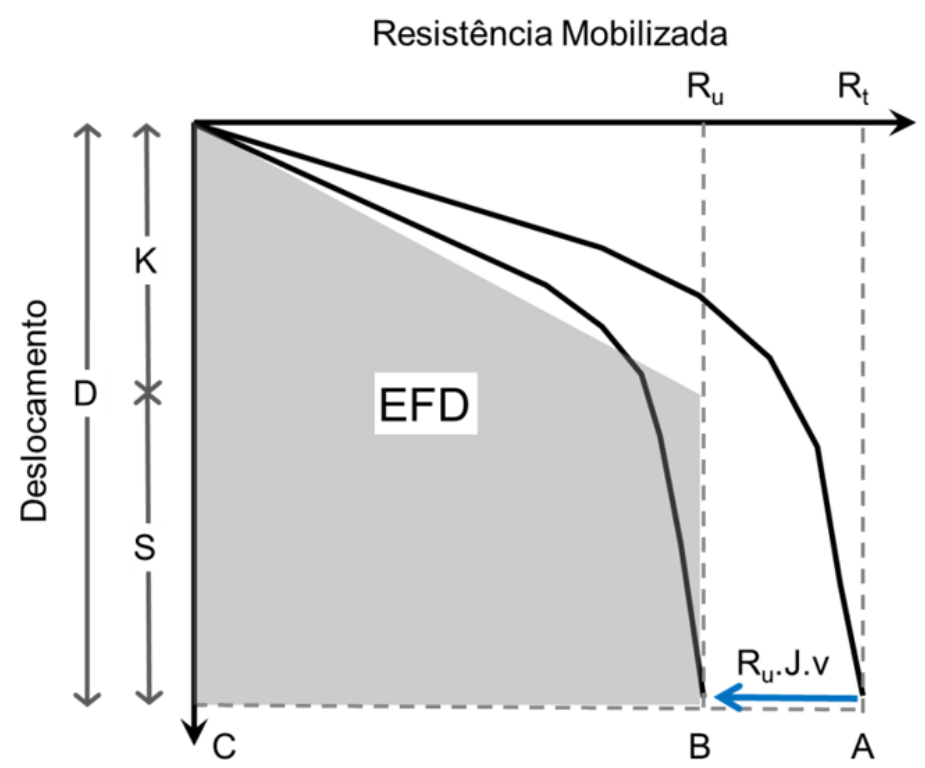

Figura 2.10 - Transformação da curva de resistência total em estática (Cintra et al., 2013).

$$
R_{u}=\frac{\xi \cdot E M X}{(S+D)}
$$

Essa expressão tem como grande vantagem à calibração de um único parâmetro $\xi$ que é calibrado diretamente com os resultados da PCD, no caso de $E M X_{\text {pode ser obtido }}$ através do ensaio ou a partir da eficiência média em função dos diferentes equipamentos de cravação pela energia potencial aplicada. O fator $S_{\text {representa o valor da nega aplicado no }}$ golpe, e $D$ é o deslocamento total que é igual ao somatório da nega e repique elástico.

Outro potencial dessa expressão é a menor influência da resiliência do solo na ponta da estaca, que afeta diretamente a determinação do quake do solo ( $C 3$ ) da expressão de Chellis (1951). 


\subsubsection{Formulação considerando a abordagem de energia}

A consideração da abordagem da energia (ou Energy Approach) proposta por Paikowsky \& Chernauskas (1992) consiste num balanço de energia entre a energia total transferida (igual à energia potencial multiplicado pela eficiência do sistema) e o trabalho realizado pelo sistema estaca-solo.

Nessa situação a resistência estática segue um modelo elastoplástico, que obedece a uma relação de força por deslocamento. Diferentemente, no método da equação da onda à estaca é discretizado em uma série de conjuntos de molas e pesos (item 2.4.5.3), calculandose as distribuições de resistência em cada trecho em toda a profundidade ao longo da estaca, simulado a partir da propagação da onda de tensão.

A equação do Energy Approach se baseia na energia de entrada no sistema, portanto apenas na seção instrumentada. Embora as perdas devido aos efeitos dinâmicos sejam consideradas pelo amortecimento viscoso, eles não são representados na equação dinâmica, portanto a velocidade da partícula ao longo da estaca não é avaliada.

Contudo, a componente dinâmica das forças resistentes, mesmo que representadas pelo amortecimento dinâmico, é responsável por outras perdas como a radiação, inercia do solo, amortecimento verdadeiro e outros. Essas perdas de energia são determinadas pela combinação da forma da estaca e pelo tipo de solo envolvente em acréscimo a velocidade de penetração.

A equação da onda considera o amortecimento e suas respectivas perdas em cada segmento discretizado e de forma indireta as perdas de energia para diferentes tipos de estacas e solos circundantes. Como resultado dessas avaliações Paikowsky \& Chernauskas (1992) apontam:

a) Existe uma pequena correlação entre o solo circundante e os parâmetros de amortecimento.

b) Enquanto a resistência total da estaca pode ser avaliada com precisão por uma análise do tipo CAPWAP, a distribuição de resistências ao longo da profundidade não é necessariamente precisa.

c) Existe uma influência do efeito escala nos parâmetros de obtenção da energia líquida ao trabalho produzido, que é em função do tipo de estaca e dos níveis de 
deslocamento.

A partir de uma relação força-deslocamento elasto-plástica (Figura 2.8) o trabalho da força resistente $-R_{u}$ é dado pela área do trapézio resultando em:

$$
W=R_{u} \cdot\left(S+\frac{K}{2}\right)
$$

Onde $\mathrm{W}$ é o trabalho total do sistema, $\mathrm{Ru}$ é a resistência mobilizada, $\mathrm{S}$ é a deformação permanente (nega) e Ké a deformação elástica do conjunto estaca-solo (repique elástico). Reordenando os termos da expressão [2.18] a resistência mobilizada vale:

$$
R_{u}=\frac{E_{\text {máx }}}{\left(S+\frac{K}{2}\right)}
$$

Essa equação é denominada pelos autores de equação básica do balanço de energia. Os parâmetros das equações são alimentados com valores medidos durante a cravação das estacas. As condições do método são:

a) A energia entregue é tomada como a energia máxima obtida pelo valor máximo da expressão [2.20].

$$
E_{d}=E_{\text {máx }}=\int_{0}^{t} V(t) \cdot F(t) \cdot d t
$$

Onde $V(t)$ e $F(t)$ são funções de velocidade e força medidas em campo.

b) A deformação elástica estaca-solo é avaliada pela diferença entre o máximo deslocamento medida no topo e a deformação permanente do solo (nega), onde o máximo valor do deslocamento é obtido por [2.21]. 


$$
S=\operatorname{máx} \int_{0}^{t} V(t) \cdot d t
$$

c) A deformação permanente é obtida pelo deslocamento final para o tempo total medido.

$$
D_{\text {final }}=\int_{0}^{t} V(t) \cdot d t
$$

Os autores recomendam a utilização dos valores de contagem de golpes em campo para a quantificação da deformação permanente. Como resultado dessas condições de contorno como equação básica da abordagem de energia definida como:

$$
R_{u}=\frac{E_{\text {máx }}}{S+\left(D_{\text {máx }}-S\right) / 2}
$$

Essa equação apenas considera as perdas de energia elasto-plástica do sistema estaca-solo e considera como a máxima resistência possível. Deve-se aplicar uma correção simples para a avaliação da capacidade de carga estática $\left({ }^{R_{S}}\right)$ considerando todas as perdas de energia dinâmicas geradas pelo solo de forma simplificada.

$$
R_{S}=K_{S P} \cdot R_{u}
$$

$K_{S P}$ é denominada de coeficiente de capacidade estática e ${ }^{R_{u}}$ é a resistência mobilizada total avaliada pela expressão [2.23].

Paikowsky e Chernauskas (1992) apresentaram a aplicação da expressão em 14 casos, sendo composto por 9 tipos diferentes de estacas e 3 tipos de terrenos com os dados extraídos de Thompson \& Devata (1980).

Os resultados foram interpretados com o uso de prova de carga dinâmica, e as curvas foram extrapoladas a fim de se uniformizar o banco de dados. Como conclusão foi apresentada a curva baseada no método em comparação com os resultados de provas de carga estática. 
Nos resultados foram observadas duas fronteiras, uma superior da razão entre os valores de capacidade de carga medidos e previstos igual a 1,25, e um inferior com esta relação igual a 0,80 . Os pontos calculados apresentaram uma boa convergência dentro dessa área - Figura 2.11.Para os casos de nega fechada existe uma boa convergência com as análises do tipo CAPWAP ou TEPWAP, contudo para relações maiores existe a ocorrência de superprevisão. Com relação ao parâmetro de ajuste para previsão da capacidade de carga estática, os valores para $K_{S P}$ variam entre 0,8 a 1,0 .

Paikowsky e Stenersen (2000) utilizaram a expressão em comparações com resultados de analises CAPWAP, e concluíram que a abordagem pela energia resulta num coeficiente de variabilidade menor do que encontrado nas análises numéricas.

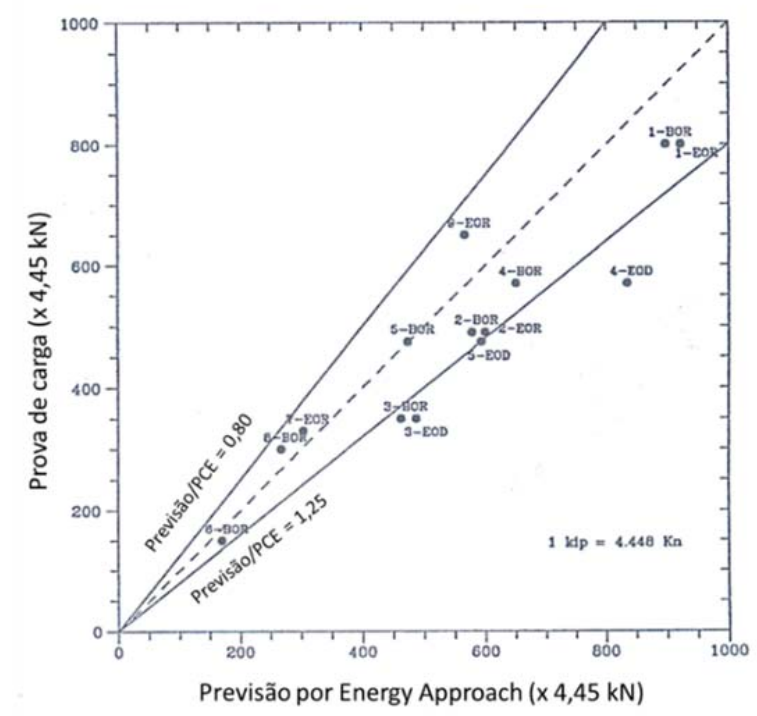

Figura 2.11: Comparação entre os resultados de PC e valores de resistência mobilizada baseado no Energy Approach (Paikowsky e Chernauskas, 1992).

Com o uso crescente de martelos hidráulicos para a cravação de estacas, Zhang (2005) apresenta uma fórmula dinâmica que parte das premissas da equação básica da energia aproximada, mas aplicando-se um conceito de energia efetiva, que pode ser definida como a parcela de energia transferida que causa diretamente a penetração permanente da estaca.

A formulação parte da definição de que a energia medida no topo da estaca, que em termos da prova de carga dinâmica é denominada de energia líquida $(E M X)$ não é 
totalmente transferida para causar a penetração da estaca no terreno, seguindo o conceito de que havendo penetração há mobilização de resistência.

Assumindo-se que a resposta do solo à cravação da estaca é perfeitamente elástica, e que a relação resistência-deslocamento é a relação entre o sistema estaca-solo durante a aplicação de um golpe - similar à condição de um martelo hidráulico, o trabalho efetuado é denominado de energia transferida $\left({ }^{{ }}{ }\right)$.

Partindo da expressão [2.18], e por definição de energia efetiva, para um golpe aplicado pelo martelo:

$$
E_{e f}=R \cdot S
$$

Para efeitos de simplificação, a energia efetiva que entra no sistema estaca-solo quando medida com o uso de provas de carga dinâmica assume o mesmo valor, portanto a eficiência do sistema pode ser definida por $e=E_{e f} / V$. Rescrevendo as equações [2.18] e [2.25], onde está em função da deformação permanente - S (nega) e da compressão elástica do sistema $-\mathrm{K}$ (repique elástico).

$$
e=\frac{S}{S+\frac{K}{2}}
$$

Com o monitoramento dos martelos hidráulicos a energia cinética aplicada pelo martelo é medida e registrada continuamente, e de igual forma é registrado a quantidade de golpes aplicados pelo martelo para a cravação da estaca, igual a um diagrama de cravação.

A quantidade de golpes aplicados multiplicado pela energia cinética média resulta na energia cinética entregue pelo sistema para a penetração da estaca no terreno. Considerando uma penetração permanente unitária, resulta no coeficiente de energia cinética para a cravação de um metro ( $K E M F)$.

A instrumentação de campo consegue registrar a energia necessária para a 
penetração da estaca, como também a energia efetiva por metro de estaca cravada (EEMP), este último é mais importante que o $K E M F$ devido ao fato de refletir a energia necessária para efetivamente causar penetração no solo. Sendo assim o $E E M P$ pode ser reescrito como:

$$
E_{e f}=R \cdot S \Rightarrow R=\frac{E_{e f}}{S} \Rightarrow R=\left(\frac{1,0 m}{S}\right) \cdot E_{e f} \Rightarrow R=N_{h} \cdot E_{e f}
$$

Onde $N_{h}$ é a quantidade de golpes necessárias para a cravação de 1,0 metro de estaca no terreno. Em muitos casos não se disponibiliza de equipamentos para medir realmente a energia liquida, portanto, é proposto que a partir de calibrações em estacas com sistemas de cravação conhecidos, estimar a energia transferida a partir da energia potencial $\left.\left.{ }_{v}\right)\right)$, utilizando-se o conceito de energia transferida por:

$$
V=\eta \cdot T
$$

Onde $\eta$ é a relação de energia transferida, sendo influenciada pelas características do sistema de cravação e da estaca, bem como pelo comportamento dinâmico do solo, que depende das características de compressibilidade e da magnitude da energia aplicada. Outra forma de obter os parâmetros é a partir da energia cinética medida (T), obtida a partir do computador de bordo do equipamento de cravação por:

$$
V=\frac{\eta}{e} \cdot T
$$

\subsubsection{Repique elástico}

Aoki (1986) cita um trabalho publicado pelo Comitê Técnico Internacional liderado pela Sociedade Japonesa de Mecânica dos Solos e Engenharia de Fundações que o estado da arte de metodologias de controle de estacas cravadas nos diversos países, a nega é o principal parâmetro na tomada de decisão no controle da capacidade de carga in situ. 
Nesse evento, Yokoyama e Kusakabe (1985) apresentaram um estudo utilizando o repique elástico, obtido no final de cravação, para a determinação da resistência última de estacas destinadas a fundações de pontes.

O repique elástico é o deslocamento temporário (recuperável) do topo da estaca quando submetida a um golpe de martelo. Aoki (1986) apresenta o uso das medidas de repique elástico para o controle de execução de obras dos tanques de álcool da Petrobrás de Brasília/DF, apoiados em estacas de concreto pré-fabricado (com diâmetro de $50 \mathrm{~cm}$, carga admissível de $1300 \mathrm{kN}$, e comprimento cravado estimado de 15,0 metros), onde foi previsto um repique de 12,5 $\mathrm{mm}$ e medido em campo $18,0 \mathrm{~mm}$.

\subsubsection{Registro em campo}

Chellis (1951) sugere para registrar o repique $(K)$ e nega $(S=C 2+C 3)$ em campo, utilizar o procedimento ilustrado na Figura 2.12. Este procedimento consiste em apoiar no terreno adjacente à estaca um referencial fixo (tábua de madeira), com um lápis apoiado a este, e fixando-se uma folha de papel na superfície da estaca, registra-se a nega e o repique elástico (Figura 2.13), devido à aplicação de um golpe com uma determinada altura de queda do martelo no topo da estaca. O objetivo é registrar o deslocamento total de uma seção da estaca próxima ao topo ao longo do tempo, devido à aplicação de um golpe de martelo.

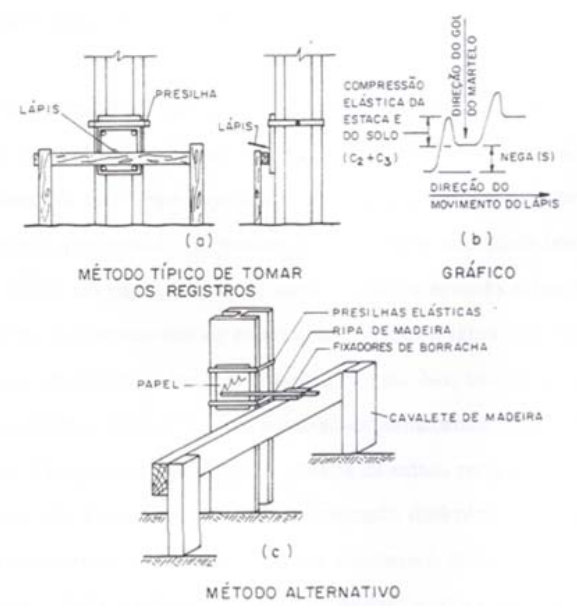

Figura 2.12 - Registro de nega e repique (Chellis, 1951 apud Rosa, 2000). 


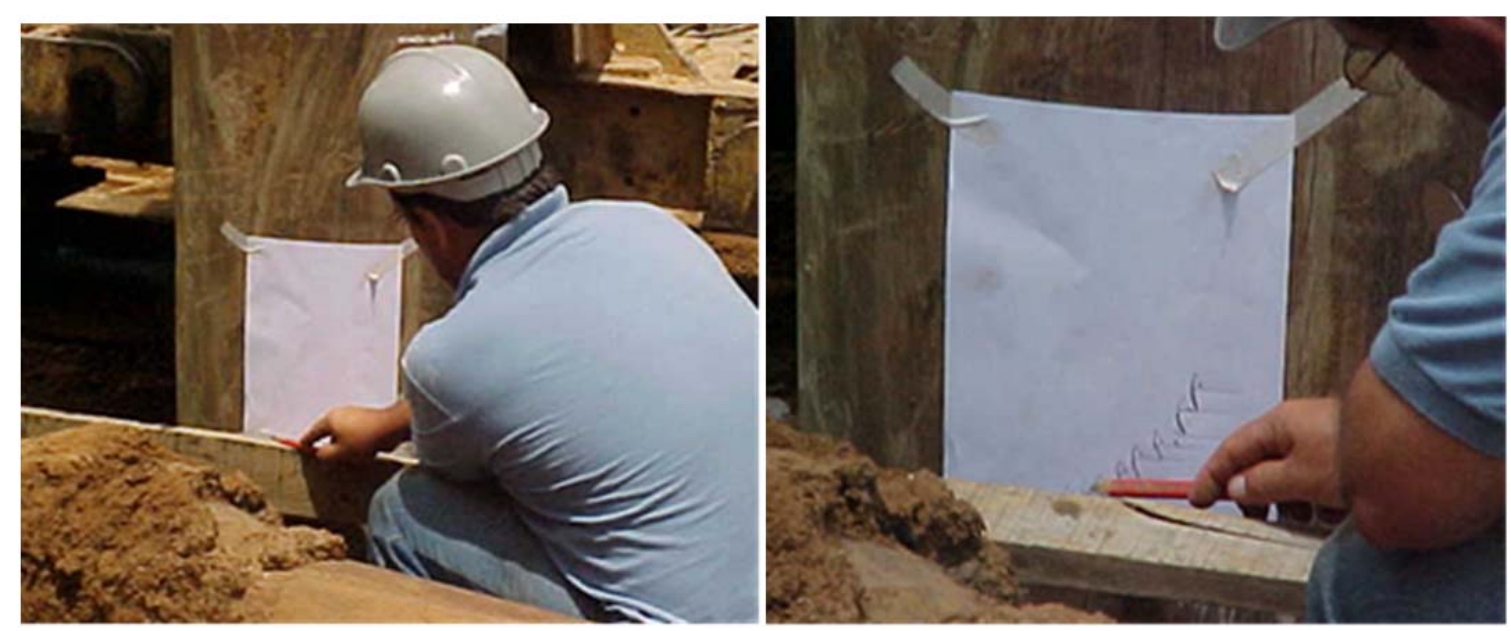

Figura 2.13- Obtenção de nega e repique através do método de Chellis (Miná, 2005).

\subsubsection{Dispositivos de registro}

Cummings (1940) registra relatos feitos pela Corps of Civil Enginners em 1927 nos quais as curvas eram registradas através de um cilindro rotativo por dois lápis, sendo um preso na cabeça da estaca e outro no martelo (Figura 2.14).

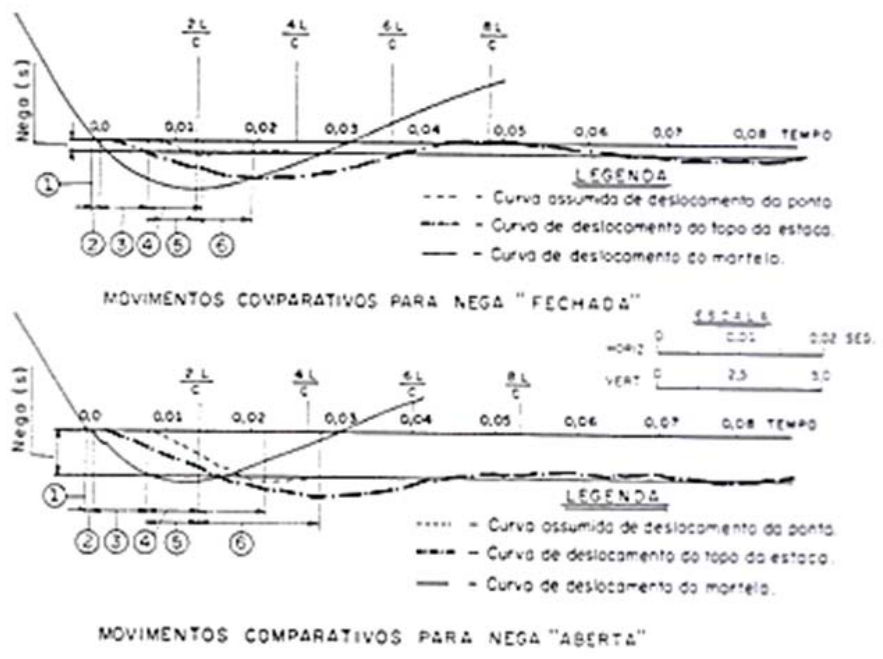

Figura 2.14 - Medidas de deslocamento do topo da estaca e martelo (Machado, 1995 apud Cummings, 1940).

Sakimoto et al. (1985) apresenta um sistema de monitoramento dos deslocamentos de uma seção próxima ao topo da estaca cravada denominado Electro-Optical Displacement Meter (E.O.D. Meter) ou medidor Eletro-Optico de deslocamento - Figura 
2.15 .

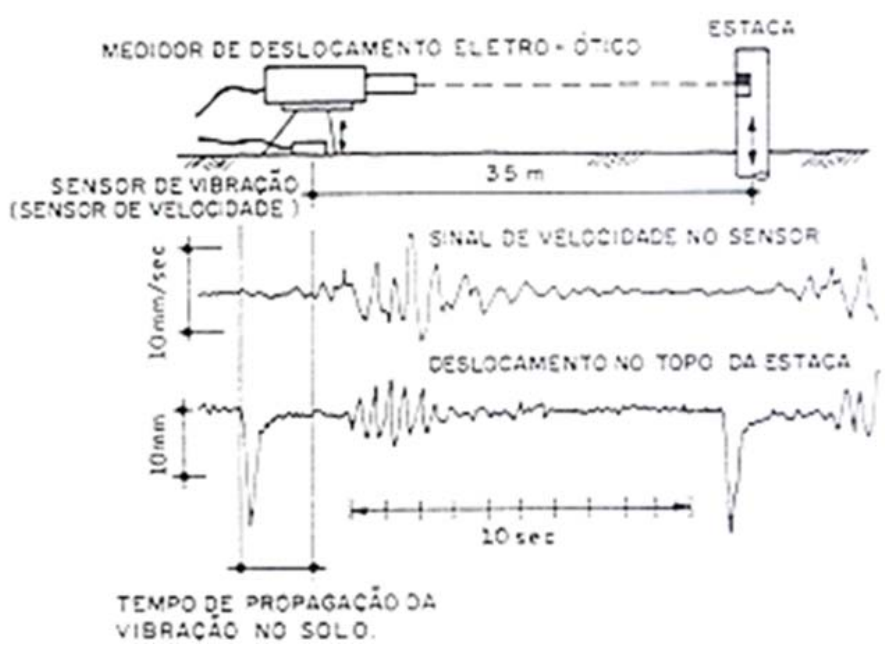

Figura 2.15 - Esquema da medição com o Electro-Optical Displacement Meter(Machado, 1995 apud Sakimoto et al., 1985).

Uto et al, (1989) propuseram para o monitoramento do topo da seção da estaca a utilização do Dynamic Piling Analyser (DPA), que utiliza de acelerômetros piezelétricos fixado na superfície da estaca para coletar o registro - Figura 2.16.

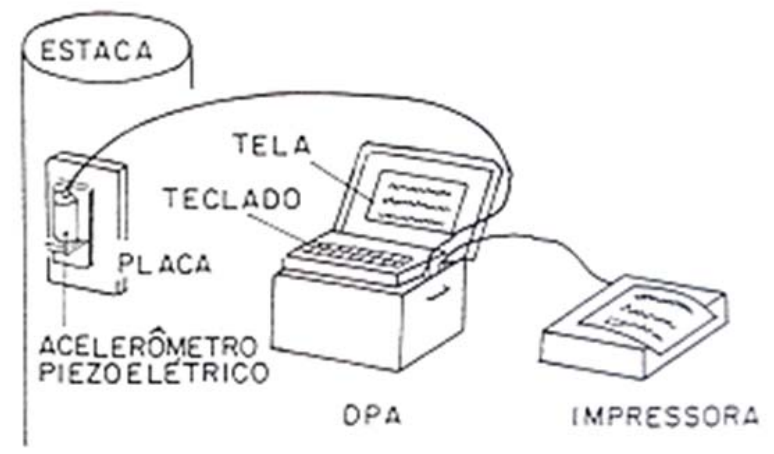

Figura 2.16 - O sistema Dynamic Piling Analyser - DPA (Uto et al. 1989).

Aoki et al. (1990) propuseram o desenvolvimento de um equipamento denominado Registrador de Deslocamento Dinâmico (RDD) composto por um cilindro metálico no qual se fixa uma folha de papel com carbono, e acoplado a um pequeno motor mantém o dispositivo girando. Umsistema ligado à estaca transfere os sinais do registro da curva de deslocamento para o papel - Figura 2.17. 


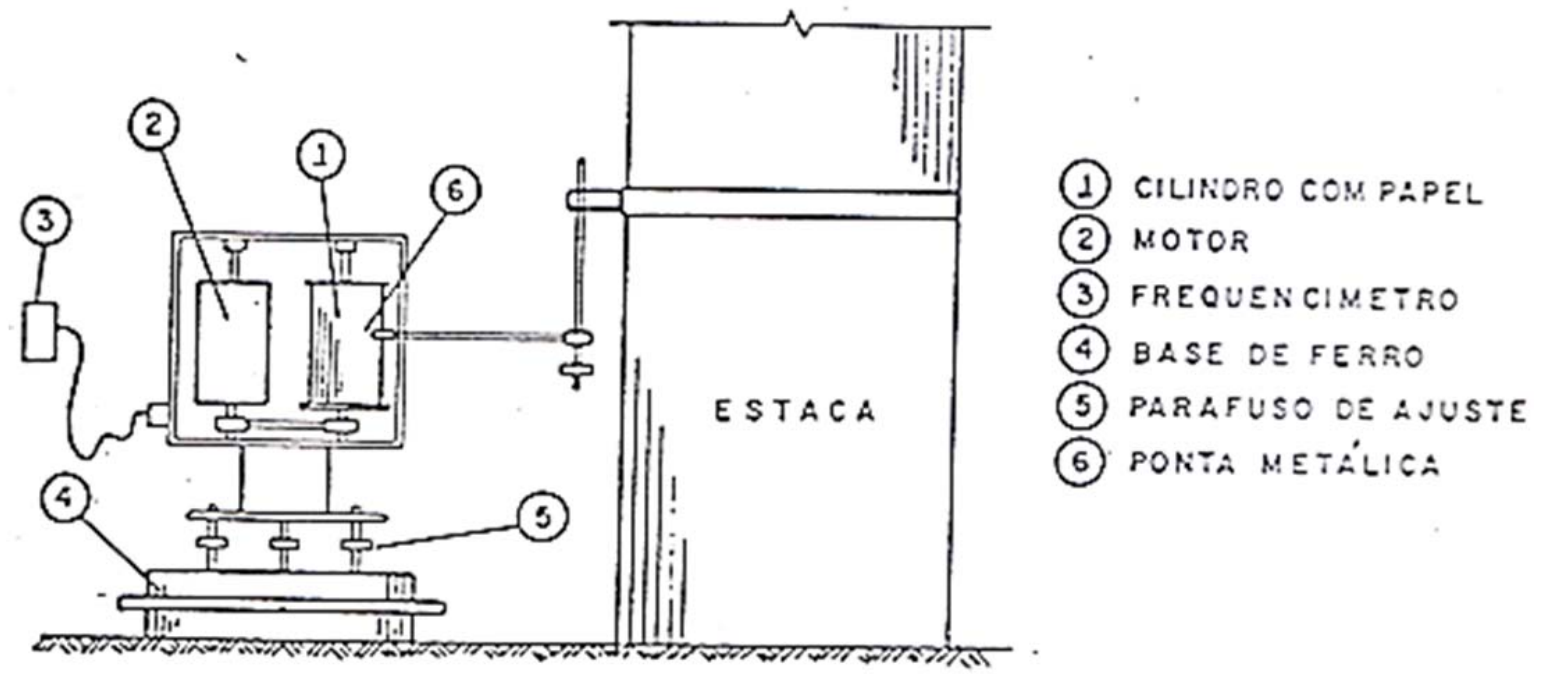

Figura 2.17 - Esquema do RDD (Aoki et al., 1990).

Machado e Dionisi (1991) apresentaram um dispositivo denominado de Repicômetro que processa sinais provenientes de um sensor, que descreve a curva de deslocamento ao longo do tempo, devido ao golpe do martelo de cravação - Figura 2.18.

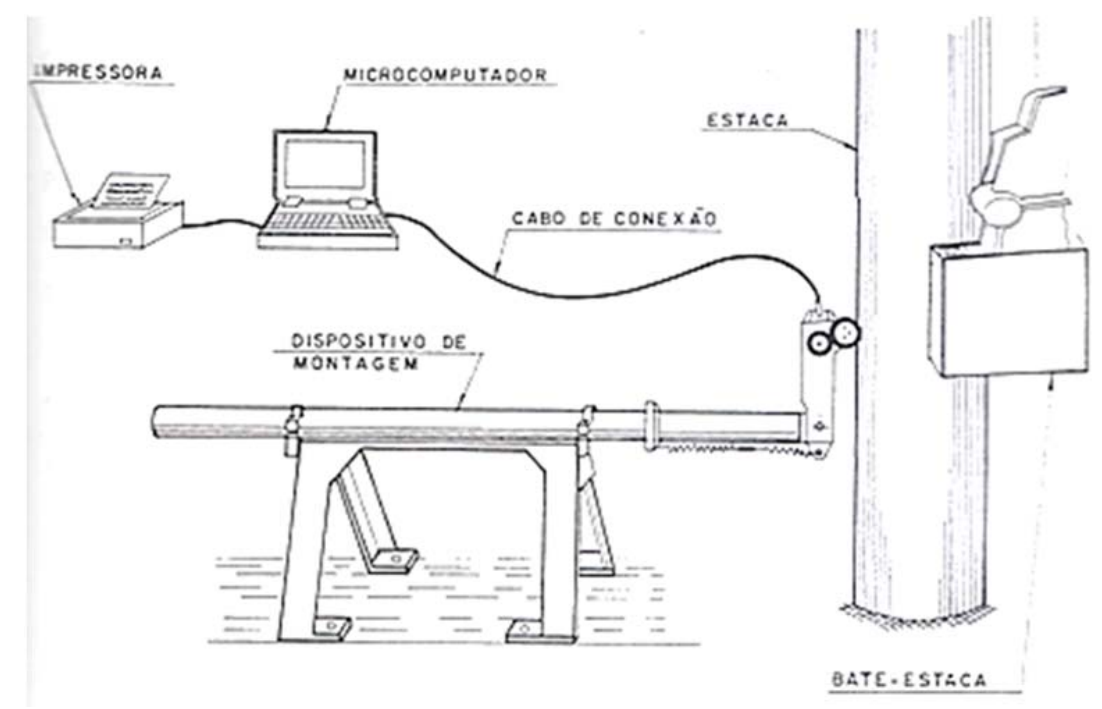

Figura 2.18 - O sistema repicômetro (Machado, 1995). 


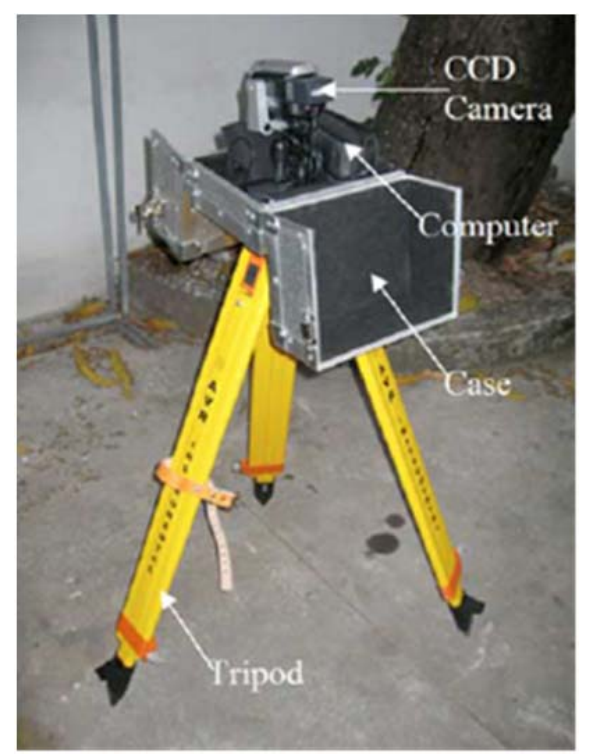

Figura2.19 - O equipamento optical rebound analyzer - PDR (Oliveira et al., 2010).

Oliveira et al. (2010) apresenta um dispositivo para o monitoramento do repique elástico e nega no final de cravação. $O$ equipamento consiste de uma câmera que fotografa um código de barras fixado na estaca e com as imagens recodifica e permite obter a curva de deslocamento ao longo do tempo. O dispositivo é denominado de Pile Driving Record e/ou optical rebound analyzer (PDR) - Figura2.19.

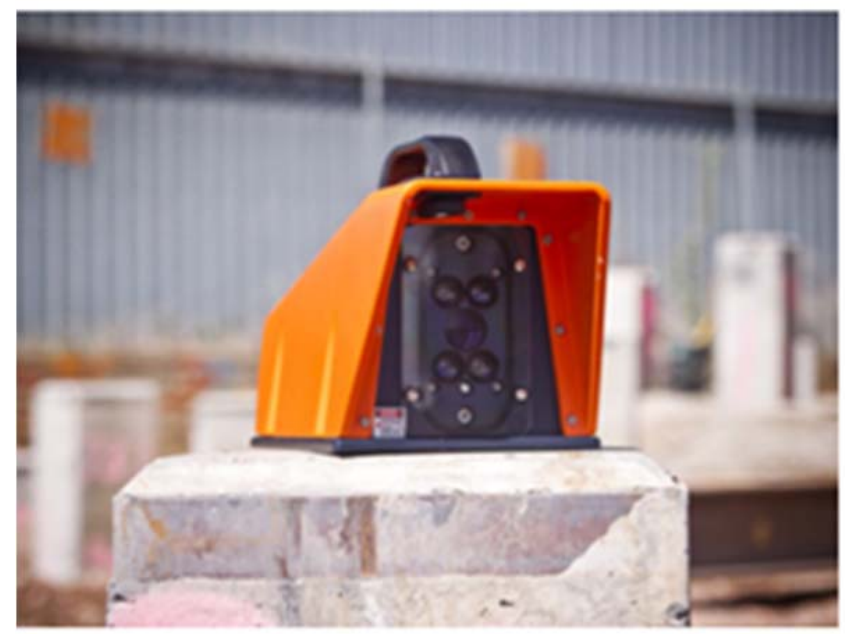

Figura2.20 - Pile Driving Monitoring - Foundation QA (2010). 
O PDM - Pile Driving Monitoring,tecnologia baseada em sinais enviados por 4 LED's, que recebem a reflexão por uma fita fixada na superfície da estaca e a partir dessa onde é calculado os deslocamentos ao longo do tempo. $\mathrm{O}$ equipamento foi desenvolvido pela Foundation QA (2010) - Figura2.20.

\subsubsection{Quake do solo (C3)}

Pela formulação proposta por Aoki (1986), mede-se em campo o repique elástico que compreende duas parcelas: o encurtamento elástico da estaca $(\mathrm{C} 2)$, e o quake do solo (C3).

Souza Filho e Abreu (1990) mediram (com o uso de um dispositivo, mostrado na Figura 2.21, interno à estaca, e concretado na ponta) valores de C3 (Tabela 2.2) para solos do Distrito Federal. Os valores encontrados variaram de $0-2,5 \mathrm{~mm}$ para areias até 7,5 $-10,0$ para argilas. Nessas analises não se contemplou qualquer influência do nível de energia.

Chellis (1951) atribui o quake do solo em função da dificuldade de cravação, para cravações fáceis a faixa de variação é de $0-0,1$ ” e para os demais casos deve se considerar o valor de 0,1 " independentemente do tipo de solo. Mas o autor alerta que para solos muito moles abaixo da ponta da estaca, o valor é superior.

Authier e Fellenius (1980) realizaram estudos teóricos com a variação de diferentes parâmetros que influenciam os valores do quake na análise da equação da onda, e que na interpretação dos resultados pouco se deu atenção a sua influência. Apresentam também casos de algumas obras que os valores da parcela de C3 aferido eram bastante superiores aos previstos, no caso da ponta houve variação de 8 a $20 \mathrm{~mm}$, e para o atrito lateral foi da ordem de $2,5 \mathrm{~mm}$.

Tabela 2.2- Valores de C3 para solos do Distrito Federal (Souza Filho e Abreu, 1990).

\begin{tabular}{cc}
\hline Tipo de Solo & C3 $(\mathrm{mm})$ \\
\hline Areias & $0-2,5$ \\
\hline Areias siltosas ou siltes arenosos & $2,4-5,0$ \\
\hline Argilas siltosas ou siltes argilosos & $5,0-7,5$ \\
\hline Argilas & $7,5-10,0$ \\
\hline
\end{tabular}




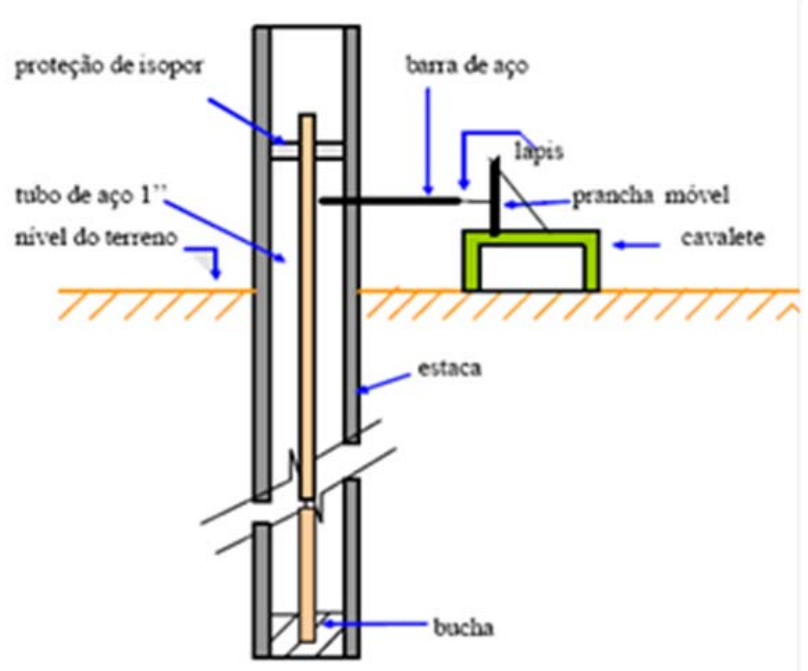

Figura 2.21 - Dispositivo interno à estaca para medição do quake - C3 (Souza Filho e Abreu, 1990 apud Rosa, 2000).

Forehand e Reese (1964) sugerem valores em relação a areias ou solos de alteração variando de $0,25 \mathrm{~cm}$ a $0,51 \mathrm{~cm}$ (Tabela 2.3 ).

Em ensaios de carregamento dinâmico, é feita a discretização da estaca ao dividir o quake do solo em função do diagrama de transferência de carga, parcela de atrito lateral e de ponta. Danziger (1990) apresenta um estudo detalhado em que foi investigada a influência do quake lateral (de atrito) e de ponta nos valores medidos em campo (Figura 2.22), e retroanalisados por um modelo numérico baseado em Smith.

Tabela 2.3- Valores de quake (Forehand e Reese, 1964).

\begin{tabular}{cc}
\hline Tipo de Solo & $\mathrm{C} 3(\mathrm{~cm})$ \\
\hline Areia grossa & 0,25 \\
\hline Areia grossa misturada & 0,25 \\
\hline Areia fina & 0,38 \\
\hline $\begin{array}{c}\text { Camada de areia e argila, mas com pelo menos } 50 \% \\
\text { da estaca em contato com areia }\end{array}$ & 0,51 \\
\hline Solo resiliente & 0,51 \\
\hline Areia e cascalho & 0,38 \\
\hline
\end{tabular}


Para o quake da ponta, Danziger (1990) concluiu que os valores aumentam com o acréscimo da resistência de ponta, e que essa variação pode ser linear. Esta conclusão está de acordo com Van Weele (1957), que já havia observado que a resistência de ponta da estaca aumenta linearmente com a compressão elástica (quake) do solo da base.

Para o quake lateral, a influência e variabilidade são bem menores que no caso da ponta, não apresentando variação com o aumento da carga. Esse fato se deve principalmente ao movimento relativo entre o fuste da estaca e a interação com o mecanismo de cisalhamento do solo. Fica bastante evidente que há uma dependência direta com o nível de energia empregado, uma vez ocorrendo incrementos gera o deslocamento da estaca em relação ao maciço de solo e maior solicitação da ponta.
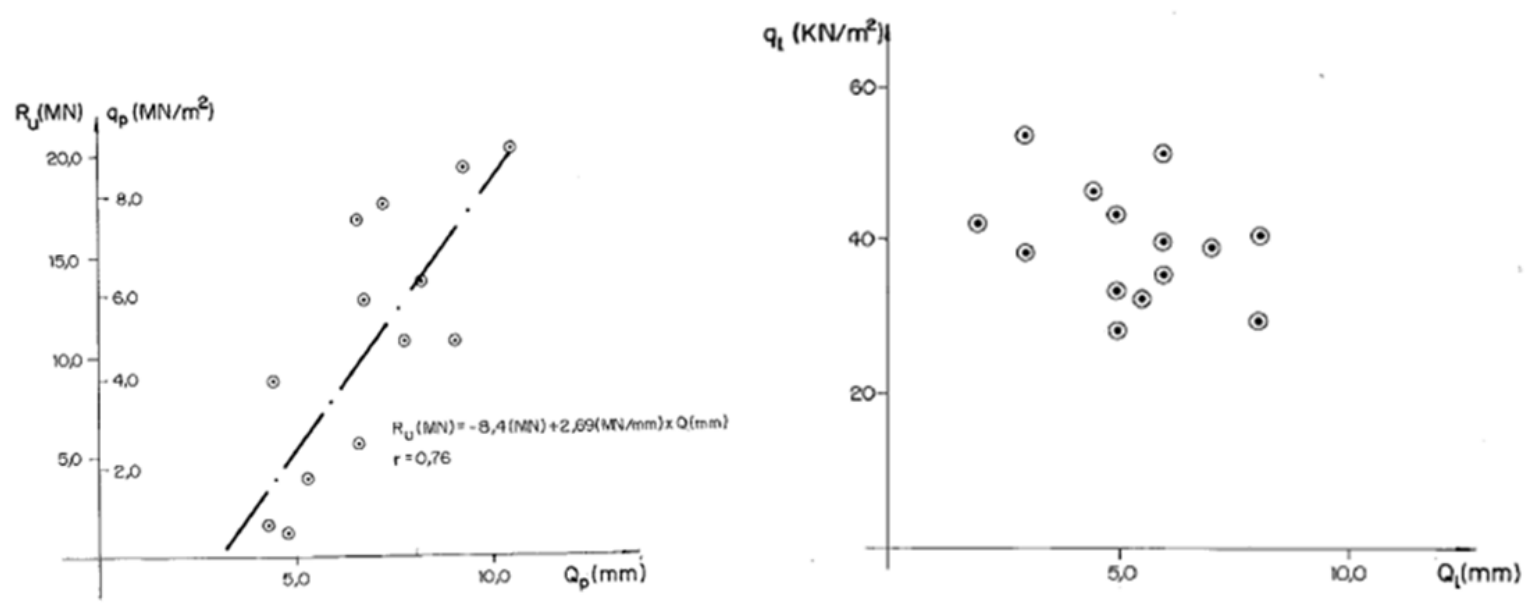

Figura 2.22 - Relação entre a resistência da estaca e quake da ponta $\left(\mathrm{Q}_{\mathrm{p}}\right)$ e lateral $\left(\mathrm{Q}_{\mathrm{L}}\right)($ Danziger, 1990).

Siqueira e Santa Maria (2001) apresentam um modelo baseado na teoria da elasticidade para a determinação de C3 pela expressão [2.30].

$$
C 3=\frac{P_{r}}{r_{b} \cdot \frac{G_{b}}{\rho}} \cdot \frac{(1-v)}{4}
$$

Na expressão o termo $P_{r}$ é a carga mobilizada, ${ }_{b}$ o raio da base, ${ }_{b}$ o módulo de cisalhamento do solo em profundidade na base, $\rho$ e a relação entre a carga de ponta/total e $v$ 
o coeficiente de Poisson.

O modelo consiste em considerar que a ruptura da ponta da estaca possa ser tratada como um caso de punção rígida atuando na superfície do solo, e dessa forma despreza o fuste e o solo circunvizinho. Dessa forma o recalque pode ser obtido por uma solução clássica da elasticidade (Timoshenko e Godier, 1970).

\subsubsection{Ensaio de Carregamento Dinâmico}

A prova de carga ou ensaio de carregamento dinâmico executado em um elemento de fundação consiste em aplicar um carregamento axial, normalmente provocado por um martelo (queda-livre, hidráulico ou diesel), em uma estaca com uma seção próxima ao topo instrumentado (Figura 2.23). O ensaio tem como objetivo avaliar a capacidade de carga do sistema estaca-solo, e adicionalmente permitem obter outros parâmetros como tensões aplicadas, energia e integridade do elemento estrutural.

No Brasil, o ensaio de carregamento dinâmico é normatizado pela NBR 13208 (2007), que prescreve a metodologia de execução do ensaio e interpretação dos resultados, fundamentado na teoria da equação da onda. Para a comprovação do desempenho da estaca, a NBR 6122 (2010) admite-se que o ensaio de carregamento dinâmico substitua a prova de carga estática na proporção de cinco para uma, respeitando-se alguns critérios estabelecidos.

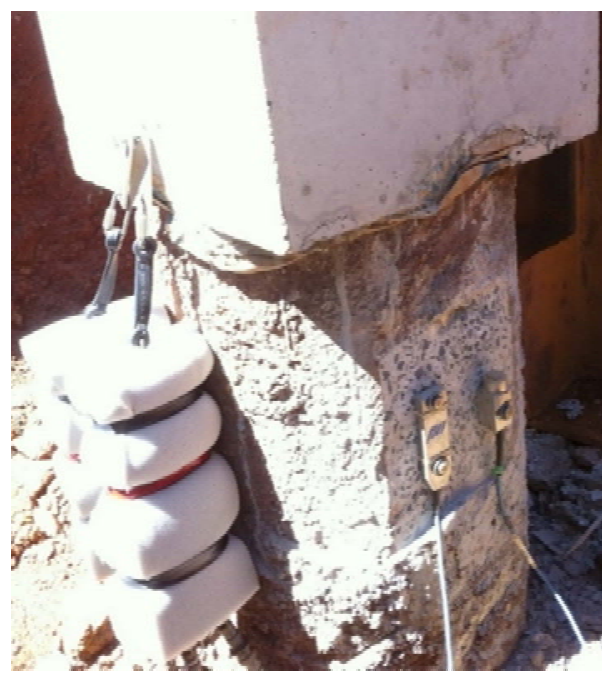

Figura 2.23 - Instalação de deflectômetro e acelerômetro em estaca do tipo hélice continua (Rosa, 2013). 
Na década de 80, este ensaio foi usado inicialmente para o controle de cravação de estacas de estacas marítimas na Petrobrás (offshore) como descrito em Niyama et al. (1982), e a partir de 1983 iniciou-se as aplicações em terra.Em meados de 1996, o ensaio de carregamento dinâmico que até a princípio era executado em estacas cravadas, passou a ser usado em estacas moldadas in loco, para avaliação da capacidade de carga (Navajas e Niyama, 1996).

Diversos fabricantes desenvolveram tecnologia quanto à instrumentação com a presença dos sensores sem fio, redução do computador de aquisição, a possibilidade de assistir remotamente o ensaio à distância, e um módulo do software que permite uma análise mais refinada em campo, que até então era apenas executado no escritório por um profissional qualificado.

O ensaio é realizado instalando-se um par de deflectômetros e acelerômetros numa seção pré-determinados a partir do terreno, posicionando-os diametralmente opostos na superfície da estaca. Os sensores são ligados a um computador com aquisição de dados (Figura 2.24) que registra os sinais ao longo do tempo, e a cada golpe aplicado no topo da estaca.

O golpe do martelo (Figura 2.25) provoca o surgimento de uma onda longitudinal e unidimensional no eixo longitudinal da estaca. Esta onda é perturbada pela interação soloestaca, o que é registrado pelos sensores ao longo do tempo. A interpretação dessa medida ao longo do tempo permite quantificar e separar as parcelas resistência de atrito lateral e ponta mobilizadas no golpe. 


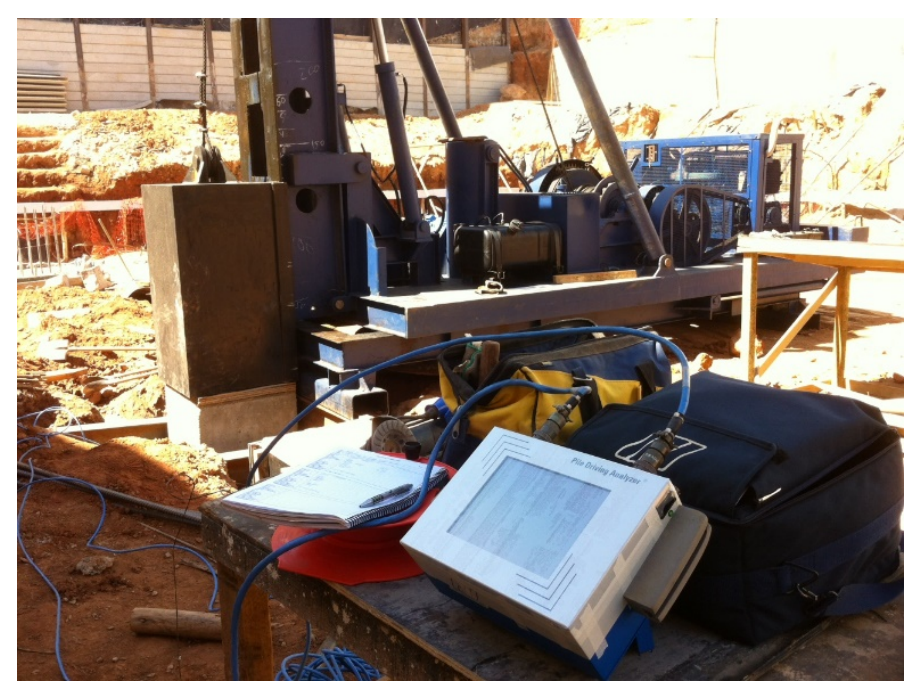

Figura 2.24 - Equipamento de aquisição de dados na PCD (Rosa, 2013).

No Brasil, para a aquisição dos dados medidos, normalmente se utiliza o sistema do Pile Driving Analyser (PDA), desenvolvido pelaPile Driving Institute (PDI). Os resultados desse sistema são interpretados pelo método CASE(método simplificado aplicado em campo) e CAPWAPC (análise numérica mais sofisticada que permite a obtenção de diversos parâmetros, realizada em escritório).

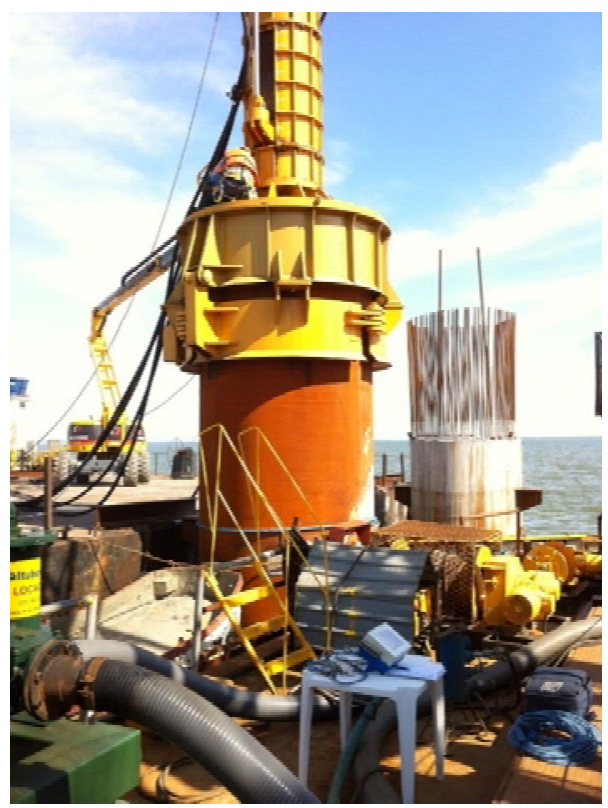

Figura 2.25 - Execução com martelo hidráulico em camisa metálica (Rosa, 2013).

Suscintamente o ensaio fornece em campo a resistência da estaca mobilizada pelo 
golpe, as tensões de compressão e tração, e energia líquida aplicada, a integridade estrutural para um golpe aplicado. A partir da análise numérica, é possível obter parâmetros dinâmicos do solo, como o quake ( $C 3$ ) e o fator de amortecimento dinâmico ( $J$ ).

\subsubsection{Energia constante}

Originalmente no Brasil, o ensaio de carregamento dinâmico era executado com a aplicação de 10 golpes de martelo com energia constante (altura de queda do martelo constante). $\mathrm{O}$ objetivo era de monitorar as resistências mobilizadas no final de cravação. $\mathrm{Na}$ década de 70 se acreditava que no momento que a nega alcançasse o valor especificado de projeto, a estaca teria a capacidade de carga de projeto (essa informação era extraída de gráficos de cravação como o apresentado na Figura 2.7).

Entretanto, como descrito em Aoki (1991), para que seja alcançada a carga de ruptura numa prova de carga dinâmica há necessidade de gerar grandes deslocamentos da estaca, possibilitando-se assim esgotar a parcela de atrito lateral, e solicitar a ponta da estaca, ou seja, próximo à ruptura a nega obrigatoriamente irá “abrir", provocando um aumento do deslocamento permanente da estaca. A resistência que se obtém para pequenas deformações são resistências mobilizadas e não valores últimos.

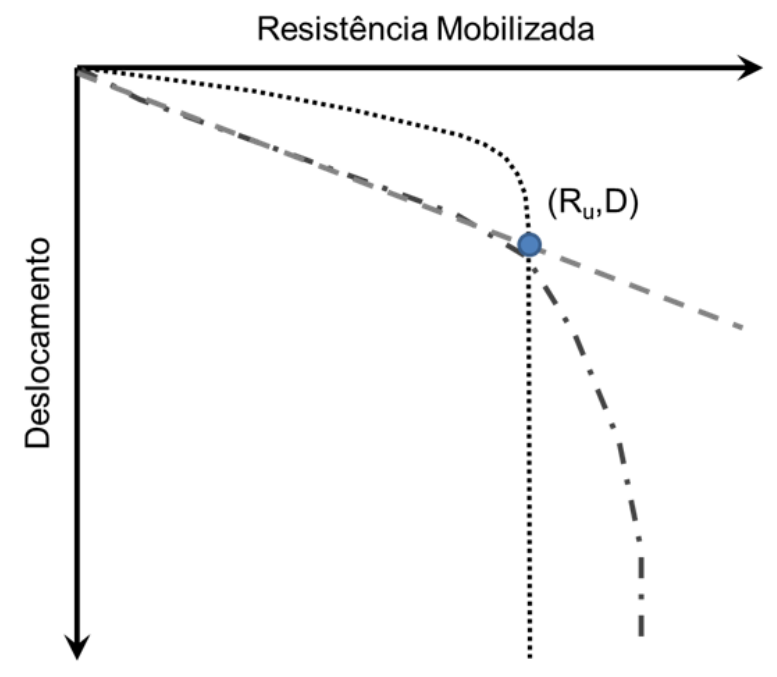

Figura 2.26 - Curva resistência mobilizada por deslocamento para PCD com energia constante. 
Outro fato importante é a nega estar atrelada a um determinado nível de energia aplicado ao sistema. Variando-se a energia de cravação, os valores de nega são alterados, podendo inclusive vir a ocorrer a recravação da estaca.

Nessa metodologia não se conhece a posição do ponto ( $R M X v s D M X)$ na curva de resistência mobilizada por deslocamento, em relação à carga de ruptura, obtendo um único par de valores de resistência total a cravação $\left({ }^{R_{t}}\right)$ por deslocamento $(D)$, passando por esse ponto infinitas curvas que se aplicando algum método de extrapolação obtém-se diferentes cargas ultimas. O ponto pode estar ainda no domínio elástico ou no regime pseudo-plástico, como ilustrado na Figura 2.26, havendo diversas possibilidades de curva.

Para o ponto obtido no ensaio pode-se passar n-curvas da prova de carga dinâmica, que não permite caracterizar a ruptura do sistema estaca-solo. Em alguns casos de obra se aplica uma metodologia de apenas avaliar um golpe com elevada energia que rompe a interação solo-estrutura, entretanto é de difícil execução exigindo elevadas massas de martelo.

Para Ávila (2001), este ensaio é uma forma mais sofisticada de avaliar a capacidade de carga em relação às fórmulas dinâmicas, por analisar o fenômeno da cravação levando-se em conta as perdas reais do sistema, usando-se um modelo mais condizente. Entretanto, não é possível traçar a curva de resistência mobilizada da estaca por deslocamento, como é feito na prova de carga estática.

\subsubsection{Energia crescente}

Nessa metodologia, os impactos sofridos pelo sistema estaca-solo são de energia crescente, para uma mesma massa de martelo variam-se as alturas de queda, pois se entende que dessa maneira é possível ter certeza que a resistência última do sistema será atingida e não apenas a mobilizada (Aoki, 1989).

Aoki (1989), ao executar uma prova de carga dinâmica numa estaca com diâmetro de 1,40 metros, mediu valores de resistência mobilizada de $5800 \mathrm{kN}$, sendo que a capacidade de carga projetada era de 12000 kN. Diante da situação, decidiu por executar uma prova de carga estática tendo alcançado o esperado, e após a extrapolação da curva carga x recalque se obteve uma carga de ruptura do sistema de $14000 \mathrm{kN}$. 
Diante desse cenário, Aoki observou que para a carga de $5800 \mathrm{kN}$ o deslocamento era de $25 \mathrm{~mm}$, e coincidia com um ponto dentro da curva obtida na PCE, e esse ponto estava relacionado a um único nível de energia aplicado (Cintra et al., 2013).

Portanto, concluiu que durante o ensaio dinâmico o golpe aplicado tinha sido insuficiente para mobilizar grande parte da resistência total da estaca. A partir de então, surgiu a ideia de realizar o carregamento dinâmico em estágios de energia de cravação crescente, de modo que se obtivesse a curva resistência mobilizada x deslocamento de modo similar à PCE. Este procedimento seria mais adequado para obtenção da carga de ruptura de uma estaca usando-se um ensaio de carregamento dinâmico.

Vários foram os trabalhos publicados a respeito do uso da prova de carga dinâmica com energia crescente,Aoki (1989 e 1991), Bernardes (1989) e Niyama (1983).

Aplicando-se diferentes níveis de energia no topo da estaca permite-se definir uma curva de resistência mobilizada por deslocamento, e assim definir em campo o momento de parar o ensaio, de forma a caracterizar uma tendência de ruptura do sistema. A Figura 2.27 apresenta uma curva característica obtida no ensaio.

Neste modo de ensaio, a definição dos níveis de energia é função do nível máximo de energia disponível (diferentes alturas - h) no sistema de cravação, da geometria da estaca. Durante a execução são controladas as tensões aplicadas no sistema, limitando-se a resistência à compressão do material da estaca.

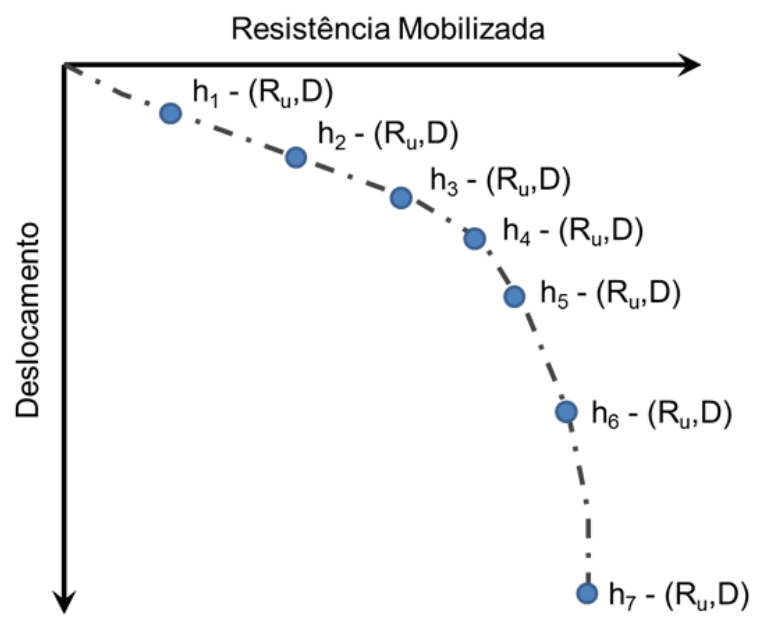

Figura 2.27 - Curva resistência mobilizada por deslocamento para PCD com energia 
crescente.

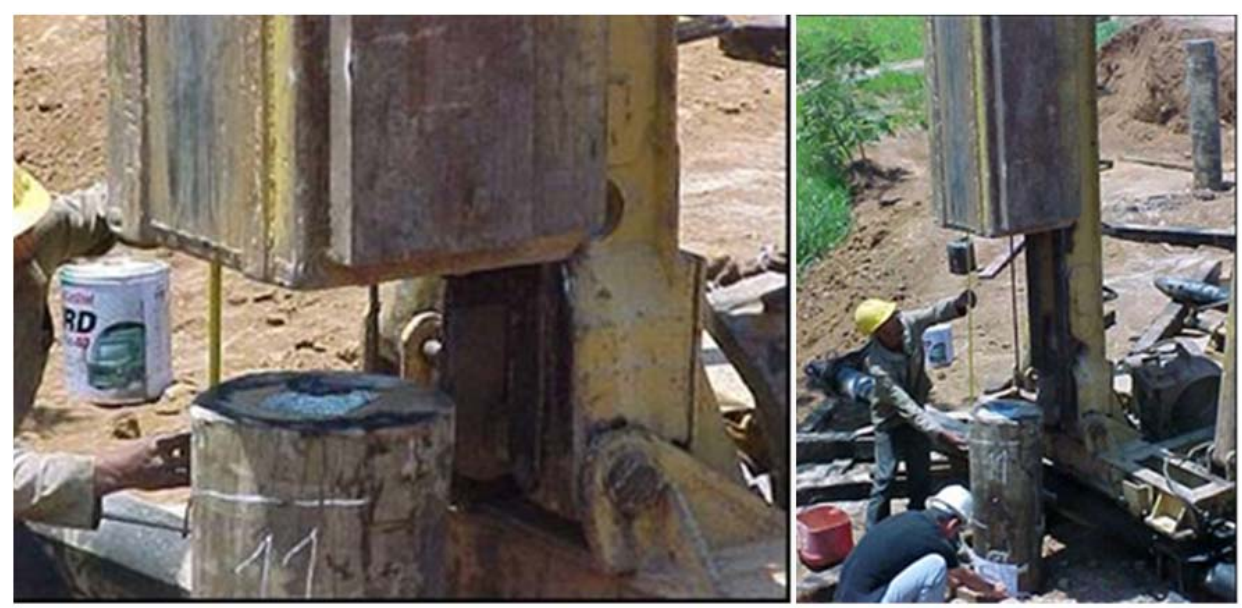

Figura 2.28 - Controle de altura na execução da PCD com energia crescente (Miná, 2005).

$\mathrm{Na}$ utilização de martelo de queda livre, os incrementos de energia são controlados pela altura de queda (Figura 2.28). No Brasil se tem a pratica de, durante a aplicação do golpe, coletar (Figura 2.29) os registros de nega e repique elástico para os diferentes golpes.

Para a avaliação dos valores de resistência da estaca mobilizada nos golpes, têmse os seguintes métodos:

a) método simplificado, do tipo "CASE";

b) método numérico, do tipo "CAPWAP".

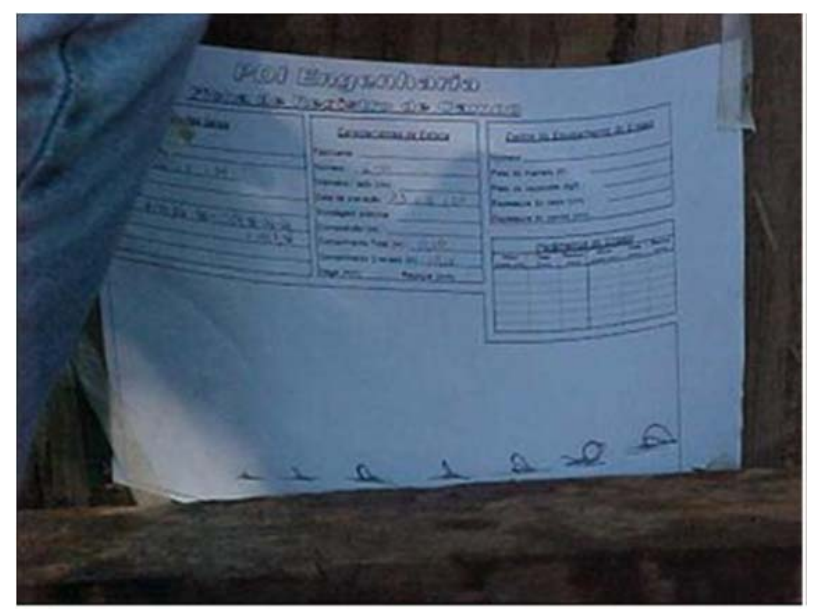

Figura 2.29: Obtenção de nega e repique para diferentes níveis de energia aplicado (Miná, 2005). 


\subsubsection{Equação da Onda}

Devido à simplicidade e facilidade de se obter parâmetros para estimar a capacidade de carga as fórmulas dinâmicas são muito utilizadas, mas em muitas situações elas levam a resultados insatisfatórios. A partir disso surgiu à necessidade de se utilizar um modelo matemático mais preciso que apresente maior confiabilidade e que possa ser aplicável a diversos tipos de maciços sem restrições.

Nesse contexto e com o avanço da eletrônica e da informática tornou-se possível utilizar a análise da cravação de estacas pela equação da onda, representa o fenômeno da propagação de ondas de tensão em barras (no interior da estaca), causado pelo impacto do martelo durante a cravação ou recravação.

Fisicamente a cravação de estacas está mais relacionada ao fenômeno de transmissão de ondas de tensão em barras do que o impacto simples e puro entre dois corpos rígidos, teorias que baseiam as fórmulas dinâmicas (Alves et al., 2004).

Timoshenko e Goodier (1951) citam que Saint Venant, em 1865 foi o primeiro a realizar estudos utilizando a propagação unidimensional da onda em barras submetidas a impactos. No entanto, a primeira solução computacional para a resolução da equação da onda aplicada em estacas cravadas só foi proposta por Smith (1960).

Velloso e Lopes (2002) apontam as seguintes vantagens para a utilização da equação da onda:

a) Permite separar as parcelas dinâmicas e estáticas da resistência oferecida pelo solo.

b) Permite avaliar a eficiência do sistema de cravação (martelo e acessórios).

c) Permite avaliar as tensões de compressão e tração no interior do elemento estrutural e outras.

Do impacto do martelo sobre a cabeça da estaca a mesma é comprimida e as partículas do material são aceleradas, formando assim uma onda de compressão que percorre o fuste com uma velocidade (c) que depende das características do material da estaca. 


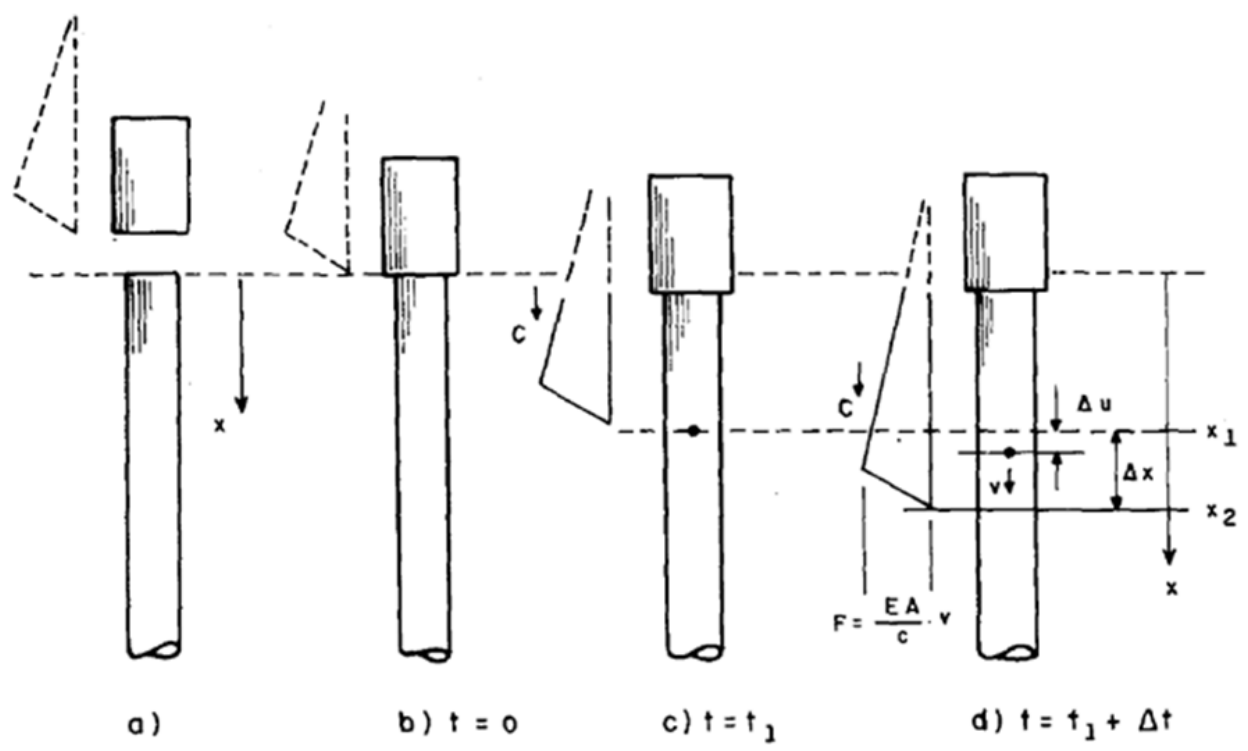

Figura 2.30 - Formação da Onda de Impacto (Niyama, 1991).

A velocidade (c) é uma constante, e depende do módulo de elasticidade e massa específica do material da estaca. Para estacas de concreto, essa velocidade (c) varia de 3000 a $4000 \mathrm{~m} / \mathrm{s}$, para o aço é aproximadamente $5100 \mathrm{~m} / \mathrm{s}$ e na madeira está entre 3000 a $3660 \mathrm{~m} / \mathrm{s}$.

A partir de um impacto aplicado no topo de uma estaca, surgi uma onda longitudinal de compressão (Figura 2.30) que irá percorrer todo o comprimento da estaca, que durante um intervalo de tempo.

Em um intervalo de tempo qualquer $\Delta \mathrm{t}$, a onda de compressão atravessou um segmento $\Delta \mathrm{x}$, intervalo que imprimiu uma velocidade $\mathrm{v}$ na partícula, que estava inicialmente em repouso $(v=0$ e $t=t 1)$, situada na frente da onda. Essa partícula $v$ deslocou-se de $\Delta u$ da sua posição inicial, que corresponde à parcela de encurtamento elástico do elemento com comprimento $\Delta \mathrm{x}$. Não se deve confundir velocidade de propagação da onda de tensão (c) com velocidade da partícula (v). A partir dessas considerações resulta nas expressões [2.31] a [2.34].

$$
\begin{gathered}
c=\frac{\Delta x}{\Delta t} \\
\varepsilon=\frac{\Delta u}{\Delta x}
\end{gathered}
$$




$$
\begin{aligned}
& v=\frac{\Delta u}{\Delta t} \\
& a=\frac{\Delta v}{\Delta t}
\end{aligned}
$$

Onde ${ }^{C}$ representa a velocidade de propagação da onda de tensão, $\varepsilon$ a deformação especifica do trecho $\Delta \mathrm{x}, \mathrm{v}$ e a velocidade e aceleração da partícula respectivamente. Combinando as expressões [2.31] e [2.33] com [2.32], resulta [2.35].

$$
\varepsilon=\frac{\Delta u}{\Delta x}=\frac{v \cdot \Delta t}{c \cdot \Delta t} \Rightarrow \varepsilon=\frac{v}{c}
$$

Pela Lei de Hooke, e substituindo a expressão [2.35] resulta em [2.36].Sendo que E representa o módulo de elasticidade do material da estaca e A- área da seção transversal. A partir da expressão [2.36] podemos ver uma proporcionalidade que existe entre $\mathrm{F}$ e v, é relacionado a um fator constante, denominado de impedância $\left(Z=\frac{E \cdot A}{c}\right)$.

De acordo com Velloso e Lopes (2002) a impedância reflete a maneira como o pulso é transmitido ao longo da estaca, quanto maior for seu valor mais elevado será o pico de tensão. Reescrevendo a expressão [2.36] resulta:

$$
\begin{gathered}
\sigma=E \cdot \varepsilon \Rightarrow \frac{F}{A}=E \cdot\left(\frac{v}{c}\right) \Rightarrow F=\left(\frac{E \cdot A}{c}\right) \cdot v \\
F=Z \cdot v \quad[2.37]
\end{gathered}
$$

Essa relação é à base das medidas da equação da onda. Durante a cravação são medidas independentemente a deformação e velocidade em uma seção do topo da estaca - a deformação é convertida em força (F) enquanto que a aceleração em velocidade (v).

A velocidade para efeitos de escala é multiplicada pela impedância, sendo o resultado comparado com o valor medido da força $(\mathrm{F})$, e essa relação serve para verificar a 
qualidade dos dados coletados inicialmente.

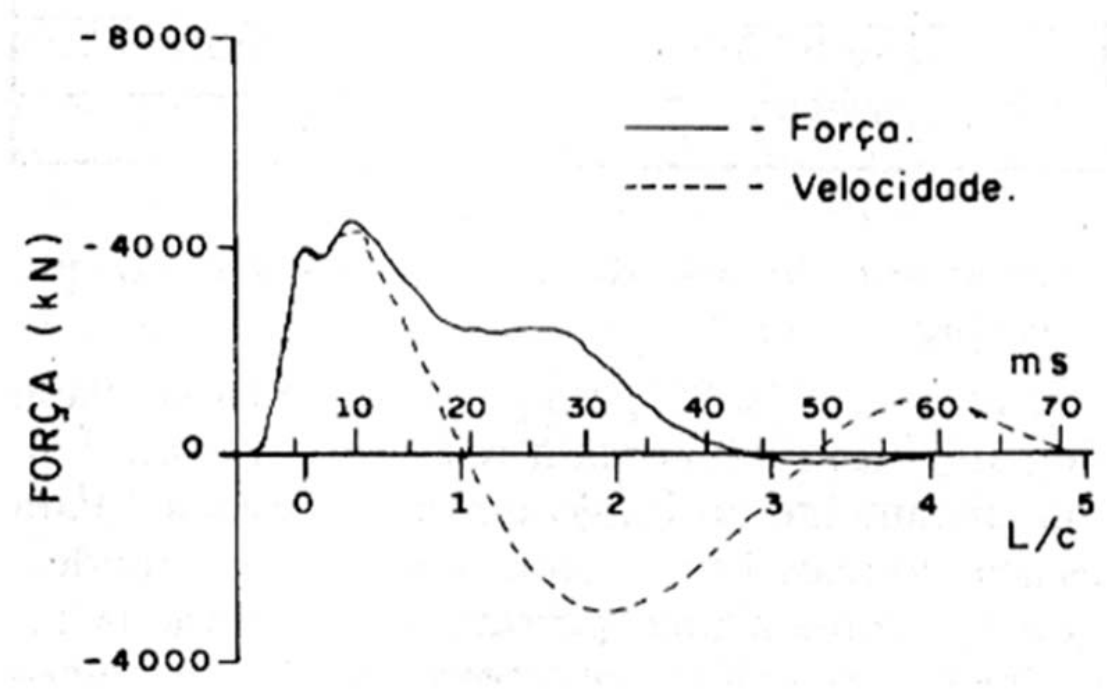

Figura 2.31: Registro das curvas de força e velocidade medido em campo (Soares, 2002).

No momento que ocorre a reflexão das ondas do fuste da estaca (devido ao atrito lateral), deixa de existir a proporcionalidade da expressão [2.37] e as curvas se afastam (Figura 2.31), sendo que a diferença entre as duas curvas é igual à soma da resistência lateral até uma determinada profundidade.

No trecho $\Delta x$ da Figura 2.30, aplicando a $2^{\circ}$ Lei de Newton temos:

$$
F=m \cdot a \Rightarrow F=(\rho \cdot A \cdot \Delta x) \cdot \frac{\Delta v}{\Delta t}
$$

Onde $\rho$ é a massa específica do material da estaca. Considerando-se as seguintes condições de contorno para o elemento inicial, $\mathrm{v} 0=0$ e $\Delta \mathrm{v}=\mathrm{v}$ (repouso), resulta:

$$
F=\left(\frac{E \cdot A}{c}\right) \cdot v=\rho \cdot A \cdot c \cdot v \Rightarrow c^{2}=\frac{E}{\rho}
$$

Podemos concluir que a velocidade de propagação da onda de tensão (c) só depende das características do material que está sendo percorrida, ou seja, do módulo de 
elasticidade (E) e da massa especifica ( $\rho$ ) da estaca. A velocidade da partícula depende de F, $\rho$ e do nível de tensões que o sistema está submetido.

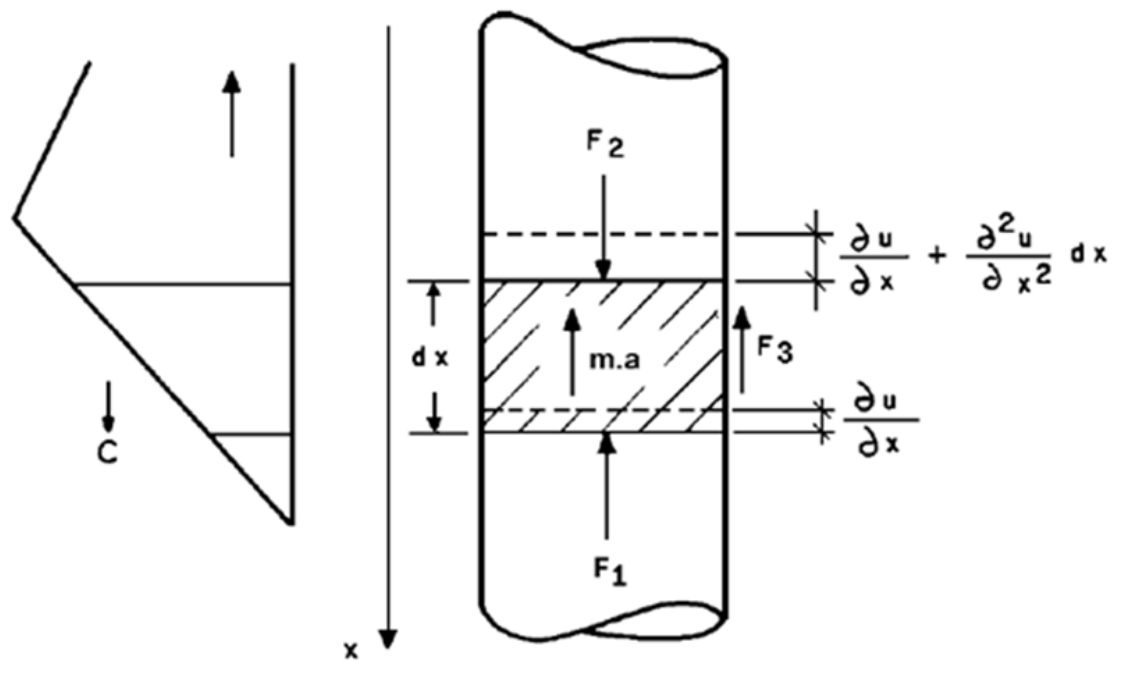

Figura 2.32: Segmento da estaca.

A partir de um segmento da estaca (Figura 2.32), com suas características (E, $\rho$ e A), submetido a um estado de tensão, em um tempo $t$ devido à propagação de uma onda longitudinal de compressão. O elemento infinitesimal dx, submetido a um estado de tensão, sofre deslocamentos elásticos devido ao carregamento, fazendo o equilíbrio das forças $\mathrm{F} 1 \mathrm{e}$ F2 (esforços normais), que atuam nas extremidades do elemento em estudo temos:

$$
\begin{gathered}
F 1=E \cdot A \cdot \frac{d u}{d x} \quad \\
F 2=E \cdot A \cdot\left(\frac{d u}{d x}+\frac{d^{2} u}{d x^{2}} \cdot d x\right)
\end{gathered}
$$

A força F3 da Figura 2.32, corresponde à parcela de resistência do solo ao longo do comprimento do elemento infinitesimal dx e m.a, que representam a resistência oferecida pelo elemento à passagem da onda. Fazendo o equilíbrio temos:

$$
m \cdot a=F 2-F 1-F 3
$$

Em que F3 é dado pela seguinte expressão: 


$$
F 3=s \cdot U \cdot d x
$$

Substituindo as expressões [2.40], [2.41] e $[2.43 F 3=s \cdot U \cdot d x$ [2.43]] em [2.42], e desenvolvendo temos:

$$
\frac{d^{2} u}{d t^{2}}=c^{2} \cdot \frac{d^{2} u}{d x^{2}}-\frac{s \cdot U}{\rho \cdot A}
$$

Alguns autores usam $R=s \cdot U$, para apenas representar que a estaca está em um meio que oferece resistência, reescrevendo a expressão [2.44] resulta:

$$
\frac{d^{2} u}{d t^{2}}-c^{2} \cdot \frac{d^{2} u}{d x^{2}}+\frac{R}{\rho \cdot A}=0
$$

A equação da onda, expressão [2.45] é uma equação diferencial parcial com duas variáveis independentes $(x, t)$. Como constantes temos $A, U, E$ e $\rho$, como variáveis dependentes temos o deslocamento $u(x, t)$, a velocidade $v(x, t)$, a aceleração $a(x, t)$ e a resistência local mobilizada $\mathrm{s}(\mathrm{x}, \mathrm{t})$.

A solução geral da equação com as suas condições de contorno para uma estaca cravada em um maciço de solo, é medir o deslocamento $\mathrm{u}(\mathrm{x}, \mathrm{t})$ ao longo do tempo no topo da estaca.

Durante a aplicação do golpe num primeiro momento a onda será descendente (wave down) em função da profundidade, e à medida que encontra resistência do solo parcelas são refletidas até chegar à ponta sendo totalmente refletida - onda ascendente (wave up).

As ondas ascendentes (originárias da reflexão) proporcionam informações dos efeitos internos e externos como o atrito lateral, danos estruturais e/ou variação de impedância e variação dos contatos de solo, os quais provocam justamente essas reflexões.

De acordo com as condições de resistência da ponta da estaca, as ondas incidentes podem ser refletidas como compressão ou tração. No caso de se ter uma baixa resistência (no caso uma camada de argila mole) a onda faz com que a ponta da estaca seja puxada para 
baixo, gerando tensões de tração. Para o caso de uma camada resistente na ponta, à onda é comprimida, e por ação-reação ocorre a reflexão e sobreposição da tensão, vindo a ser o dobro do valor inicial, ocasionando-se o esmagamento da ponta.

Em geral, cada onda percorre uma distância $d x$, tem sua amplitude reduzida para

$1 / 2 \cdot R A(x)$, em que $R A(x)$ é uma parcela da resistência de atrito lateral na posição ${ }^{X}$, assim como cada onda ascendente tem um incremento no mesmo valor. Através da teoria pode deduzir que a resistência à penetração $R_{T}$ vale:

$$
R_{T}=\frac{1}{2} \cdot\left[\left(F_{t 1}+F_{t 2}\right)+Z \cdot\left(v_{t 1}-v_{t 2}\right)\right]
$$

\subsubsection{Modelo de Smith}

Smith (1960) apresentou uma solução para a equação da onda por meio do método das diferenças finitas, permitindo avaliar parâmetros da cravabilidade para cada intervalo de tempo. A estaca, o martelo, capacete, cepo e coxim são representados (Figura 2.33) por uma série de elementos interligados por molas e amortecedores, ligados aos elementos da estaca, capazes de simular o deslocamento de uma onda de tensão causado pelo impacto do martelo.

Pereira (2003) apresenta, como as principais limitações do modelo de Smith (1960), as incertezas quanto à energia transferida para a estaca, inerentes a simplificações efetuadas na determinação da velocidade do impacto do martelo, e dos coeficientes de restituição do sistema de amortecimento (capacete, cepo e coxim/torta). Para minimizar essa deficiência, a instrumentação foi instalada próximo ao topo da estaca, mas abaixo do amortecimento.

Com base no trabalho de Smith (1960) é possível inserir informações sobre a estaca, equipamento de cravação, e sistema de amortecimento permitindo estimar e avaliar o comportamento da estaca durante a cravação. Dessa forma é possível avaliar a eficiência do sistema de cravação para um determinado tipo de estaca e solo, simulando o processo de cravação e podendo interferir em possíveis problemas ou dúvidas que possa existir em campo. 


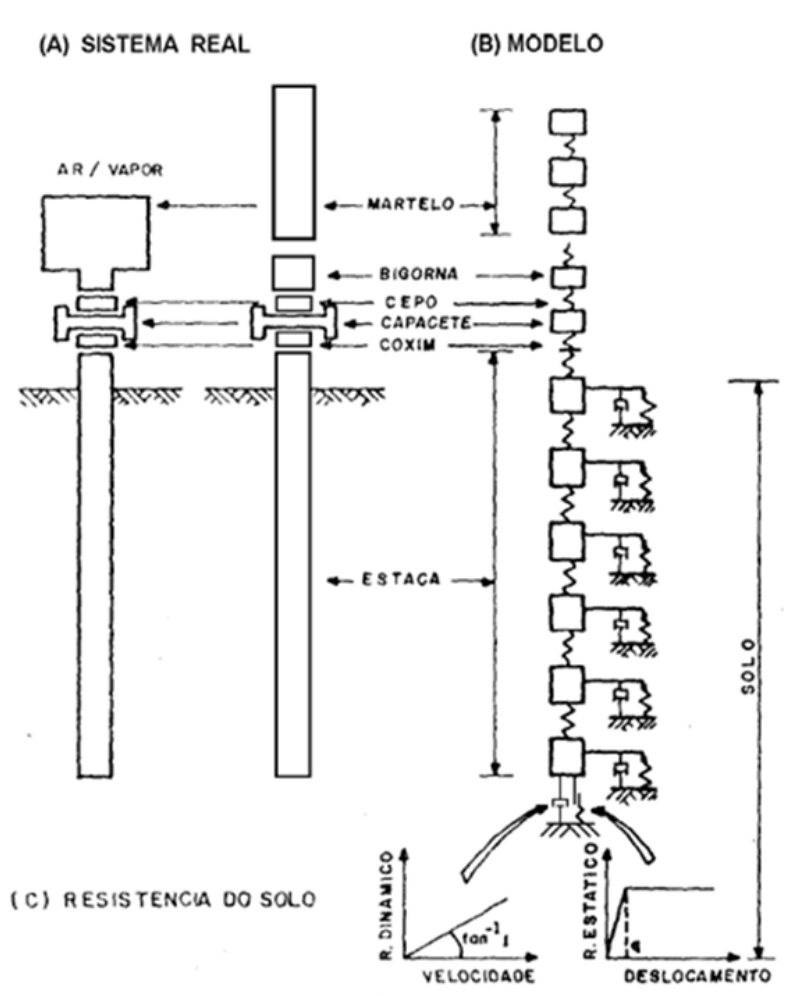

Figura 2.33 - Idealização de Smith para resolução da equação da onda para estacas (Smith, 1960).

Para que o modelo seja válido são adotadas as seguintes hipóteses:

a) As velocidades, os deslocamentos e as forças devem ser calculados em cada instante, de forma a serem diferentes do instante anterior apenas de quantidades que representem as alterações ocorridas nesse intervalo de tempo.

b) Em cada intervalo de tempo definido, as velocidades, deslocamentos e forças têm valores constantes.

Para poder representar a interação dinâmica estaca-solo durante a passagem da onda de tensão, Smith propôs o uso de um modelo simplificado, onde a resistência do solo a cravação (Rt) é composta de duas parcelas, uma estática $(R u)$ e outra não estática $(R d)$ representado por um modelo reológico composto de um elemento de atrito em série com uma mola, e ambos em paralelo com um amortecedor (modelo visco-elasto-plástico). Matematicamente o modelo é expresso pela expressão [2.47].

$$
R_{t}=R u+R_{d}
$$


Onde $R_{t}$ representa a resistência mobilizada do solo à cravação.

A parcela estática da reação do solo possui comportamento elasto-plástico, admitindo o diagrama força versus deslocamento linear (Figura 2.34) e partir desse diagrama obtém-se a expressão [2.48]. O deslocamento que ocorre o escoamento plástico do solo é denominado de "quake" e representado pela letra $Q$.

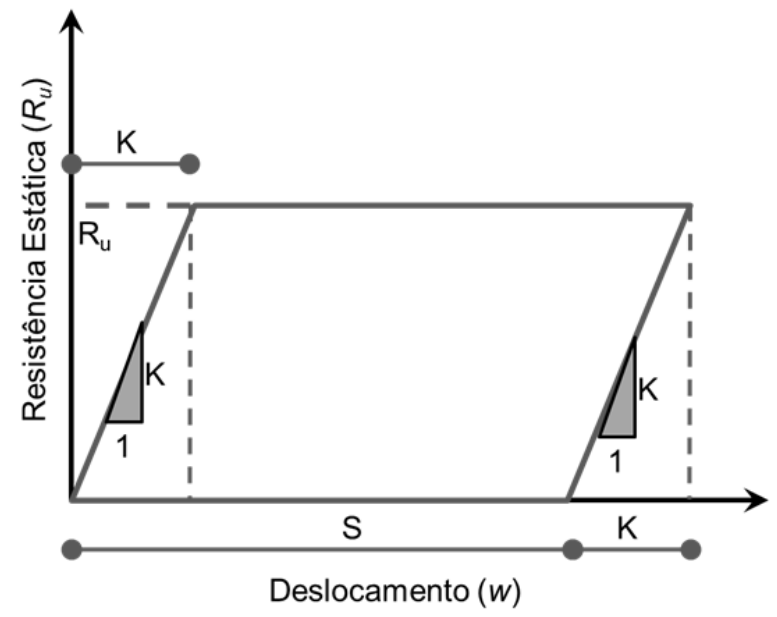

Figura 2.34 - Representação da parcela estática da reação do solo a cravação.

Smith ainda admite que a parcela não estática da reação à cravação é proporcional a velocidade, e também a reação estática oferecida pelo solo durante a solicitação (Figura 2.35).

Smith considera que independentemente do solo e da geometria da estaca, o quake (C3) é igual a 2,54 mm, tanto para a ponta quanto para o atrito lateral. Também é proposto que o parâmetro JSmith seja igual a $0,492 \mathrm{~s} / \mathrm{m}$ para a ponta, e um terço desse valor para o atrito lateral (Alves et al., 2004). 


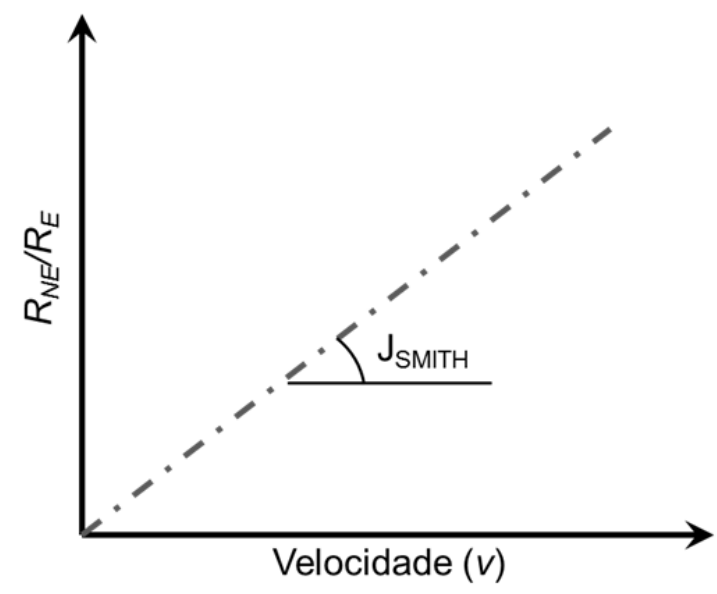

Figura 2.35 - Representação da parcela não estática da reação do solo a cravação.

$$
R t=R_{u} \cdot\left(1+J_{\text {Smith }} \cdot v\right)[2.48]
$$

\subsubsection{Método CASE}

O método CASE se baseia na teoria da propagação da onda unidimensional, sendo um modelo simplificado, sem discretizar à estaca em elementos, considerando-se apenas o fenômeno da cravação como o impacto entre duas barras (Niyama, 1991). São assumidos como valores de entrada que a estaca é elásticos, homogêneos, com seção constante. Utilizam-se os registros de força e velocidade no topo da estaca, sendo a velocidade obtida por integração do sinal de aceleração.

Seu principal objetivo é determinar a capacidade de carga estática da estaca no momento da cravação. Admitindo-se que exista um registro contínuo no tempo, dos valores de força e velocidade medidos em uma seção próxima ao topo da estaca, o resultado pode ser expresso através de um par de curvas conforme a Figura 2.31.

Considera-se que todas as reflexões da onda são devidas à resistência oferecida principalmente pela ponta da estaca, e que o mesmo se comporte como um corpo rígido e perfeitamente plástico, o solo é admitido idealmente plástico e que os movimentos entre estaca-solo são desprezados (Goble et al., 1992). Dessa maneira a resistência total mobilizadaé a expressão [2.46]. Todas as ondas refletidas são devidas a resistência oferecida pelo solo a penetração. 
O método CASE, utiliza uma solução fechada da equação da onda, na qual os sinais de força e velocidade são registrados em uma determinada seção da estaca, nos instantes de tempo t1 (o golpe atinge maior intensidade) e t2 (onda refletida na ponta da estaca e retornou à seção instrumentada).

O tempo t2 é dado pelo tempo inicial mais o que foi gasto pela onda para ir do topo até a base da estaca e retornar, podendo ser quantificado através da expressão [2.49] e em função do comprimento da estaca abaixo dos sensores ( $L$ ).

$$
t_{2}=t_{1}+2 \cdot \frac{L}{c}
$$

A parcela devida à resistência dinâmica $(\mathrm{Rd})$ da expressão [2.48] é admitida neste caso de estar totalmente concentrada na ponta de estaca. Dessa forma a Rd é considerada por simplificação como proporcional a velocidade na ponta de estaca, obtendo:

$$
R_{d}=J_{c} \cdot v_{p}=J_{c} \cdot Z \cdot v_{p}
$$

Onde $R_{d}$ é a resistência mobilizada dinâmica do solo a cravação, $J_{c}$ a constante de amortecimento do método CASE e $v_{p}$ a velocidade na ponta da estaca. A resistência total mobilizada $\left(R_{t}\right)$ pode ser decomposta em uma parcela dinâmica $\left(R_{d}\right)$ e outra estática $\left(R_{u}\right)$, resultando em:

$$
R_{t}=R u+R_{d}[2.51]
$$

A definição da constante de amortecimento (JCASE) depende do tipo de solo abaixo da ponta da estaca. Através de várias estacas instrumentadas correlacionadas com provas de cargas, Goble et al. (1996) sugere os valores da Tabela 2.4. Através dessas considerações a parcela dinâmica da resistência.

A contribuição da parcela de resistência dinâmica na resistência total depende diretamente do fator de amortecimento (JCASE), em que o parâmetro pode ser assumido em função do perfil geológico do local, determinado a partir dos resultados de prova de carga 
estática conduzidos até a ruptura, ou determinados através de retroanálises com o método CAPWAP (Pereira, 2003).

Tabela 2.4 -Valores de $\mathrm{J}_{\mathrm{CASE}}$ (Goble et al., 1996 e Rausche, 1985).

\begin{tabular}{cccc}
\hline \multirow{2}{*}{ Tipo de Solo } & $\begin{array}{c}\text { Goble et al. } \\
(1985)\end{array}$ & \multicolumn{2}{c}{$\begin{array}{c}\text { Rausche et al. } \\
(1985)\end{array}$} \\
\cline { 2 - 4 } & $\mathrm{J}_{\mathrm{CASE}}$ & Variação & $\mathrm{J}_{\mathrm{CASE}}$ \\
\hline Areia & $0,10-0,15$ & $0,05-0,20$ & 0,05 \\
\hline Areia siltosa ou silte arenoso & $0,15-0,20$ & $0,15-0,30$ & 0,15 \\
\hline Silte & $0,25-0,40$ & $0,20-0,45$ & 0,30 \\
\hline Argila siltosa ou silte argiloso & $0,40-0,70$ & $0,40-0,70$ & 0,55 \\
\hline Argila & $0,70-1,00$ & $0,60-1,10$ & 1,10 \\
\hline
\end{tabular}

Segundo Fleming et al. (1992) as simplificações adotadas no método, quanto a adoção de um fator de amortecimento a priori são consideráveis, pelo fato de que a resistência estática pode ser bastante sensível ao valor de Jc utilizado. Pereira (2003) apresenta uma compilação de resultados de provas de carga estáticas conduzidas até à ruptura para auxiliar na definição dos valores do fator de amortecimento (Figura 2.36) e que não provoquem desvios na resistência mobilizada superior a $20 \%$.

Portanto, a capacidade de carga estática da estaca utilizada no método $(\mathrm{Ru})$, é obtida subtraindo-se da parcela dinâmica ( $\mathrm{Rd})$ da resistência total mobilizada (Rt). Equacionando matematicamente:

$$
R_{s}=R_{t}-J_{c} \cdot\left(2 \cdot F 1-R_{t}\right)
$$

Pelo método, ${ }^{R}$ depende da velocidade da ponta da estaca, do valor da constante de amortecimento (ou damping) e da impedância ( $Z$ ), entretanto se o deslocamento da ponta tender a zero, consequentemente a resistência dinâmica tenderá a zero. Nesse caso a resistência estática $(\mathrm{Ru})$ será obtida pela diferença entre a total $\left({ }^{R_{t}}\right)$ e dinâmica $\left({ }^{R_{d}}\right)$, podendo ser praticamente insensível ao valor de ${ }^{J_{c}}$ (Rosa, 2000). 


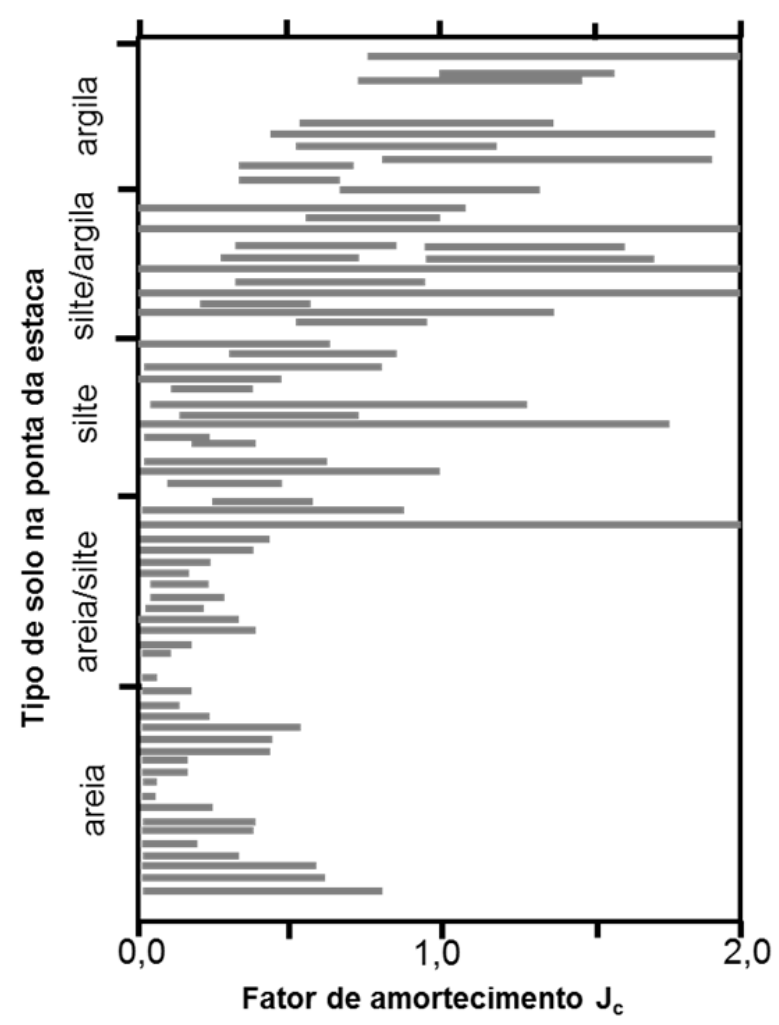

Figura 2.36 - Fatores de amortecimento dinâmico em função do tipo de solo na ponta da estaca (Pereira, 2003 apud Rausche et al., 1985, Goble et al., 1975).

Rausche et al. (1985) citam possibilidades de erros/desvios na determinação da resistência mobilizada pelo processo:

a) A resistência mobilizada pode não ser totalmente mobilizada no instante $t_{1}+2 L / c$.

b) A energia aplicada pode não ser suficiente para mobilizar todas as forças resistentes do solo, ou seja, pode não ocorrer a ruptura do sistema estaca-solo (Aoki, 1997).

c) A onda de tensão pode ser curta relativamente ao comprimento da estaca sobre o qual estão atuando as forças resistentes.

d) A resistência de ponta pode não ser solicitada no tempo $t_{1}+2 L / c$.

e) O valor da resistência mobilizada pode variar com o tempo por conta de efeitos de recuperação/cicatrização (setup) ou relaxação do solo. 


\subsubsection{Método CAPWAP}

O método CAPWAP (CAse Pile Wave Analysis Program) é uma rotina computacional, desenvolvida a partir da equação da propagação da onda de tensão, permitindo uma análise mais elaborada a partir dos registros da variação ao longo do tempo dos sinais de velocidade e força obtidos em campo. Através desse método é possível determinar a capacidade de carga estática do solo, com o valor do fator de amortecimento analisado, sua distribuição ao longo do fuste e na ponta utilizando o algoritmo de Smith (1960).

Para a realização da análise inicialmente são conhecidos os dados da estaca (diâmetro e comprimento) e seu material (E e v) e adotados parâmetros relacionados ao solo ( $\mathrm{K}$ - coeficiente de mola, quake e outros). A partir desses dados o programa resolve a equação da onda utilizando o modelo numérico de Smith, e como condição de contorno uma das variáveis (normalmente a velocidade medida), obtendo-se como resultado a outra variável (a força medida).

Velloso e Lopes (2010) comentam que outro tipo de interpretação dos sinais de cravação consiste em prever a priori a velocidade no ponto onde foram instalados os sensores, e com parâmetros iniciais - tendo como partida a curva de força, velocidade ou onda $(W)$ medida. Comparando a primeira simulação com os dados medidos pode-se se verificar o ajuste entre curvas, e eventualmente ajustá-los, retroanalisando o modelo inicial, dá se iterativamente até que ocorra uma convergência (melhor ajuste - best match) entre a curva simulada com a medida.

Dentro dos programas comerciais disponíveis que utilizam a equação da onda na análise dos registros do ensaio dinâmico, tem-se: TNO-WAVE do Instituto de Pesquisas da TNO Holanda (Middendorp, 1987) e o francês SIMBAT (Paquet, 1988) e IPT (1987). Algumas universidades desenvolveram rotinas similares, podemos citar o trabalho de Danziger (1991) e Pereira (2003).

Aoki (1997) comenta que a principal vantagem do CAPWAP em comparação com ao método CASE é que o mesmo não oferece apenas os valores de R, mas também as parcelas de resistência pela ponta $(\mathrm{Rp})$ e atrito lateral local $(\operatorname{Rs}(\mathrm{x}))$ para cada segmento da estaca. O método ainda apresenta os valores do método CASE como RMX e RSU e, o correspondente 
coeficiente de amortecimento ( ${ }^{J}$ CASE) resultando na resistência que coincida com o valor de $\mathrm{R}$ do CAPWAP.

A partir dos parâmetros do solo calibrados com os registros de campo, é possível simular pelo programa uma prova de carga estática obtendo-se assim uma curva cargarecalque simulada. Inicialmente se assume que a velocidade é igual à zero, e para cada nível de carregamento na ponta realiza-se uma análise usando os modelos do solo e da estaca determinados anteriormente no CAPWAP, e como resultado se obtém para cada carregamento na ponta os valores de força axial e deslocamento do topo da estaca.

Para Findlay et al. (1997), a resposta da resistência mobilizada de uma estaca com base na equação da onda não está diretamente ligada ao tipo de solo, podendo o programa ser aplicado nos diversos tipos de terreno, entretanto é essencial o seu conhecimento, permitindo ao operador da análise refinar o modelo.

Entretanto, Danziger (1996) ao analisar sinais de estacas cravadas em areia conclui, para um mesmo conjunto de sinais de $F$ e $V$, que é possível obter diferentes soluções da análiseCAPWAP, para o mesmo best match, portanto a solução não é única e depende dos inputs do operador.

\subsubsection{Influências na resistência mobilizada}

O resultado de uma prova de carga dinâmica pode sofrer influências de diversos fatores, sendo os mais relevantes: o nível de energia empregado na execução do ensaio e o efeito setup (depende do tempo entre a cravação e a execução da prova de carga).

Fellenius et al. (1989) apresenta na sua publicação diversos casos de estacas cravadas em que se avaliou o ganho de resistência a partir de provas de carga dinâmicas, em diversos intervalos de tempo, comprovando-se o ganho de resistência ao longo do tempo. $\mathrm{O}$ maior ganho de resistência ocorre nos primeiros dias após a cravação, citando o caso da estaca B-2, obteve um ganho de $150 \%$ nos primeiros 2 dias após a cravação, e com 16 dias o ganho foi de $300 \%$ em relação a resistência mobilizada no final de cravação.

Goble e Likins (1996) observam que a prova de carga dinâmica executada com mais dias após a cravação, permite melhores estimativas da resistência mobilizada com relação a uma prova de carga estática. 
O efeito setup está diretamente ligado às características do terreno e a execução, Tan et al. (2004) cita casos em que o ganho de resistência foi de 3 a 4 vezes maior que a resistência mobilizada no final de cravação, e conclui que em solos arenosos submersos considera o tempo de 24 horas como suficiente para dissipação do excesso de pressão neutra.

Hannigan et al. (1996) para solos arenosos sugere o tempo mínimo de 5 a 7 dias. Entretanto Stevens (2004) recomenda que para solos argilosos haja necessidade de intervalo de tempo de semanas a meses.

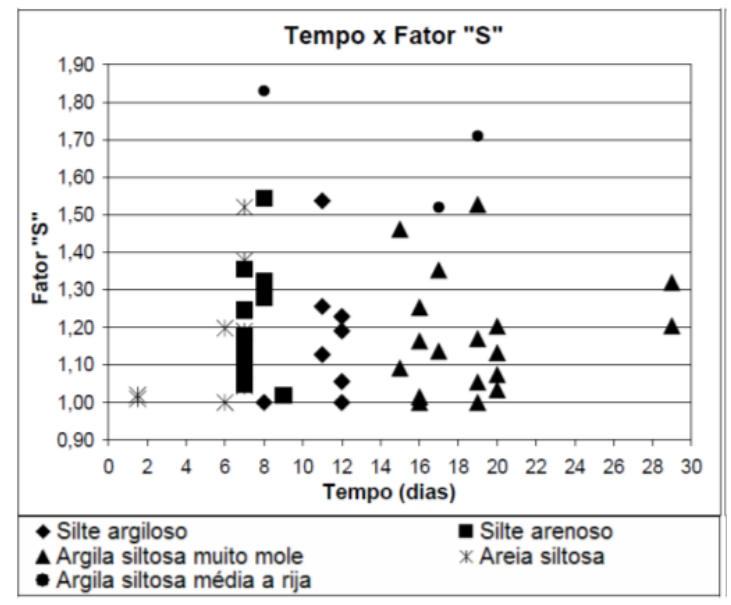

Figura 2.37 - Diagrama da relação $S$ em função do tempo (Paraíso e Costa, 2010).

Para Bilfinger (2010) o fenômeno do setup é muito conhecido pelo ponto de vista qualitativo, mas sua quantificação tem se demonstrado complexa. Os possíveis mecanismos que explicam sua ocorrência se dividem em dois grandes grupos: os ligados ao excesso de poropressão gerada durante o processo de cravação da estaca e os que independem desse fenômeno.

Paraíso e Costa (2010) interpretaram os resultados de provas de carga dinâmica em 56 estacas cravadas em solos da região Sul, Sudeste e Nordeste, ensaiados em diversas idades. Eles obtiveram para a relação $S$ (razão adimensional empírico entre a resistência mobilizada no tempo $t$ (recravação da estaca) e o tempo $t_{0}$ - resistência no final da cravação) valores variando de 1,0 a 1,8 (Figura 2.37).

Pelo modelo de Denver e Skov (1988) em que estabelecem que o efeito setup em estacas cravadas, para qualquer tipo de solo, evolui proporcionalmente com o logaritmo do 
tempo através da expressão [2.53].

$$
Q(t)=Q_{0} \cdot\left[1+A \cdot \log \left(\frac{t}{t_{0}}\right)\right]
$$

Onde $Q(t)$ e $Q_{0}$ são as resistências mobilizadas no tempo $t$ e $t_{0}$, em dias após o final da cravação e $A$ é o coeficiente adimensional empírico em função do tipo de solo. Para os dados de Paraíso e Costa (2010) foi considerado na analise o tipo de solo na ponta das estacas, resultando-se nos parâmetros apresentados na Tabela 2.5.

Para esses valores de AMÉDIO representados graficamente na equação de Denver e Skov (1988), a Figura 2.38 apresenta as curvas de cicatrização em função tempo, para os diferentes tipos de solo na ponta da estaca.

Soares et al. (2006) apresentam um conjunto de resultados de provas de carga estáticas, realizadas em diversas idades, em estacas instaladas num deposito de argilas marinhas na região metropolitana de Recife. O ganho de resistência foi da ordem de $15,1 \%$.

Mello et al. (1998) apresenta resultados de ensaios executados na margem esquerda do Porto de Santos, na região do Tecon II, em que o valor médio da cicatrização do solo foi de 3,27 com uma dispersão de 0,21. Bilfinger (2010) apresenta resultados de ensaios nas regiões do Tecon III e IV, obtendo para o valor médio de setup e dispersão 1,61 e 0,16 (Tecon III) e 1,68 e 0,09 (Tecon IV). Para a região de Cubatão, na obra do armazém de fertilizantes da Ultrafértil se tem uma média de 2,03 e dispersão de 0,19. Um caso no Porto de Itapoá, no litoral de Santa Catarina, o setup médio foi de 1,68 para uma dispersão de 0,13.

Tabela 2.5 - Fator A de Denver e Skov (1998) em função do tipo de material na ponta das estacas (Paraíso e Costa, 2010).

\begin{tabular}{cc}
\hline Tipo de Solo & $\begin{array}{c}\text { Fator } \\
\mathrm{A}_{\text {MÉDIO }}\end{array}$ \\
\hline Argila siltosa média a rija & 0,512 \\
\hline Silte arenoso & 0,224 \\
\hline Silte argiloso & 0,221 \\
\hline
\end{tabular}




\begin{tabular}{cc}
\hline Areia siltosa & 0,154 \\
\hline Argila siltosa muito mole & 0,139 \\
\hline
\end{tabular}

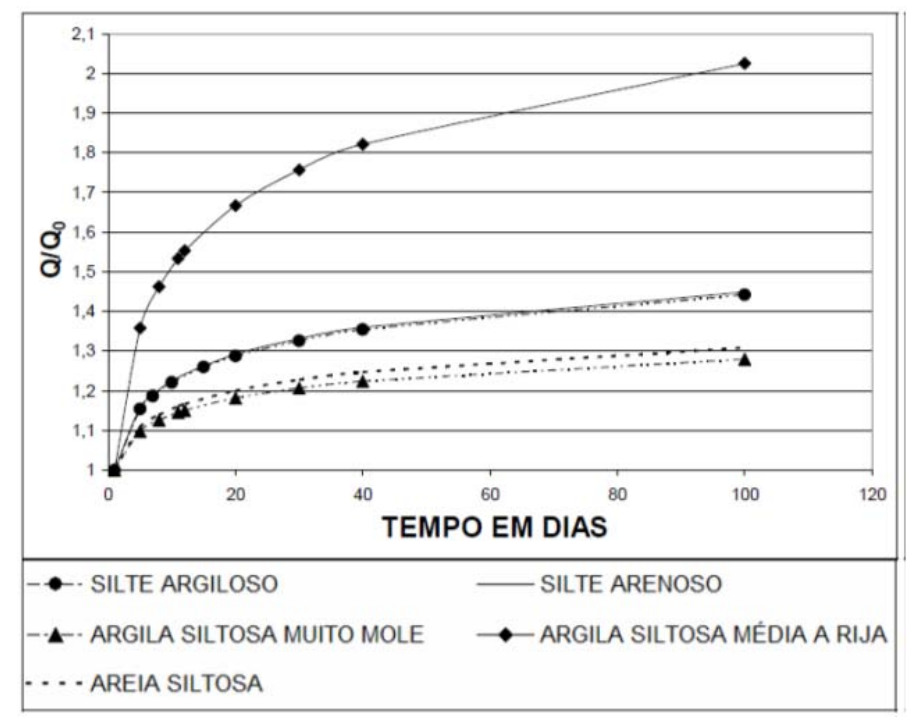

Figura 2.38 - Curvas de $Q(t) / Q_{0}$ em função do tempo (Paraíso e Costa, 2010).

\subsubsection{Comparação com PCE}

Em vários trabalhos é possível observar que as previsões da resistência estática por meio das formulações dinâmicas é um processo confiável, desde que sejam respeitadas as condições impostas pelos autores a suas expressões, principalmente as limitações aos tipos de solo. Ávila (2001) constatou que o controle de cravação por meio de métodos baseados no repique elástico é válido para estacas metálicas, Rosa (2000) obteve as mesmas constatações para elementos de concreto pré-moldado, e Miná (2005) em estacas de madeira.

Aoki e Niyama (1991) apresentam uma avaliação comparativa entre provas de carga dinâmica com energia crescente e prova de carga estática no campo experimental da EP-USP. Os autores concluem que os resultados mostraram bastante concordância, não somente a carga de ruptura, mas também na curva carga-deslocamento (Figura 2.39).

Likins e Rausche (2004) apresentaram um estudo em que compilaram uma série de resultados de provas de carga dinâmica e estática, na mesma estaca, e foram apresentados durante os eventos do StressWave (um banco de dados de 303 casos históricos). 

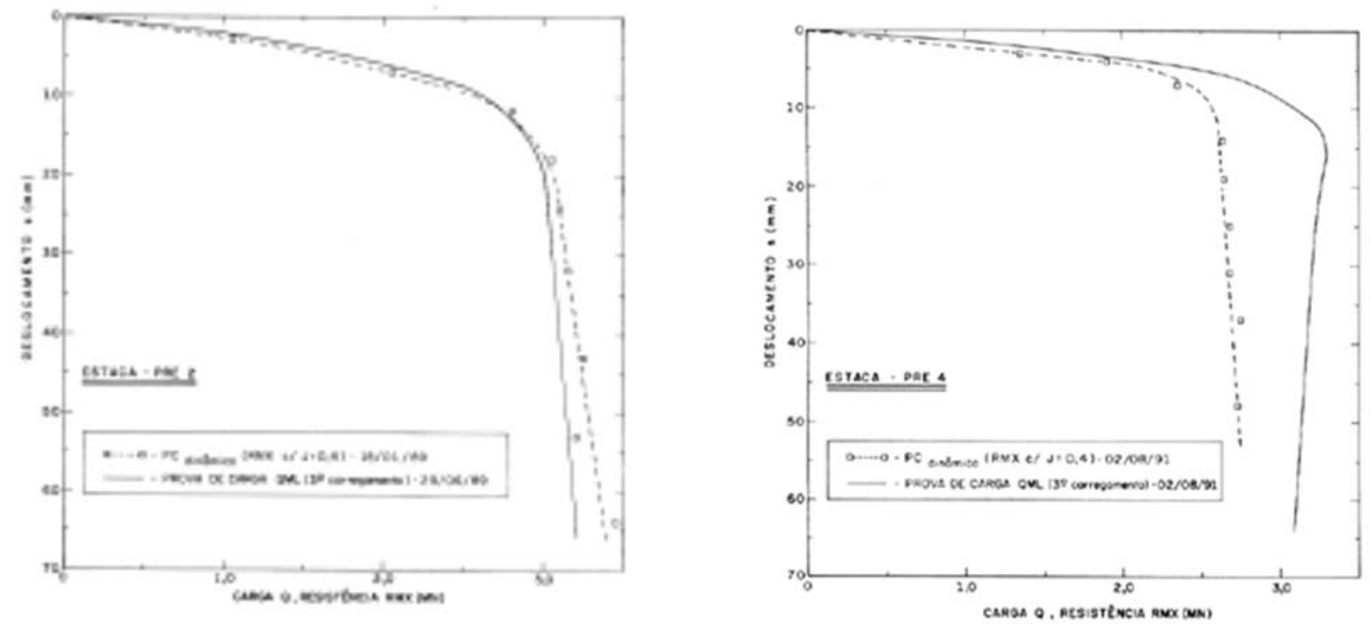

Figura 2.39 - Comparação das curvas de carga-deslocamento entre Ensaios de Carregamento Dinâmico com Energia Crescente e Prova de Carga Estática (Aoki e Niyama, 1991).

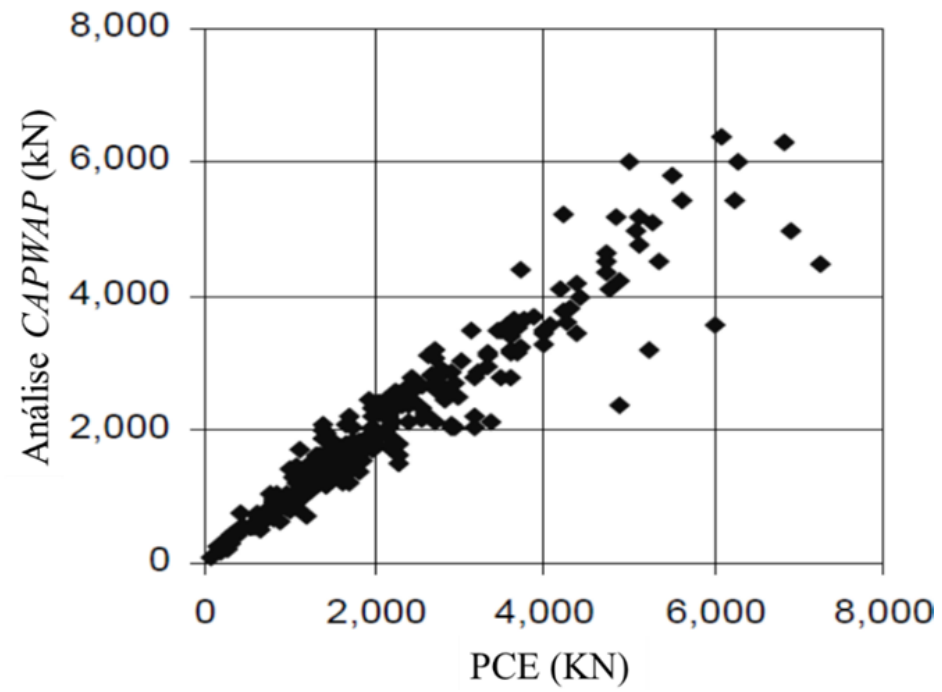

Figura 2.40 - Resultados dos estudos de comparação entre resultados de provas de carga dinâmica e estática (Likins e Rausche, 2004).

A Figura 2.40 apresenta todos esses casos num gráfico de resistência mobilizada pelo CAPWAP (CW) pela prova de carga estática (SLT - Static Load Test), obtendo-se como valor médio da razão $\frac{C W}{S L T}$ 0,98, com um coeficiente de variação de $16,9 \%$. 


\subsection{Intepretação da curva carga - recalque}

Para a interpretação das curvas carga-recalque foram aplicados alguns métodos de extrapolação, os quais são: Chin-Kondner (1963, 1970 e 1971), Davisson (1972), da NBR 6122 (2010), Van der Veen (1953) modificado por Aoki (1979), Mazurkiewcz (1972) e Décourt (1996). Além desses métodos, as curvas foram interpretadas e estudadas pelas relações modificadas de Cambefort (1964), pelo método das duas retas segundo Massad e Lazo (1998) e dos trabalhos de Massad (1992, 1993, 1995 e 1998).

\subsubsection{Métodos de extrapolação}

\subsubsection{Método de Chin-Kondner (1963, 1970 e 1971)}

O método de Chin (1970 e 1971) baseado no trabalho de Kondner (1971) permite a extrapolação da carga de ruptura em provas de carga do tipo lenta ou rápida. $\mathrm{O}$ método consiste em plotar num gráfico no eixo das abcissas os recalques e no eixo das ordenas a relação recalque/carga aplicada, ajustando uma reta entre os pontos, conforme Figura 2.41.

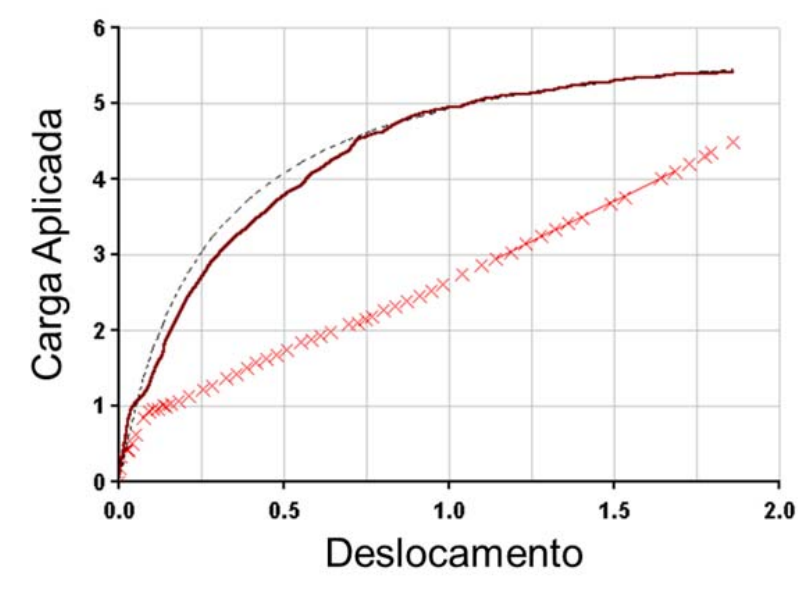

Figura 2.41 - Método de extrapolação proposto por Chin-Kondner (1971).

Pelo inverso do coeficiente angular da curva $(\mathrm{Cl})$ obtém-se a carga limite última expressão [2.54].

$$
Q_{u}=\frac{1}{C 1}
$$




\subsubsection{Método da NBR (2010) e Davisson (1972)}

O método proposto por Davisson (1972) supõe que a carga limite é convencionada por uma equação [2.55] que depende do diâmetro da estaca, da compressão elástica e que não exceda $4 \mathrm{~mm}$ de deformação. Graficamente a carga de ruptura é convencionada com o ponto que cruza a equação elástica com a curva da prova de carga, sendo esquematicamente representado na Figura 2.42.

$$
\rho=\left(4+\frac{b}{120}\right)+\frac{Q \cdot L}{E \cdot S}
$$

Para a NBR 6122 (2010) é muito similar ao método de Davisson (1972) alterando apenas a consideração referente ao deslocamento plástico inicial, conforme a expressão abaixo:

$$
\rho=\frac{D}{30}+\frac{Q \cdot L}{E \cdot S}
$$

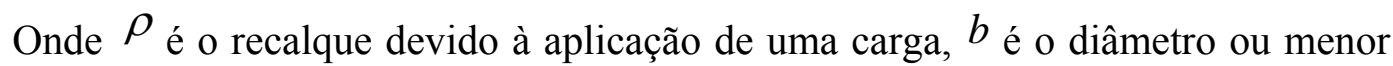
lado de uma estaca, $L$ é o comprimento cravado, $Q$ a carga aplicada, $E$ é o módulo de elasticidade do concreto e $S$ é a área da seção transversal.

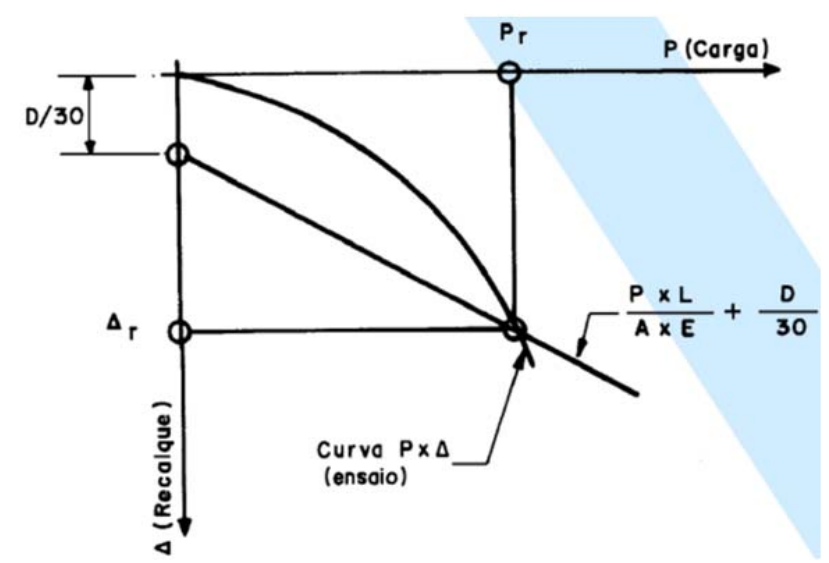

Figura 2.42 - Definição da carga de ruptura convencionada.

\subsubsection{Método de Van der Veen (1953) modificado por Aoki (1979)}

O método propõe que a extrapolação da carga de ruptura se de através de uma relação entre carga aplicada e deslocamento no topo da estaca tem um formato de uma 
exponencial. Aoki (1979) após extrapolar diversas PCE propõe a adoção de uma equação linear no modelo logarítmico para um melhor ajuste. Portanto a expressão resulta:

$$
Q=\text { Qult } \cdot\left(1-e^{-\alpha \cdot r+\beta}\right)
$$

Onde $Q$ é a carga aplicada no topo da estaca, $Q_{u l t}$ é a carga de ruptura, $\alpha$ é o coeficiente que define a fôrma da curva e $\rho$ é o recalque devido à carga aplicada.

A partir dessa equação plota-se um gráfico (Figura 2.43) que no eixo das abcissas fica $\ln \left(1-Q / Q_{u l t}\right)$ e no eixo das ordenadas os recalques, e simulam-se várias possibilidades para $Q_{u l t}$. A curva que apresentar o melhor coeficiente angular $R^{2}$, será considerada a carga de ruptura.

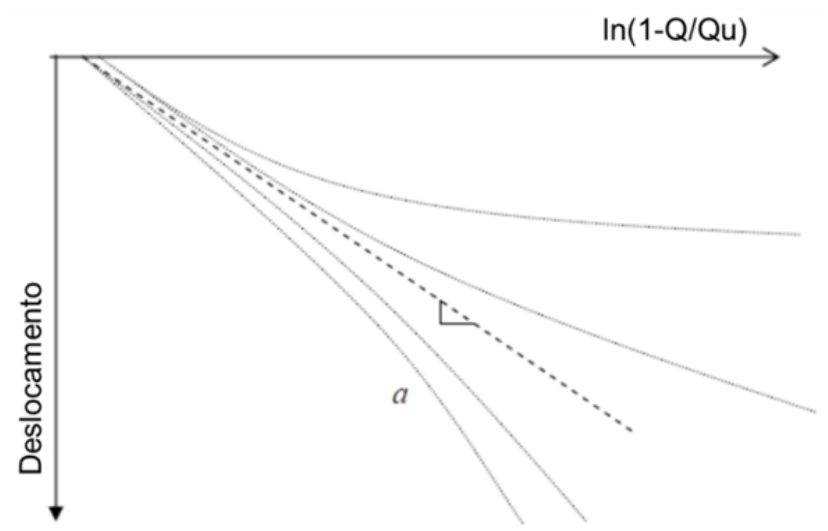

Figura 2.43 - Método gráfico de Van der Veen (1953).

\subsubsection{Método de Mazurkiewicz (1972)}

Mazurkiewicz (1972) propôs um método de extrapolação da curva carga aplicada por deslocamento, supondo como uma curva parabólica. O método é gráfico e consiste traçar linhas paralelas horizontais com a mesma distância entre si interceptando a curva. Os pontos que cruzam a curva do ensaio são projetados verticalmente até a intersecção com o eixo das abcissas, correspondente a carga de topo. 


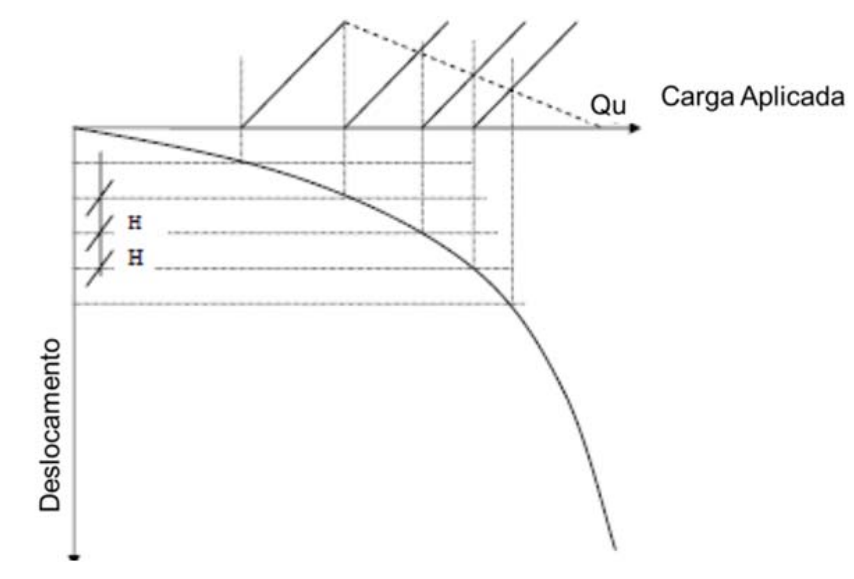

Figura 2.44 - Método gráfico de Mazurkiewicz (1972).

Segmentos de reta com 45 em relação ao eixo das abcissas são traçadas, e a interseção entre a reta de 45 e a vertical traçada a partir da curva do ensaio, geram uma nova reta, que a intersecção com o eixo das abcissas resulta na carga de ruptura do método. A Figura 2.44 apresenta a construção do método.

\subsubsection{Décourt (1996)}

Décourt (1996) propôs o método da rigidez infinita utilizando o conceito da rigidez, que é a relação entre a carga aplicada no topo da estaca dividido pelo recalque correspondente, elaborando-se um gráfico onde no eixo das abcissas representa à carga aplicada e na ordenada a rigidez.

Segundo o autor o gráfico de rigidez permite visualizar a distância entre o ponto de máxima carga aplicada e a ruptura física, através de uma extrapolação linear ou logarítmica, como sendo o ponto da curva que a corresponde à rigidez nula, sendo atribuído como a carga de ruptura do método.

Posteriormente Décourt (2008) apresentou uma ampliação do método propondo uma metodologia de interpretação da curva par obtenção da parcela de atrito lateral a partir da instrumentação de topo da prova de carga estática. Quando os carregamentos avançaram a grandes deformações é possível definir dois domínios a partir da curva de rigidez: no trecho em que a transferência é por ponta, a relação entre a curva carga aplicada por rigidez é curva, tornando-se uma reta num gráfico logarítmico, esse valor é definido como limite superior do 
atrito lateral $\left(Q_{S L}\right)$.

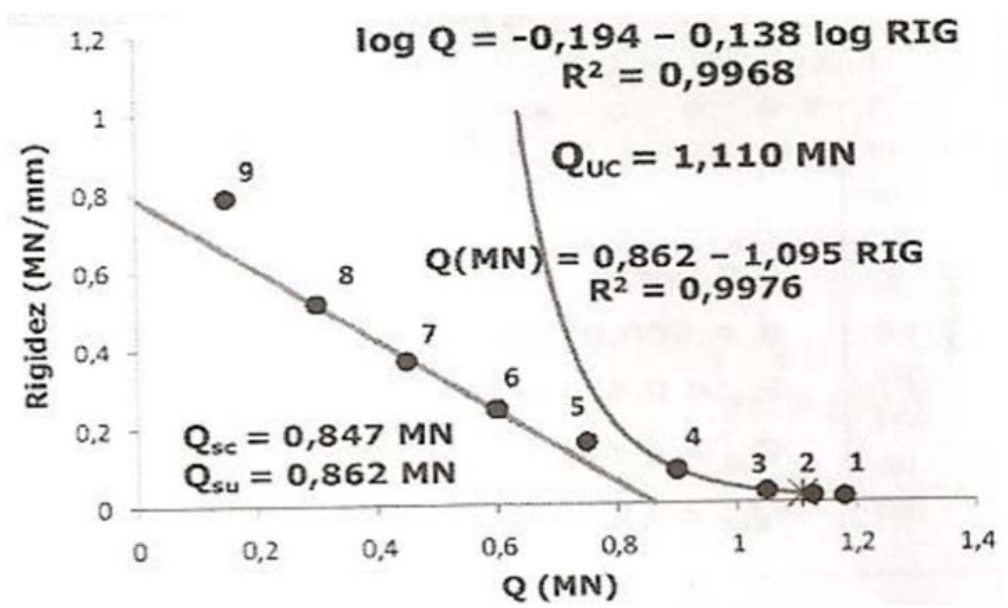

Figura 2.45 - Representação do limite inferior e superior do atrito lateral.

Quando a predominância de atrito lateral, a curva é aproximadamente uma reta no gráfico de carga aplicada por rigidez, e esse valor é definido como limite inferior do atrito. Portanto o método fornece uma faixa de valores para o atrito lateral, e comumente se adota o valor médio.

\subsubsection{Massad (1992, 1993, 1995 e 1998)}

Para o caso de uma estaca vertical, isolada e submetida a um carregamento axial pode ser tratada pelas relações propostas por Cambefort (1964) para o atrito lateral ( $f$ ) e resistência de ponta $\left({ }^{q}\right)$ sendo representadas pelas funções apresentadas na Figura 2.46 com o recalque da estaca.
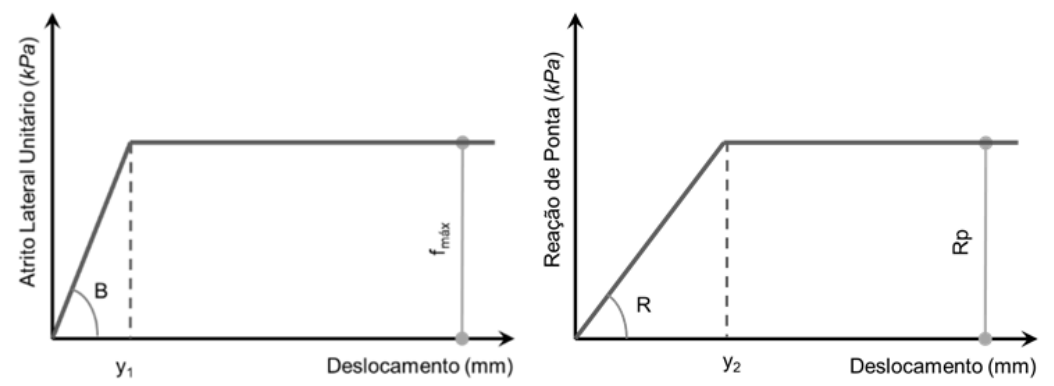

Figura 2.46 - Funções existentes entre atrito lateral e ponta em função do recalque $-1^{\circ}$. e $2^{\circ}$.

Relação de Cambefort (1964).

Analisando as relações de Cambefort (1964) podem-se escrever as seguintes 
expressões:

$$
\begin{aligned}
& f=\left\{\begin{array}{lll}
B \cdot y & \text { se } & y<y_{1} \\
f_{\text {máx }}=B \cdot y_{1} & & y \geq y_{1}
\end{array}\right. \\
& q=\left\{\begin{array}{lll}
R \cdot y & \text { se } & y<y_{2} \\
R_{p}=R \cdot y_{2} & & y \geq y_{2}
\end{array}\right.
\end{aligned}
$$

A partir da expressão [2.60] que controla a transferência de carga da estaca para o solo, pode se escrever segundo Massad (1991) a expressão [2.61].

$$
\begin{gathered}
\frac{d^{2} y}{d x^{2}}=\frac{\pi \cdot D \cdot f}{E \cdot S} \\
\frac{d^{2} y}{d x^{2}}=\left\{\begin{array}{lll}
\frac{k}{h^{2}} \cdot y & \text { se } & y<y_{1} \\
\frac{k}{h^{2}} \cdot y_{1} & & y \geq y_{1}
\end{array}\right.
\end{gathered}
$$

A partir das relações de Cambefort a rigidez relativa estaca-solo $(k)$ pode ser definida como:

$$
k=\frac{Q_{L R U P}}{K_{r} \cdot y_{1}}
$$

Onde $Q_{\text {LRUP }}$ é o atrito lateral na ruptura e definido pela expressão[2.63], $f_{\text {máx }}$ é o atrito lateral unitário na ruptura, $h_{\mathrm{o}}$ comprimento da estaca, $y_{1}$ o deslocamento necessário para o esgotamento do atrito lateral unitário, $K_{r}$ a rigidez da estaca como elemento estrutural (expressão [2.64]) $S$ a área da seção transversal da estaca e $E$ o módulo de elasticidade do material da estaca.

$$
Q_{\text {LRUP }}=\pi \cdot D \cdot f_{\text {máx }} \cdot h
$$




$$
K_{r}=\frac{E \cdot S}{h}
$$

Em um ensaio de carregamento é possível identificar quatro estágios no fenômeno de transferência de carga, associados com cinco diferentes pontos na curva carga-recalque instrumentados no topo (Figura 2.47).

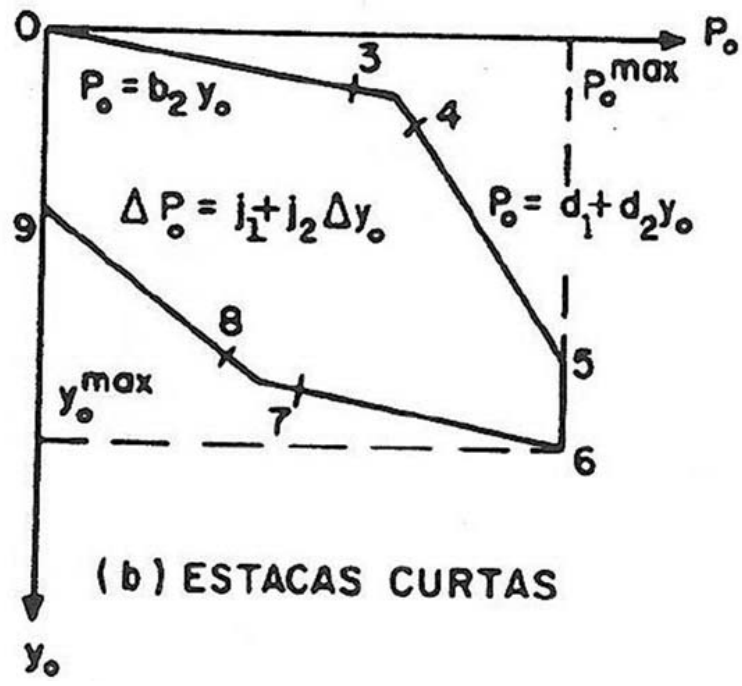

Figura 2.47 - Curva carga-recalque teórica a partir da instrumentação de topo (Massad e Lazo, 1998).

O primeiro estágio que corresponde no trecho entre os pontos 0-3 corresponde ao desenvolvimento da resistência de ponta e atrito lateral ao longo da parte pseudo-elástica em referência a $1^{\circ}$ relação de Cambefort, em particular no ponto 3 as condições de contorno são: $y=y_{1}$ e $f=f_{u}=f_{\text {máx }}$.

Para os pontos 3-4, o segundo estágio está relacionado à mobilização progressiva da resistência lateral ultima ( $\left.f_{u}\right)$ do topo para a ponta. No terceiro estágio (pontos 4-5), conforme o carregamento no topo é incrementado, o solo no nível da ponta reage ao longo da parte pseudo-elástica seguindo a $2^{\circ}$ relação de Cambefort alcançando a ruptura no ponto 5 , que corresponde ao estágio quatro (pontos 5-6).

À medida que é incrementado o carregamento axial da estaca na execução da prova de carga, surge em sua ponta uma carga residual $\left(P_{h}\right)$ que fica aprisionada, permitindo explicar o formato da curva carga-recalque em estacas escavadas submetidas a um segundo carregamento. 
Por um ponto de vista físico, a existência da carga residual significa que a ponta da estaca já está reagindo quando o atrito lateral começa a ser mobilizado (positivamente) e logo após a cravação da estaca atua de cima para baixo (negativamente), prendendo a estaca no terreno e equilibrando a carga residual na ponta. Para o próximo nível de carregamento há necessidade num primeiro momento de reverter esse atrito lateral antes de ocorrer uma mobilização efetiva, a isso se denomina de reversão do atrito lateral.

Massad (1992) propôs uma generalização de um modelo matemático, desenvolvido inicialmente para estacas escavadas, a introdução de um fator $\mu_{\text {para }}$ quantificar a ação da carga residual, quanto uma modificação nas relações de Cambefort para considerar o fenômeno de reversão do atrito lateral. Matematicamente o fator ${ }^{\mu}$ pode ser expresso por:

$$
\mu=1+\frac{P_{h}}{A_{l r}}
$$

Onde $P_{h}$ é a carga residual, $A_{l r}$ o atrito lateral na ruptura, $f_{\text {res }}$ o atrito lateral residual e $f_{u} \mathrm{o}$ atrito lateral unitário ultimo.

A grande vantagem de se trabalhar com o fator ${ }^{\mu}$ residem no fato de se poder analisar globalmente o comportamento da curva carga-recalque seja ela escavada ou cravada. Para o caso de estacas escavadas ${ }^{\mu}=1,0$, para o caso de estacas cravadas com transferência por ponta ${ }^{\mu}=2,0$ e para as condições de estacas cravadas por atrito é admitido: $1,0<\mu<2,0$.

Para a aplicação dos conceitos e fórmulas apresentadas anteriormente adotou-se o roteiro de interpretação proposto por Ghilardi (2005). A seguir será comentada uma breve descrição dos passos e expressões empregadas.

No trecho da curva entre os pontos (0-3) procurou-se fazer um ajuste parabólico entre a carga $\left(P_{0}\right)$ e recalque $\left(y_{0}\right)$ obtidos a partir da instrumentação de topo, que converteu num gráfico plotando $P_{0}^{2}$ por ${ }^{y_{0}}$. Ajustou-se nesse gráfico uma reta determinando a constante $c 1$ e o coeficiente angular $c 2$ permitindo assim obter o atrito lateral ao longo de toda a estaca 
na ruptura, majorado pelas tensões residuais $(\mu \cdot A l r)$, o deslocamento necessário para o esgotamento do atrito lateral da estaca $\left(\mu \cdot y_{1}\right)$ e o coeficiente de rigidez relativa estaca-solo ( $k$ ) resulta nas expressões:

$$
\begin{gathered}
\mu \cdot \operatorname{Alr}=\frac{1}{2 \cdot K_{r} \cdot c_{2}} \quad \text { [2.66] } \\
\mu \cdot y_{1}=2 \cdot c_{1} \quad[2.67] \\
k=\frac{\mu \cdot A l r}{K_{r} \cdot \mu \cdot y_{1}}
\end{gathered}
$$

Se resultar num $\mathrm{k}>10$, a estaca pode ser tratada como uma estaca longa e ficam bem definidos, com boa precisão os pontos 3 e 4 . Se $\mathrm{k}<2$ os pontos 3 e 4 estão próximos, demonstrando uma tendência de comportamento rígido, ou seja, de uma estaca curta, e o método da parábola perde a validade. Para os casos intermediários de k deve ser analisar a tendência e interpretar com cautela.

Para os pontos 4-5 faz-se um ajuste da reta obtendo a equação [2.69].

$$
P_{0}=d_{1}+d_{2} \cdot y_{0} \quad[2.69]
$$

Por sua vez o atrito lateral na ruptura pode ser definido pela expressão [2.70].

$$
\mu \cdot A_{l r}=\frac{d_{1}}{1-\frac{d_{2}}{2 \cdot K_{r}}}
$$

Onde $\mu \cdot A l r$ é o atrito lateral na ruptura, $\mu$ o fator de majoração do atrito lateral, $d_{1} \mathrm{o}$ coeficiente linear da reta e $d_{2}$ o coeficiente angular do ajuste. Para o trecho de descarregamento, entre os pontos 8-9 ajusta-se uma reta aos pontos da curva obtendo a expressão [2.71]. A partir dessas considerações e das expressões anteriores, determina-se o 
valor de $2 \cdot$ Alr pela expressão [2.72].

$$
\begin{gathered}
\Delta P_{0}=j_{1}+j_{2} \cdot \Delta y_{0} \\
2 \cdot A l r=\frac{j_{1}}{1-\frac{j_{2}}{2 \cdot K_{r}}}
\end{gathered}
$$

A partir da obtenção desses fatores consegue-se definir o fator de majoração do atrito lateral, que está diretamente ligada à carga residual aprisionada na ponta da estaca a partir da expressão [2.73].

$$
\mu=\frac{\mu \cdot A l r}{A l r}
$$

\subsubsection{Adimensionalização de curvas de prova de carga dinâmica}

$\mathrm{Na}$ interpretação de resultados de provas de carga dinâmicas os principais fatores que podem modificar as análises: a caracterização da ruptura do sistema estaca-solo em relação ao nível de energia empregado e a idade entre a cravação e ensaio da estaca, denominado de setup.

Aoki e Cintra (1997) propõem uma nova forma de interpretar as curvas da prova de carga dinâmica par estacas cravadas considerando uma abordagem de energia, caracterizando a carga de ruptura a partir da invariância da resistência e energia de deformação, durante dois golpes consecutivos de energia crescente.

Além desse evento, mudanças naturais na resistência da camada de solo podem ocorrer devido a incrementos de energia, que em excesso correspondem à carga de ruptura, que é igual à adição de trabalho pelas forças não conservativas. Outra vantagem de se trabalhar com as curvas da prova de carga dinâmica de energia crescente é a possibilidade de definir qual o elo fraco no sistema estaca-solo, ou seja, se a ruptura está sendo comandada pelo elemento estrutural ou pelo solo.

Aoki e Cintra (1997) propõem uma forma conveniente de interpretar as curvas da 
prova de carga dinâmica através de curvas adimensionalizadas, apresentando gráficos em que as variáveis são adimensionalizadas pelas relações $E M X / E R E, R M X / R E, D M X / B, K / B$ e $S / B$.

Normalmente a ruptura média estrutural é denominada por $R E$ para um deslocamento igual a $10 \%$ do diâmetro externo $(B)$ da estaca, para adimensionalização dos parâmetros de força e deslocamento. Para o trabalho das forças não conservativas incluindo o damping se utiliza a relação da energia teórica, expressa por:

$$
E R E=\frac{(R E)^{2} \cdot L}{A \cdot E}
$$

Onde $L$ é o comprimento cravado abaixo da seção instrumentada, $A$ é a área da seção transversal e $E$ é o módulo de elasticidade do concreto.

Através das curvas adimensionalizadas, a Figura 2.48apresenta as curvas de carga $\mathrm{x}$ deslocamento e carga $\mathrm{x}$ energia para uma estaca com a ruptura sendo comandada pelo elemento estrutural, enquanto que a Figura 2.49 apresenta outro caso sendo comandado pela resistência do solo, tendo numa relação de $R M X / R E$ igual a $60 \%$ caracterizada por um trecho assintótico.

Outra vantagem dessa metodologia de se trabalhar com curvas adimensionalizadas é a possibilidade de trabalhar com diferentes diâmetros e verificar uma tendência para as diferentes curvas que mobilizaram diferentes resistências mobilizadas para a mesma obra. 

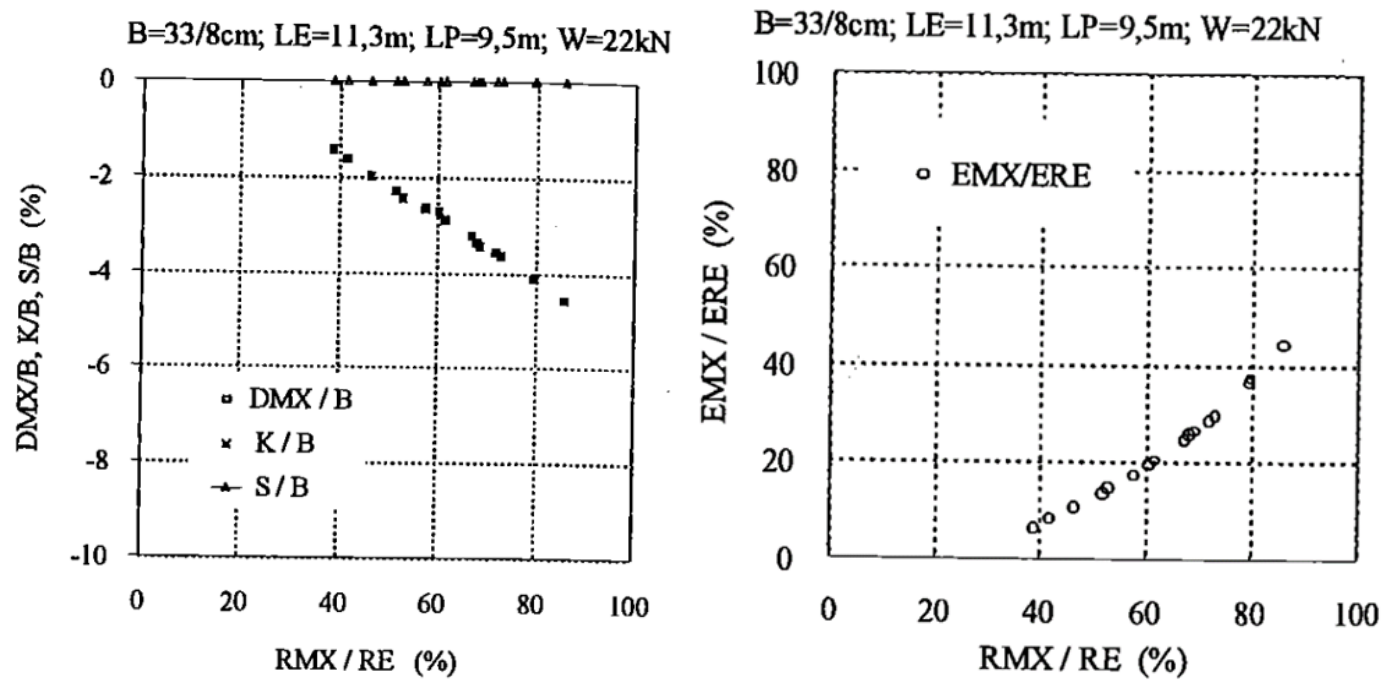

Figura 2.48 - Curvas adimensionalizadas - comportamento da estaca sendo comandada pela resistência do elemento estrutural.

$B=33 / 8 \mathrm{~cm} ; L E=11,3 \mathrm{~m} ; \mathrm{LP}=9,6 \mathrm{~m} ; \mathrm{W}=22 \mathrm{kN}$

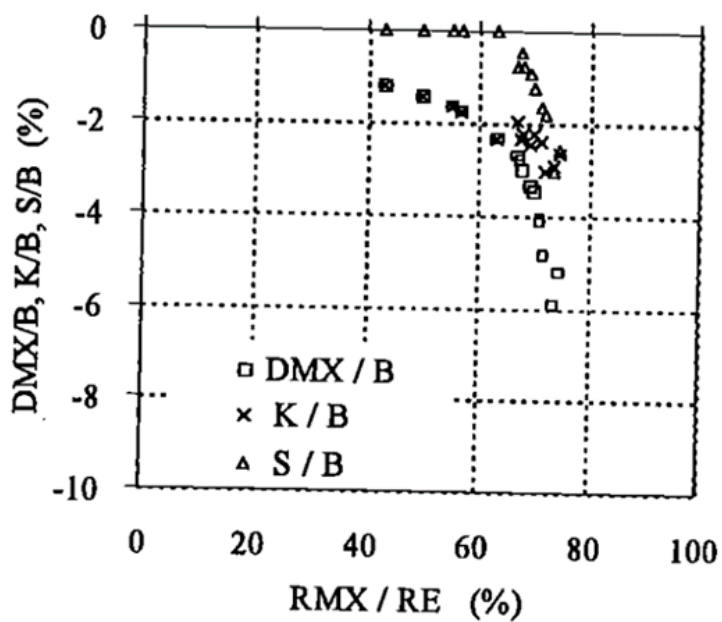

$B=33 / 8 \mathrm{~cm} ; L E=11,3 \mathrm{~m} ; L P=9,6 \mathrm{~m} ; W=22 \mathrm{kN}$

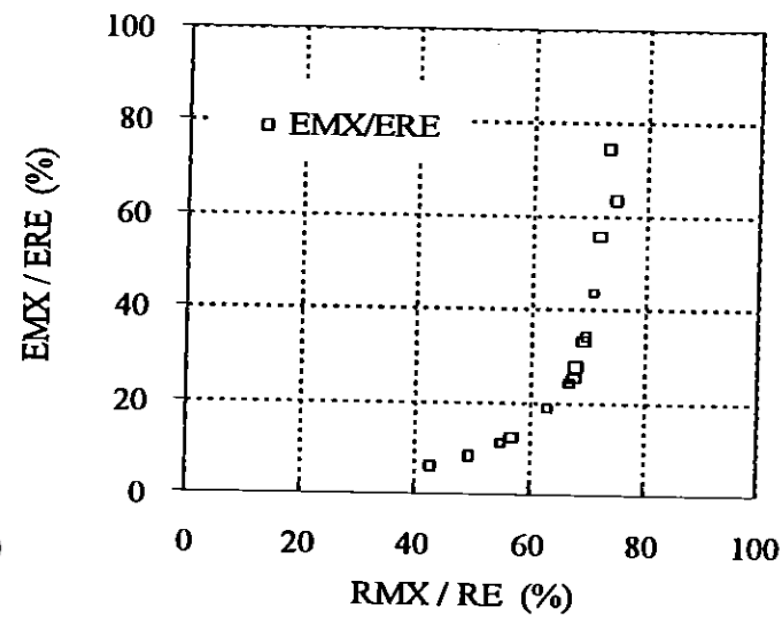

Figura 2.49 - Curvas adimensionalizadas - comportamento da estaca sendo comandada pela resistência do solo (Aoki e Cintra, 1997).

\subsection{Fenômeno do Embuchamento}

No caso de cravação de estacas com seção transversal vazada, durante a travessia das camadas é comum que o material de solo na ponta da estaca adentre internamente, sendo compactada a medida da aplicação dos golpes ganhando resistência até um determinando momento que cessa a penetração, passando a deslocar juntamente com a estaca, podendo ser considerado essa coluna de solo como parte da estaca. 
Esse fenômeno é muito comum em estacas metálicas tubadas, contribuindo com uma parcela de atrito interno ao tubo ou como resistência de ponta. Em estacas de concreto são poucos os estudos sobre embuchamento.

Paikowsky e Whitman (1990), baseados em analises de modelos reduzidos de estacas cravadas em areia definiram três estágios de formação da bucha: a) sem bucha (quando a relação altura da bucha- $p$ /diâmetro- $d$ da estaca $<2$ ), b) bucha parcialmente formada (relação $p / d>2$, entretanto a bucha se movimenta durante a cravação da estaca) e c) bucha totalmente formada (relação $p / d>5$ e depois de formada, a bucha se desloca juntamente com a estaca).

Kishida (1967), Niyama (1992), Soo et al. (1980) e Lehane e Randolph (2001) propuseram modelos matemáticos para a consideração do atrito desenvolvido pela bucha interna a estaca, bem como a definição do comprimento crítico para formação da bucha. 


\section{Materiais e Métodos}

Neste capítulo é apresentado o caso de estudo, com a descrição do local e dos registros coletados em campo. O projeto consistia na construção de um porto em Santa Catarina com a utilização de estacas pré-fabricadas vazadas de concreto armado centrifugado, com diâmetro externo de $700 \mathrm{~mm}$, espessura da parede de $110 \mathrm{~mm}$ e resistência característica $\left(f_{c k}\right)$ de $35 \mathrm{MPa}$.

Foi realizada uma extensa campanha de investigação do subsolo, totalizando 103 ensaios SPT, 9 ensaios de palheta caracterizando-se 97 pontos em profundidade, e 9 ensaios CPTU com 28 ensaios de dissipação. A Figura 3.1 apresenta uma implantação dos módulos.

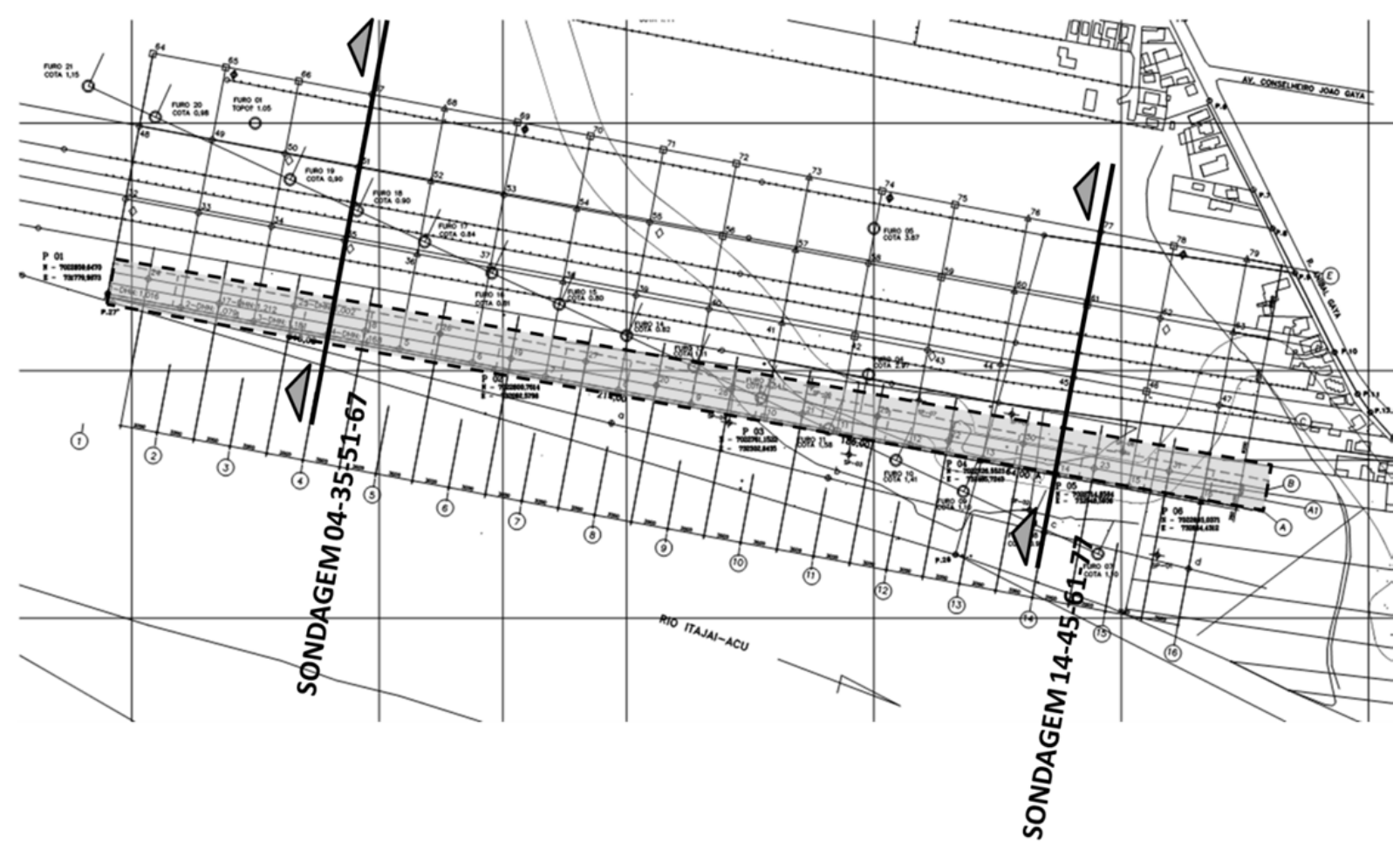

Figura 3.1 - Implantação da obra e dos módulos.

O projeto previa a construção de cais de atracação estaqueado - laje (objeto do estudo) e a área do retroporto em que seria desenvolvida através de um extenso aterro. $\mathrm{O}$ 
principal condicionante do projeto era as características geológico-geotécnicas, devido à presença de uma espessa camada de argila mole, intercalada com lentes de areia de maior resistência muito comum em regiões portuárias e ao longo da costa brasileira.

Para as estacas, são apresentados: as condições geológica-geotécnicas, o projeto de fundações, o processo de execução, os ensaios realizados nas estacas (provas de carga dinâmica e estática), e o controle executivo (registros de nega e repique elástico).

\subsection{Características Geológico-Geotécnicas}

A área de implantação do Porto fica situada às margens do rio Itajaí-Açu, e é composto por um grande pacote de sedimentos de origem fluvial, do Quaternário, seguido em profundidade pela presença de cascalhos, seixos, fragmentos de rocha (solo de alteração) e rocha metamórfica. Marques e Lacerda (2004) citam que nessa região há sobreposição de sedimentos fluviais, flúvio-marinhos e flúvio-lacunares, originados pelas mudanças climáticas e lentas variações do nível do mar ao longo dos anos.

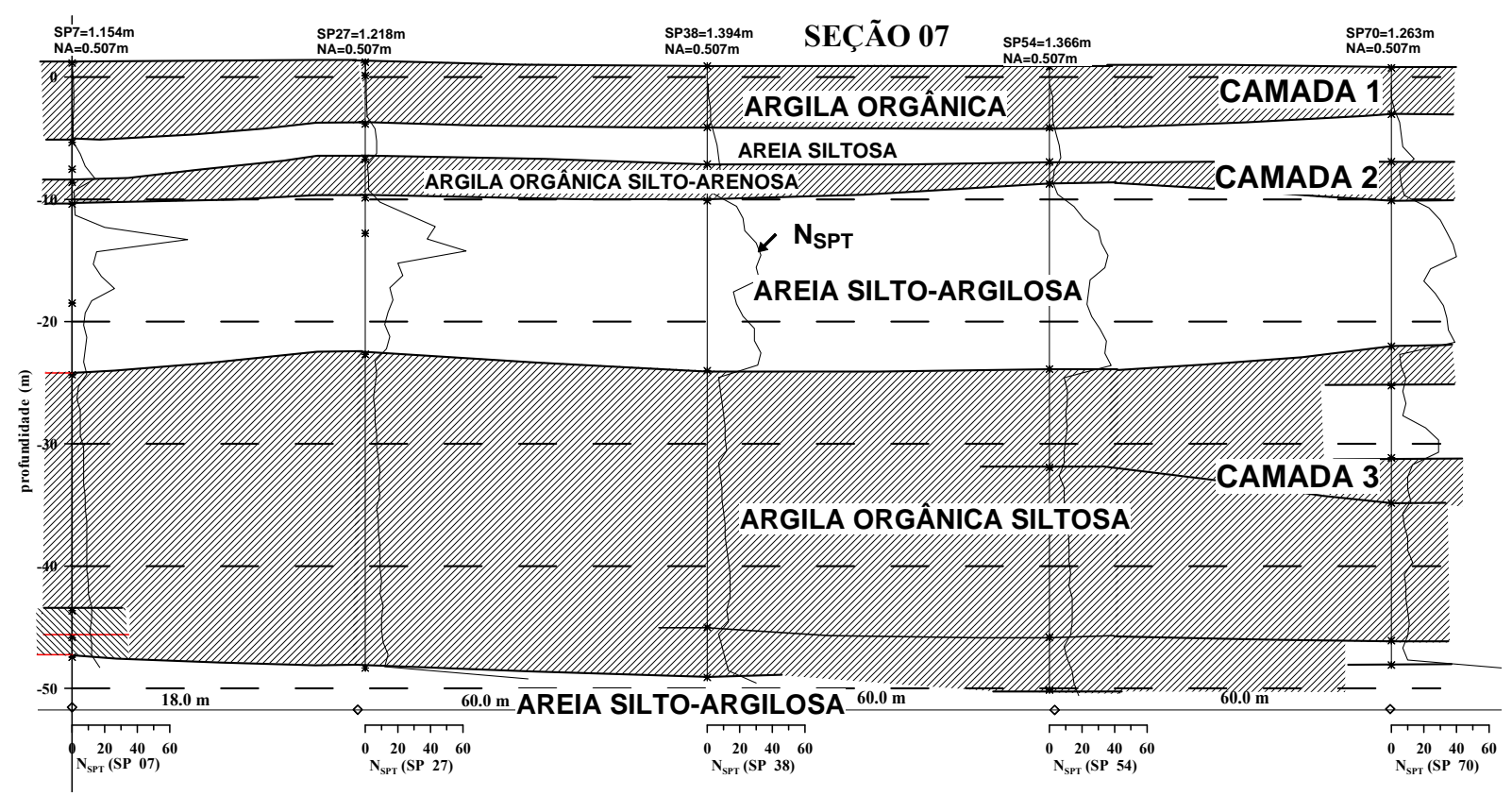

Figura 3.2 - Seção geológico-geotécnica do depósito sedimentar (Marques e Lacerda, 2004).

Nos ensaios SPT, o impenetrável à percussão ocorre a cerca de 52,0 metros de profundidade, tendo alcançado 84,0 metros nas sondagens mistas. Na zona próxima do 
impenetrável à percussão, foi identificada a ocorrência de argilas duras ou areias finas intercaladas com seixos.

No ANEXO são apresentadas seções longitudinais e transversais do subsolo e sua indicação está localizada das seções está indicada na implantação da obra (Figura 3.1).

O depósito de argila apresenta três camadas com propriedades mecânicas distintas, intercaladas por areias finas e grossas, em muitos casos com elevados índices de resistência a penetração $\left(N_{S P T}\right)$. O lençol freático é superficial ou se encontra no topo da camada de argila mole, ao longo de toda a área. A Figura 3.2 apresenta a seção geológicogeotécnica e a Tabela 3.1 os principais parâmetros geotécnicos das argilas.

Tabela 3.1 - Parâmetros geotécnicos das camadas de argila de Santa Catarina (Marques e Lacerda, 2004).

\begin{tabular}{cccccc}
\hline Camada & $\begin{array}{c}\text { Prof. Topo } \\
(\mathrm{m})\end{array}$ & $\mathrm{SPT}$ & $\gamma_{\mathrm{n}}\left(\mathrm{kN} / \mathrm{m}^{3}\right)$ & $\mathrm{e}_{0}$ & $\mathrm{~S}_{\mathrm{u}}(\mathrm{kPa})$ \\
\hline Argila 1 & $0-7$ & $0-5$ & $14-17$ & $1,26-2,70$ & $3-20$ \\
\hline Argila 2 & $6-16,5$ & $0-8$ & $13,8-16,8$ & $1,37-2,82$ & $30-60$ \\
\hline Argila 3 & $16,5-38$ & $4-35$ & $14,8-17,7$ & $1,12-2,01$ & $>60$ \\
\hline
\end{tabular}

As características geotécnicas das argilas são semelhantes às dos depósitos da Baixada Santista (Massad, 1994), sendo que na Tabela 3.2 são apresentados os parâmetros geotécnicos para comparação com a Tabela 3.1.

Tabela 3.2 - Parâmetros geotécnicos das argilas da Baixada Santista (Massad, 1994).

\begin{tabular}{ccccc}
\hline Camada & $\begin{array}{c}\text { Prof. Topo } \\
(\mathrm{m})\end{array}$ & $\mathrm{SPT}$ & $\begin{array}{c}\gamma_{\mathrm{n}} \\
\left(\mathrm{kN} / \mathrm{m}^{3}\right)\end{array}$ & $\begin{array}{c}\mathrm{S}_{\mathrm{u}} \\
(\mathrm{kPa})\end{array}$ \\
\hline Mangue & $0-5$ & 0 & 13 & 3 \\
\hline Argila SFL & $0-10$ & $0-4$ & $13,5-16,3$ & $10-60$ \\
\hline Argila AT & $20-45$ & $5-25$ & $15-16,3$ & $>100$ \\
\hline
\end{tabular}

A Figura 3.3 - Perfil de sondagem SP32 (Marques e Lacerda, 2004). apresenta um perfil característico de sondagem (Marques e Lacerda, 2004), com as camadas de argila 
destacadas, e as intercalações de areias ao longo da profundidade. Paralelamente aos resultados do ensaio SPT estão plotados o teor de umidade natural, a resistência não-drenada obtida pelo ensaio de palheta (VMT), as medições de $q_{T}$ e $U$ obtidos pelo ensaio de cone elétrico CPTU - dados obtidos por correlações, e resultados dos ensaios de adensamento $\left({ }^{e_{0}}\right.$, $\left.\sigma_{v m}^{\prime}, C_{C} \mathrm{e}^{C_{v}}\right)$

Para o projeto de fundações havia o interesse na camada de areia intermediária (destacado na Figura 3.3 - Perfil de sondagem SP32 (Marques e Lacerda, 2004).), variando na profundidade de 8,0 a 16,0 metros. Ao longo da área, apresentam-se três possibilidades de material na ponta das estacas, conforme:

a) Areia fina siltosa, medianamente compacta a muito compacta, cinza clara, com índice de resistência a penetração ( ${ }^{N_{S P T}}$ ) médio de 40 golpes $/ 30 \mathrm{~cm}$ finais - atuante nas áreas do módulo 18 a 11.

b) Areia fina com matriz argilosa, fofa a medianamente compacta, cinza, com índice de resistência a penetração $\left({ }^{N}\right.$ SPT $)$ médio de 15 golpes $/ 30 \mathrm{~cm}$ finais - atuante nas áreas do módulo 01 a 08.

c) Zona de transição possuindo uma mistura dos materiais descritos acima, com $N_{\text {SPT }}$ variando de 2 a 60 golpes $/ 30 \mathrm{~cm}$ finais - atuante nas áreas do módulo 09 e 10.

\subsection{Execução das estacas}

Pelos condicionantes geológico-geotécnico ao longo de toda a área e pela variabilidade da estratigrafia do terreno, o projeto de fundações previa para a execução de estacas pré-moldadas a necessidade da cravação avançar até o solo de alteração e próximo ao topo rochoso, conduzindo assim a comprimentos da ordem de 50,0 metros.

Devido à grande quantidade de estacas e a necessidade de grandes comprimentos foram estudadas outras alternativas afim de viabilizar o empreendimento, sendo o melhor custo benefício a solução em estacas do tipo Franki, com o bulbo sendo formado na camada de areia intermediaria, com $600 \mathrm{~mm}$ de diâmetro, resistência característica do concreto ( $\left.f_{c k}\right)$ 
de $25 \mathrm{MPa}$ e comprimentos da ordem de 15,0 metros.

O projeto de estruturas (Figura 3.4) previa a construção de uma linha de estacas pranchas conectadas ao longo de todo o cais para proteger e permitir a execução de dragagem para rebaixar o calado nessa região, permitindo assim a atracação dos navios. Após esse primeiro alinhamento, haveria estruturas para receber grandes pontes rolantes para retirada de contêineres dos navios, e portanto sofrendo uma maior ação de cargas devido a ação do vento.

Partindo dessa premissa o projeto de fundações foi desenvolvido para combater uma combinação de esforços horizontais com compressão atuando no topo das estacas, e para combater as solicitações o estaqueamento foi dimensionado mesclando estacas verticais e inclinadas $(1: 4)$.

Posteriormente, devido a presença de estacas inclinadas, a dinâmica e logística da obra, o projeto foi alterado para estacas de concreto armado pré-fabricado centrifugado, tipo SCAC, com diâmetro de $700 \mathrm{~mm}$, para uma carga de trabalho média de $1850 \mathrm{kN}$.

As estacas seriam cravadas com o uso de martelo de queda livre, com as torreguia inclinadas, com massa mínima de $60 \mathrm{kN}$ e energia mínima de cravação de $70 \mathrm{kN} . \mathrm{m}$. O controle de execução foi fixado estabelecendo-se a princípio o valor de nega máximo ( ${ }^{S_{\text {máx }}}$ e e repique elástico mínimo $\left(K_{\min }\right)$, estimados inicialmente de um estudo sob os dados dos ensaios de campo, sendo necessário o atendimento das duas condições para se paralisar a cravação.

Durante a cravação das primeiras estacas e ao longo do desenvolvimento do projeto esses valores foram calibrados com o uso provas de cargas dinâmicas. A Figura 3.5apresenta uma vista aérea durante a execução da obra.

$\mathrm{Na}$ execução da fundação, em $10 \%$ das estacas foram registrados os diagramas de cravação (Figura 3.6), e no momento em que fosse atendido o critério de parada deveria ser registrado na ficha de cravação, além dos dados da estaca o registro dos valores de nega e repique elástico obtidos em campo.

A ficha de cravação (Figura 3.7) é um registro de campo que contém a data de conclusão da cravação, dados do equipamento de cravação (nome, peso do martelo, altura de queda, altura do cepo e coxim e o peso do capacete), o comprimento cravado no nível do 
terreno, a cota do terreno, as composições e rastreabilidade da fabricação das estacas, e o registro de nega e repique elástico medido no final de cravação.

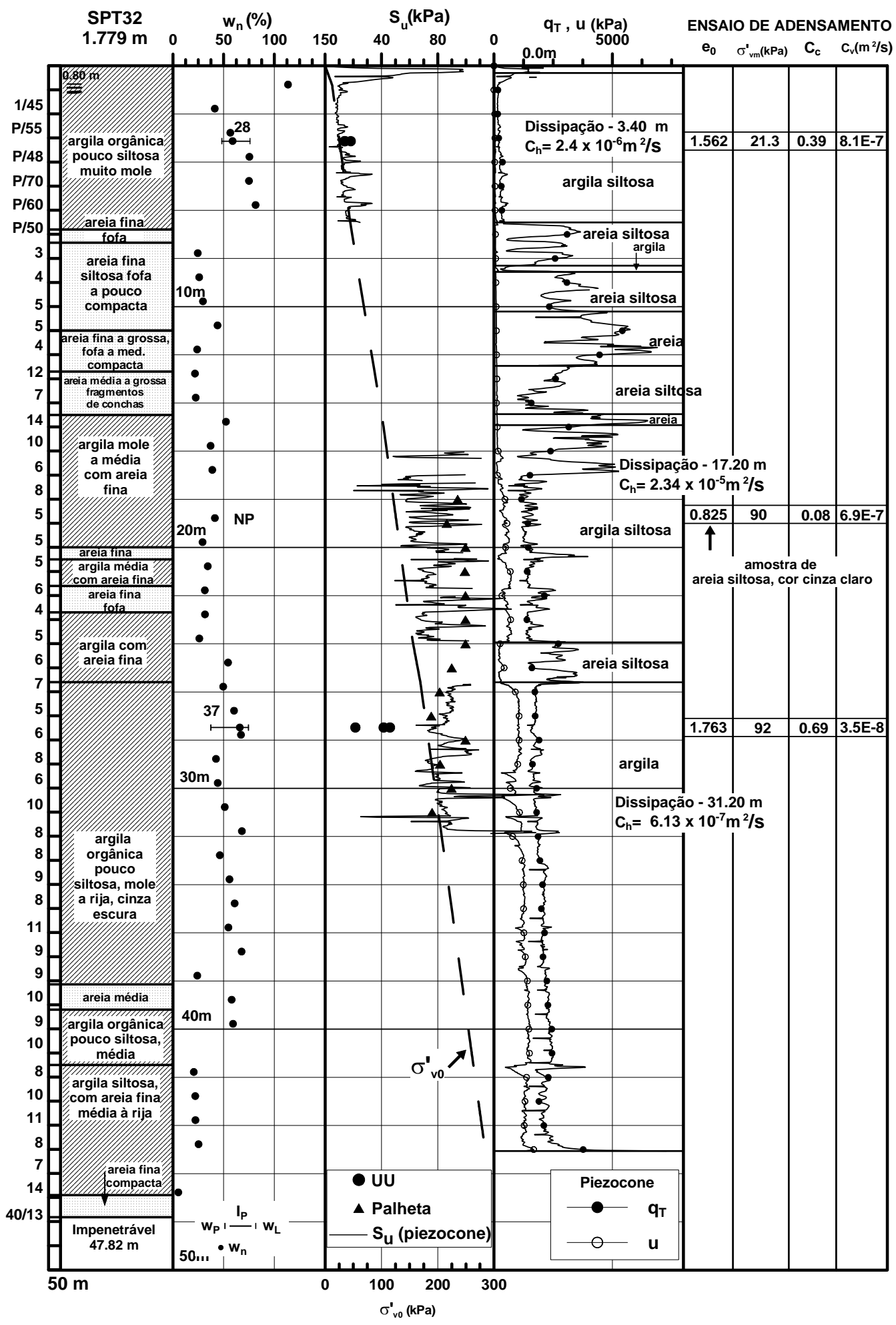


Figura 3.3 - Perfil de sondagem SP32 (Marques e Lacerda, 2004).

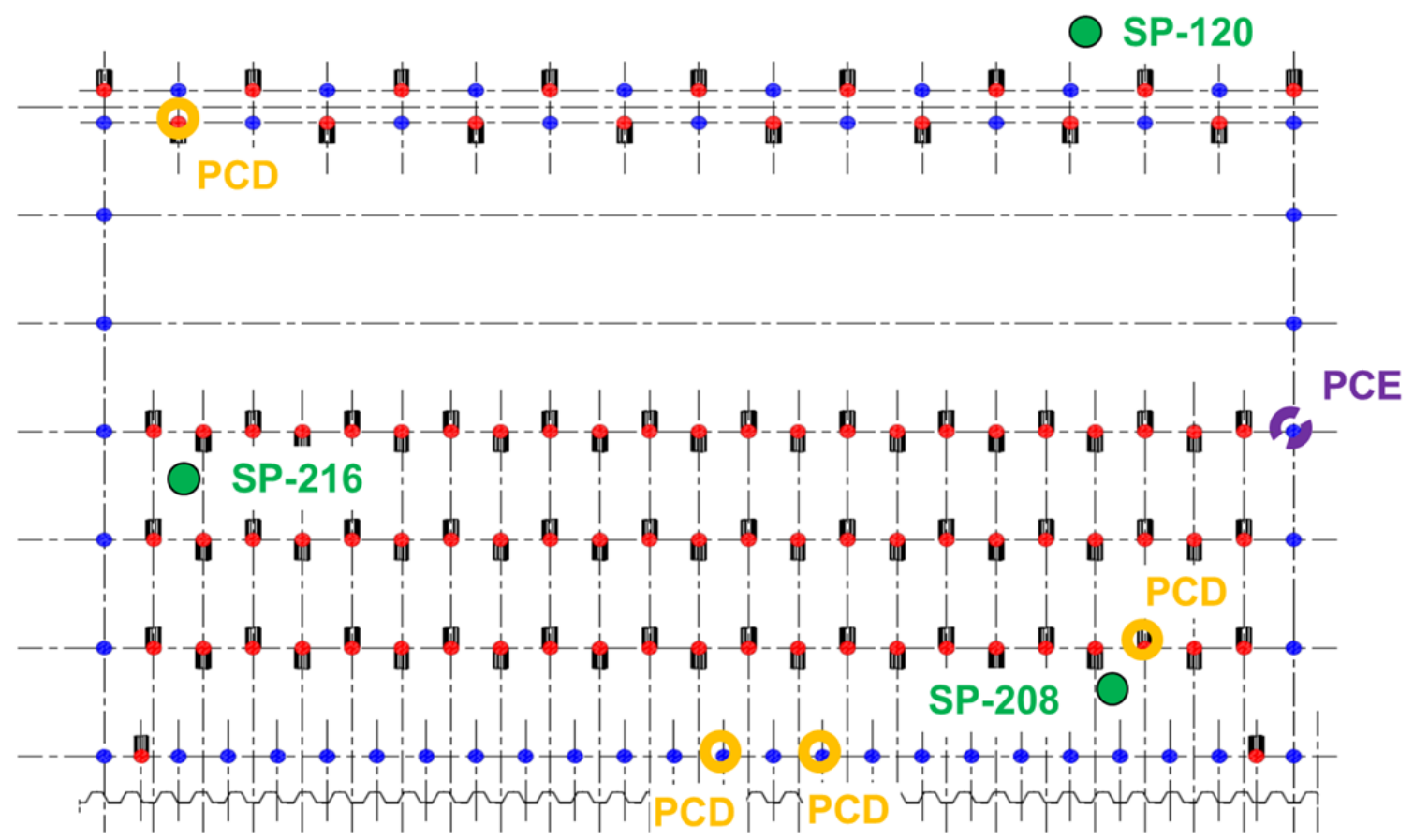

Figura 3.4 - Projeto de fundações do porto (módulo típico).

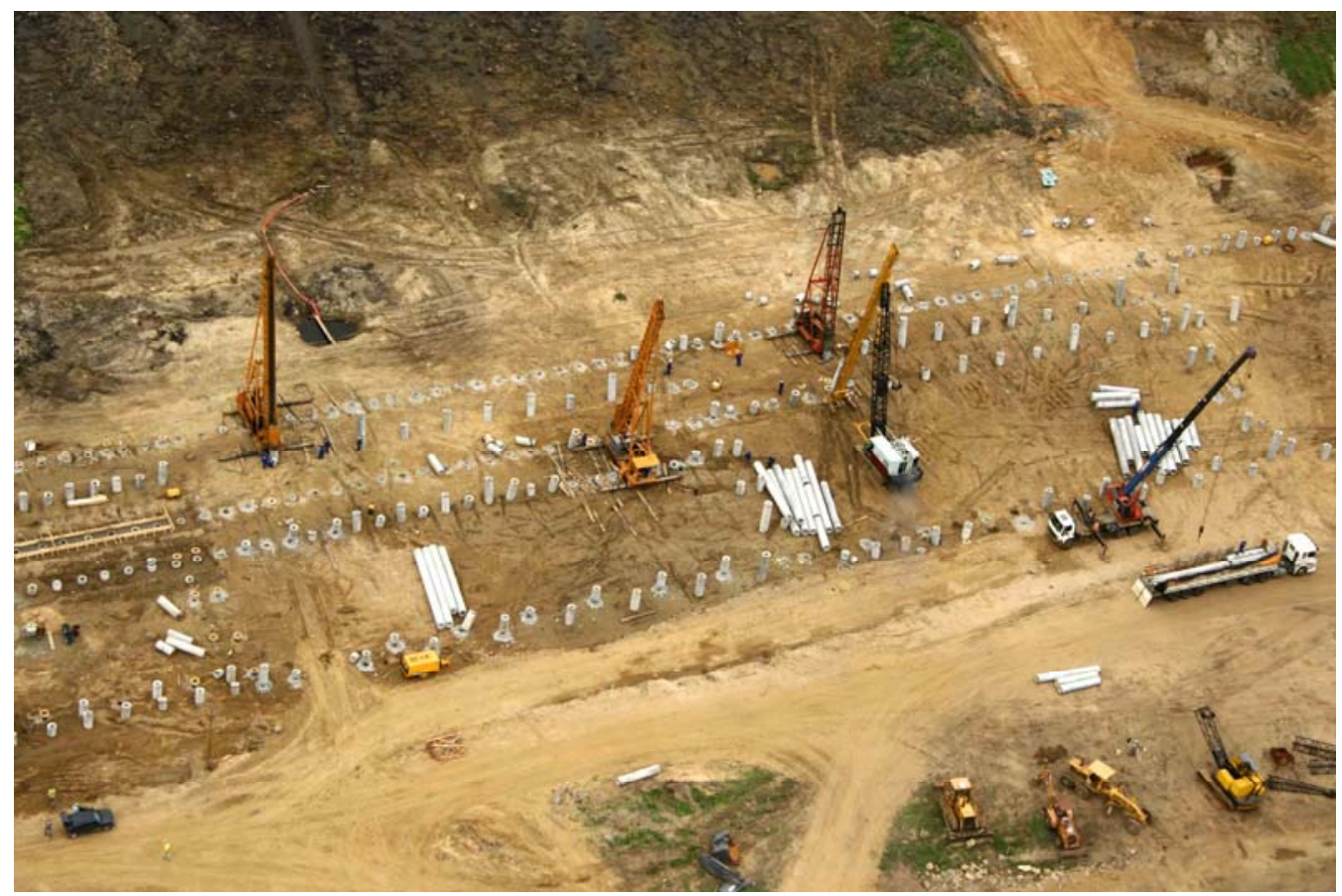

Figura 3.5 - Vista aérea da execução do projeto (SCAC, 2012). 


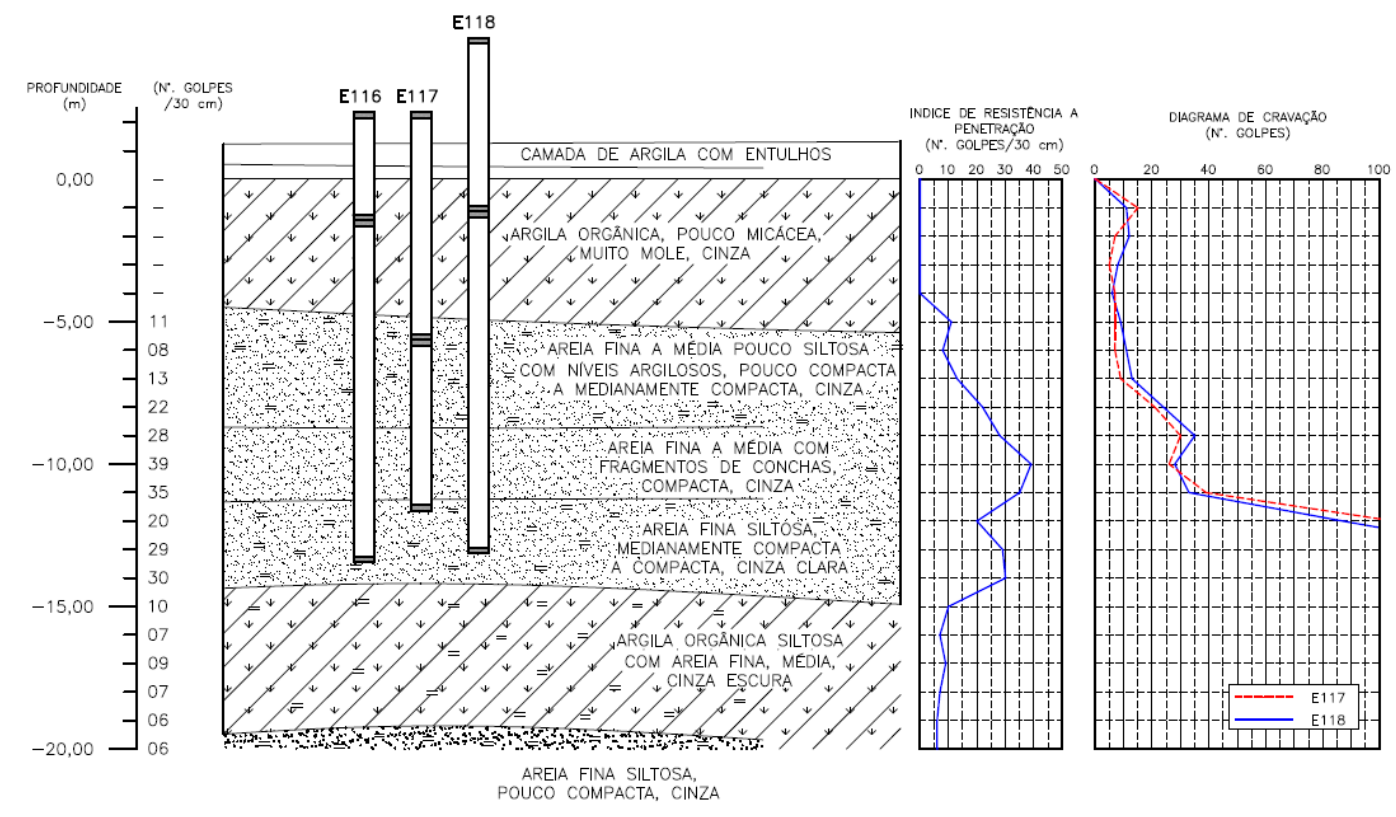

Figura 3.6 - Diagrama de cravação em comparação com o perfil de sondagem mais próximo módulo 18.

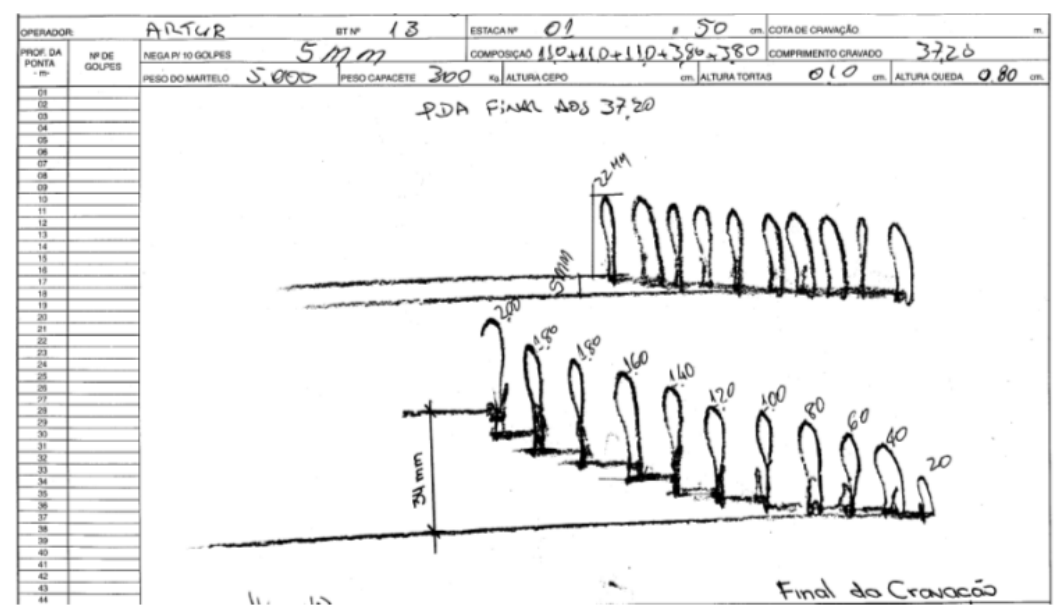

Figura 3.7 - Modelo da ficha de cravação registrado na obra.

\subsection{Provas de carga dinâmicas}

Em função das características do terreno foram definidas a princípio, a fim de calibrar a metodologia de projeto a execução de estacas testes, inicialmente forma selecionadas aleatoriamente 4 estacas (Tabela 3.4), onde seriam executadas provas de carga 
estáticas (Figura 3.10) e em 3 estacas foi possível de realizar prova de carga dinâmica anteriormente a estática, permitindo assim dimensionar o sistema de reação, conhecer a evolução do ganho de capacidade de carga ao longo do tempo e correlacionar com os parâmetros calibrados para definir o critério de parada das estacas.

As provas de carga dinâmica foram executadas por uma firma especializada e externa à obra, e foram executados ensaios com a metodologia de energia crescente (Aoki, 2000) e em atendimento as recomendações da NBR 13208 (1994).

Durante a execução do ensaio e no momento da aplicação dos golpes, foram coletados registros (Figura 3.8) de nega e repique elástico para cada altura de golpe e/ou energia fornecida ao sistema. Para a execução do ensaio, havia disponíveis na obradois martelos de queda-livre, com massas de $60 \mathrm{kN}$ e $70 \mathrm{kN}$, e durante a aplicação dos golpes variou-se à altura de queda de 0,20 $\mathrm{m}$ a 1,60 $\mathrm{m}$, com incrementos de 0,20 m. Em alguns casos foi necessário avançar o ensaio com novos incrementos ou alterar a metodologia de coletada dos dados, devido principalmente a baixos valores de resistência mobilizada no ensaio, ou de ter atingido níveis extremos de tensão aplicado no concreto de compressão ( $f_{c k}=35 M P a$ ) e tração ( $f_{t k}=3,5 \mathrm{MPg}$, que poderia vir a danificar o elementos estrutural.

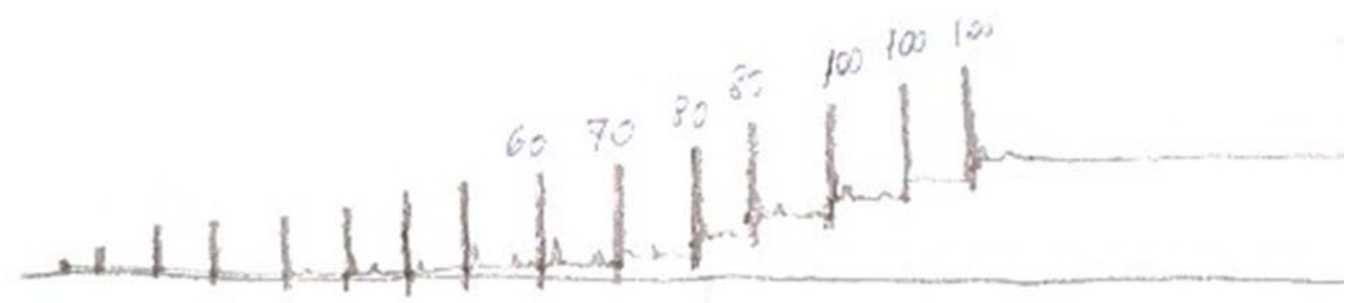

Figura 3.8 - Registro dos sinais de nega e repique elástico durante a execução da PCD com energia crescente.

O equipamento utilizado nos ensaios era da marca Pile Dynamics Inc., modelo PAK, conectados por cabos a um par de deflectometros e acelerômetros instalados próximo a superfície do terreno. Antes da aplicação dos golpes na cabeça da estaca, foram inseridos 5 coxins/tortas de madeirit, com a finalidade de distribuir uniformemente as tensões resultantes 
do impacto. No método CASE em campo, introduziu-se a geometria da seção transversal, o comprimento cravado, a distância da ponta da estaca ao nível de sensores, o módulo de elasticidade teórico do material da estaca, que no caso para o concreto com $f_{c k}=35 \mathrm{MPc}$ resulta num módulo de secante $E_{C S}=29,5 G P G$, posteriormente esse valor seria reavaliado pelo sinal coletado e reinterpretado os resultados.

No total foram executadas 74 provas de carga dinâmicas distribuídas aleatoriamente no projeto, tendo como premissa sempre executar no mínimo 4 ensaios/módulo. A

Tabela 3.3 apresenta um resumo geral dos dados coletados dos ensaios, representado pelo golpe de maior energia

Tabela 3.3 - Resultados das provas de carga dinâmica amostradas em campo.

\begin{tabular}{ccccccccccc}
\hline $\mathrm{N}^{\circ}$. & $\mathrm{N}^{\circ}$. Estaca & $\begin{array}{c}\text { Compr. } \\
\text { Cravado } \\
(\mathrm{m})\end{array}$ & $\begin{array}{c}\text { Tipo } \\
(\text { I ou V) }\end{array}$ & $\begin{array}{c}\text { Setup } \\
\text { dias })\end{array}$ & $\begin{array}{c}K \\
(\mathrm{~mm})\end{array}$ & $\begin{array}{c}S_{10 g p} \\
(\mathrm{~mm})\end{array}$ & $\begin{array}{c}R M X \\
(\mathrm{kN})\end{array}$ & $\begin{array}{c}E M X \\
(\mathrm{kN} . \mathrm{m})\end{array}$ & $\begin{array}{c}E_{\text {POT }} \\
(\mathrm{kN} . \mathrm{m})\end{array}$ & $\begin{array}{c}e \\
(\%)\end{array}$ \\
\hline 1 & E113M18 & 15,70 & Vertical & 0 & 15,0 & 28,0 & 2504 & 59 & 112 & 52,2 \\
\hline 2 & E113RM18 & 15,80 & Vertical & 6 & 15,0 & 28,0 & 2912 & 44 & 112 & 38,8 \\
\hline 3 & E125M18 & 15,00 & Vertical & 0 & 12,0 & 29,0 & 3058 & 63 & 98 & 64,6 \\
\hline 4 & E132M18 & 14,00 & Vertical & 3 & 13,0 & 33,0 & 2779 & 40 & 112 & 35,3 \\
\hline 5 & E018M18 & 12,30 & Vertical & 0 & 12,0 & 29,0 & 3112 & 54 & 98 & 54,9 \\
\hline 6 & E062M18 & 13,80 & Inclinada & 0 & 14,0 & 34,0 & 3328 & 60 & 84 & 71,4 \\
\hline 7 & E094M18 & 12,70 & Inclinada & 1 & 12,0 & 20,0 & 2637 & 64 & 140 & 45,7 \\
\hline 8 & E052M14 & 12,70 & Inclinada & 0 & 15,0 & 34,0 & 2437 & 51 & 84 & 60,5 \\
\hline 9 & E113M14 & 13,10 & Vertical & 0 & 13,0 & 10,0 & 2879 & 43 & 84 & 51,4 \\
\hline 10 & E124M14 & 12,30 & Vertical & 4 & 15,0 & 20,0 & 3170 & 65 & 112 & 58,0 \\
\hline 11 & E128M14 & 15,60 & Vertical & 0 & 14,0 & 20,0 & 3351 & 77 & 112 & 69,0 \\
\hline 12 & E128RM14 & 15,60 & Vertical & 5 & 14,0 & 20,0 & 2689 & 55 & 140 & 38,9 \\
\hline 13 & E085M15 & 13,90 & Inclinada & 0 & 15,0 & 16,0 & 2653 & 63 & 175 & 35,7 \\
\hline 14 & E124M15 & 13,40 & Vertical & 0 & 15,0 & 29,0 & 3005 & 56 & 112 & 49,6 \\
\hline 15 & E138M15 & 13,70 & Inclinada & 1 & 15,0 & 21,0 & 2614 & 48 & 126 & 38,4 \\
\hline & & & & & & & & & &
\end{tabular}




\begin{tabular}{|c|c|c|c|c|c|c|c|c|c|c|}
\hline 16 & E028M17 & 13,45 & Vertical & 8 & 14,0 & 13,0 & 3061 & 46 & 126 & 36,7 \\
\hline 17 & E038M17 & 13,65 & Vertical & 16 & 14,0 & 34,0 & 2518 & 47 & 126 & 37,4 \\
\hline 18 & E053M17 & 14,50 & Inclinada & 0 & 14,0 & 16,0 & 2871 & 72 & 84 & 85,7 \\
\hline $\mathrm{N}^{\circ}$. & $\mathrm{N}^{\circ}$. Estaca & $\begin{array}{c}\text { Compr. } \\
\text { Cravado } \\
\text { (m) }\end{array}$ & $\begin{array}{c}\text { Tipo } \\
\text { (I ou V) }\end{array}$ & $\begin{array}{l}\text { Setup } \\
\text { (dias) }\end{array}$ & $\begin{array}{c}K \\
(\mathrm{~mm})\end{array}$ & $\begin{array}{l}S_{10 g p} \\
(\mathrm{~mm})\end{array}$ & $\begin{array}{l}R M X \\
(\mathrm{kN})\end{array}$ & $\begin{array}{c}E M X \\
(\mathrm{kN} . \mathrm{m})\end{array}$ & $\begin{array}{c}E_{P O T} \\
\text { (kN.m) }\end{array}$ & $\begin{array}{c}e \\
(\%)\end{array}$ \\
\hline 19 & E098M17 & 13,40 & Inclinada & 0 & 14,0 & 14,0 & 2643 & 63 & 112 & 56,5 \\
\hline 20 & E012M11 & 13,10 & Vertical & 4 & 15,0 & 10,0 & 2968 & 74 & 112 & 66,1 \\
\hline 21 & E036M11 & 12,40 & Vertical & 5 & 15,0 & 19,0 & 2846 & 64 & 112 & 57,1 \\
\hline 22 & E119M11 & 12,60 & Vertical & 0 & 15,0 & 14,0 & 3591 & 105 & 126 & 83,7 \\
\hline 23 & E009M12 & 12,40 & Inclinada & 3 & 13,0 & 20,0 & 2636 & 43 & 70 & 62,0 \\
\hline 24 & E033M12 & 12,70 & Inclinada & 4 & 13,0 & 18,0 & 2850 & 76 & 182 & 41,6 \\
\hline 25 & E013M13 & 12,40 & Inclinada & 4 & 12,0 & 15,0 & 2192 & 35 & 84 & 41,1 \\
\hline 26 & E037M13 & 13,50 & Vertical & 26 & 15,0 & 22,0 & 2919 & 44 & 126 & 34,8 \\
\hline 27 & E107M13 & 12,50 & Inclinada & 4 & 13,0 & 15,0 & 2171 & 47 & 126 & 36,9 \\
\hline 28 & E138M13 & 12,60 & Inclinada & 0 & 14,0 & 9,0 & 2628 & 75 & 112 & 67,1 \\
\hline 29 & E082M14 & 12,80 & Inclinada & 4 & 16,0 & 22,0 & 3297 & 98 & 126 & 77,7 \\
\hline 30 & E007M15 & 13,20 & Inclinada & 4 & 15,0 & 23,0 & 2799 & 50 & 84 & 59,5 \\
\hline 31 & E060M16 & 13,10 & Inclinada & 3 & 14,0 & 14,0 & 2669 & 67 & 112 & 59,6 \\
\hline 32 & E026M09 & 13,74 & Vertical & 4 & 16,0 & 32,0 & 2950 & 51 & 84 & 60,1 \\
\hline 33 & E038M09 & 12,50 & Vertical & 3 & 15,0 & 28,0 & 3132 & 41 & 70 & 58,7 \\
\hline 34 & E134M09 & 16,48 & Vertical & 4 & 15,0 & 30,0 & 1655 & 49 & 98 & 49,8 \\
\hline 35 & E135M09 & 13,53 & Vertical & 5 & 17,0 & 20,0 & 2761 & 61 & 140 & 43,6 \\
\hline 36 & E121M10 & 13,40 & Vertical & 3 & 17,0 & 21,0 & 2986 & 91 & 140 & 64,7 \\
\hline 37 & E121RM10 & 13,90 & Vertical & 0 & 17,0 & 21,0 & 2931 & 101 & 126 & 80,4 \\
\hline 38 & E049M12 & 12,90 & Inclinada & 3 & 14,0 & 27,0 & 3046 & 90 & 196 & 46,0 \\
\hline 39 & E113M08 & 13,20 & Vertical & 1 & 17,0 & 28,0 & 3666 & 62 & 98 & 63,5 \\
\hline 40 & E035M09 & 12,93 & Vertical & 2 & 15,0 & 20,0 & 3345 & 69 & 98 & 70,6 \\
\hline 41 & E083M09 & 13,00 & Inclinada & 1 & 17,0 & 10,0 & 3139 & 83 & 98 & 85,0 \\
\hline 42 & E121M09 & 13,50 & Vertical & 2 & 15,0 & 32,0 & 3161 & 80 & 70 & 114,0 \\
\hline 43 & E123M09 & 13,50 & Vertical & 5 & 16,0 & 30,0 & 2929 & 56 & 84 & 66,1 \\
\hline 44 & E124M09 & 36,85 & Vertical & 6 & 18,0 & 38,0 & 2952 & 56 & 84 & 67,0 \\
\hline
\end{tabular}




\begin{tabular}{|c|c|c|c|c|c|c|c|c|c|c|}
\hline 45 & E125M09 & 14,80 & Vertical & 6 & 15,0 & 23,0 & 2681 & 53 & 98 & 54,3 \\
\hline 46 & E128M08 & 13,80 & Vertical & 2 & 17,0 & 32,0 & 3325 & 64 & 112 & 56,8 \\
\hline 47 & E129M08 & 24,40 & Vertical & 6 & 17,0 & 26,0 & 2985 & 50 & 84 & 59,0 \\
\hline $\mathrm{N}^{\circ}$. & $\mathrm{N}^{\circ}$. Estaca & $\begin{array}{l}\text { Compr. } \\
\text { Cravado } \\
\text { (m) }\end{array}$ & $\begin{array}{c}\text { Tipo } \\
\text { (I ou V) }\end{array}$ & $\begin{array}{l}\text { Setup } \\
\text { (dias) }\end{array}$ & $\begin{array}{c}K \\
(\mathrm{~mm})\end{array}$ & $\begin{array}{l}S_{10 g p} \\
(\mathrm{~mm})\end{array}$ & $\begin{array}{c}R M X \\
(\mathrm{kN})\end{array}$ & $\begin{array}{c}E M X \\
(\mathrm{kN} . \mathrm{m})\end{array}$ & $\begin{array}{c}E_{P O T} \\
\text { (kN.m) }\end{array}$ & $\begin{array}{c}e \\
(\%)\end{array}$ \\
\hline 48 & E130M08 & 19,00 & Vertical & 7 & 20,0 & 30,0 & 2840 & 77 & 112 & 68,8 \\
\hline 49 & E131M08 & 14,00 & Vertical & 7 & 16,0 & 31,0 & 3054 & 47 & 84 & 56,4 \\
\hline 50 & E006M05 & 12,60 & Vertical & 3 & 15,0 & 17,0 & 3395 & 86 & 98 & 88,1 \\
\hline 51 & E052M05 & 13,20 & Inclinada & 3 & 12,0 & 19,0 & 3008 & 53 & 70 & 75,9 \\
\hline 52 & E122M05 & 13,60 & Vertical & 3 & 15,0 & 20,0 & 3270 & 48 & 84 & 57,0 \\
\hline 53 & E123M05 & 13,80 & Vertical & 3 & 13,0 & 21,0 & 3040 & 59 & 84 & 69,9 \\
\hline 54 & E022M06 & 12,70 & Vertical & 4 & 15,0 & 20,0 & 3108 & 73 & 112 & 65,0 \\
\hline 55 & E076M06 & 12,30 & Inclinada & 3 & 15,0 & 20,0 & 2980 & 57 & 84 & 68,2 \\
\hline 56 & E128M06 & 13,40 & Vertical & 5 & 15,0 & 23,0 & 2585 & 66 & 84 & 78,6 \\
\hline 57 & E139M06 & 14,00 & Vertical & 8 & 14,0 & 30,0 & 3242 & 97 & 98 & 98,9 \\
\hline 58 & E021M07 & 12,60 & Inclinada & 4 & 15,0 & 20,0 & 2403 & 46 & 84 & 55,2 \\
\hline 59 & E075M07 & 12,50 & Inclinada & 4 & 16,0 & 19,0 & 2962 & 61 & 70 & 87,0 \\
\hline 60 & E116M07 & 13,80 & Vertical & 11 & 14,0 & 19,0 & 3350 & 73 & 126 & 58,1 \\
\hline 61 & E122M07 & 13,20 & Vertical & 11 & 15,0 & 31,0 & 3405 & 90 & 98 & 91,7 \\
\hline 62 & E034M03 & 13,10 & Vertical & 11 & 14,0 & 21,0 & 2626 & 46 & 70 & 66,3 \\
\hline 63 & E035M03 & 12,70 & Vertical & 4 & 15,0 & 16,0 & 2550 & 82 & 119 & 69,2 \\
\hline 64 & E040M03 & 12,80 & Inclinada & 6 & 14,0 & 10,0 & 2990 & 50 & 98 & 50,5 \\
\hline 65 & E126M03 & 12,90 & Vertical & 3 & 15,0 & 31,0 & 3239 & 84 & 112 & 75,2 \\
\hline 66 & E018M04 & 13,20 & Vertical & 12 & 17,0 & 13,0 & 2670 & 63 & 98 & 63,8 \\
\hline 67 & E039M04 & 12,40 & Vertical & 9 & 15,0 & 18,0 & 2977 & 46 & 98 & 47,3 \\
\hline 68 & E126M01 & 12,60 & Vertical & 6 & 16,0 & 22,0 & 3195 & 66 & 98 & 67,7 \\
\hline 69 & E137M01 & 12,00 & Vertical & 11 & 15,0 & 21,0 & 3003 & 69 & 70 & 97,9 \\
\hline 70 & E007DPN & 19,00 & Vertical & 2 & 12,0 & 10,0 & 2593 & 30 & 70 & 42,1 \\
\hline 71 & E114M02 & 12,20 & Vertical & 4 & 15,0 & 20,0 & 3203 & 83 & 126 & 65,6 \\
\hline 72 & E118M02 & 14,20 & Vertical & 11 & 14,0 & 25,0 & 3040 & 51 & 98 & 52,1 \\
\hline 73 & E025M03 & 12,70 & Inclinada & 7 & 15,0 & 17,0 & 3252 & 62 & 98 & 63,2 \\
\hline
\end{tabular}




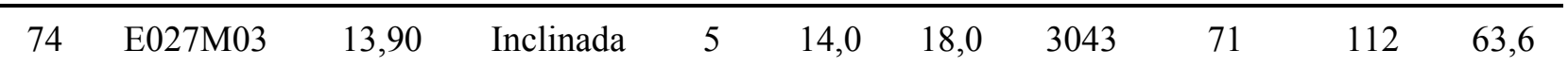

\subsection{Prova de carga estática}

As provas de carga estáticas foram executadas apenas em estacas verticais, sendo executado o ensaio do tipo lento ( $S M L)$, atendendo-se as recomendações da NBR 12131 (2006). O sistema de reação era composto por tirantes (Figura 3.9) com vigas cruzadas no topo. Para a medição das cargas foi utilizada uma célula de carga, e os deslocamentos foram registrados por quatro pares de extensômetros.

A Tabela 3.4 apresenta as características das estacas selecionadas, com o diâmetro, comprimento cravado, registro de nega e repique elástico no final de cravação, o tipo de material na ponta e o índice de resistência a penetração( $\left.N_{S P T}\right)$ na ponta e ao longo do fuste.
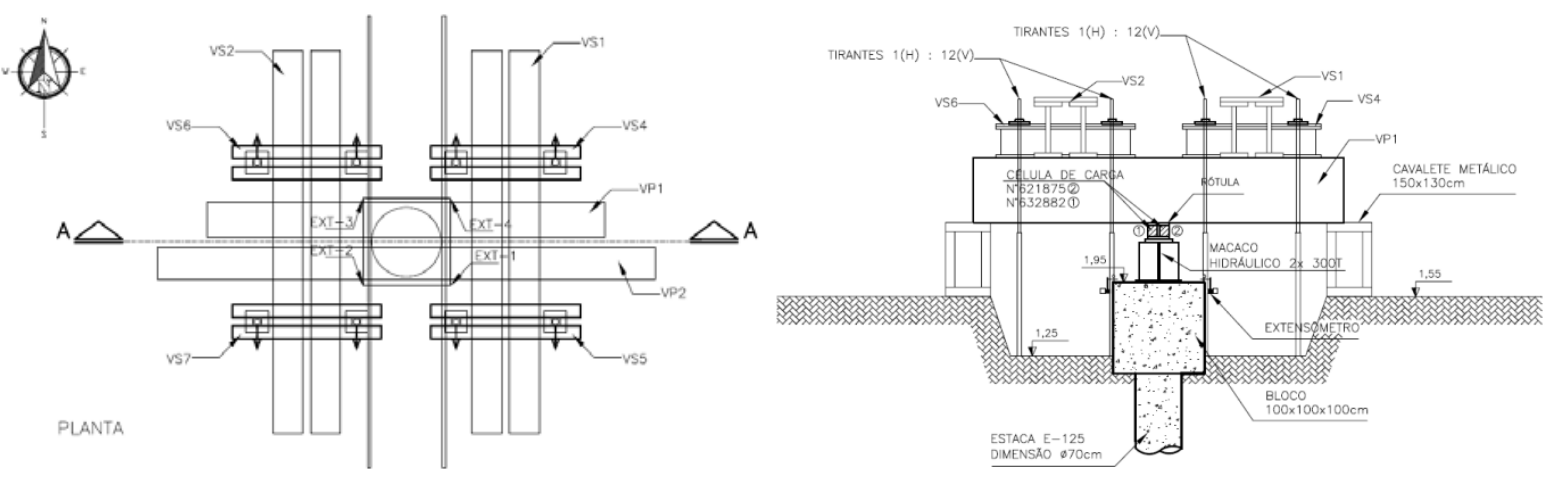

Figura 3.9 - Esquema (planta e perfil) da prova de carga estática.

Tabela 3.4 - Características das estacas selecionadas para execução das provas de carga estáticas.

\begin{tabular}{lccccccccc}
\hline No.Estaca & $\begin{array}{c}\text { Diâmetro } \\
(\mathrm{cm})\end{array}$ & $\begin{array}{c}\text { Comp. } \\
\text { Cravado } \\
(\mathrm{m})\end{array}$ & $\begin{array}{c}\text { Setup } \\
(\text { dias })\end{array}$ & $\begin{array}{c}\mathrm{K} \\
(\mathrm{mm})\end{array}$ & $\begin{array}{c}\mathrm{S}_{10 \mathrm{gp}} \\
(\mathrm{mm})\end{array}$ & $\begin{array}{c}\mathrm{SPT} \\
\text { próximo }\end{array}$ & $\begin{array}{c}N_{S P T} \\
(\mathrm{gp} / 30 \mathrm{~cm})\end{array}$ & Material na ponta da estaca \\
\hline E114M02 & 70 & 12,20 & 70 & 15 & 20 & SP-02 & 36 & 20 & $\begin{array}{c}\text { Areia fina siltosa, medianamente } \\
\text { compacta a compacta, cinza clara. }\end{array}$ \\
\hline E018M04 & 70 & 13,20 & 71 & 17 & 13 & SP-25 & 19 & 8 & $\begin{array}{c}\text { Areia fina com presença de argila } \\
\text { orgânica, cinza clara. }\end{array}$ \\
\hline E125M09 & 70 & 14,90 & 59 & 15 & 23 & SP-08 & 20 & 11 & Areia fina siltosa, pouco compacta \\
\hline
\end{tabular}


a compacta, cinza clara

Areia fina a média com

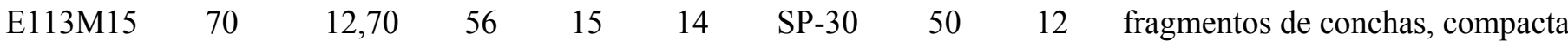
a muito compacta, cinza.

Nas estacas E114 M02, E018 M04 e E125 M09 foram executadas provas de carga dinâmica com o objetivo de conhecer inicialmente a resistência mobilizada pela estaca, para dimensionar o sistema de reação, e aferir a metodologia de previsão. As estacas foram ensaiadas em 4, 12 e 6 dias após a cravação, respectivamente.

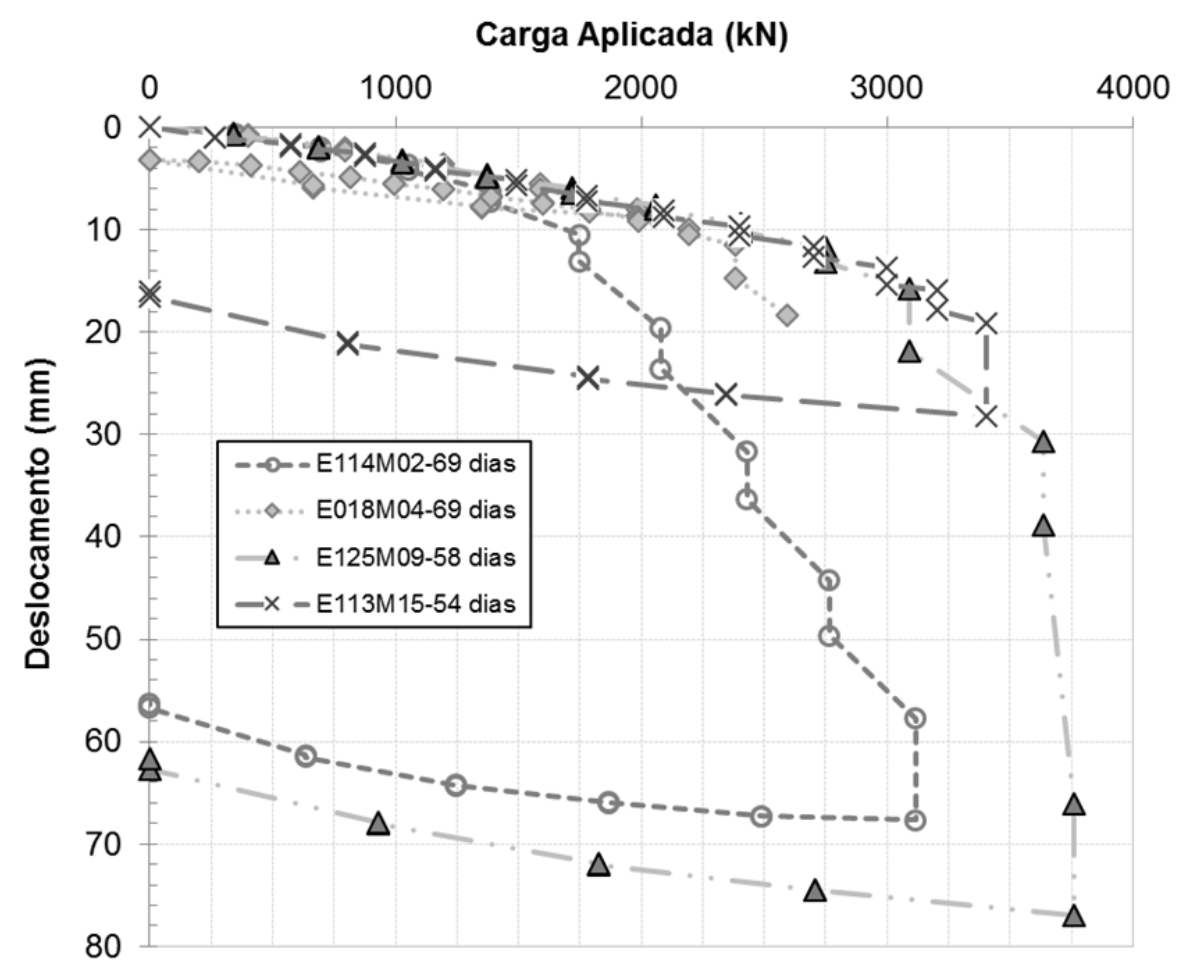

Figura 3.10 - Curva carga aplicada x deslocamento para 4 PCE. 


\section{Resultados e Discussões}

Nesse capítulo são apresentados os resultados obtidos a partir dos diversos tipos de ensaios executados. São também comparados os resultados das previsões de capacidade de carga das estacas com os valores medidos nas provas de carga, e apresentada a análise dos diferentes parâmetros que influenciam no controle do estaqueamento em campo.

Inicialmente, a partir dos resultados dos ensaios SPT, foi feita a previsão da capacidade de carga das quatro estacas testadas com prova de carga estática, executadas na fase de projeto.

O controle empregado em campo foi à realização de diagramas de cravação das estacas, que apresentou uma boa convergência com o perfil da sondagem mais próxima. Quando a estaca estava próxima do comprimento definido em projeto, foi feito o registro da nega e repique elástico até que se alcançasse o critério inicialmente estabelecido.

Após a execução das estacas, foram executadas provas de carga dinâmica, para a avaliação da resistência mobilizada nas primeiras idades (tempo após a cravação). Posteriormente, foi executada prova de carga estática com maior idade, em média de 60 dias, permitindo-se assim a dissipação de efeitos que influenciassem na avaliação da resistência.

A partir desses dados, se estabeleceram correlações entre os diversos métodos de verificação da resistência mobilizada com a previsão, refinando-se o dimensionamento, aliadoaos registros de campo.

Para validação desse procedimento, e melhor compreensão da variabilidade do terreno, durante a execução da obra (cravação das 2506 estacas), estabeleceu-se a rotina de monitorar a capacidade de carga das estacas com a execução de 74 provas de carga dinâmicas aleatórias. 
Com os resultados das provas de carga dinâmicas, foi realizada a mesma análise feita com base nos resultados das estacas testadas por prova de carga estática. O objetivo foi verificar as premissas iniciais, e conhecer a dispersão dos resultados da prova de carga dinâmica e do controle empregado.

Os resultados das provas de carga foram comparados e correlacionados com os obtidos por meio das fórmulas dinâmicas de Chellis (1951), Smith modificado por Aoki (2011) e do Energy Approach, de modo a calibrar, para este caso de obra, os parâmetros utilizados nestas expressões. Cada expressão possui parâmetros que foram calibrados com os resultados das PCD, sendo conhecido seu valor médio e dispersão.

São apresentados neste capítulo: os resultados de todas as calibrações, as influências na obtenção dos parâmetros nas diferentes fórmulas dinâmicas, as correlações com as provas de carga dinâmica e estática.

\subsection{Estacas testes}

\subsubsection{Previsão de capacidade de carga}

Como apresentado no capitulo 3, no local do projeto foi realizado uma extensa campanha de ensaios SPT, que permitiu caracterizar as composições das camadas de solo (horizontes) até um indicativo da profundidade de início do solo de alteração.

Nas previsões de capacidade de carga a partir dos ensaios SPT, foram utilizados os métodos de Aoki e Velloso (1975) e Décourt e Quaresma (1978).

Para a definição inicial do comprimento necessário de estaca, para a aplicação dos diferentes métodos semi-empíricos, foi adotado como premissas o cálculo para estacas cravadas, seção com diâmetro externo de $700 \mathrm{~mm}$, espessura de parede de $110 \mathrm{~mm}$, resultando numa seção interna de $480 \mathrm{~mm}$, dessa forma nos cálculos considerou-se seção vazada, com ponta aberta e carga de trabalho de $1850 \mathrm{kN}$.

Pelos diferentes perfis individuais de sondagem, a profundidade de parada das estacas variou de 14,0 a 15,0 metros, identificando a ponta em três diferentes areias, conforme descrito no item 3.1. A seção geológica-geotécnica da região pode ser observada na Figura 3.2 . 
As Figura4.1 a Figura4.4 apresentam os perfis de sondagem das locações onde seriam realizadas as estacas testes, destacando-se a camada de areia intermediária, onde a princípio se instalaria a ponta das estacas.

Décourt (1999) cita que quando se trabalha com terrenos com grande variabilidade, em que a sondagem mais próxima retrata uma grande capacidade de carga e as vizinhas partem para o oposto, demonstrando baixas capacidades de carga ele recomenda-se adotar para a primeira previsão além da estaca vizinha, homogeneizar os valores de $N_{S P T}$ adotando um valor médio, denominado pelo autor de $\mathrm{N}$ equivalente $\left({ }^{N_{\text {equiv }}}\right)$ para um perfil de sondagem típico.

Essa sondagem na realidade não existe, entretanto ela permite homogeneizar todo o entorno do elemento de fundação levando em consideração uma maior amostragem.

No caso dos dados empregados, existe em diversas localizações do terreno uma grande discrepância entre a estratigrafia e a resistência $N_{S P T}$ para a sondagem mais próxima e vizinhas, pelas características próprias desse terreno os dados não foram homogeneizados em função de um valor de $N_{\text {equiv }}$, e sim calculou-se para cada perfil individual de sondagem a capacidade de carga e em função da profundidade e homogeneizou-se através da média os valores de resistência das parcelas de atrito lateral $(R I)$ e ponta $(R P)$ e pela soma das duas resultou no total ( $R T$ ).

A fim de ilustrar a variabilidade do terreno, nas Figura4.1 a Figura4.4 são apresentadas a sondagem mais favorável e desfavorável para cada estaca, considerando um raio de influência de 100 metros, apresentando a previsão da capacidade de carga para os métodos semi-empíricos comentados.

Nestes perfis (Figura4.1a Figura4.4), se identifica uma grande variabilidade da camada de areia pelas faixas de dispersão. Para contemplar está variabilidade nas previsões, utilizou-se o conceito de seção homogeneizada $\left({ }^{N}{ }\right)$ de Décourt (1994), levando-se em consideração a camadas e resistência dos materiais. A Figura4.1 a Figura4.4apresentam as previsões de capacidade de carga obtidas para as estacas teste, separando-se as parcelas resistência por atrito lateral e de ponta para cada método aplicado. 
Observa-se pela Tabela 4.1 que o método Aoki e Velloso 91975) proporcionou valores de capacidade de carga superiores aos previstos pelo método Décourt e Quaresma (1978), para o caso das sondagens SP-02 e SP-30 com valores da ordem de $28 \%$ e $26 \%$ respectivamente. Esse fato está diretamente condicionado pela resistência de ponta, com as estacas assentadas sobre a camada de areia compacta. Em termos de atrito lateral as previsões foram similares.

Tabela 4.1 - Previsões a partir dos métodos semi-empíricos para as estacas testes.

\begin{tabular}{|c|c|c|c|c|c|c|c|c|c|c|c|}
\hline \multirow{2}{*}{$\begin{array}{l}\mathrm{N}^{\mathrm{o}} \text {. } \\
\text { Estaca }\end{array}$} & \multirow{2}{*}{$\begin{array}{l}\text { Comp. } \\
\text { Cravado } \\
\text { (m) }\end{array}$} & \multirow{2}{*}{ Sondagem } & \multicolumn{3}{|c|}{ Aoki-Velloso(1975) } & \multicolumn{3}{|c|}{$\begin{array}{c}\text { Décourt-Quaresma } \\
\text { (1978) }\end{array}$} & \multicolumn{3}{|c|}{$\frac{\text { Aoki-Velloso }}{\text { Décourt - Quaresma }}$} \\
\hline & & & $\begin{array}{l}\mathrm{RL} \\
(\mathrm{kN})\end{array}$ & $\begin{array}{c}\mathrm{RP}(\mathrm{k} \\
\mathrm{N})\end{array}$ & $\begin{array}{l}\mathrm{RT}(\mathrm{k} \\
\mathrm{N})\end{array}$ & $\begin{array}{l}\mathrm{RL}(\mathrm{k} \\
\mathrm{N})\end{array}$ & $\begin{array}{l}\mathrm{RP}(\mathrm{k} \\
\mathrm{N})\end{array}$ & $\begin{array}{l}\mathrm{RT}(\mathrm{k} \\
\mathrm{N})\end{array}$ & $\begin{array}{l}\text { RL } \\
{[\text { ] }}\end{array}$ & $\mathrm{RP} \quad[$ & RT [ \\
\hline \multirow{2}{*}{$\begin{array}{l}\text { E114 } \\
\text { M02 }\end{array}$} & \multirow{2}{*}{12,20} & SP02 & 1446 & 3769 & 5215 & 1441 & 2638 & 4079 & 1,00 & 1,43 & 1,28 \\
\hline & & $\mathrm{SP}-\mathrm{N}_{\mathrm{EQ}}$ & 862 & 2055 & 2917 & 940 & 1670 & 2610 & 0,92 & 1,23 & 1,12 \\
\hline \multirow{2}{*}{$\begin{array}{l}\text { E018 } \\
\text { M04 }\end{array}$} & \multirow{2}{*}{13,20} & SP25 & 747 & 1865 & 2612 & 905 & 1627 & 2532 & 0,83 & 1,15 & 1,03 \\
\hline & & $\mathrm{SP}-\mathrm{N}_{\mathrm{EQ}}$ & 589 & 1063 & 1652 & 818 & 945 & 1763 & 0,72 & 1,12 & 0,94 \\
\hline \multirow{2}{*}{$\begin{array}{l}\text { E125 } \\
\text { M09 }\end{array}$} & \multirow{2}{*}{14,90} & SP08 & 713 & 2428 & 3141 & 916 & 2463 & 3379 & 0,78 & 0,99 & 0,93 \\
\hline & & $\mathrm{SP}-\mathrm{N}_{\mathrm{EQ}}$ & 1356 & 3343 & 4699 & 1363 & 3207 & 4570 & 0,99 & 1,04 & 1,03 \\
\hline \multirow{2}{*}{$\begin{array}{l}\text { E113 } \\
\text { M15 }\end{array}$} & \multirow{2}{*}{12,70} & SP30 & 699 & 2700 & 3399 & 865 & 1893 & 2758 & 0,81 & 1,43 & 1,23 \\
\hline & & $\mathrm{SP}-\mathrm{N}_{\mathrm{EQ}}$ & 470 & 2091 & 2561 & 838 & 1725 & 2563 & 0,56 & 1,21 & 1,00 \\
\hline \multirow{2}{*}{\multicolumn{2}{|c|}{$\begin{array}{l}\text { Para resultados } \\
\text { com }\end{array}$}} & Média & 901 & 2691 & 3592 & 1032 & 2155 & 3187 & 0,85 & 1,25 & 1,12 \\
\hline & & DesvP. & 272 & 544 & 812 & 205 & 395 & 542 & 0,07 & 0,18 & 0,14 \\
\hline \multicolumn{2}{|c|}{$\begin{array}{c}\text { SP2, SP25,SP08 e } \\
\text { SP30 }\end{array}$} & CV (\%) & 30,2 & 20,2 & 22,6 & 19,8 & 18,3 & 17,0 & 8,76 & 14,50 & 12,29 \\
\hline \multirow{3}{*}{\multicolumn{2}{|c|}{$\begin{array}{l}\text { Para resultados } \\
\quad \text { com } \\
\text { SP- } \\
N_{E Q} \text { somente }\end{array}$}} & Média & 819 & 2138 & 2957 & 990 & 1887 & 2877 & 0,80 & 1,15 & 1,02 \\
\hline & & DesvP. & 290 & 603 & 871 & 187 & 660 & 847 & 0,16 & 0,07 & 0,05 \\
\hline & & CV (\%) & 35,4 & 28,2 & 29,4 & 18,9 & 35,0 & 29,4 & 19,8 & 5,97 & 5,13 \\
\hline
\end{tabular}

A relação entre os dois métodos no caso do atrito lateral vario entre 0,72 a 1,00 , para a ponta entre 0,99 a 1,43 que resultou na resistência total em variações de 0,93 a 1,28.

Observa-se na previsão que a camada de areia compacta é bastante variável ao longo da profundidade, e formada por diversas camadas com resistências variáveis ao longo de toda a área do projeto. Mesmo adotando o critério de homogeneizar as previsões com as 
sondagens vizinhas ainda é bastante pronunciável essa tendência de variação.

A partir das Figuras 4.1 a 4.4 apresenta os perfis utilizados na previsão de cada uma das estacas e na profundidade de 10,0 a 15,0 metros é possível verificar a variação na medida do NSPT para as sondagens próximas as estacas observando os valores máximos e mínimos, e consequentemente a variação nas previsões para cada um dos métodos aplicados no estudo. 
N. Golpes (golpes $/ 30 \mathrm{~cm}$ finais)

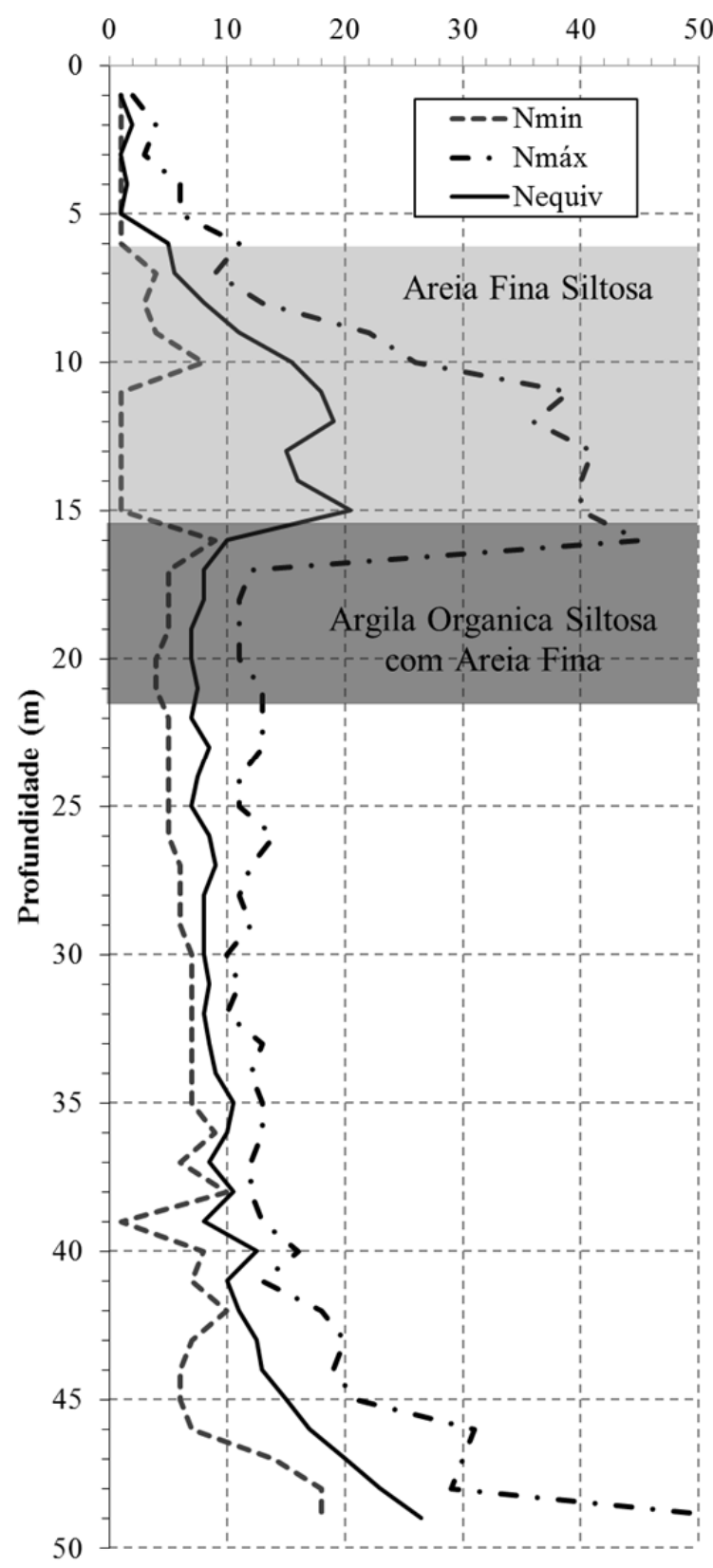

Capacidade de Carga $(\mathrm{kN})$

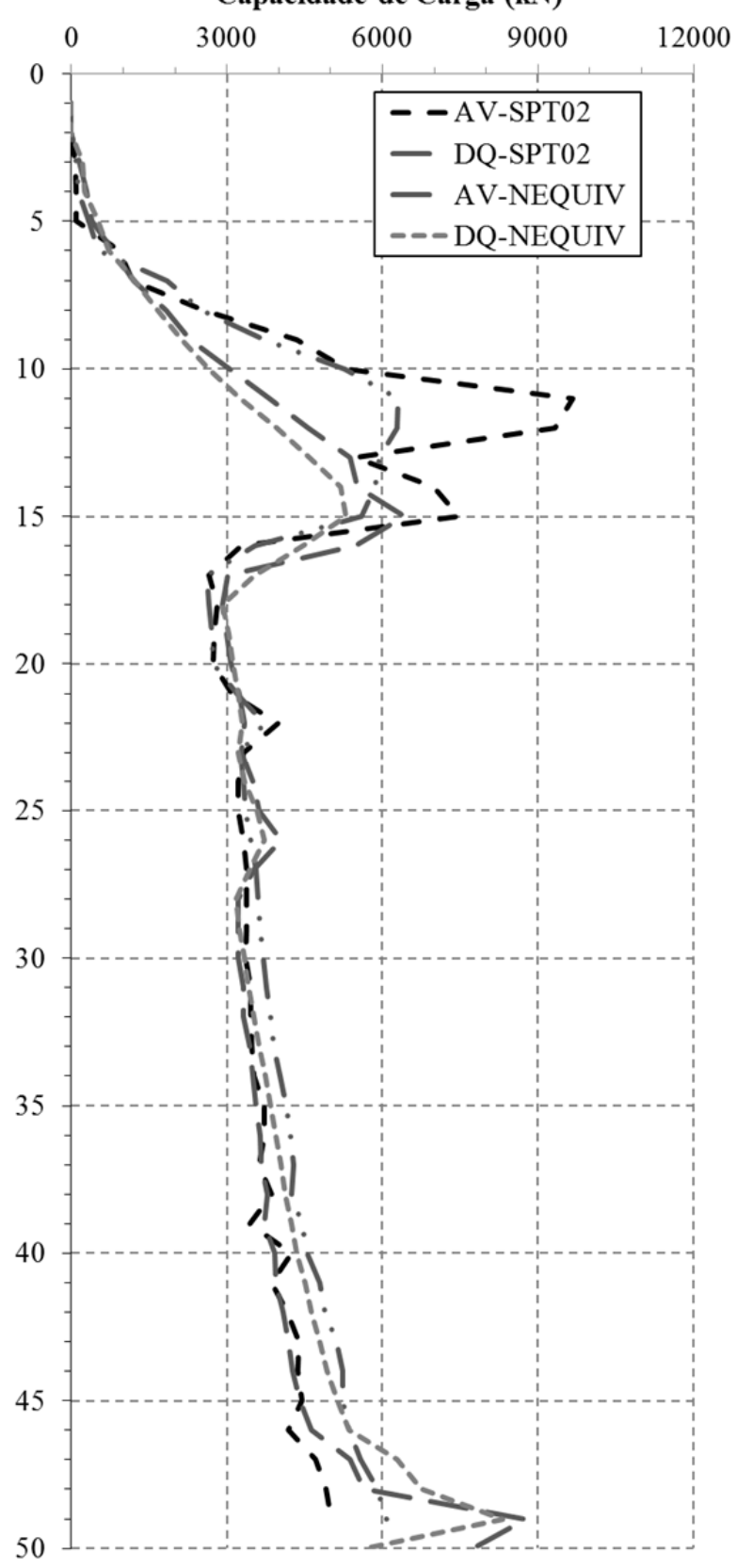

Figura4.1 - Comparação entre os valores de $N_{S P T}$ e previsão pelos métodos semi-empíricos para a sondagem mais próxima (SP-02) e próximas (SM-01, SP-03, SP-17 e SP-24) para a estaca E114M02. 
N. Golpes (golpes $/ 30 \mathrm{~cm}$ finais)

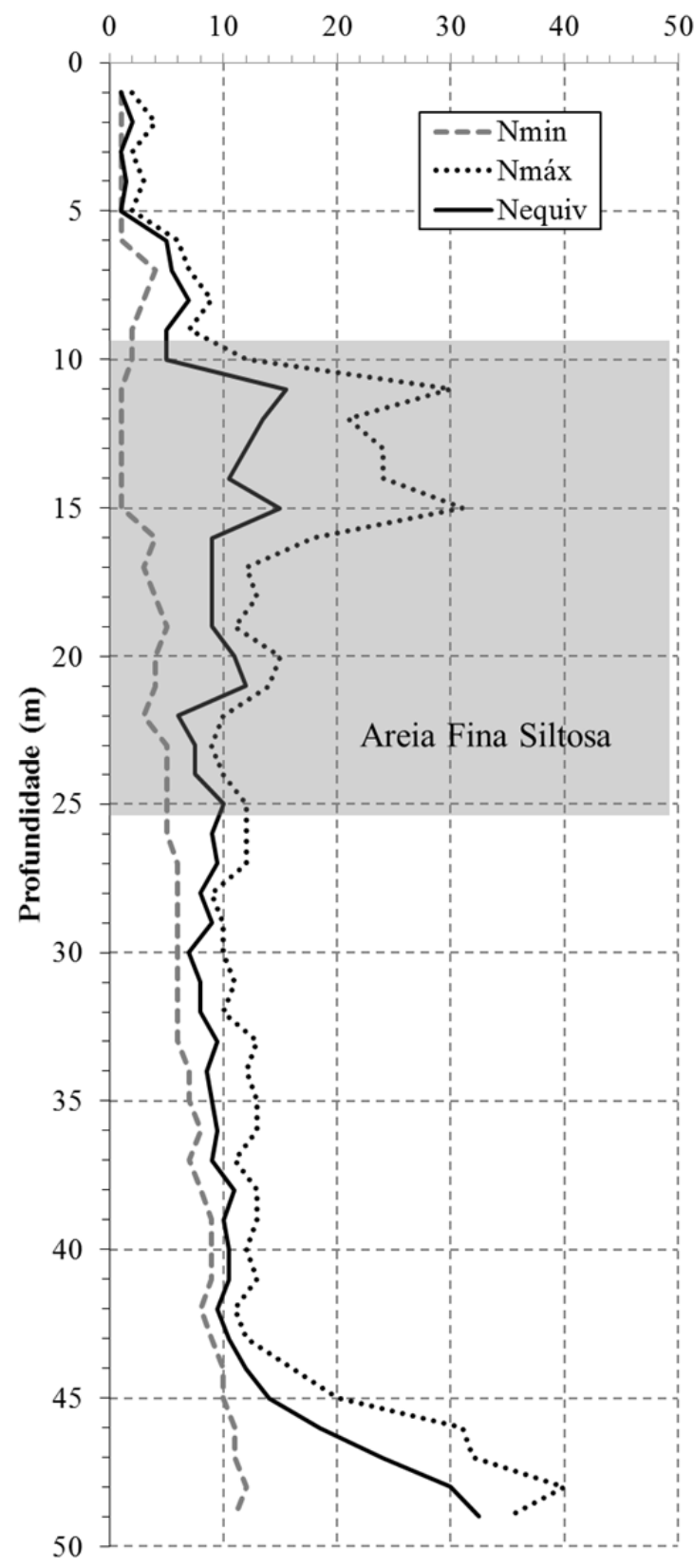

\section{Capacidade de Carga (kN)}

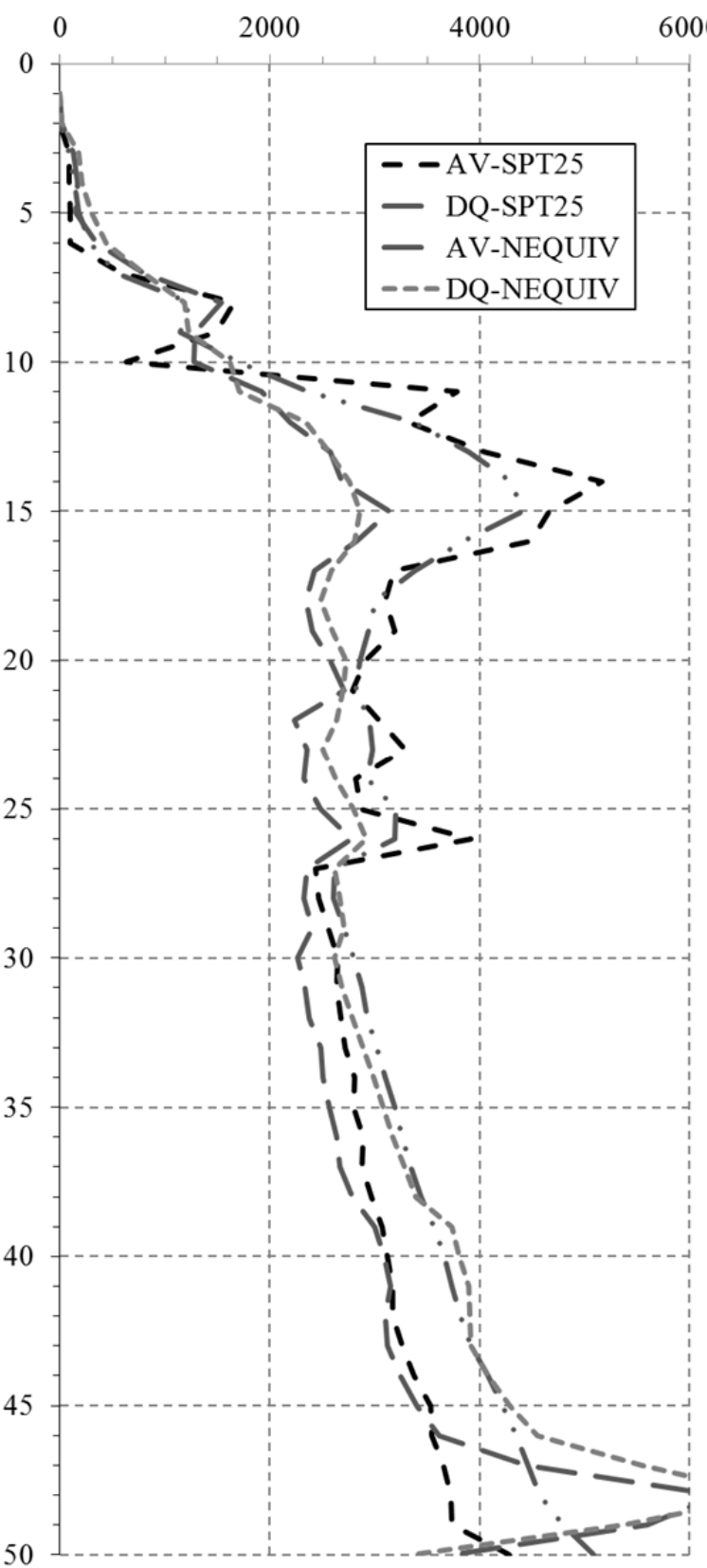

Figura4.2 - Comparação entre os valores de $N_{S P T}$ e previsão pelos métodos semi-empíricos para a sondagem mais próxima (SP-25) e próximas (SP-03, SP-04, SP-17 e SP-18) para a estaca teste E018M04. 

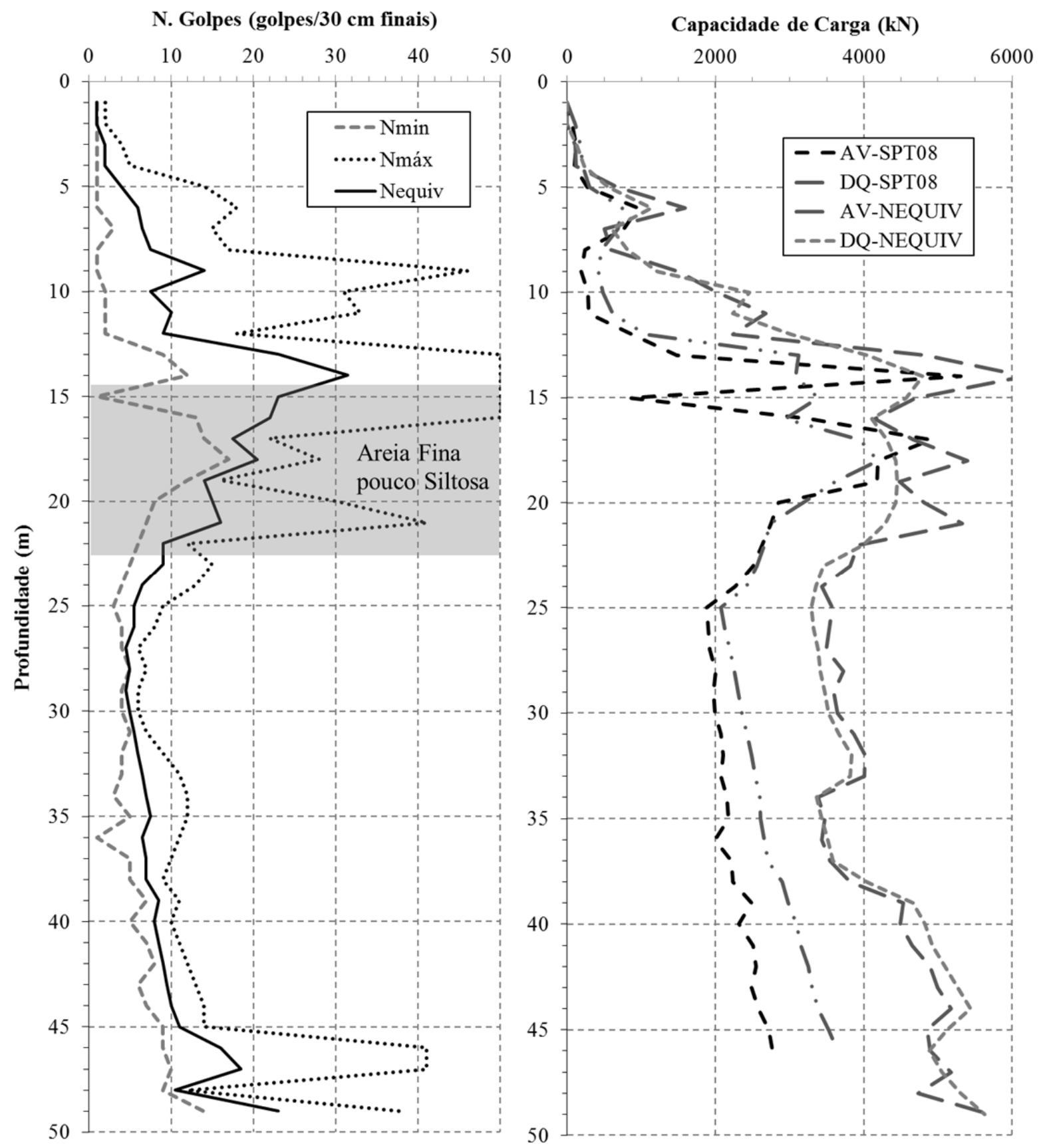

Figura4.3 - Comparação entre os valores de $N_{S P T}$ e previsão pelos métodos semi-empíricos para a sondagem mais próxima (SP-08) e próximas (SP-07, SP-09, SM-20 e SP-27) para a estaca teste E125M09. 

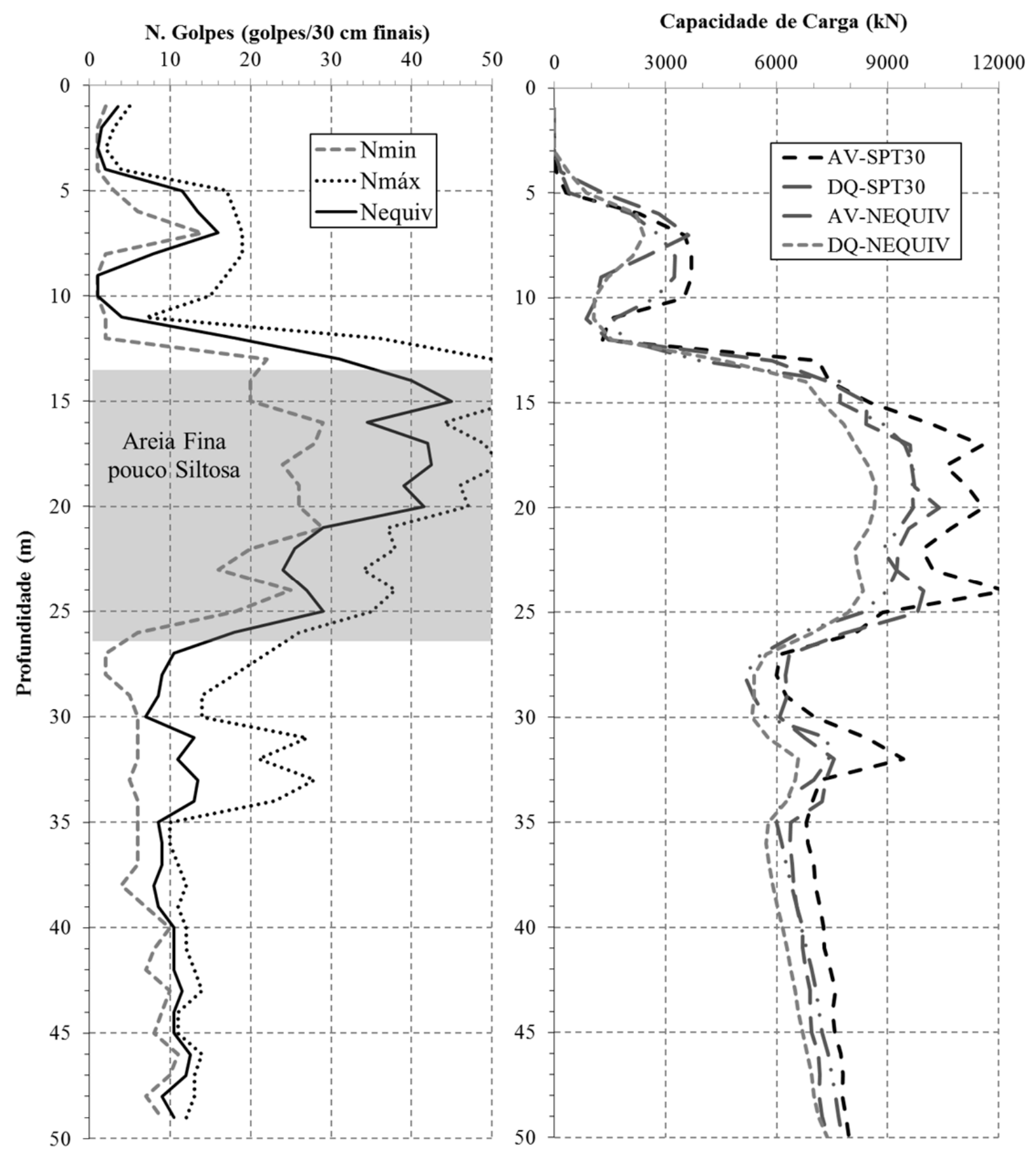

Figura4.4 - Comparação entre os valores de $N_{S P T}$ e previsão pelos métodos semi-empíricos para a sondagem mais próxima (SP-30) e próximas (SP-13, SP-14, SP-22 e SP-23) para a estaca teste E113M15. 


\subsubsection{Provas de carga dinâmica}

Nas estacas testes foram executadas provas de carga dinâmica para verificar a capacidade de carga da estaca, calibrar os parâmetros de execução, alimentar as premissas de projeto, e contribuir para o dimensionamento da prova de carga estática, a ser executada.

Os ensaios foram executados nas estacas E114M02, E018M04 e E125M09 nas idades de 4, 12 e 6 dias após a cravação, respectivamente. Pelo formato da curva resistência mobilizada por deslocamento (Figura 4.5) os ensaios nas três estacas apresentaram uma mesma tendência, com resistência mobilizada na faixa de 2600 a $3000 \mathrm{kN}$, para um deslocamento de $24 \mathrm{~mm}$.

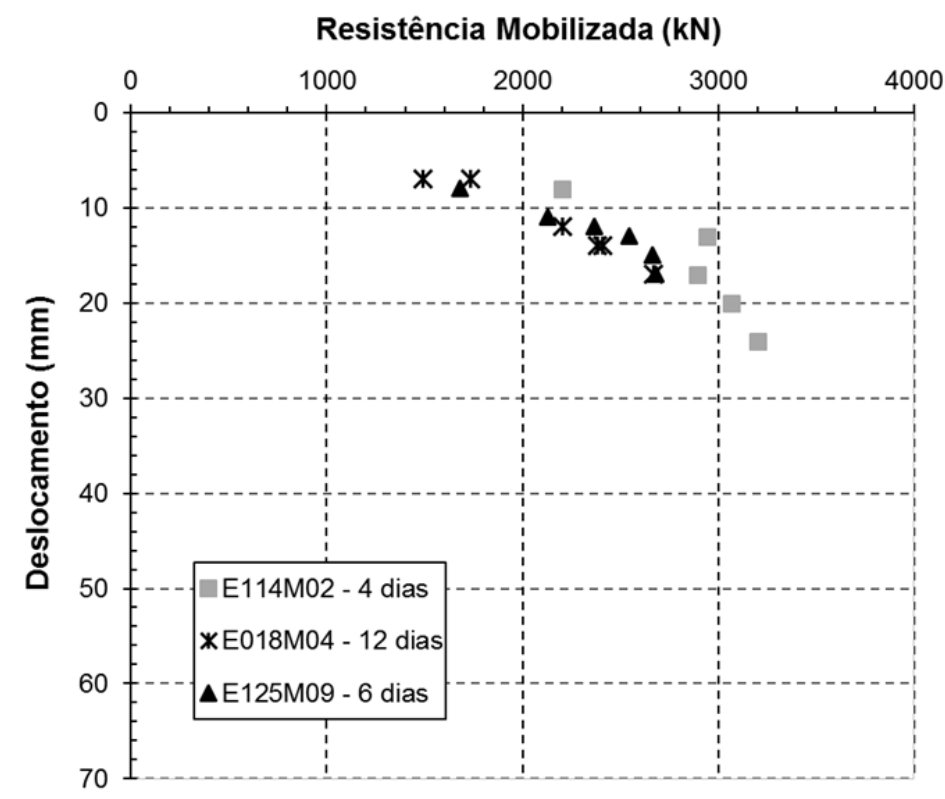

Figura 4.5 - Resultados da prova de carga dinâmica em três estacas testes.

$\mathrm{Na}$ estaca $\mathrm{n}^{\circ}$. E114M02, pela análise CAPWAP para o golpe de maior energia, obteve-se como a resistência mobilizada $(R M X) 3203 \mathrm{kN}$, para a energia líquida $(E M X)$ de 82,6 kN.m, com energia potencial de 126,0 kN.m (considerando-se a massa do martelo de 70 $\mathrm{kN}$ e altura de queda de 1,80 m), o que mostra uma eficiência do sistema de 65,5\%. Quanto ao diagrama de transferência, a parcela de atrito lateral ( $R S$ ) foi de $780 \mathrm{kN}$ e ponta $(R P)$ de 2423 kN (distribuição percentual de $24,4 \%$ e $75,6 \%$ da resistência em relação a $R M X$. 
Pela retroanálise, o fator de amortecimento dinâmico $(J)$ foi igual a 0,36 . Inserindo-o na análise CASE (Tabela 4.2), avaliou-se a resistência ( $R M X)$, deslocamento ( $D M X$ ), energia liquida ( $E M X)$ e tensões aplicadas (compressão - CSX e tração - $T S X$ ) para os demais níveis de energia aplicados.

Tabela 4.2 - Resultados obtidos pelo método CASE - estaca n ${ }^{\circ}$ E114M02.

\begin{tabular}{ccccccc}
\hline $\begin{array}{c}N^{\circ} . \\
\text { Golpe }\end{array}$ & $\begin{array}{c}\mathrm{H}_{\text {QUEDA }} \\
(\mathrm{m})\end{array}$ & $\begin{array}{c}\text { RMX } \\
(\mathrm{kN})\end{array}$ & $\begin{array}{c}\text { DMX } \\
(\mathrm{mm})\end{array}$ & $\begin{array}{c}\text { EMX } \\
(\mathrm{kN} . \mathrm{m})\end{array}$ & $\begin{array}{c}\text { CSX } \\
(\mathrm{MPa})\end{array}$ & $\begin{array}{c}\text { TSX } \\
(\mathrm{MPa})\end{array}$ \\
\hline 1 & 0,4 & 2202 & 8,0 & 13,9 & 10,2 & 1,1 \\
\hline 2 & 0,7 & 2940 & 13,0 & 31,2 & 14,4 & 1,5 \\
\hline 3 & 1,1 & 2892 & 17,0 & 50,0 & 19,1 & 1,5 \\
\hline 4 & 1,4 & 3064 & 20,0 & 64,0 & 21,6 & 1,3 \\
\hline 5 & 1,8 & 3203 & 24,0 & 82,6 & 24,9 & 1,2 \\
\hline
\end{tabular}

Para a estaca $n^{\circ}$. E018M04, pela análise CAPWAP o valor de $R M X$ é de 2670 $\mathrm{kN}$, para um $(E M X)$ de 62,5 kN.m, e eficiência do sistema de cravação de $63,7 \%$, para $(J)$ de 0,57. Pelo diagrama de transferência de resistência, o atrito foi de $1150 \mathrm{kN}$ (43,1\% do $R M X)$ e a ponta de $1520 \mathrm{kN}(56,9 \%$ do $R M X)$. A Tabela 4.3apresenta os parâmetros do ensaio para os outros níveis de energia aplicados, considerando o fator de amortecimento obtido no CAPWAP.

Tabela 4.3- Resultados obtidos pelo método CASE - estaca nº. E018M04.

\begin{tabular}{ccccccc}
\hline $\begin{array}{c}\mathrm{N}^{\circ} . \\
\text { Golpe }\end{array}$ & $\begin{array}{c}\mathrm{H}_{\text {QUEDA }} \\
(\mathrm{m})\end{array}$ & $\begin{array}{c}\text { RMX } \\
(\mathrm{kN})\end{array}$ & $\begin{array}{c}\text { DMX } \\
(\mathrm{mm})\end{array}$ & $\begin{array}{c}\text { EMX } \\
(\mathrm{kN} . \mathrm{m})\end{array}$ & $\begin{array}{c}\mathrm{CSX} \\
(\mathrm{MPa})\end{array}$ & $\begin{array}{c}\text { TSX } \\
(\mathrm{MPa})\end{array}$ \\
\hline 1 & 0,4 & 1493 & 7,0 & 9,4 & 8,7 & 1,3 \\
\hline 2 & 0,4 & 1736 & 7,0 & 11,4 & 9,5 & 0,7 \\
\hline 3 & 0,8 & 2207 & 12,0 & 27,1 & 14,0 & 1,4 \\
\hline 4 & 1,0 & 2384 & 14,0 & 41,7 & 17,5 & 2,3 \\
\hline 5 & 1,0 & 2411 & 14,0 & 42,2 & 19,9 & 0,8 \\
\hline 6 & 1,4 & 2670 & 17,0 & 62,5 & 24,8 & 0,9 \\
\hline
\end{tabular}


Para a estaca $\mathrm{n}^{\circ}$. E125M09, obteve-se $R M X$ de $2681 \mathrm{kN}$, para $E M X$ de 53,2 kN.m, e eficiência do sistema de 54,3\% para um fator de amortecimento $(J$ ) de 0,98 . Quanto as parcelas da resistência, $1292 \mathrm{kN}(48,2 \%$ do $R M X)$ correspondente ao atrito lateral e 1389 $\mathrm{kN}(51,8 \%$ do $R M X)$ a carga de ponta. A Tabela 4.4apresenta os resultados da análise CASE para os demais níveis de energia aplicados, considerando o fator de amortecimento obtido no CAPWAP.

Tabela 4.4 - Resultados dos método CASE - estacan ${ }^{\circ}$.E125M09.

\begin{tabular}{ccccccc}
\hline $\begin{array}{c}\mathrm{N}^{\circ} \\
\text { Golpe }\end{array}$ & $\begin{array}{c}\mathrm{H}_{\text {QUEDA }} \\
(\mathrm{m})\end{array}$ & $\begin{array}{c}\text { RMX } \\
(\mathrm{kN})\end{array}$ & $\begin{array}{c}\text { DMX } \\
(\mathrm{mm})\end{array}$ & $\begin{array}{c}\text { EMX } \\
(\mathrm{kN} . \mathrm{m})\end{array}$ & $\begin{array}{c}\text { CSX } \\
(\mathrm{MPa})\end{array}$ & $\begin{array}{c}\text { TSX } \\
(\mathrm{MPa})\end{array}$ \\
\hline 1 & 0,4 & 1680 & 8,0 & 10,7 & 9,1 & 1,2 \\
\hline 2 & 0,6 & 2130 & 11,0 & 21,2 & 12,0 & 1,7 \\
\hline 3 & 0,8 & 2369 & 12,0 & 27,9 & 14,2 & 2,0 \\
\hline 4 & 1,0 & 2547 & 13,0 & 34,4 & 15,9 & 2,2 \\
\hline 5 & 1,2 & 2663 & 15,0 & 43,4 & 18,0 & 2,2 \\
\hline 6 & 1,4 & 2681 & 17,0 & 53,2 & 19,8 & 2,4 \\
\hline
\end{tabular}

\subsubsection{Registros de nega e repique elástico}

Durante a execução das provas de carga, para cada golpe aplicado foram registrados os sinais de nega e repique elástico. Com as leituras destes sinais, a resistência mobilizada da estaca foi interpretada a partir das fórmulas dinâmicas de Chellis (1951) e Smith modificado por Aoki (2011).

\subsubsection{Estaca nº. E114M02}

Pelos registros de campo, para cada nível de energia, buscou-se por retroanálise, utilizando-se a expressão de Chellis, determinar o valor do quake ( ${ }^{C}$ ) do solo correspondente (Tabela 4.5).

A Figura 4.6 apresenta a relação entre EMX e C3. O melhor ajuste foi: $C 3=5,33 \cdot \ln (E M X)-10,32$ para um $\mathrm{R} 2$ de 0,994. A partir dessa expressão foram determinados os valores do quake do solo para os diferentes níveis de energia empregados no 
ensaio, e denominado de ${ }^{C 3_{\text {ajuste }}}$ (Tabela 4.5).

Para o fator $f$ - relação atrito/ponta foi empregada os valores obtidos através da análise CAPWAP para o golpe de maior energia da separação das parcelas de atrito ( $R P$ ) e ponta $(R I)$, extrapolando o resultado para os demais golpes, sendo adotado como constante. A partir das parcelas de resistência aplicou-se a equação [4.1]

$$
f=\frac{0,5 \cdot R L+R P}{R L+R P}
$$

Para a fórmula de Smith modificado por Aoki (2011), o melhor ajuste com a PCD resultou no valor de $\xi$ igual a 1,10 . A eficiência $(e)$ do sistema de cravação para os diversos níveis de energia aplicados foi em média de 64,9\%, com exceção do primeiro golpe que foi de $49,6 \%$.

Tabela 4.5 - Interpretação dos registros da estaca ${ }^{\circ}$. E114M02.

\begin{tabular}{cccccccccc}
\hline $\begin{array}{c}\mathrm{N}^{\circ} \\
\text { Golpe }\end{array}$ & $\begin{array}{c}\mathrm{E}_{\mathrm{POT}} \\
(\mathrm{kN} . \mathrm{m})\end{array}$ & $\begin{array}{c}\mathrm{e} \\
(\%)\end{array}$ & $\begin{array}{c}\mathrm{S}_{\mathrm{gp}} \\
(\mathrm{mm})\end{array}$ & $\begin{array}{c}\mathrm{K} \\
(\mathrm{mm})\end{array}$ & $\begin{array}{c}\mathrm{C} 3_{\mathrm{RMX}} \\
(\mathrm{mm})\end{array}$ & $\begin{array}{c}\text { C3ajuste. } \\
(\mathrm{mm})\end{array}$ & $\mathrm{f}$ & $\begin{array}{c}\mathrm{RM}_{\mathrm{CH}} \\
(\mathrm{kN})\end{array}$ & $\begin{array}{c}\mathrm{RM}_{\mathrm{SMM}} \\
(\mathrm{kN})\end{array}$ \\
\hline 1 & 28,0 & 49,6 & 0,0 & 8,0 & 4,07 & 5,04 & 0,88 & 1658 & 1911 \\
\hline 2 & 49,0 & 63,7 & 0,5 & 12,5 & 7,25 & 7,79 & 0,88 & 2638 & 2542 \\
\hline 3 & 77,0 & 64,9 & 1,0 & 16,0 & 10,84 & 9,40 & 0,88 & 3699 & 3056 \\
\hline 4 & 98,0 & 65,3 & 2,5 & 17,5 & 12,03 & 10,24 & 0,88 & 4069 & 3129 \\
\hline $5^{1}$ & 126,0 & 65,6 & 5,0 & 19,0 & 13,28 & 11,10 & 0,88 & 4423 & 3133 \\
\hline
\end{tabular}

Notas:

${ }^{1}$ - análise CAPWAP realizada para o golpe de maior energia.

Na Tabela 4.5, para cada golpe aplicado, foi correlacionada à energia potencial aplicada ( ${ }^{E_{\text {POT }}}$ ), a eficiência resultante (e), os valores do registro de nega $\left({ }^{S p}\right)$ e repique elástico $(K)$. A partir dos dados, são apresentados pela fórmula dinâmica de Chellis os valores do quake do solo obtido pela retroanálise da equação ( $C 3_{R M X}$ ), tendo como parâmetro de entrada o valor de $R M X$ da PCD, o $C 3_{\text {ajuste }}$, o fator de transferência de carga $(f)$ da 
análise CAPWAP, e os valores de resistência mobilizada na estaca calculada pela expressão de Chellis ( $\left.R M_{C H}\right)$ e pela expressão de Smith modificado ( $\left.R M_{S M M}\right)$.

Pela análise CAPWAP, no golpe de maior energia $\left(5^{\circ}\right.$ golpe) o quake $(C 3)$ do solo foi de $16,31 \mathrm{~mm}$, enquanto que, por retroanálise por Chellis resultou em 13,28 $\mathrm{mm}(81 \%$ do valor medido no CAPWAP).

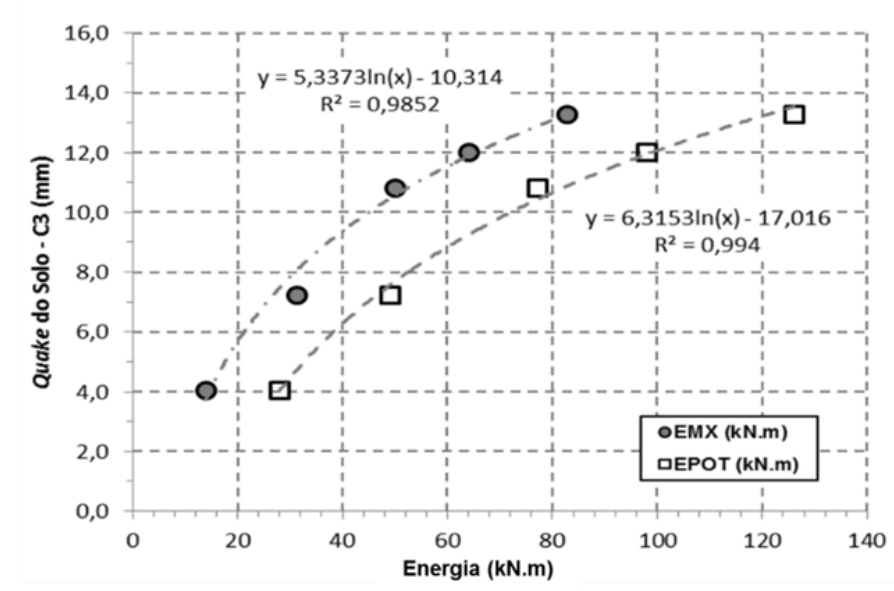

Figura 4.6 - Gráfico de quake do solo ( $C 3$ ) versus $E M X / E_{P O T}$ a partir da retro analise da

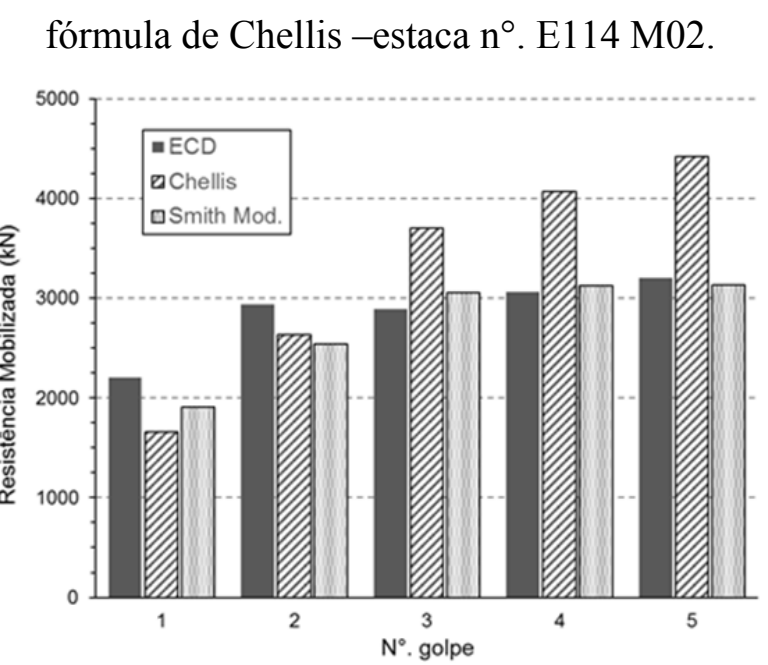

Figura 4.7 - Comparação entre as resistências mobilizadas obtidas pelos ECD e fórmulas dinâmicas - estaca $n^{\circ}$. E114M02.

A partir dos valores de resistência mobilizada na estaca RM (Figura 4.7), obtidos nas fórmulas dinâmicas, nota-se que a expressão de Smith se mostra mais coerente com os 
resultados obtidos nos ensaios de carregamento dinâmico (ECD ou PCD).

\subsubsection{Estaca nº. E018M04}

Pela análise CAPWAP nesta estaca para o golpe de maior energia, obteve-se um valor de $R M X_{\text {igual a }} 2670 \mathrm{kN}$ (considerando-se que a estaca foi ensaiada 12 dias após a cravação), para $E M X$ de 62,5 kN.m, com energia potencial de 98,0 kN.m (e = 63,7 \%).

Pelos registros de campo coletados durante a execução da PCD (Tabela 4.6) e interpretados pela analise CAPWAP, se retroanalisou os valores de C3 usando-se a expressão

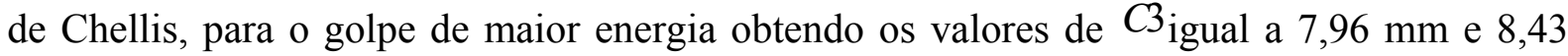
mm para a análise CAPWAP e a fórmula de Chellis respectivamente. Para os diferentes níveis de energia empregados versus os valores do quake do solo traçou-se uma curva onde o melhor ajuste foi através da expressão $C 3=2,28 \cdot \ln (E M X)-0,95$ para um R2 igual a 0,947 (Figura 4.8).

Tabela 4.6 - Registros de nega e repique elástico - estaca nº. E018M04.

\begin{tabular}{cccccccccc}
\hline $\begin{array}{c}\mathrm{N}^{\circ} \\
\text { Golpe }\end{array}$ & $\begin{array}{c}\mathrm{E}_{\text {POT }} \\
(\mathrm{kN} . \mathrm{m})\end{array}$ & $\begin{array}{c}\mathrm{e} \\
(\%)\end{array}$ & $\begin{array}{c}\mathrm{S}_{\mathrm{gp}} \\
(\mathrm{mm})\end{array}$ & $\begin{array}{c}\mathrm{K} \\
(\mathrm{mm})\end{array}$ & $\begin{array}{c}\mathrm{C}_{\mathrm{RMX}} \\
(\mathrm{mm})\end{array}$ & $\begin{array}{c}\mathrm{C} 3 \text { ajuste } \\
(\mathrm{mm})\end{array}$ & $\mathrm{f}$ & $\begin{array}{c}\mathrm{RM}_{\mathrm{CH}} \\
(\mathrm{kN})\end{array}$ & $\begin{array}{c}\mathrm{RM}_{\mathrm{SMM}} \\
(\mathrm{kN})\end{array}$ \\
\hline 1 & 24,0 & 39,2 & 0,0 & 7,0 & 4,44 & 3,71 & 0,78 & 1922 & 1343 \\
\hline 2 & 24,0 & 47,5 & 0,0 & 7,0 & 4,03 & 4,37 & 0,78 & 1538 & 1629 \\
\hline 3 & 48,0 & 56,5 & 1,0 & 11,0 & 7,22 & 7,31 & 0,78 & 2154 & 2085 \\
\hline 4 & 60,0 & 69,5 & 3,0 & 11,0 & 6,92 & 8,78 & 0,78 & 1297 & 2453 \\
\hline 5 & 60,0 & 70,3 & 2,0 & 12,0 & 7,87 & 8,82 & 0,78 & 1858 & 2638 \\
\hline 6 & 84,0 & 74,4 & 4,0 & 13,0 & 8,43 & 10,16 & 0,78 & 1661 & 2976 \\
\hline
\end{tabular}




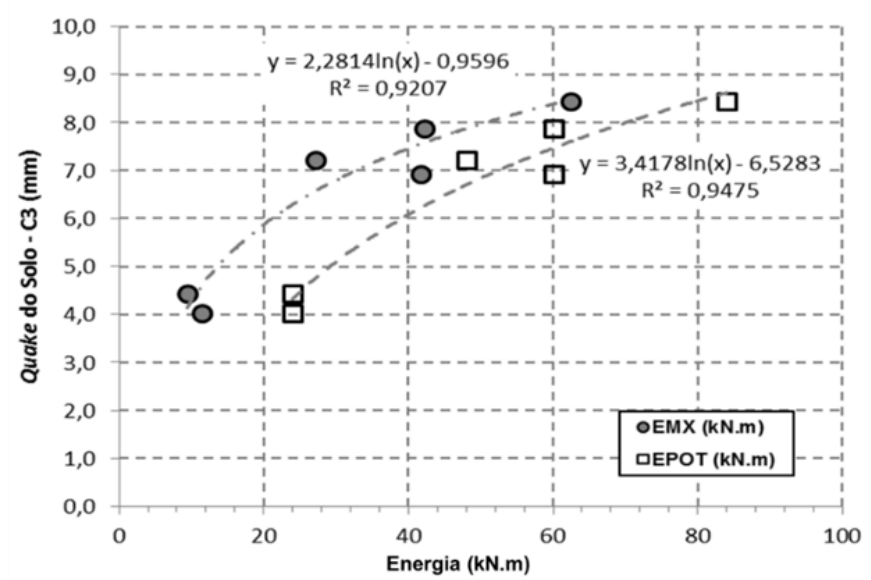

Figura 4.8 - Gráfico de quake do solo ( $C 3$ ) versus $E M X / E_{P O T}$ a partir da retroanálise da fórmula de Chellis -estaca nº. E018 M04.

Comparando-se os resultados das fórmulas dinâmicas com os da PCD (Figura4.9) para os diversos níveis de energia aplicados, pela expressão de Chellis a variação foi de $2,4 \%$ a $45,6 \%$, enquanto que por Smith essa faixa foi de $2,9 \%$ a $11,5 \%$. Para essa condição o melhor ajuste de $\xi$ resultou igual a 1,00.Nessa situação, para os golpes $n^{\circ} .4$ a 6 , os valores de RM calculados por Chellis apresentaram-se mais distantes dos resultados da PCD.

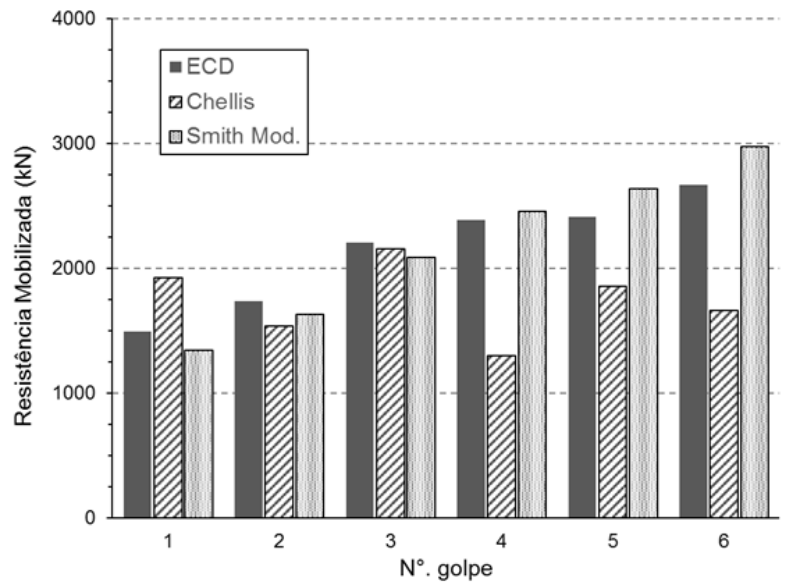

Figura4.9 -Comparação entre as resistências mobilizadas obtidas pelos ECD e fórmulas dinâmicas - estaca $n^{\circ}$. E018 M04. 


\subsubsection{Estaca nº. E125M09}

Nesta estaca, pela análise CAPWAP obteve-se $R M X$ igual a $2681 \mathrm{kN}$, para $E M X$ de 53,2 kN.m, energia potencial de 96,0 kN.m (eficiência do sistema de cravação de 54,3 \%). A estaca foi ensaiada 6 dias após a cravação.

Pelos sinais de nega e repique para cada golpe aplicado, comparando-se com os resultados das PCD, por retroanálise da fórmula de Chellis, o quake ( $C 3$ ) do solo para o golpe de maior energia foi de $9,99 \mathrm{~mm}$ (9,52 $\mathrm{mm}$ foram obtidos na análise CAPWAP). A Tabela 4.7 apresenta os demais valores de C3 calculados. A Figura4.10 apresenta os valores de C3 em função da energia aplicada no sistema. O melhor ajuste desta relação foi: $C 3=3,40 \cdot \ln (E M X)-3,91$.

O melhor ajuste do parâmetro $\xi$, usado na expressão de Smith, foi é igual a 1,00, para uma eficiência média do sistema de 51,1\%. Recalculando-se os valores da resistência mobilizada usando-se as fórmulas dinâmicas, e comparando-as com os resultados da PCD (Figura 4.11), como resultado observa-se que para os valores obtidos via fórmula de Chellis a variação foi de $1,0 \%$ a $7,7 \%$, enquanto que pela expressão de Smith a faixa está entre $0 \%$ a $25,1 \%$.

Tabela 4.7- Registros de nega e repique elástico- estaca $n^{\circ}$. E125M09.

\begin{tabular}{cccccccccc}
\hline $\begin{array}{c}\mathrm{N}^{\circ} \\
\text { Golpe }\end{array}$ & $\begin{array}{c}\mathrm{E}_{\mathrm{POT}} \\
(\mathrm{kN} . \mathrm{m})\end{array}$ & $\begin{array}{c}\mathrm{e} \\
(\%)\end{array}$ & $\begin{array}{c}\mathrm{S}_{\mathrm{gp}} \\
(\mathrm{mm})\end{array}$ & $\begin{array}{c}\mathrm{K} \\
(\mathrm{mm})\end{array}$ & $\begin{array}{c}\mathrm{C}_{\mathrm{RMX}} \\
(\mathrm{mm})\end{array}$ & $\begin{array}{c}\mathrm{C} 3 \text { ajuste } \\
(\mathrm{mm})\end{array}$ & $\mathrm{f}$ & $\begin{array}{c}\mathrm{RM}_{\mathrm{CH}} \\
(\mathrm{kN})\end{array}$ & $\begin{array}{c}\mathrm{RM}_{\mathrm{SMM}} \\
(\mathrm{kN})\end{array}$ \\
\hline 1 & 28,0 & 38,2 & 0,5 & 7,5 & 4,36 & 4,15 & 0,76 & 1791 & 1259 \\
\hline 2 & 42,0 & 50,5 & 0,5 & 10,5 & 6,52 & 6,48 & 0,76 & 2151 & 1843 \\
\hline 3 & 56,0 & 49,8 & 0,5 & 11,5 & 7,07 & 7,41 & 0,76 & 2186 & 2232 \\
\hline 4 & 70,0 & 49,1 & 0,5 & 12,5 & 7,74 & 8,12 & 0,76 & 2340 & 2548 \\
\hline 5 & 84,0 & 51,7 & 1,0 & 14,0 & 9,02 & 8,92 & 0,76 & 2719 & 2713 \\
\hline 6 & 98,0 & 54,3 & 2,0 & 15,0 & 9,99 & 9,61 & 0,76 & 2884 & 2800 \\
\hline
\end{tabular}




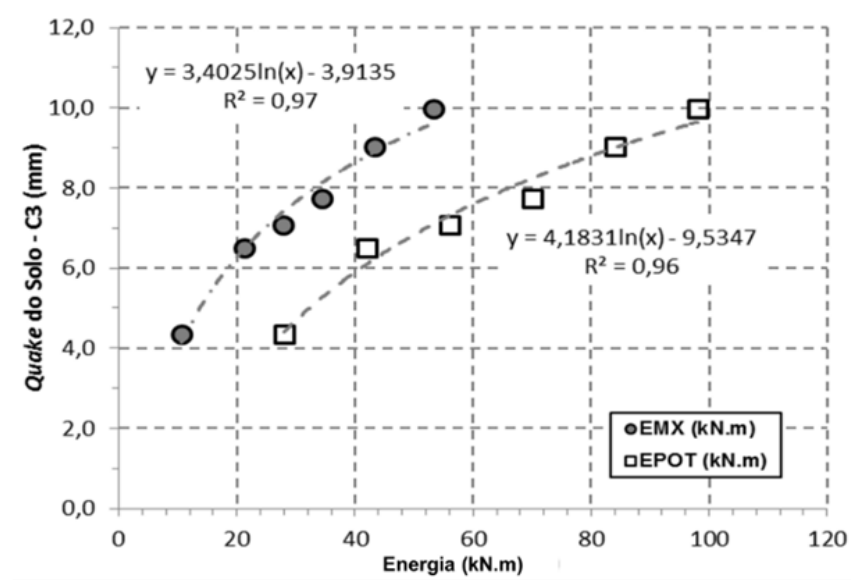

Figura4.10 - Gráfico de quake do solo ( $C 3$ ) versus $E M X / E_{P O T}$ a partir da retroanálise da fórmula de Chellis - estaca ${ }^{\circ}$. E125M09.

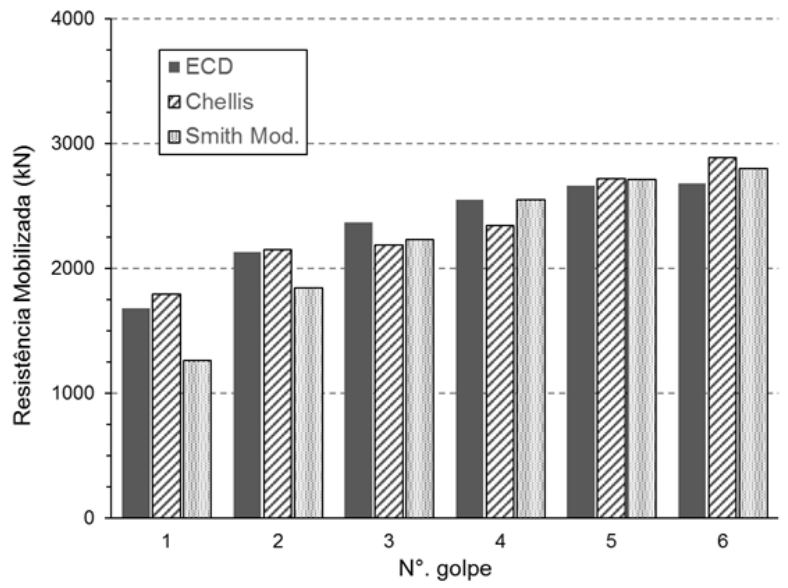

Figura 4.11 - Comparação entre as resistências mobilizadas obtidas pelos ECD e fórmulas dinâmicas - estaca nº. E125 M09.

\subsubsection{Interpretação da PCD em termos de carga de ruptura}

$\mathrm{Na} \mathrm{PCD}$, é muito comum que o ponto de maior energia não tenha caracterizado a carga de ruptura do sistema estaca-solo, sendo dificultada a sua comparação direta com os resultados da PCE. Nessa condição, não existe um método de extrapolação para ruptura física sob carregamento dinâmico, normalmente se convenciona uma carga de ruptura $P R_{R M X}$.

Aplicando-se aos resultados das curvas carga x deslocamento,obtidas das PCD, os métodos da NBR 6122 (2010), Davisson (1973), e de Van der Veen (1953),foram 
interpretadas as cargas de ruptura mostradas na Tabela 4.8.

Tabela 4.8 - Interpretação da carga de ruptura para os resultados dos PCD.

\begin{tabular}{ccccccccc}
\hline & $\begin{array}{c}\text { Intervalo de } \\
\text { tempo após }\end{array}$ & & $P R_{R M X}$ & $(\mathrm{kN})-$ Métodos de Interpretação & \multicolumn{2}{c}{$\mathrm{PR}_{\mathrm{RMX}} / \mathrm{RMX}$} \\
\cline { 3 - 9 } N & $\begin{array}{c}\text { cravação } \\
\text { (dias) }\end{array}$ & PCD & $\begin{array}{c}\text { NBR } \\
6122\end{array}$ & $\begin{array}{c}\text { Davisson } \\
(1973)\end{array}$ & $\begin{array}{c}\text { Van der } \\
\text { Veen } \\
(1953)\end{array}$ & Mínimo & Máximo \\
\hline E114 M02 & 4 & 3203 & na & 2983 & 3116 & 0,93 & 0,97 \\
\hline E018 M04 & 12 & 2670 & na & 2453 & 3668 & 0,92 & 1,37 \\
\hline E125 M09 & 6 & 2681 & na & 2681 & 2919 & 1,00 & 1,09 \\
\hline
\end{tabular}

O método da NBR 6122 (2010) não foi aplicado devido ao nível de deslocamento dos ensaios ter sido inferior à curva limite. Para os demais métodos, o intervalo da relação PRRMX/RMX obteve como mínimo e máximo os valores de 0,92 a 1,37 respectivamente, e ambos estão ligados à estaca E018M04. Essa tendência se deve ao fato de que os pontos ficaram lineares impossibilitando a aplicação de um método de extrapolação.

\subsubsection{Provas de carga estáticas}

As provas de carga estática (PCE) serviram de referência para a verificação dos métodos de previsão de capacidade de carga das estacas testes, e para avaliar o desempenho do sistema estaca-solo. As características das estacas, comprimentos, cargas aplicadas e deslocamentos das PCE são mostrados na Tabela 4.9. A Figura 4.12 apresenta as curvas resultantes das PCE e das PCD (com extrapolação).

No ensaio da estaca $n^{\circ}$. E018 M04, ocorreram problemas com as reações. Portanto o ensaio foi interrompido para a carga aplicada de $2591 \mathrm{kN}$ e deslocamento de $18,32 \mathrm{~mm}$. A curva da estaca $n^{\circ}$. E125 M09 apresentou os trechos de mobilização bem definidos, alcançando-se um deslocamento máximo estabilizado de $\rho=67,69 \mathrm{~mm}$. Neste ensaio realizado 58 dias após a cravação, foi possível caracterizar a carga de ruptura. 
Tabela 4.9 - Características das estacas ensaiadas e resultados da PCE.

\begin{tabular}{cccccccccc}
\hline $\begin{array}{c}\text { Estaca } \\
\mathrm{N}^{\circ} .\end{array}$ & $\begin{array}{c}\text { Diâmetro } \\
(\mathrm{cm})\end{array}$ & $\begin{array}{c}\text { Comp. } \\
\text { Cravado } \\
(\mathrm{m})\end{array}$ & $\begin{array}{c}\mathrm{S}_{10 \text { golpes }} \\
(\mathrm{mm})\end{array}$ & $\begin{array}{c}\mathrm{K} \\
(\mathrm{mm})\end{array}$ & Setup $($ dias $)$ & $\begin{array}{c}\mathrm{Q}_{\text {max }} \\
(\mathrm{kN})\end{array}$ & $\begin{array}{c}\rho_{\operatorname{máx}} \\
(\mathrm{mm})\end{array}$ & $\begin{array}{c}\rho_{\text {res. }} \\
(\mathrm{mm})\end{array}$ \\
\hline E114M02 & 70 & 12,20 & 20 & 15 & 70 & 3117 & 67,69 & 56,28 \\
\hline E018M04 & 70 & 13,20 & 13 & 17 & 71 & 2591 & 18,32 & na \\
\hline E125M09 & 70 & 14,90 & 23 & 15 & 59 & 3760 & 76,95 & 61,63 \\
\hline E113M15 & 70 & 12,70 & 14 & 15 & 56 & 3406 & 28,16 & 15,69 \\
\hline
\end{tabular}
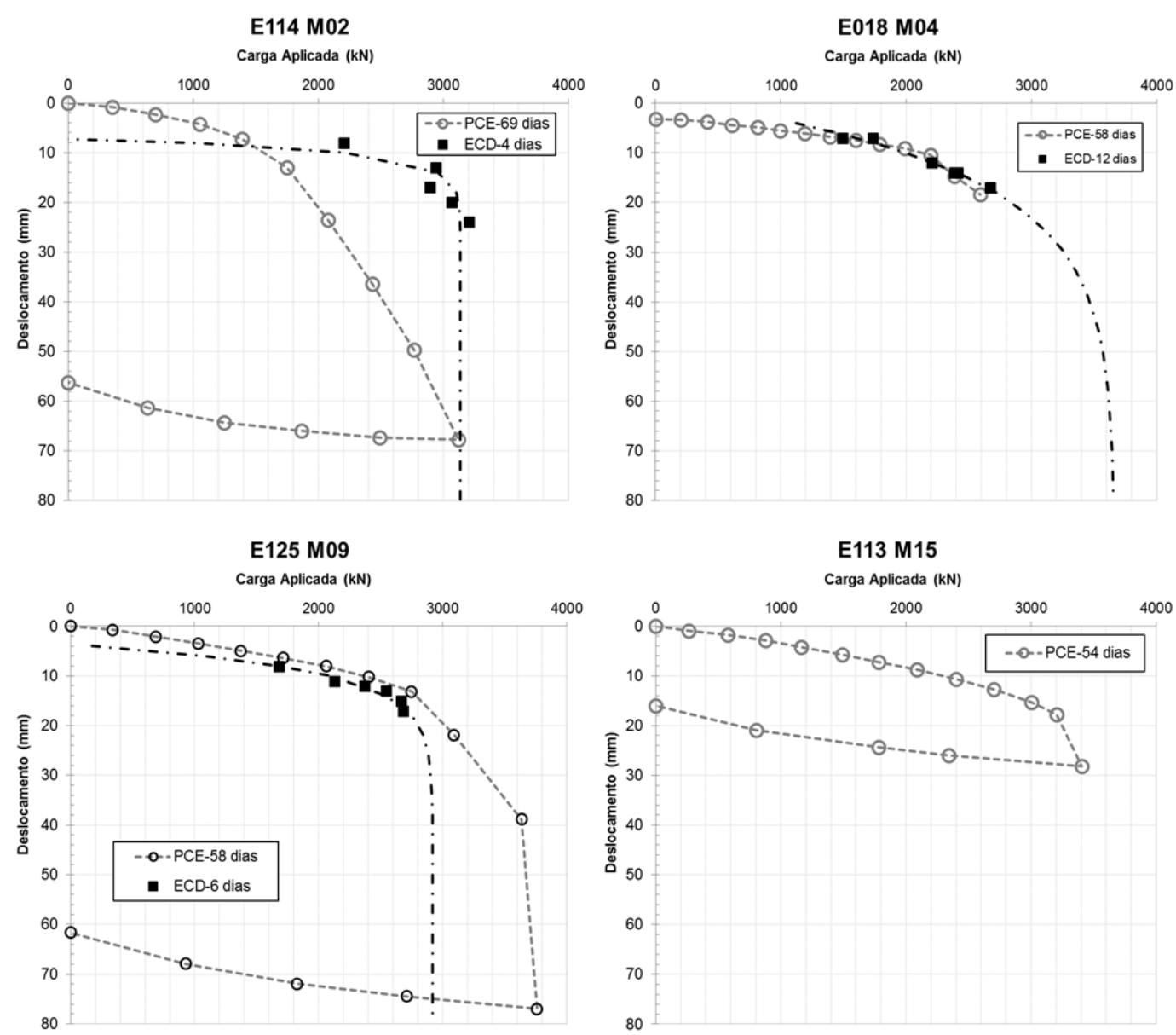

Figura 4.12 - Curvas carga $\mathrm{x}$ deslocamento das provas de carga.

Para as estacas $n^{\circ}$ E114M02 e E135M09 os ensaios conseguiram avançar até deslocamentos da ordem de 70,0 mm, caracterizando-se uma tendência de carga de ruptura do sistema. 
Para o caso da estaca $\mathrm{n}^{\circ}$. E113M15, a maior parte da curva está no trecho linear, e o deslocamento máximo foi da ordem de 25,0 mm. Esse comportamento é explicado pelo ensaio ter sido realizado em uma estaca na região em que a camada de areia apresentava a maior resistência à penetração $N_{S P T}$ (igual a 30 golpes $/ 30 \mathrm{~cm}$ finais).

\subsubsection{Interpretação da carga de ruptura}

A partir das curvas das PCE, foram aplicados métodos de interpretação para definição da carga de ruptura. Nessa análise foram utilizados os critérios de interpretação de Van der Veen (1953), com a expressão modificada por Aoki (1979), Mazurkiewicz (1972), Décourt (1996), Chin (1970), Davisson (1973), Massad (1992) e a NBR 6122 (2010).

\subsubsection{Método de rigidez infinita (Décourt, 1996)}

O método da rigidez infinita além de permitir conhecer a carga de ruptura (ou tendência) tem a vantagem de estimar a faixa de variação do domínio da resistência por atrito lateral a partir dos dados da instrumentação de topo da estaca.

A partir da formulação matemática do método, foi feita para cada prova de carga, a curva de rigidez por carga aplicada (Figura 4.13), com a interpretação dos domínios da resistência por atrito lateral e de ponta.

Como algumas considerações do método, foi adotado como critério de ruptura convencional a carga equivalente a um deslocamento maior ou igual a $10 \%$ do diâmetro da estaca, que resultou num deslocamento limite de $7 \mathrm{~cm}$.

Para a estaca $\mathrm{n}^{\circ}$. E114 M02, a carga de ruptura convencionada $\left(Q_{u}\right)_{0}$ foi de 3151 $\mathrm{kN}$, adotando-se como ponto de regressão $\left(Q_{\text {reg }}\right)$ de $1049 \mathrm{kN}$ para um deslocamento de 23,54 mm. Nessas condições, o domínio do atrito lateral tem como limite inferior $\left(Q_{s l}\right)_{\text {e superior }}$ $\left(Q_{\text {su }}\right)$ os valores de $1536 \mathrm{kN}$ e $2393 \mathrm{kN}$ respectivamente. 

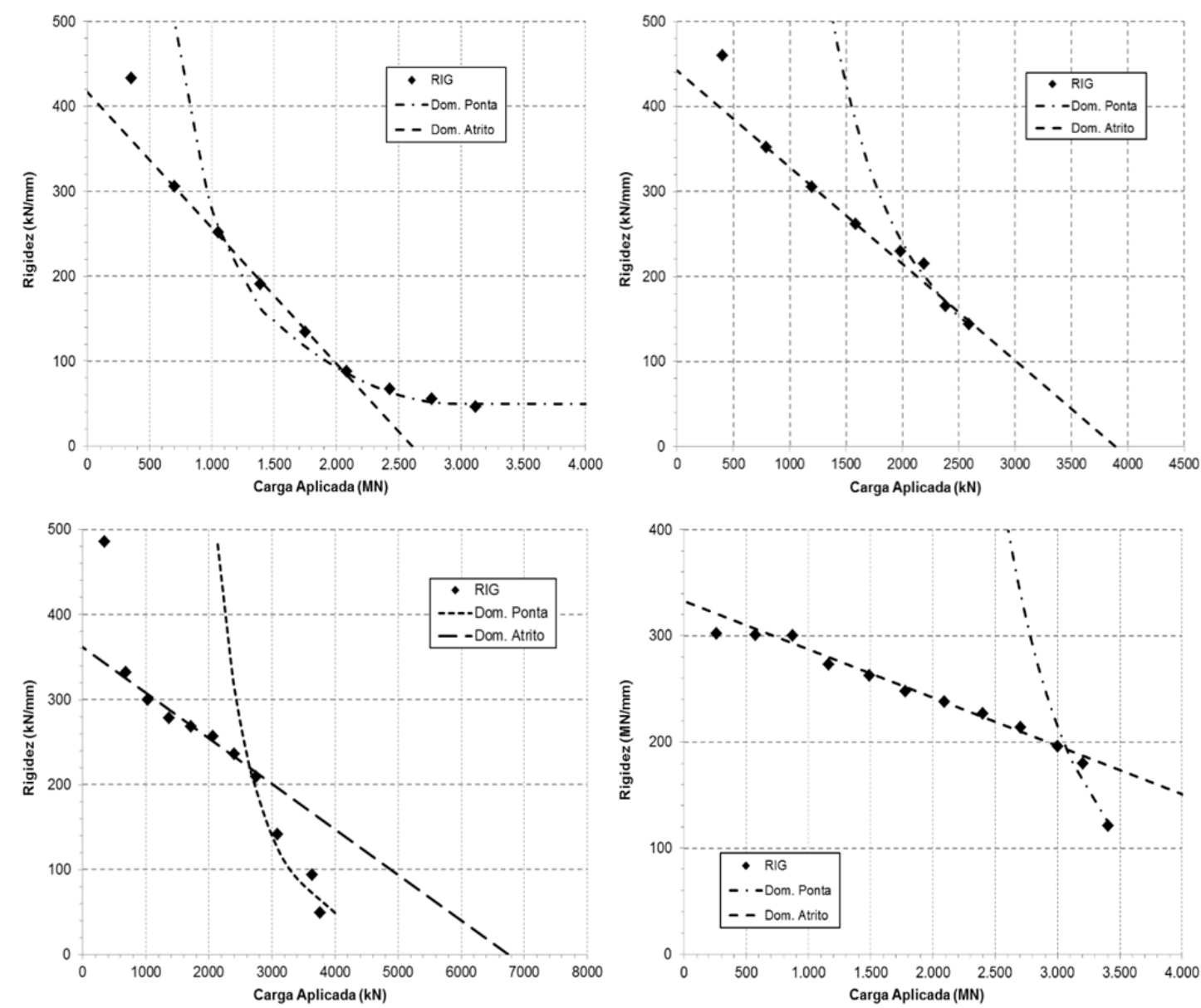

Figura 4.13 - Curvas de aplicação do método da rigidez para as estacas nº. E114 M02, E018 M04, E125 M09 e E113 M15 - PCE.

No caso da estaca $n^{\circ}$. E018 M04, a carga de ruptura convencionada é de $4104 \mathrm{kN}$, para o ponto de regressão igual a $1984 \mathrm{kN}$, com deslocamento de 8,64 mm. Como resultado, o domínio de atrito lateral teve como limite inferior e superior os valores de $1686 \mathrm{kN}$ a $3452 \mathrm{kN}$ respectivamente.

Nesse ensaio não foi possível uma interpretação da carga de ruptura confiável, devido ao ensaio ter sido paralisado prematuramente por uma deficiência do sistema de reação, dessa maneira o a curva carga-recalque continua no trecho elástico o que não permite ser conclusivo quanto a faixa de variação do atrito lateral.

Para a estaca $n^{\circ}$. E125 M09 foi possível caracterizar a ruptura durante a execução do ensaio para grandes deslocamentos $(\rho=76,95 \mathrm{~mm})$. Como ruptura convencional obteve-se 
o valor de $3889 \mathrm{kN}$ para o ponto de regressão $\left(Q_{\text {reg }}\right)$ adotado de $2404 \mathrm{kN}$, com deslocamento de $10,18 \mathrm{~mm}$.

Pelos gráficos de rigidez, a faixa de domínio da resistência por atrito lateral estaria entre $2151 \mathrm{kN}$ e $5322 \mathrm{kN}$. Diferentemente dos dois casos em que a curva da PCE não se aproximou da ruptura, nessa situação houve um alinhamento na vertical do $\left(Q_{r e g}\right)_{\mathrm{e}}\left(Q_{u}\right)_{0}$, ocasionado uma convergência nas faixas de domínio atrito lateral.

A estaca $n^{\circ}$. E113 M15, foi cravada na região com melhor resistência da camada de areia e com maior homogeneidade. Pelo gráfico de rigidez desta estaca, foi adotada como carga de ruptura convencional $4073 \mathrm{kN}$, e ponto de regressão $\left(Q_{\text {reg }}\right)_{\text {de }} 3001 \mathrm{kN}$, para um deslocamento máximo do ensaio de $15,32 \mathrm{~mm}$. A faixa de domínio inferior e superior da resistência por atrito lateral está entre $2701 \mathrm{kN}$ e $5570 \mathrm{kN}$.

\subsubsection{Método de Massad (1992)}

Com base no modelo matemático apresentado no item 2.5.3, procedeu-se com as análises das provas de carga com o objetivo de avaliar a influência das cargas residuais na ponta da estaca, daria indícios do efeito de embuchamento, e obter a parcela de atrito lateral atuante ao longo da profundidade.

Tabela 4.10 - Características geométricas das estacas analisadas.

\begin{tabular}{|c|c|c|c|c|c|c|c|c|c|c|}
\hline \multirow[b]{2}{*}{$\begin{array}{c}\mathrm{N}^{\circ} . \\
\text { Estaca }\end{array}$} & \multirow[b]{2}{*}{$\begin{array}{c}\mathrm{f}_{\mathrm{ck}} \\
(\mathrm{MPa})\end{array}$} & \multirow[b]{2}{*}{$\begin{array}{c}\mathrm{E}_{\mathrm{CS}} \\
(\mathrm{GPa})\end{array}$} & \multicolumn{2}{|c|}{ Geometria } & \multirow[b]{2}{*}{$\begin{array}{l}\text { Área } \\
\text { (m2) }\end{array}$} & \multicolumn{3}{|c|}{ Comprimento } & \multicolumn{2}{|c|}{ Rigidez } \\
\hline & & & $\begin{array}{c}\text { Diâmetro } \\
\text { Externo } \\
(\mathrm{m})\end{array}$ & $\begin{array}{c}\text { Espessura } \\
\text { Parede } \\
\text { (m) }\end{array}$ & & $\begin{array}{l}\mathrm{h} \\
(\mathrm{m})\end{array}$ & $\begin{array}{l}\mathrm{h} 1 \\
(\mathrm{~m})\end{array}$ & $\begin{array}{c}\mathrm{h} 1 / \mathrm{h} \\
{[]}\end{array}$ & $\begin{array}{c}\mathrm{Kr} \\
(\mathrm{kN} / \mathrm{mm})\end{array}$ & $\begin{array}{c}\mathrm{K}_{\mathrm{r} 1} \\
(\mathrm{kN} / \mathrm{mm})\end{array}$ \\
\hline E114M02 & 35 & 28,2 & 0,70 & 0,11 & 0,181 & 12,2 & 6,0 & 0,49 & 417,7 & 849,3 \\
\hline E125M09 & 35 & 28,2 & 0,70 & 0,11 & 0,181 & 14,8 & 6,6 & 0,45 & 344,3 & 772,1 \\
\hline E113M15 & 35 & 28,2 & 0,70 & 0,11 & 0,181 & 12,7 & 8,5 & 0,67 & 401,2 & 599,5 \\
\hline E018M04 & 35 & 28,2 & 0,70 & 0,11 & 0,181 & 13,2 & 6,8 & 0,52 & 386,1 & 749,6 \\
\hline
\end{tabular}

A Tabela 4.10 apresenta as características geométricas das provas de carga 
analisadas, e com base nesses parâmetros e através do método da parábola aplicando ao trecho de carregamento determinou-se nesse trecho a parcela de mobilização do atrito lateral (Tabela 4.11).

Onde $f_{c k}$ é a resistência característica do concreto, $E_{C S}$ é o modulo de elasticidade secante, $h$ é o comprimento cravado da estaca, $h 1$ é o comprimento cravado na primeira camada de solo, que no caso corresponde ao deposito de argila mole, $\mathrm{Kr}$ é a rigidez de todo o sistema estacasolo e Krl a rigidez referente à camada de argila mole.

Tabela 4.11 - Resultados do método da parábola.

\begin{tabular}{ccccccc|cc}
\hline \multicolumn{1}{c}{} & \multicolumn{7}{c}{ Mobilização do Atrito } \\
N. Estaca & $\mathrm{c} 2$ & $\mathrm{c} 1$ & $\begin{array}{c}\mu . A l r \\
(\mathrm{kN})\end{array}$ & $\begin{array}{c}\mu . A l r 1 \\
(\mathrm{kN})\end{array}$ & $\begin{array}{c}\mu . \mathrm{y} 1 \\
(\mathrm{~mm})\end{array}$ & $\mathrm{k}$ & $\mathrm{k} 1$ \\
\hline E114M02 & $1,84 \mathrm{E}-06$ & 0,50 & 650 & 320 & 1,00 & 1,56 & 0,38 \\
\hline E125M09 & $1,47 \mathrm{E}-06$ & 1,92 & 990 & 442 & 3,84 & 0,75 & 0,15 \\
\hline E113M15 & $1,51 \mathrm{E}-06$ & 2,29 & 826 & 553 & 4,58 & 0,45 & 0,20 \\
\hline E018M04 & $1,22 \mathrm{E}-06$ & 4,34 & 1060 & 546 & 8,68 & 0,32 & 0,08 \\
\hline
\end{tabular}

Onde $c 1$ e $c 2$ são respectivamente o coeficiente angular e o ponto de $\mathrm{y}=0$ de ajuste na curva de carga aplicada ao quadrado pelo recalque, $\mu$. Alr é o atrito lateral na ruptura de toda a estaca considerando a carga residual na ponta, $\mu$. Alr 1 é o atrito lateral total da primeira camada de solo (argila mole) atuante considerando as tensões residuais, $\mu \cdot y 1$ deslocamento necessário para se atingir o esgotamento do atrito lateral da estaca considerando as tensões residuais, $k$ e $k 1$ são os coeficientes de rigidez relativa estaca-solo considerando toda a estaca e a primeira camada respectivamente.

Para a obtenção do atrito lateral total na ruptura ao longo e toda a estaca ( $\mu \cdot A l r$ ) aplicou-se o método das duas retas nas curvas das provas de carga - Tabela 4.12.

A partir desses parâmetros aplicou-se no trecho de descarregamento o modelo matemático afim de obter o fator de majoração do atrito lateral - Tabela 4.13. 
Tabela 4.12 - Aplicação do método das duas retas.

\begin{tabular}{|c|c|c|c|c|c|c|}
\hline \multirow[b]{2}{*}{$\begin{array}{l}\mathrm{N}^{\circ} . \\
\text { Estaca }\end{array}$} & \multicolumn{6}{|c|}{ Método das Duas Retas } \\
\hline & $\mathrm{m}=2 \mathrm{~K}_{\mathrm{r}}$ & $\mathrm{a}$ & $\mathrm{b}$ & $\begin{array}{c}\mathrm{y}_{0} \\
(\mathrm{~mm})\end{array}$ & $\begin{array}{c}\mathrm{P}_{0}=\mu . \mathrm{A}_{\mathrm{lr}} \\
(\mathrm{kN})\end{array}$ & $\begin{array}{r}\mu . \mathrm{A}_{\mathrm{lr} 2} \\
(\mathrm{kN})\end{array}$ \\
\hline E114M02 & 835 & 0,0457 & $-75,4$ & 2,03 & 1694 & 1375 \\
\hline E125M09 & 689 & 0,3074 & $-1078,9$ & 5,12 & 3526 & 3085 \\
\hline E113M15 & 802 & 0,0510 & $-145,7$ & 3,65 & 2926 & 2373 \\
\hline E018M04 & 772 & 0,0197 & $-32,6$ & 2,29 & 1770 & 1224 \\
\hline
\end{tabular}

Onde $a$ e $b$ são os coeficientes angulares e o intercepto do ajuste de uma reta no trecho final da curva de carga aplicada por deslocamento, $y_{0}$ é o recalque medido no topo da estaca, $P_{0}$ é a carga aplicada no topo da estaca e $\mu$. Alr 2 é o atrito lateral na ruptura correspondente ao trecho da estaca embutida na camada de solo mais resistente - ponta em areia.

Tabela 4.13 - Obtenção do fator de majoração do atrito lateral $(\mu)$.

\begin{tabular}{ccccccccc}
\hline & \multicolumn{7}{c}{ Descarregamento } \\
\cline { 2 - 9 } $\mathrm{N}^{\circ}$. & $\mathrm{j}_{1}$ & $\mathrm{j}_{2}$ & $2 . \mathrm{A}_{\mathrm{lr} 1}$ & $\mathrm{~A}_{\mathrm{lr} 1}$ & $\mu . \mathrm{A}_{\mathrm{lr} 1}$ & $\mu$ & $\mu . \mathrm{y}_{1}$ & $\mathrm{y}_{1}$ \\
& $(\mathrm{kN})$ & $(\mathrm{kN} / \mathrm{mm})$ & $(\mathrm{kN})$ & $(\mathrm{kN})$ & $(\mathrm{kN})$ & & $(\mathrm{mm})$ & $(\mathrm{mm})$ \\
\hline E114M02 & 0,105 & 0,00000101 & 586 & 293 & 320 & 1,09 & 1,00 & 0,91 \\
\hline E125M09 & 1,455 & 0,00000095 & 685 & 342 & 442 & 1,29 & 3,84 & 2,98 \\
\hline E113M15 & 1,257 & 0,00000089 & 937 & 468 & 553 & 1,18 & 4,58 & 3,88 \\
\hline E018M04 & 1,042 & 0,00000086 & 778 & 389 & 546 & 1,40 & 8,68 & 6,18 \\
\hline
\end{tabular}

Onde $j 1$ e $j 2$ são o coeficiente angular e a intersecção respectivamente na curva $\left(P_{0}-P_{0, \text { máx }}\right)^{2}$ pelo recalque do ajuste linear, Alr 1 é o atrito lateral na ruptura correspondente ao trecho de estaca cravada na camada de argila mole, $\mu$ é o fator de majoração do atrito lateral e $y 1$ é o deslocamento necessário para se atingir o esgotamento do atrito lateral na estaca.

Ghilardi (2005) analisou o efeito de embuchamento de estacas metálicas na região da Baixada Santista analisando a partir do modelo de Massad (1992) que leva em 
consideração as Leis de Camberfort Modificadas com a introdução do fator $\mu$, que quantifica a ação de cargas residuais na ponta da estaca, e que permitiu no estudo em questão avaliar o comportamento de estaca com ponta aberta embuchada e fechada.

O fator $\mu$ varia de 1,0 - condição sem cargas residuais ou ponta aberta a 2,0 que é a situação em que a carga residual é igual a resistência de ponta (relacionar com a ponta fechada). Aplicando o mesmo conceito nas estacas testes foram encontrados resultados do fator $\mu$ de 1,09 (E11M02), 1,40 (E018M04), 1,29 (E125M09) e 1,18 (E113M15), demonstrando-se uma tendência ao embuchamento.

No trabalho de Ghilardi (2005) para o caso de estacas metálicas com diâmetro de $36 \mathrm{~cm}$, para o grupo de pontas fechada e comprimento cravado da ordem de 45,0 metros o fator $\mu$ variou de 1,4 a 1,7, para o grupo das estacas embuchadas $\mu$ variou de 1,4 a 2,0 e para as não-embuchadas $\mu$ é igual a 1,0 .

Como resultado do método, a Tabela 4.14 apresenta um resumo das parcelas de atrito lateral e ponta considerando para a carga de ruptura igual ao valor do método de Van der Veen (1953) modificado por Aoki (1979) - item 4.1.6.4.

Tabela 4.14 - Resultados das parcelas de atrito e ponta.

\begin{tabular}{cccccc}
\hline $\begin{array}{c}\mathrm{N}^{\circ} . \\
\text { Estaca }\end{array}$ & $\begin{array}{c}\mathrm{f}_{\text {máx,Alr1 }} \\
\left(\mathrm{kN} / \mathrm{m}^{2}\right)\end{array}$ & $\begin{array}{c}\mathrm{f}_{\text {máx,Alr2 }} \\
\left(\mathrm{kN} / \mathrm{m}^{2}\right)\end{array}$ & $\begin{array}{c}\mathrm{A}_{\mathrm{lr}} \\
(\mathrm{kN})\end{array}$ & $\begin{array}{c}\mathrm{RP} \\
(\mathrm{kN})\end{array}$ & $\begin{array}{c}\mathrm{Q}_{\text {ult. }} \\
(\mathrm{kN})\end{array}$ \\
\hline E114M02 & 22,2 & 92,3 & 1.551 & 1.958 & 3.509 \\
\hline E125M09 & 23,6 & 132,6 & 2.733 & 1.032 & 3.765 \\
\hline E113M15 & 25,1 & 217,7 & 2.479 & 1.018 & 3.497 \\
\hline E018M04 & 26,0 & 62,0 & 1.261 & 1.449 & 2.710 \\
\hline
\end{tabular}

Onde $f_{\text {máxAlr1 }}$ e $f_{\text {máxAlr2 }}$ representam o fator de atrito unitário para as camadas de solo menos (argila mole) e mais (areia compacta) resistente respectivamente, $Q_{u l t}$ é a carga de ruptura extrapolada pelo método de Van der Veen e $R P$ é a resistência de ponta resultante.

\subsubsection{Método da NBR 6122 (2010) e Davisson (1972)}

Os métodos de Davisson (1972) e da NBR 6122 (2010) foram aplicados nas 
curvas carga $\mathrm{x}$ deslocamento, das estacas ensaiadas por prova de carga estática, para a determinação da carga de ruptura (Figura4.14). A Tabela 4.15 apresenta a síntese destes resultados.

Tabela 4.15 - Valores das cargas de ruptura e deslocamentos na ruptura.

\begin{tabular}{ccccc}
\hline Critério & \multicolumn{2}{c}{ NBR 6122 } & \multicolumn{2}{c}{ Davisson (1972) } \\
\hline$N^{\circ}$. Estaca & $\begin{array}{c}\mathrm{P}_{\mathrm{C}, \mathrm{NBR}} \\
(\mathrm{kN})\end{array}$ & $\begin{array}{c}\mathrm{D}_{\mathrm{C}, \mathrm{NBR}} \\
(\mathrm{mm})\end{array}$ & $\begin{array}{c}\mathrm{P}_{\mathrm{C}, \mathrm{DAV}} \\
(\mathrm{kN})\end{array}$ & $\begin{array}{c}\mathrm{D}_{\mathrm{C}, \mathrm{DAV}} \\
(\mathrm{mm})\end{array}$ \\
\hline E114 M02 & 2196 & 27,72 & 1751 & 13,14 \\
\hline E018 M04 & $\mathrm{na}^{1}$ & $\mathrm{na}$ & 2412 & 14,94 \\
\hline E125 M09 & 3408 & 31,85 & 2893 & 16,86 \\
\hline E113 M15 & $\mathrm{na}^{1}$ & $\mathrm{na}$ & 3054 & 16,04 \\
\hline
\end{tabular}

Notas:

${ }^{1}$ - a curva carga aplicada por deslocamento não interceptou a reta limite do método.
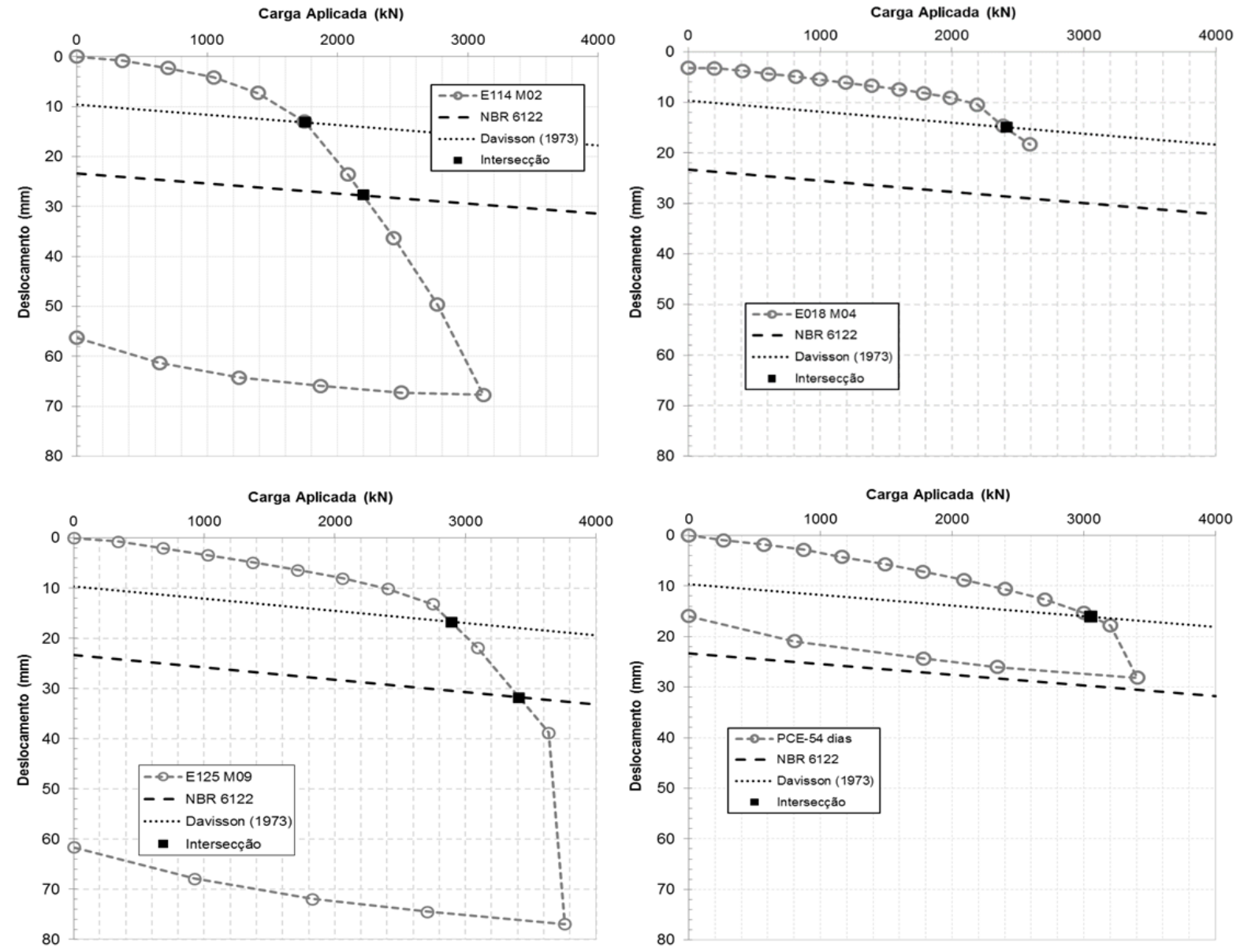
Figura4.14 - Aplicação dos métodos da NBR 6122 (2010) e Davisson (1972) para as estacas testes.

No caso das estacas E018M04 e E113M15, a curva obtida no ensaio não alcançou os limites da reta do método da NBR 6122 (2010).Com relação aos resultados, pelos dois métodos os resultados foram variados. As cargas de ruptura convencionadas por Davisson (1972) variaram de $1751 \mathrm{kN}($ E114M02) a $3054 \mathrm{kN}$ (E113M15).

Quanto aos deslocamentos na ruptura, o limite imposto pela NBR 6122 (2010) resultou num valor médio de 29,8 mm enquanto que por Davisson (1972) esse valor foi mais conservador, e da ordem de 15,2 $\mathrm{mm}$.

\subsubsection{Método de Van Der Veen (1953) modificado por Aoki (1979)}

Para a obtenção das cargas de ruptura das PCEs, foi também aplicado o método de Van der Veen (1953) com a modificação da equação proposta por Aoki (1979). A Figura 4.15 apresenta as curvas extrapoladas por este método. A faixa de variação da carga de ruptura foi de $2821 \mathrm{kN}$ a $3709 \mathrm{kN}$, sendo que as estacas E125 M09 e E113 M15 tiveram a mesma tendência em torno de $3730 \mathrm{kN}$. Na Tabela 4.16é apresentado os parâmetros utilizados no ajuste da curva (A e B), a carga de ruptura obtida ( $Q_{u l t}$ ), a máxima carga aplicada no ensaio ( $Q_{\text {máx }}$ ), o coeficiente de ajuste R2 e a classificação proposta por Cintra et al. (2013) para a extrapolação do método de Van der Veen.

Entretanto, à estaca E114M02 apresentou um comportamento distinto das outras estacas, em que os acréscimos de deslocamentos são proporcionais aos acréscimos de carga aplicada, e não se caracteriza claramente a carga de ruptura, que nesse caso $Q_{u l t}$ é igual a 3505 $\mathrm{kN}$.

Cintra et al. (2013) propõe um sistema de classificação da qualidade da extrapolação pelo método de Van der Veen modificado por Aoki entre a carga de ruptura obtida e a máxima aplicada no ensaio, e para relação $\left(\frac{Q_{u l t}}{Q_{\text {máx }}}-1\right) \times 100 \leq 25 \%$ e Qult $<R E$, atendendo a essa condições os resultados são confiáveis. Para todos os casos a extrapolação é 
confiável, conforme analise apresentada na Tabela 4.16.

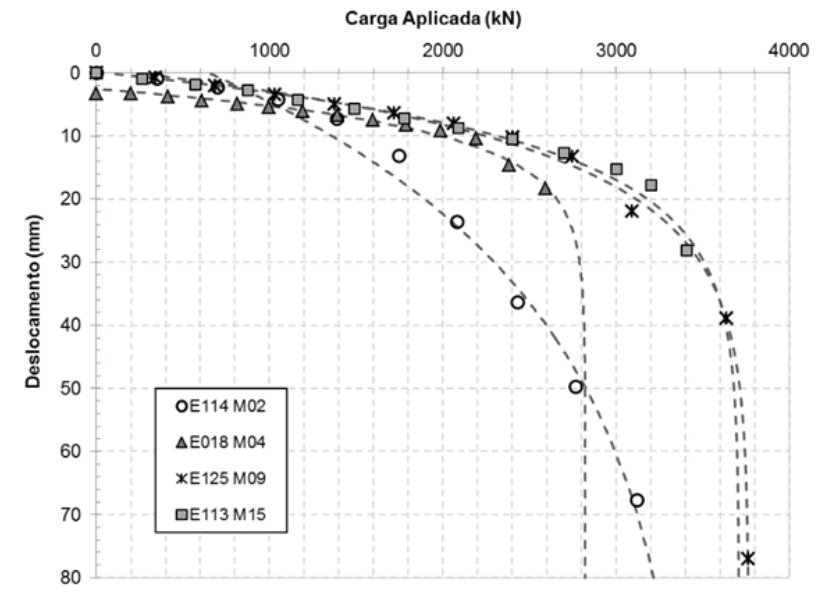

Figura 4.15 - Aplicação do método de Van der Veen (1953) modificado por Aoki (1979) para as PC (E114 M02, E018 M04, E125 M09 e E113 M15).

Tabela 4.16 - Resultados obtidos pelo método de Van der Veen modificado por Aoki com as correspondentes cargas de ruptura.

\begin{tabular}{|c|c|c|c|c|c|c|c|}
\hline \multirow[b]{2}{*}{$\mathrm{N}^{\circ}$. Estaca } & \multicolumn{2}{|c|}{ Coef. Método } & \multirow[b]{2}{*}{$\begin{array}{l}\text { Qult. } \\
(\mathrm{kN})\end{array}$} & \multirow[b]{2}{*}{$\begin{array}{l}\mathrm{Q}_{\text {máx }} \\
(\mathrm{kN})\end{array}$} & \multirow[b]{2}{*}{$\mathrm{R}^{2}$} & \multicolumn{2}{|c|}{ Cintra et al. (2013) } \\
\hline & A & $\mathrm{B}$ & & & & $\left(\frac{Q_{u l t}}{Q_{\text {máx }}}-1\right) \times 100$ & Classificação \\
\hline E114 M02 & 0,029 & 0,204 & 3505 & 3117 & 0,986 & $12,4 \%$ & Confiável \\
\hline E018 M04 & 0,200 & 0,047 & 2710 & 2591 & 0,990 & $4,6 \%$ & Confiável \\
\hline E125 M09 & 0,083 & 0,076 & 3766 & 3760 & 0,998 & $0,2 \%$ & Confiável \\
\hline E113 M15 & 0,136 & $-0,160$ & 3497 & 3497 & 0,990 & $2,7 \%$ & Confiável \\
\hline
\end{tabular}

\subsubsection{Método de Mazurkiewicz (1972)}

O método proposto por Mazurkiewicz (1972) foi possível apenas de ser aplicado nas estacas n. E114M02 e E125M09 (Figura 4.16), sendo a previsão das cargas de ruptura de $4100 \mathrm{kN}$ e $3900 \mathrm{kN}$ respectivamente. As demais estacas não apresentaram mais de três pontos no trecho plástico que permitisse obter um resultado confiável, por essa razão foi desprezado a análise. 

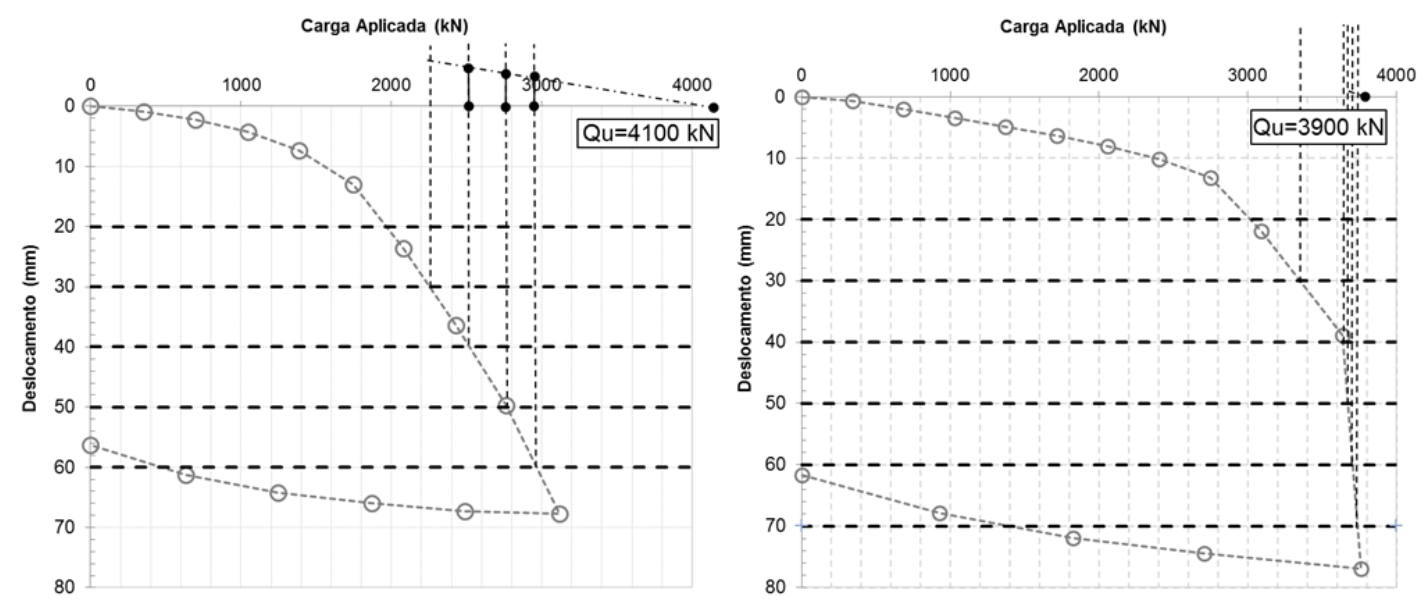

Figura 4.16 - Aplicação do método de Mazurkiewicz (1972) as PC das estacas nº E114 M02 e E125 M09.

\subsubsection{Método de Chin (1970)}

Para os resultados das PCE, foi aplicado o método de Chin (1970) para cada estaca (Figura 4.17). São apresentadas as curvas de $\rho / Q$ pelo deslocamento do topo, com as equações de ajuste linear para a calibração dos parâmetros $C 1$ e $C 2$, determinando-se assim a carga de ruptura para cada caso.

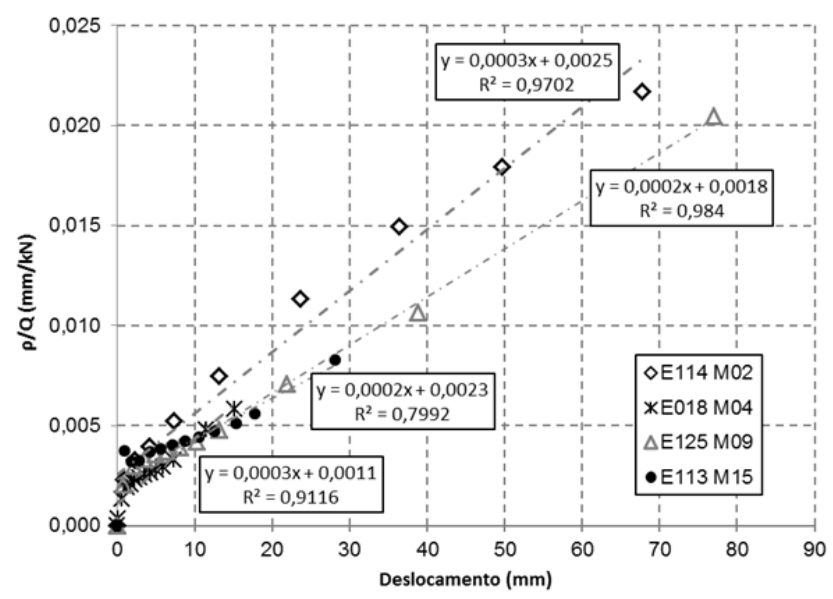

Figura 4.17: Aplicação do método de Chin (1970) para as PC.

Nesse caso, existe uma tendência de proximidades entre os ajustes de reta do método de Chin para um valor da ordem de $4168 \mathrm{kN}$ a $4931 \mathrm{kN}$. No caso das estacas E114 M02 e E018 M04 foram obtidos valores menores devido aos baixos deslocamentos 
registrados nos ensaios, o que condicionou a um ajuste de reta pelos trechos iniciais.

Tabela 4.17 - Resultados da carga de ruptura obtidos pelo método de Chin (1970).

\begin{tabular}{cccc}
\hline N . Estaca & $\mathrm{C} 1$ & $\mathrm{C} 2$ & $\begin{array}{c}\mathrm{P}_{\text {ult. }} \\
(\mathrm{kN})\end{array}$ \\
\hline E114 M02 & 0,00031 & 0,0025 & 3259 \\
\hline E018 M04 & 0,00033 & 0,0011 & 3032 \\
\hline E125 M09 & 0,00024 & 0,0018 & 4168 \\
\hline E113 M15 & 0,00020 & 0,0023 & 4931 \\
\hline
\end{tabular}

\subsubsection{Interpretação da carga de ruptura}

No contexto das interpretações da carga de ruptura das estacas em todos os casos a ruptura está sendo comandada pelo solo da ponta da estaca. A variabilidade nos resultados pode ser explicado pelo fato de que o material na ponta apresentava uma série de faixas intercalando materiais de maior e menor resistência, oriundos da gênese geológica desse solo flúvio-lagunar.

Para os diferentes métodos de interpretação da carga de ruptura, a Tabela 4.18 mostra os valores obtidos, e para os dados disponíveis determinou-se o valor médio.

O método de Décourt, Van der Veen e Chin demonstram uma tendência de convergência dos resultados, por isso foram usados no cálculo do valor médio. No caso dos métodos de Davisson e da NBR 6122, os valores foram subestimados. A discussão desses resultados será explorada na comparação com os dados da previsão e PCDs no item 4.1.8.

A estaca $n^{\circ}$. E018M04 foi a que apresentou a maior dispersão entre os métodos de extrapolação, fato este ligado a questão do ensaio ter paralisado prematuramente, o que resultou numa carga de ruptura subestimada (na faixa de $2412 \mathrm{kN}$ ) em relação aos demais casos.

Dos resultados obtidos na PCE, a Tabela 4.19 apresenta uma comparação da carga máxima aplicada no ensaio com a carga de ruptura extrapolada. Esta comparação mostra que as cargas de ruptura extrapoladas não ultrapassam 19\% da carga máxima no ensaio. 
Tabela 4.18 - Resumo das interpretações da carga de ruptura das PC.

\begin{tabular}{ccccccccccc}
\hline & \multicolumn{7}{c}{ Cargas de Ruptura (kN) - Métodos de Interpretação } & \\
\cline { 2 - 9 } N . Estaca & $\begin{array}{c}\text { Décourt } \\
(1996)\end{array}$ & $\begin{array}{c}\text { NBR } \\
6122\end{array}$ & $\begin{array}{c}\text { Davisso } \\
\mathrm{n}(1973)\end{array}$ & $\begin{array}{c}\text { Van der } \\
\text { Veen } \\
(1953)^{1}\end{array}$ & $\begin{array}{c}\text { Mazurkiewic } \\
\mathrm{z}(1972)\end{array}$ & $\begin{array}{c}\text { Chin } \\
(1970)\end{array}$ & Media & $\begin{array}{c}\text { Desvio } \\
\text { Padrão }\end{array}$ & $\begin{array}{c}\text { CV } \\
(\%)\end{array}$ \\
\hline E114 M02 & 3151 & 2196 & 1751 & 3505 & 4100 & 3259 & 2994 & 867 & 29,0 \\
\hline E018 M04 & 4104 & na $^{2}$ & 2412 & 2821 & na $^{3}$ & 3032 & 3092 & 722 & 23,3 \\
\hline E125 M09 & 3889 & 3408 & 2893 & 3765 & 3900 & 4168 & 3671 & 454 & 12,4 \\
\hline E113 M15 & 4073 & na $^{2}$ & 3054 & 3709 & na $^{3}$ & 4931 & 3942 & 783 & 19,9 \\
\hline
\end{tabular}

Notas:

${ }^{1}$ - Método de Van der Veen (1953) modificado por Aoki (1979).

${ }^{2}$ - não foi possível aplicar o método devido a problemas no carregamento da PC - E018M04.

${ }^{3}$ - pela justificativa apresentada no item ${ }^{2}$ não possui um trecho bem definido o suficiente para aplicação do método.

Tabela 4.19 - Resultado da interpretação das cargas de rupturas das PC.

\begin{tabular}{cccccccccc}
\hline No. Estaca & $\begin{array}{c}\text { Comp. } \\
(\mathrm{m})\end{array}$ & $\begin{array}{c}\mathrm{S}_{10 \mathrm{gp}} \\
(\mathrm{mm})\end{array}$ & $\begin{array}{c}\mathrm{K} \\
(\mathrm{mm})\end{array}$ & $\begin{array}{c}\text { Setup } \\
(\text { dias })\end{array}$ & $\begin{array}{c}\mathrm{Q}_{\text {máx }} \\
(\mathrm{kN})\end{array}$ & $\begin{array}{c}\mathrm{Q}_{\text {ult. }}{ }^{1} \\
(\mathrm{kN})\end{array}$ & $\begin{array}{c}\mathrm{Q}_{\text {ult. }} \mathrm{Q}_{\text {máx }} \\
(\mathrm{mm})\end{array}$ & $\begin{array}{c}\rho_{\text {máx }} \\
(\mathrm{mm})\end{array}$ \\
\hline E114M02 & 12,20 & 20 & 15 & 70 & 3117 & 2994 & 0,96 & 67,69 & 56,28 \\
\hline E018M04 & 13,20 & 13 & 17 & 71 & 2591 & 3092 & 1,19 & 18,32 & $\mathrm{na}^{2}$ \\
\hline E125M09 & 14,90 & 23 & 15 & 59 & 3760 & 3671 & 0,97 & 76,95 & 61,63 \\
\hline E113M15 & 12,70 & 14 & 15 & 56 & 3406 & 3942 & 1,15 & 28,16 & 15,69 \\
\hline
\end{tabular}

Notas:

${ }^{1}$ - Qult . se refere ao parâmetro médio daTabela 4.18 .

${ }^{2}$ - o carregamento foi interrompido prematuramente.

\subsubsection{Comparação dos Resultados}

A partir das previsões de capacidade de carga para as estacas testes (Tabela 4.1), dos primeiros resultados de ensaios de carregamentos dinâmicos (Tabela 4.8), e das provas de 
carga estática (Tabela 4.18), nessa etapa da dissertação, pretendeu-se relacionar os demais resultados com o objetivo de uma melhor compreensão do comportamento das estacas, e correlacionar com as próximas etapas.

A análise foi feita individualmente para cada uma das quatro estacas teste.

\subsubsection{Estaca nº. E114M02}

Os resultados obtidos pelas provas de carga estática, dinâmica e registros de campo apresentaram-se convergentes. Numa primeira interpretação há uma pequena influência devido ao efeito set-up (aumento da resistência com o tempo devido à cicatrização) sobre a resistência mobilizada, levando-se em consideração que os ensaios ocorreram em diferentes idades.

Quanto aos valores previstos baseado na homogeneização das sondagens vizinhas a estaca teste obteve os resultados mais próximos dos valores medidos em relação à sondagem SP-02.

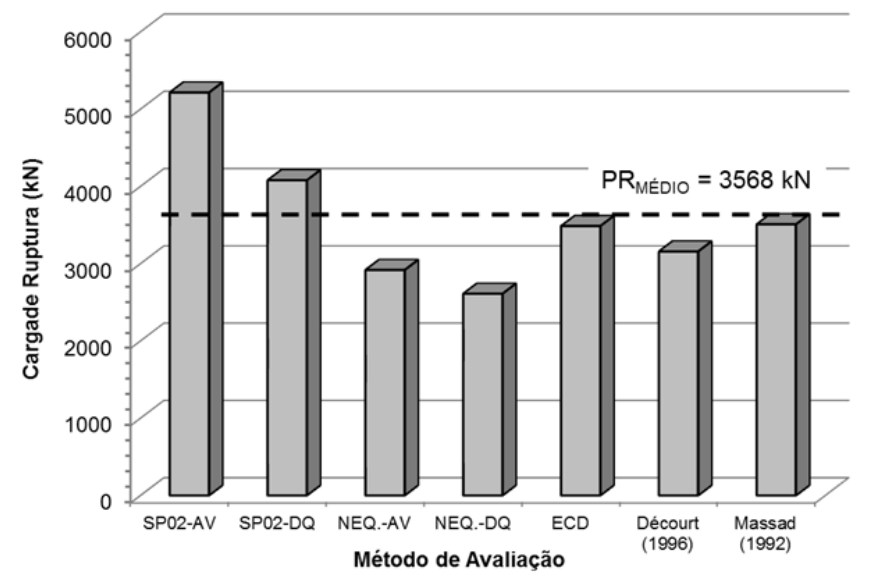

Figura 4.18 - Comparação de capacidade de carga em função das previsões ( $\left.N_{S P T} \mathrm{e} N_{E Q U I V}\right)$, dos resultados da PCE, PCD, registros de nega e repique- estaca $n^{\circ}$. E114M02.

Considerando a ponta das estacas aberta, a faixa de variação da relação dos valores previstos/medidos (Figura 4.18) foi de 0,75 a 1,50 para a carga de ruptura obtida na prova de carga dinâmica, e de 0,83 a 1,65 em relação à prova de carga estática. Para os diversos métodos de avaliação resultou numa carga média $\left(P R_{\text {MÉDIO }}\right)$ de 3568 kN. 

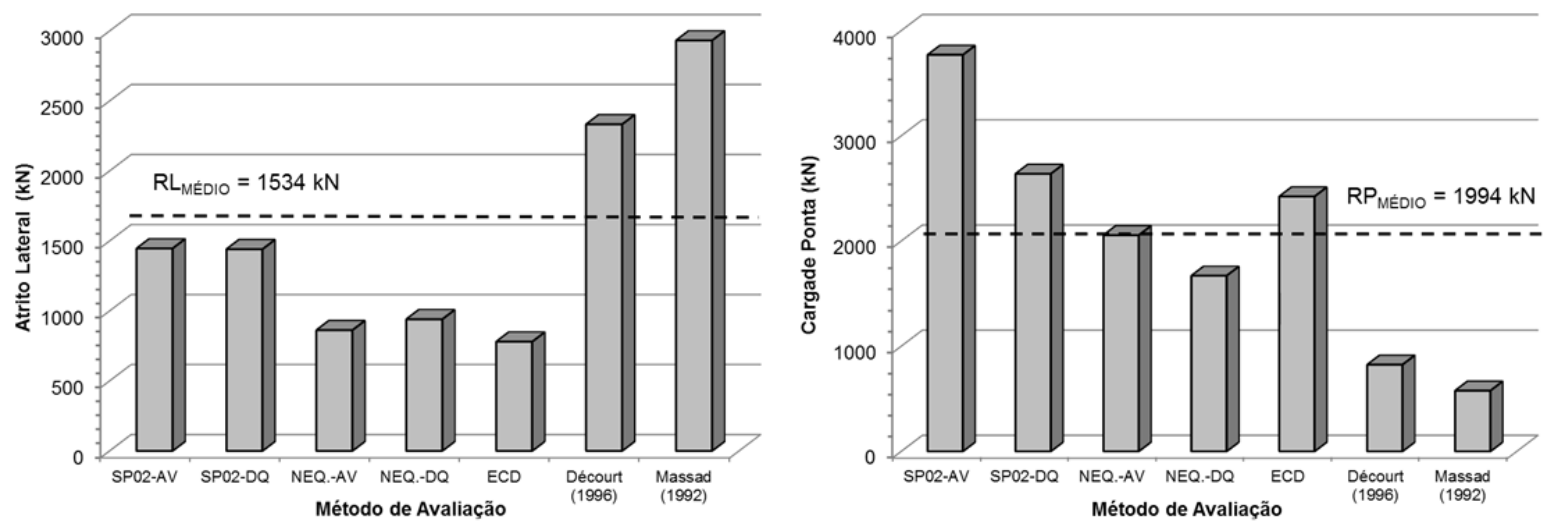

Figura4.19 - Comparação das parcelas de resistência lateral e ponta em função das previsões ( $N_{S P T}$ e $\left.N_{E Q U I V}\right)$, dos resultados da PCE, PCD, registros de nega e repique- estaca ${ }^{\circ}$. E114M02.

Pela comparação da parcela de resistência por atrito lateral (Figura4.19.a), a avaliação através da prova de carga dinâmica convergiu para os valores da previsão baseada nas sondagens vizinhas $\left(N_{E Q U I V}\right)$. Como um valor médio obteve-se $1534 \mathrm{kN}$ para todos os métodos de avaliação, enquanto que a interpretação da parcela lateral pelas provas de carga dinâmica superestimaram os demais métodos de avaliação, obtendo valores de $2333 \mathrm{kN}$ para o método de Décourt (1996) e 2932 kN (Massad, 1992).

Na parcela de resistência de ponta (Figura4.19.b) houve uma convergência entre o resultado da prova de carga dinâmica com as previsões baseadas no $N_{E Q U I V}$, tendo como valor médio ( $\left.R P_{M E ́ D I O}\right) 1994 \mathrm{kN}$ e os valores obtidos a partir da interpretação das PCE subestimou tendo 824 kN e 577 kN para os métodos de Décourt (1996) e Massad (1992) respectivamente.

Para as cargas de ruptura comparando os resultados extrapolados das provas de carga estática e dinâmica com os valores previstos (Figura 4.20), o limite inferior foi definido pelas sondagens vizinhas com o método Décourt-Quaresma e superior com a sondagem mais próxima prevista pelo método Aoki-Velloso. Em súmula os resultados previstos pelo processo de homogeneização com as sondagens vizinhas se demonstraram mais confiável em termos da carga de ruptura quanto na distribuição por atrito lateral e ponta. 


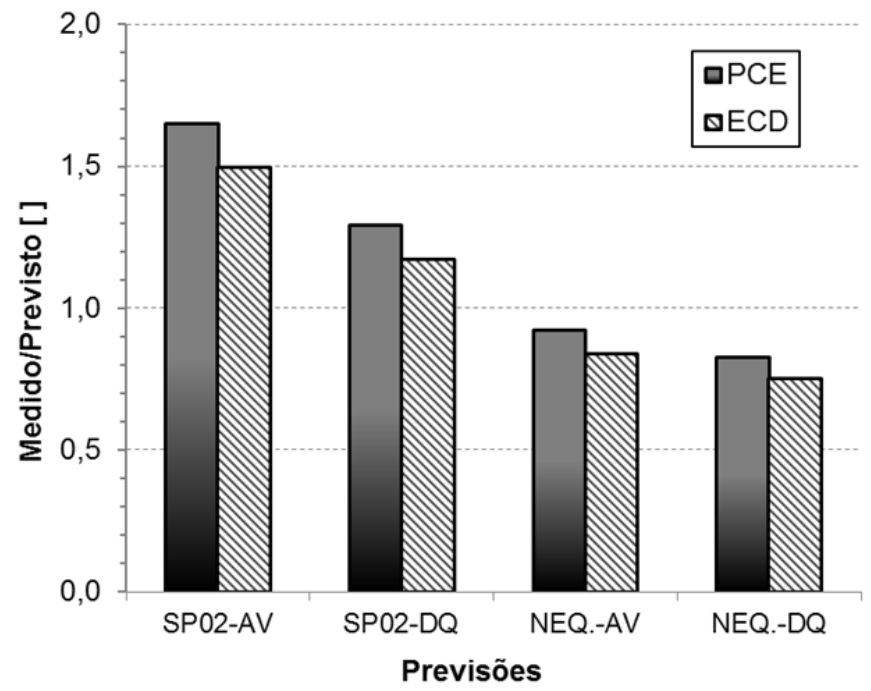

Figura 4.20 - Comparação da carga de ruptura ( $R T$ ) obtida pelo PCD e PCE em relação as previsões dos métodos semi-empírico - estaca ${ }^{\circ}$. E114M02.

\subsubsection{Estaca nº E018M04}

A partir dos diversos métodos de avaliação da capacidade de carga do elemento isolado de fundação, para a carga de ruptura obteve o valor médio ( $\left.P R_{M E ́ D I O}\right)$ de $2720 \mathrm{kN}$, em que as previsões baseadas a partir da sondagem mais próxima (Figura4.21) foi mais próximo da média do que o critério de homogeneização das sondagens.

Na parcela de atrito lateral (Figura 4.22.a) o resultado medido pela prova de carga dinâmica e pela interpretação da PCE por Massad (1992) se aproximaram dos valores previstos, sendo nesse caso uma maior convergência dos resultados com o método semiempírico Décourt-Quaresma. O atrito médio $\left({ }^{R L}{ }_{\text {MÉDIO }}\right)$ foi de $2720 \mathrm{kN}$. 


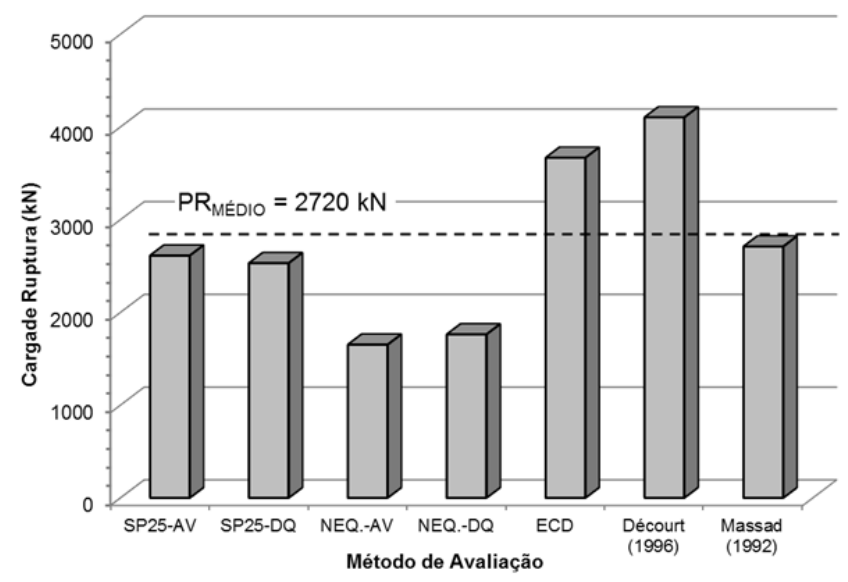

Figura4.21 - Comparação de capacidade de carga em função das previsões ( ${ }^{N_{S P T}} \mathrm{e}^{N_{E Q U I V}}$ ), dos resultados da PCE, PCD, registros de nega e repique- Estaca n . E018 M04.
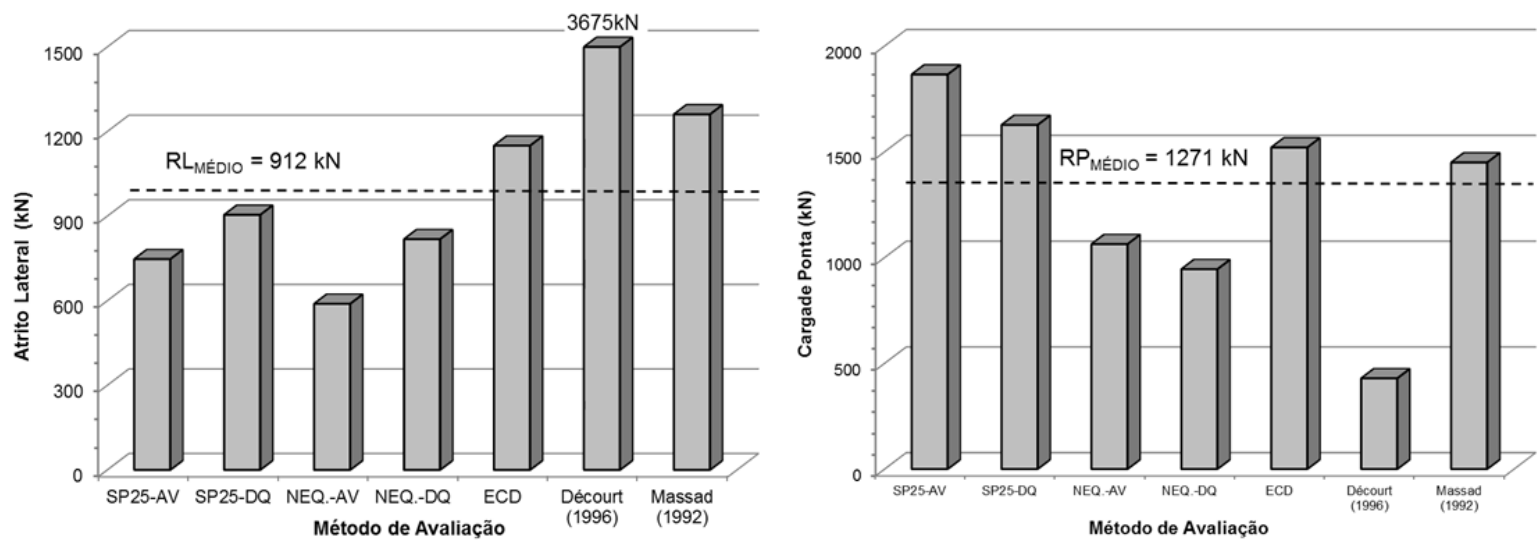

Figura 4.22 - Comparação das parcelas de resistência lateral e ponta em função das previsões ( $N_{S P T}$ e $\left.N_{E Q U I V}\right)$, dos resultados da PCE, PCD, registros de nega e repique - estaca ${ }^{\circ}$. E018 M04.

No caso da interpretação da PCE por Décourt (1992) superestimou a parcela de atrito obtendo $3675 \mathrm{kN}$, e esse valor acabou sendo condicionado pelo ensaio ter sido paralisado prematuramente não permitindo caracterizar o trecho plástico com clareza, apenas uma pequena tendência, influenciando o resultado.

Para a parcela de resistência de ponta (Figura 4.22.b) houve uma melhor convergência entre os valores previstos/medidos, sendo subestimado pela previsão baseada nas sondagens vizinhas e pelo método de Décourt (1996), que por sua vez está atrelado a 
definição da faixa de variação do atrito influenciada pela parada prematura do ensaio.

Comparando-se as cargas de ruptura previstas, em relação à sondagem mais próxima (SP-25), com os resultados extrapolados dos ensaios de campo (Figura 4.23) foram encontradas relações entre os valores medidos/previstos na faixa de 0,48 a 0,71 para as provas de carga dinâmica e 0,61 a 0,96 para os estáticos, comprovando nesse caso que a sondagem mais próxima é mais realista para a previsão.

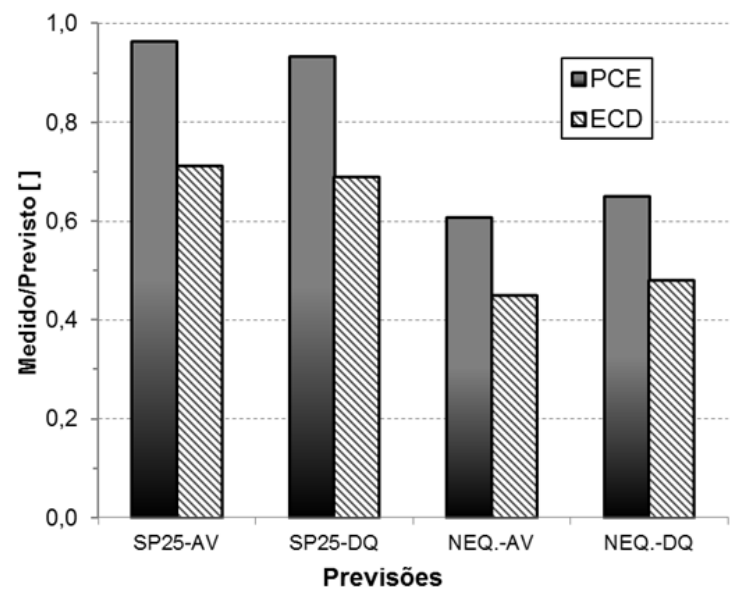

Figura 4.23 - Comparação da carga de ruptura (RT) obtida pelo PCD e PCE em relação as previsões por métodos semi-empírico - Estaca nº. E018 M04.

\subsubsection{Estaca nº. E125 M09}

$\mathrm{Na}$ avaliação da capacidade de carga do elemento de fundação existe uma boa convergência entre os valores medidos e interpretados (Figura4.24) com a previsão baseada nas sondagens da vizinhança, e nos casos da sondagem mais próxima (SP-08) é subestimado, tendo valores entre $2000 \mathrm{kN}$ e $2221 \mathrm{kN}$. Como um valor médio ( $P R_{\text {MÉDIO }}$ ) obteve $3008 \mathrm{kN}$.

Para o atrito lateral (Figura4.25.a), a previsão pelas sondagens vizinhanças se aproximou dos resultados obtidos das provas de carga dinâmicas, tendo como valor médio entre os diversos métodos de avaliação de $1498 \mathrm{kN}$, sendo que na previsão pela sondagem mais próxima (SP-08) valores de $713 \mathrm{kN}$ e $916 \mathrm{kN}$ para os métodos semi-empíricos de Décourt-Quaresma e Aoki-Velloso respectivamente. 


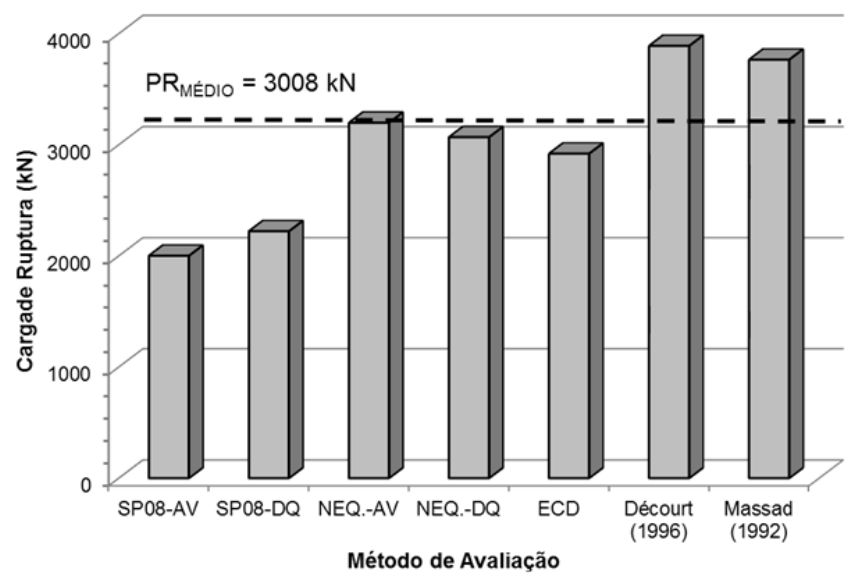

Figura4.24 - Comparação de capacidade de carga em função das previsões ( ${ }^{N_{S P T}} \mathrm{e}^{N_{E Q U I V}}$ ), dos resultados da PCE, PCD, registros de nega e repique - estaca ${ }^{\circ}$. E125 M09.
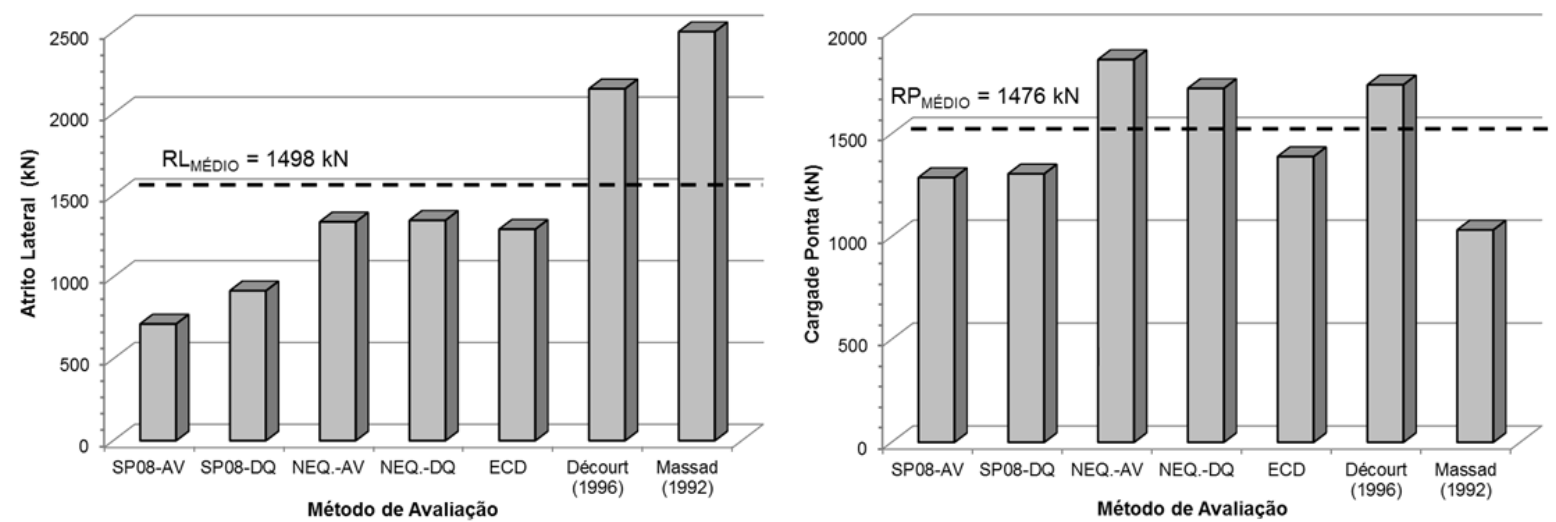

Figura4.25 - Comparação das parcelas de resistência lateral e ponta em função das previsões ( $\left.N_{S P T} \mathrm{e}^{N_{E Q U I V}}\right)$, dos resultados da PCE, PCD, registros de nega e repique-estaca $\mathrm{n}^{\circ}$. E125 M09.

Em relação ao valor médio representa uma redução de $47 \%$ e $61 \%$, enquanto que para a interpretação das provas de carga dinâmica superestimaram em $43 \%$ e $82 \%$ em relação a $R L_{\text {MÉDIO }}$. Para a parcela de ponta (Figura4.25.b) os valores previstos e medidos convergiram para o valor médio $\left(R P_{M E ́ D I O}\right)$ de $1746 \mathrm{kN}$, sendo que os métodos de avaliação variam de $1032 \mathrm{kN}$ (Massad, 1992) a $1861 \mathrm{kN}$ (Aoki-Velloso com $N_{E Q U I V}$ ), que em termos percentuais representa redução de $59 \%$ e incremento de $7 \%$.

Comparando-se as cargas de ruptura previstas (Figura4.26) com as medidas de 
campo, para a prova de carga dinâmica a faixa foi de 0,69 a 1,10 enquanto que para a prova de carga estática variou de 0,51 a 0,82 em relação a carga extrapolada.

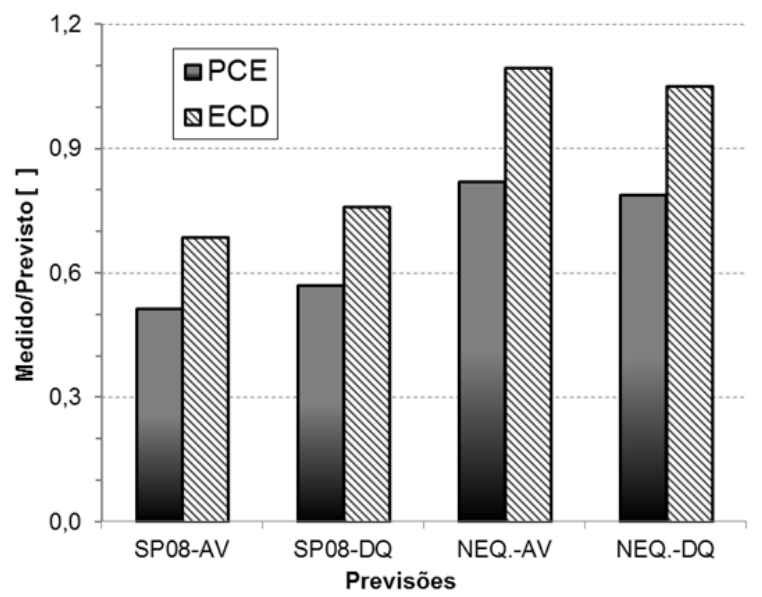

Figura4.26 - Comparação da carga de ruptura (RT) obtida pelo PCD e PCE em relação as previsões por métodos semi-empírico - Estaca nº. E125 M09.

\subsubsection{Estaca $n^{\circ}$. E113 M15}

Pela comparação da resistência total (Figura 4.27), observou-se uma boa aproximação entre a previsão através dos ensaios SPT com os medidos na prova de carga estática, a carga de ruptura média é de $3140 \mathrm{kN}$ sendo mais representativo a sondagem mais próxima.

Com relação à parcela de resistência por atrito lateral (Figura4.28), os métodos de previsão convergem para um resultado médio de $826 \mathrm{kN}$, enquanto que a interpretação das PCE pelo método da rigidez (Décourt, 1996) prevê $2983 \mathrm{kN}$ e por Massad (1992) foi de 1261 kN. Para a previsão da resistência ponta, a interpretação pelo método de Massad (1992) que prevê a influência de cargas residuais na ponta da estaca na obtenção do diagrama de transferência resultou num valor médio de 2171 kN, enquanto que Décourt (1996) subestima os resultados obtendo $865 \mathrm{kN}$. 


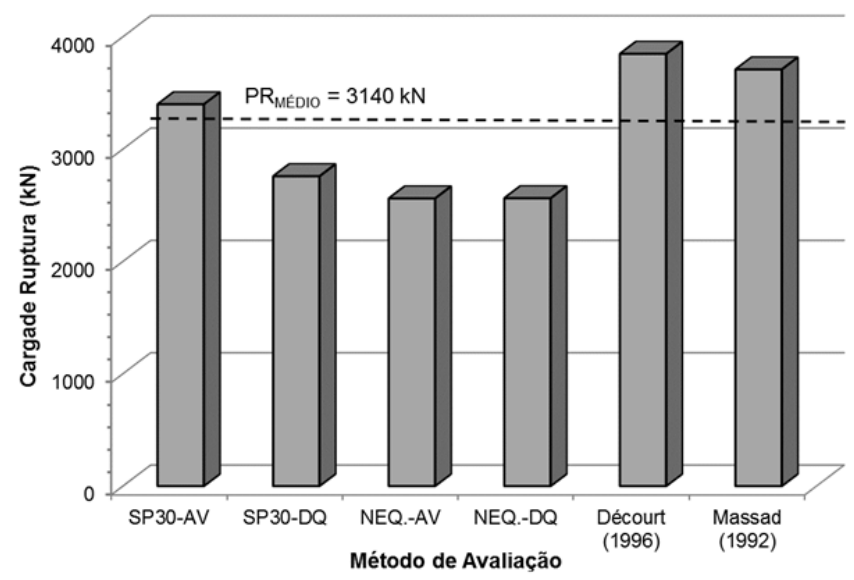

Figura 4.27 - Comparação de capacidade de carga em função das previsões ( $\left.N_{S P T} \mathrm{e}^{N_{E Q U I V}}\right)$, dos resultados da PCE, PCD, registros de nega e repique - Estaca ${ }^{\circ}$. E113 M15.
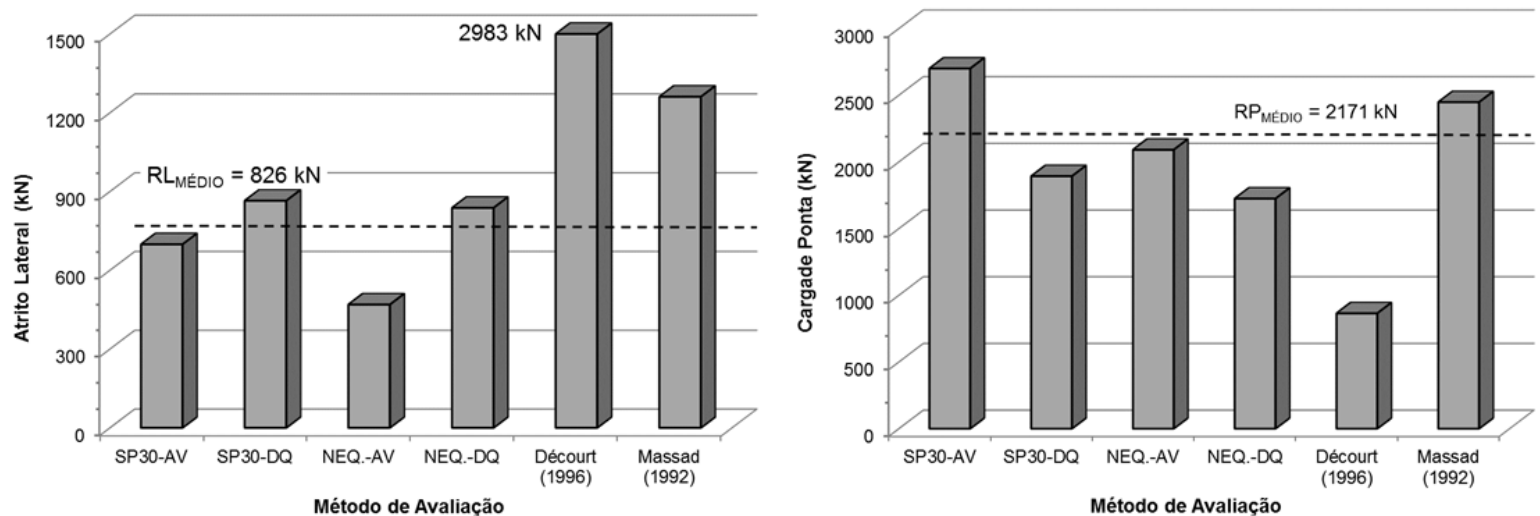

Figura4.28 - Comparação das parcelas de resistência lateral e ponta em função das previsões ( $N_{S P T} \mathrm{e}^{N_{\text {EQUIV }}}$ ), dos resultados da PCE, PCD, registros de nega e repique - Estaca ${ }^{\circ}$. E113 M15.

Para esse caso de previsão, o método Décourt-Quaresma apresentou a razão entre a carga de ruptura medida/prevista de 0,72 para a sondagem vizinha (SP-30) e 0,67 para o perfil homogeneizado. Pelo método Aoki-Velloso os fatores foram de 0,88 e 0,67 respectivamente. 


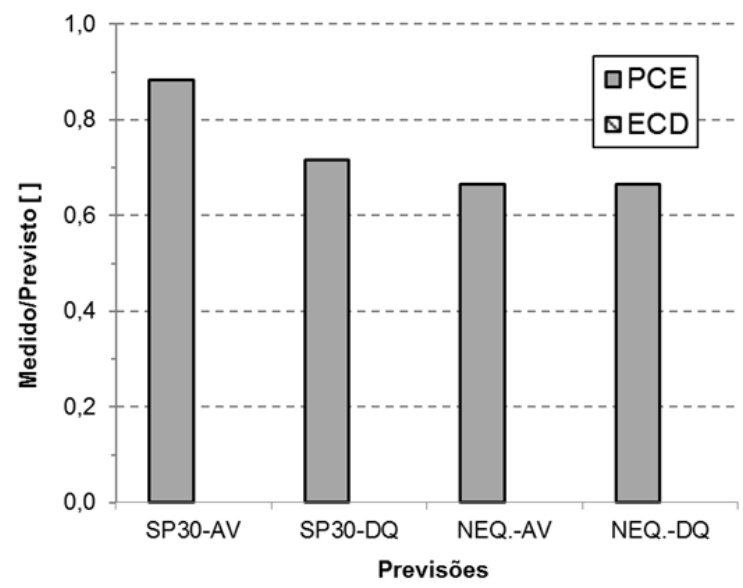

Figura 4.29 -Comparação da carga de ruptura (RT) obtida pelo PCD e PCE em relação as previsões por métodos semi-empírico - Estaca nº ${ }^{\circ}$ E113 M15.

\subsection{Controle do estaqueamento por prova de carga dinâmica}

\subsubsection{Introdução}

As provas de carga dinâmicas foram realizadas durante a execução das estacas em diversas idades (em relação ao momento final da cravação), e com diferentes equipamentos, usando-se o método de energia crescente, com o registro da nega e repique elástico. No total foram executados 74 ensaios distribuídos aleatoriamente ao longo do projeto (Figura 4.30).

Para a interpretação dos sinais, no golpe de maior energia foi utilizado o programa CAPWAP, e com os parâmetros obtidos, os demais golpes foram reanalisados no CASE.

Devido à facilidade de execução das $\mathrm{PCD}$, grande parte dos ensaios ocorrem entre final de cravação a 2 dias. Nessa situação, foram ensaiadas uma amostra de 22 estacas, que representam $29,7 \%$ das estacas ensaiadas, enquanto que os demais ensaios foram realizados após um maior intervalo de tempo (Figura 4.30). Dessa forma, foi possível caracterizar o crescimento da resistência mobilizada da estaca ao longo do tempo, e verificar possíveis influências do efeito set-up nos resultados. 


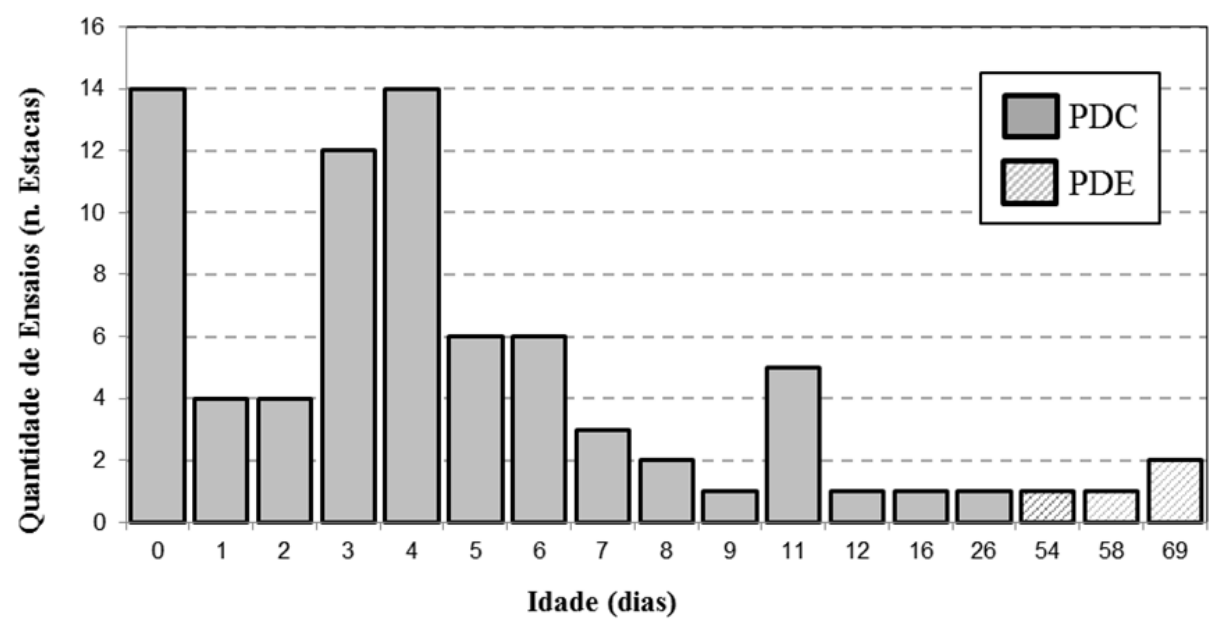

Figura 4.30 - Histograma da quantidade de ensaios realizados em função da idade relativa ao momento final da cravação.

\subsubsection{Interpretação dos Ensaios}

Pelas analises CAPWAP, realizadas nos golpes de maior energia, os resultados foram decompostos entre a máxima resistência mobilizada no ensaio $(R M X)$, nas parcelas de atrito lateral e ponta, e quando necessário através da carga de ruptura ( $P R_{R M X}$ ) extrapolada.

Para os resultados dos ensaios em cada idade, foi plotado um gráfico (Figura4.31) que apresenta o valor médio de $R M X$ igual a $2925 \mathrm{kN}$, desvio padrão de $337 \mathrm{kN}$, com coeficiente de variação $(C V)$ de $11,5 \%$. Comparando-se com os valores médios de $P R_{R M X} \quad$ o valor médio foi de $3295 \mathrm{kN}$, com desvio de $483 \mathrm{kN}$ e $C V$ de $14,6 \%$.

Em 89\% ( $\mathrm{n}=66$ ensaios) das PCD realizadas no golpe de máxima energia, os

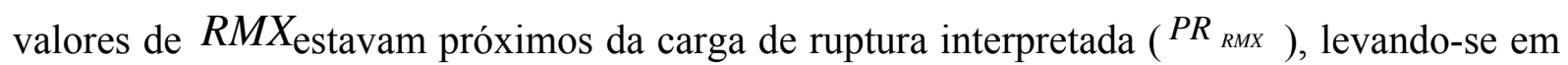
consideração as diferentes idades, o que resultou numa relação entre $R M X / P R_{R M X}$ de 1,13 .

Nos ensaios realizados em até 2 dias após a cravação, há uma variação da ordem de $1000 \mathrm{kN}$ em torno do valor médio de $R M X$, o que representa um $C V$ de $34,1 \%$. Para os casos de ensaios com idades superiores a 5 dias, a dispersão entre os limites mínimo e máxima é da ordem de $200-300$ kN. Portanto, ocorreu neste caso uma menor influência dos efeitos do tempo na variabilidade das resistências mobilizadas nas estacas.

Pelas analises CAPWAP foram obtidas as parcelas de resistência de atrito lateral e 
ponta em função da idade. Plotando-se esses dados num gráfico (Figura4.32), à medida que se aumenta a idade da estaca, ocorre uma inversão nos diagramas de transferência de carga. Deste modo, o mecanismo preponderante da resistência da estaca foi inicialmente pela ponta, e no final transferiu-se para atrito lateral.

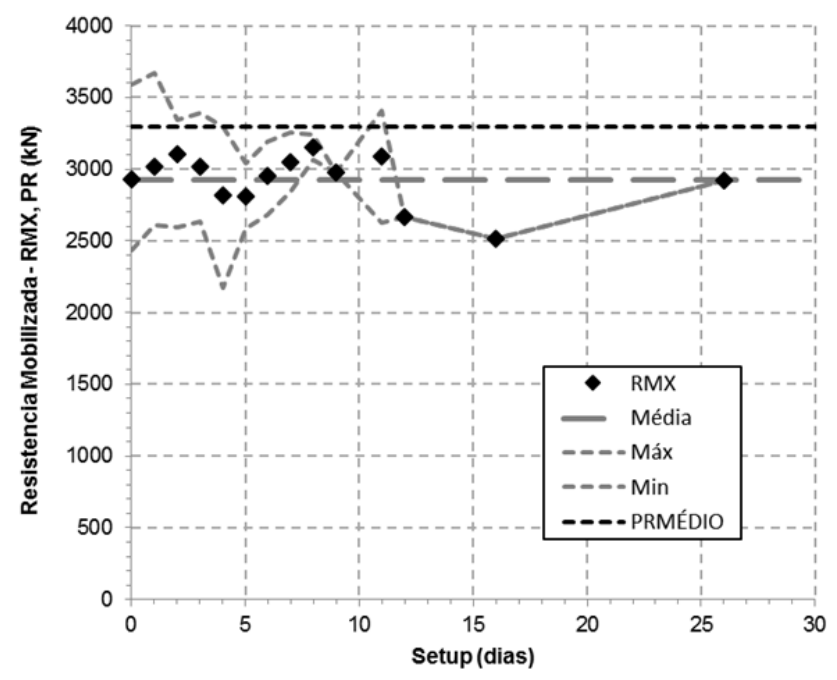

Figura4.31 - Valores médios, mínimos e máximos de RMX em função do setup de cravação das estacas $-\mathrm{n}=74 \mathrm{ECD}$.

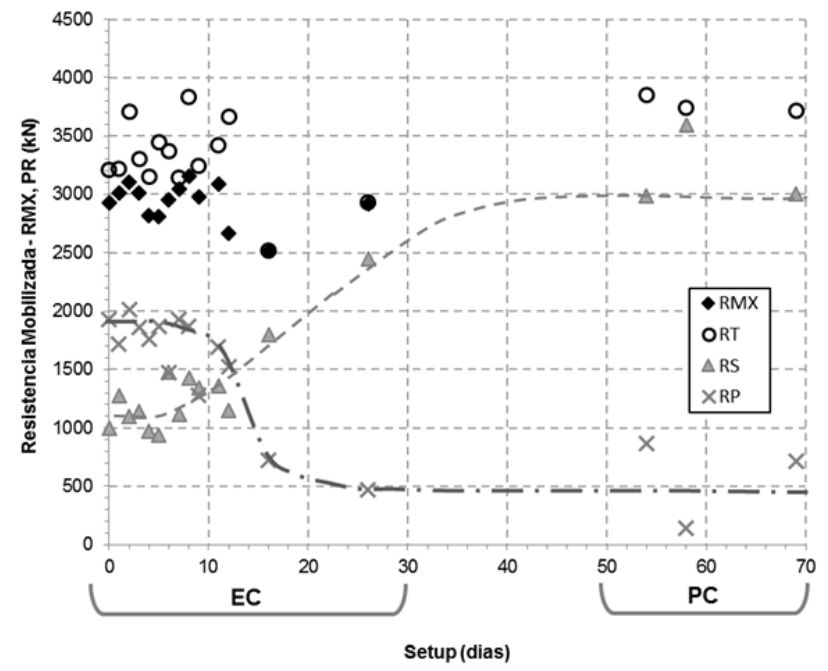

Figura4.32 - Valores médios da $R M X, P R_{R M X}, R S$ e $R T$ em função da idade.

A resistência de ponta até a idade de 9 dias se mantém constante e com valor médio da ordem de $2000 \mathrm{kN}$ e depois estabiliza. A partir dessa idade, a resistência por atrito 
lateral aumenta com a idade das estacas, partindo de um valor médio de $1000 \mathrm{kN}$ (final de cravação) até $2500 \mathrm{kN}$ (28 dias).

\subsubsection{Considerações sobre a interpretação dos ensaios}

$\mathrm{Na}$ interpretação dos resultados, existe a influência das variabilidades geotécnicasgeológicas, dos equipamentos de execução, do processo de homogeneização, e do critério de parada das estacas nas resistências mobilizadas. Num segundo momento se faz necessário balizar os diversos resultados para que estejam no mesmo grau de comparação, e não se trabalhe apenas com dados isolados.

A seguir apresentam-se interpretações em relação ao nível de tensões aplicados nos diversos ensaios, à mobilização da resistência, e à eficiência do sistema de cravação, avaliando-se as potencias influências e características dos ensaios.

\subsubsection{Tensões dinâmicas atuantes}

Durante o processo de cravação, e na execução do PCD, em cada golpe aplicado pelo sistema de cravação são geradas tensões ao longo da estaca, e que em função de atravessar as camadas de solo, vão ser absorvidas ou transferidas, podendo modificar uma tensão inicialmente de compressão em tração, no caso da ponta da estaca não encontrar resistência.

Um outro fator bastante pratico com relação às medidas de tensões na estaca, é de verificar em cada caso (ou ensaio) se há uma tendência de ruptura do solo, pois nessa situação as tensões no material serão elevadas mas as resistências mobilizadas são baixas, o que em algumas situações podem quebrar ou danificar o elemento estrutural.

Para a situação de estudo buscou-se correlacionar as macro-regiões geológicas definidas anteriormente na transferência de tensões na ponta da estaca, e para essas regiões

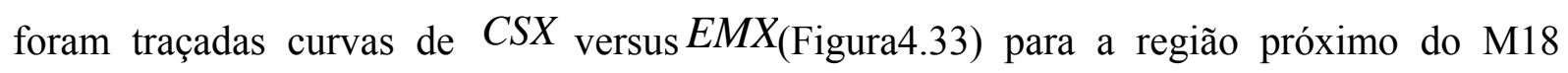
(elevados valores de ${ }^{N_{S P T}}$ ), na zona de transição M09 e próximo a região do M01 (baixos valores de $N_{S P T}$ ) - conforme descritivos no item Previsão de capacidade de carga. 


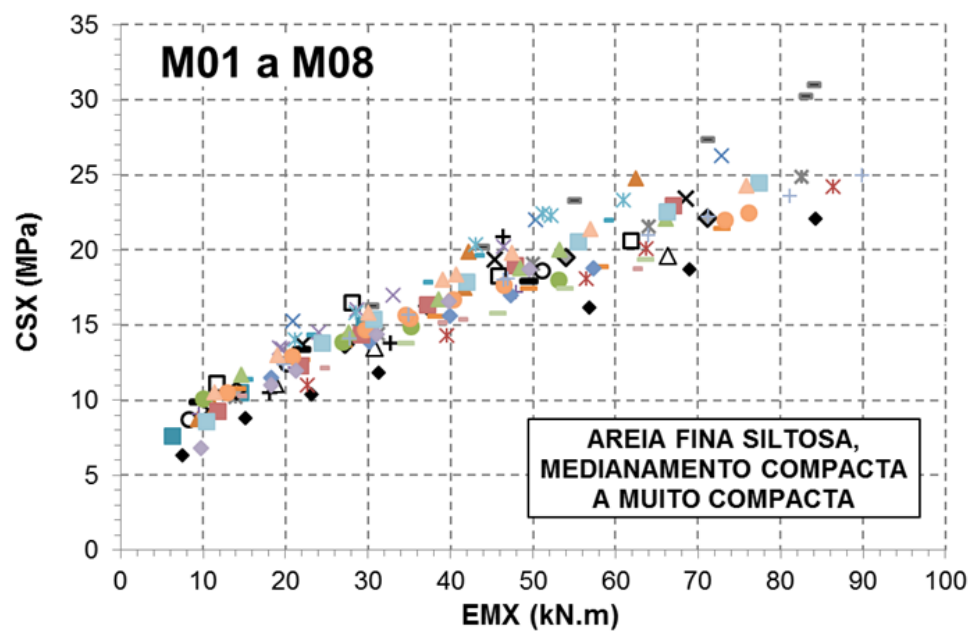

\begin{tabular}{|c|c|}
\hline E007DPN & $\Delta \mathrm{E} 126 \mathrm{M} 01$ \\
\hline XE137 M01 & *E114 M02 \\
\hline oE118 M02 & 口E025 MO \\
\hline ๑E027 M03 & + E034 MO \\
\hline -E035 M03 & - E040 M0 \\
\hline •E126 M03 & $\triangle \mathrm{E} 018 \mathrm{M} 04$ \\
\hline ×E039M04 & * E006M05 \\
\hline - E052M05 & $+\mathrm{E} 122 \mathrm{M} 05$ \\
\hline -E123M05 & -E022M06 \\
\hline E076M06 & E128M06 \\
\hline$\triangle \mathrm{E} 139 \mathrm{M} 06$ & $\times$ E021M07 \\
\hline * E075M07 & E116M07 \\
\hline + E122M07 & -E113M08 \\
\hline -E128M08 & $\Delta \mathrm{E} 129 \mathrm{M} 08$ \\
\hline E130M08 & $\triangle \mathrm{E} 131 \mathrm{MO}$ \\
\hline
\end{tabular}

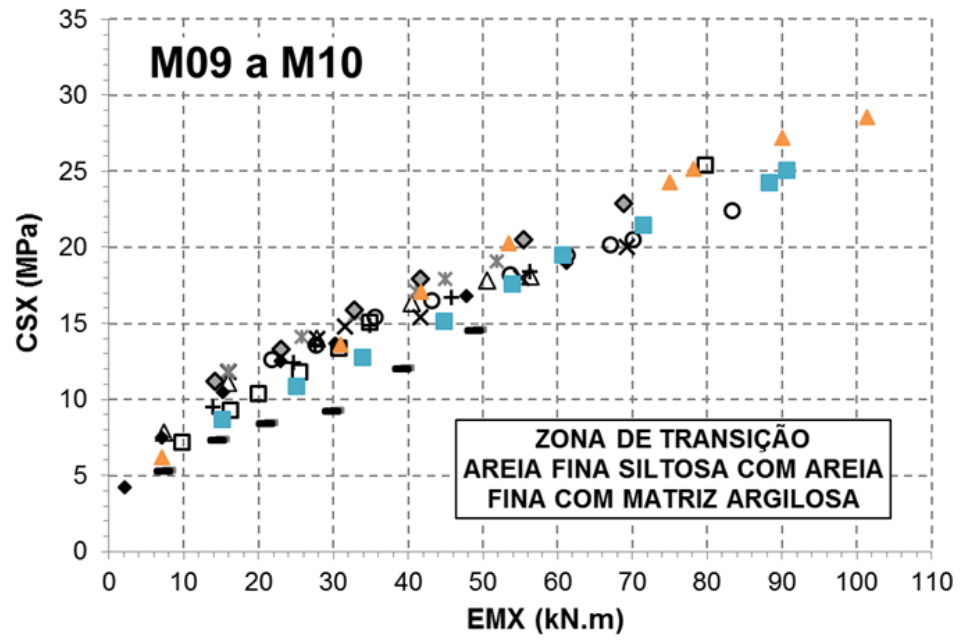

\begin{tabular}{|ll}
\hline E026 M09 & $\times E 035$ M09 \\
×E038 M09 & oE083 M09 \\
口E121 M09 & $\diamond E 123$ M09 \\
$+E 124 M 09$ & $-E 125$ M09 \\
$-E 134$ M09 & $\bullet E 135$ M09 \\
$-E 121 M 10$ & $\triangle E 121 R M 10$
\end{tabular}

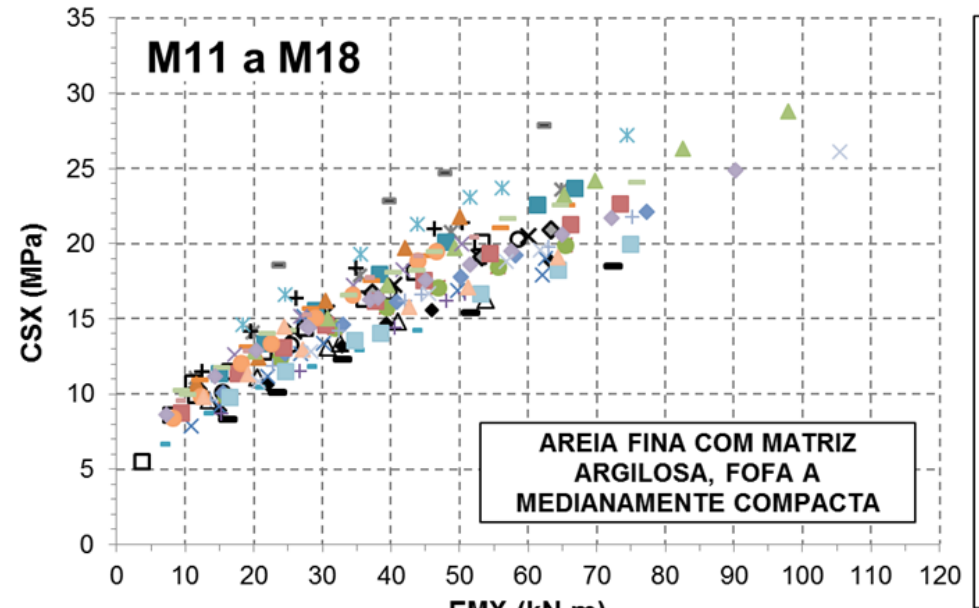

\begin{tabular}{|c|c|}
\hline$\Delta \mathrm{E} 018 \mathrm{M} 18$ & XE062 M18 \\
\hline *E094 M18 & oE113 M18 \\
\hline 口E113R M18 & ॰E125 M18 \\
\hline +E028 M17 & -E038 M17 \\
\hline -E053 M17 & - E098 M17 \\
\hline E060M16 & $\triangle \mathrm{E} 007 \mathrm{M} 15$ \\
\hline ×E085M15 & *E124M15 \\
\hline -E138M15 & + E052M14 \\
\hline -E113M14 & $-\mathrm{E} 124 \mathrm{M} 14$ \\
\hline E128M14 & E128RM14 \\
\hline$\triangle \mathrm{E} 082 \mathrm{M} 14$ & $\times \mathrm{E} 013 \mathrm{M} 13$ \\
\hline *E037M13 & -E107M13 \\
\hline +E138M13 & -E009M12 \\
\hline -E033M12 & E049M12 \\
\hline E012M11 & $\triangle \mathrm{E} 036 \mathrm{M} 11$ \\
\hline$\times$ E119M11 & \\
\hline
\end{tabular}

Figura4.33 - Curva de tensões de compressão ( $C S X$ ) pela energia liquida ( $E M X$ ) para os ECD para os diferentes materiais na ponta da estaca. 
Em todos os gráficos o eixo vertical - CSX foi limitado a resistência característica do concreto - fck $=35 \mathrm{MPa}$.

A tensão de compressão manteve um comportamento de incremento com a energia líquida em todas as regiões, para as regiões M09, M17 e M18 as curvas são bem similares limitando as tensões de compressão em torno de $25 \mathrm{MPa}$ para uma faixa dos golpes de maior energia entre 60 a 70 kN.m. Em nenhuma dessas curvas o trecho final apresentou um comportamento linear, que corresponde a ruptura da ponta da estaca e consequentemente do sistema.

Para a região do M01 a M03, os níveis de energia empregados foram maiores, chegando a energia líquida da ordem de 90 kN.m, e para a estaca E040M03 atingiu a tensão de compressão de $30 \mathrm{MPa}$. Não houve nenhuma indicio de ruptura, entretanto os maiores níveis de energia empregados denotam uma provável limitação da resistência mobilizada ou proximidade com a carga de ruptura, mas um comportamento bastante similar ao das demais regiões, mesmo tendo a camada de solo da ponta com menor resistência - $N_{S P T}$.

\subsubsection{Mobilização da resistência}

Devido à variabilidade geológica em termos da resistência total, houve uma homogeneidade dos dados nas diversas regiões. A Figura 4.34 apresentam uma série de curvas adimensionalizadas da resistência mobilizada $(R M X)$ pela capacidade estrutural do elemento estrutural ( $R E$ ) versus o deslocamento máximo medido no ensaio ( $D M X)$ pelo diâmetro da estaca (D), que nessa situação é constante para todas as áreas.

A partir da interpretação das curvas adimensionalizadas, fica muito mais claro o comportamento carga $\mathrm{x}$ deslocamento das diversas estacas, havendo uma tendência de ruptura, que corresponderia ao índice $R M X / R E$ da ordem de 35 a 45\%, independente da região onde se encontra à estaca. Nesse caso deve-se lembrar que a análise está sendo realizada para um único diâmetro.

No caso da estaca E040M03 e E083M09, é bastante notório no trecho final das 
curvas o comportamento linear, que caracteriza a ruptura do sistema. Em termos do deslocamento encontra-se um valor de aproximadamente $3 \%$ em relação ao diâmetro da estaca, e da ordem de $21,0 \mathrm{~mm}$.
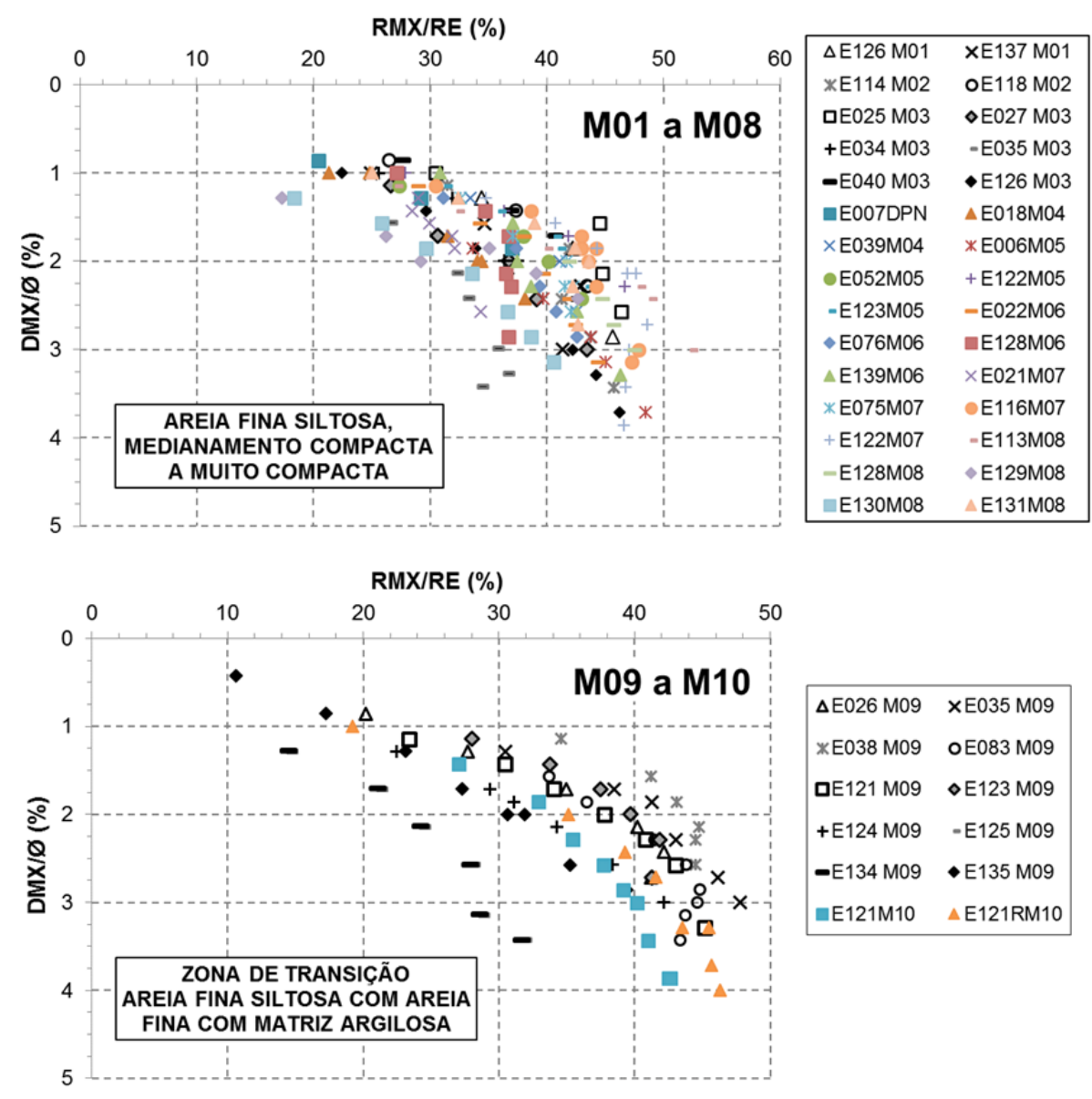

\begin{tabular}{|c|c|}
\hline$\Delta E 026 \mathrm{M} 09$ & XE035 M09 \\
\hline ЖE038 M09 & OE083 M09 \\
\hline 口E121 M09 & $\diamond \mathrm{E} 123 \mathrm{M} 09$ \\
\hline +E124 M09 & -E125 M09 \\
\hline -E134 M09 & - E135 M09 \\
\hline $\mathrm{E} 121 \mathrm{M} 10$ & $\triangle \mathrm{E} 121 \mathrm{RM} 10$ \\
\hline
\end{tabular}

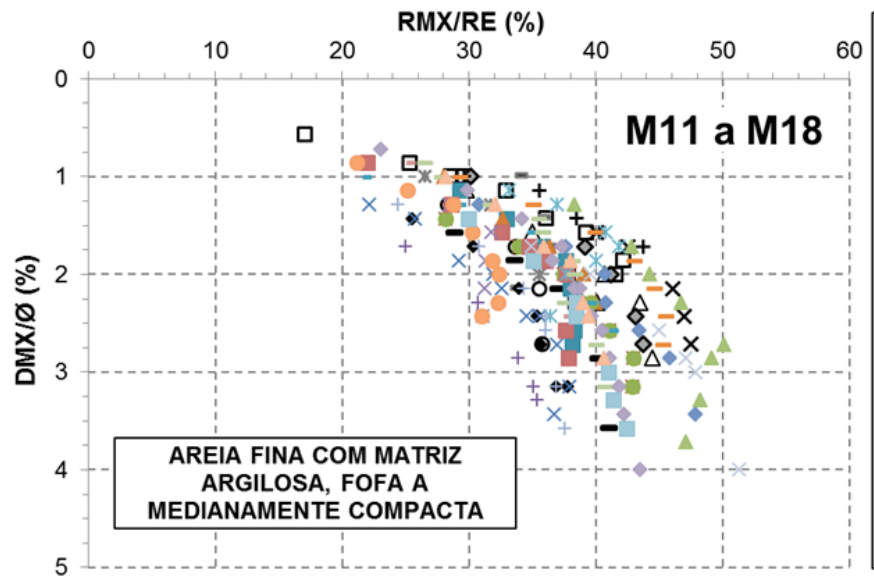

\begin{tabular}{|c|c|}
\hline$\Delta \mathrm{E} 018 \mathrm{M} 18$ & XE062 M18 \\
\hline жE094 M18 & oE113 M18 \\
\hline QE113R M18 & $\diamond \mathrm{E} 125 \mathrm{M} 18$ \\
\hline +E028 M17 & -E038 M17 \\
\hline -E053 M17 & • E098 M17 \\
\hline EE060M16 & $\triangle E 007 M 15$ \\
\hline$\times \mathrm{E} 085 \mathrm{M} 15$ & *E124M15 \\
\hline -E138M15 & + E052M14 \\
\hline$\triangle \mathrm{E} 082 \mathrm{M} 14$ & -E113M14 \\
\hline$-E 124 M 14$ & $\diamond \mathrm{E} 128 \mathrm{M} 14$ \\
\hline E128RM14 & $\times \mathrm{E} 013 \mathrm{M} 13$ \\
\hline жЕ037M13 & E107M13 \\
\hline +E138M13 & -E009M12 \\
\hline -E033M12 & E049M12 \\
\hline E012M11 & $\triangle \mathrm{E} 036 \mathrm{M} 11$ \\
\hline E119M11 & \\
\hline
\end{tabular}

Figura 4.34 - Curvas adimensionalizada de $R M X / R E$ pelo $D M X$ / $\Phi$ para a região doM01 ao M08, M09/M10 e do M11 ao M18. 


\subsubsection{Eficiência da energia de cravação}

Com a utilização de diversos equipamentos, a dinâmica da obra e o caminhamento dos equipamentos faz-se necessário estabelecer um controle das eficiências do sistema de cravação, devido às variabilidades que podem ser geradas por problemas mecânicos, manutenção preventiva, excentricidades no sistema de cravação, e outras deficiências.

Os efeitos relacionados à perda de eficiência influenciam diretamente nos registros de nega e repique, ocasionando uma resistência à cravação que na verdade é uma limitação da energia líquida que está solicitando o sistema estaca-solo. No total da obra, o projeto trabalhou com sete equipamentos com martelo de queda livre, onde cinco contavam com massa de martelo de $70 \mathrm{kN}$, e os outros dois martelos de $60 \mathrm{kN}$.

A Tabela 4.20 apresenta, considerando-se os 74 ECD executados, a distribuição por equipamento utilizado no projeto com seu parâmetro de eficiência média $\left(e_{\text {MÉDI) }}-\right.$ avaliado através dos dados de energia crescente, conforme ilustrado na Figura4.35. Apresenta-se a energia potencial aplicada no final de cravação no registro de campo $\left(E_{P O T F C}\right)$.

Pelas análises dos diversos níveis de carregamento aplicados nas PCD, foram construídas curvas que correlacionam o quake do solo (C3) com a energia líquida do equipamento, similar ao apresentado para o equipamento BE-02 na Figura4.36. A partir desse ajuste, foi determinado para cada equipamento um valor médio de $C 3$ considerando-se a energia de coleta dos registros do final de cravação $\left(C 3_{F C}\right)$.

Para as curvas de eficiência, observou-se uma influência no formato das curvas quando na cravação de estacas instaladas verticais e inclinadas. Na primeira situação, as curvas tendem a um comportamento crescente com a $E_{P O T}$, enquanto que para as estacas inclinadas há uma tendência de linearidade. Um exemplo pode ser observado na Figura4.35 onde o equipamento BE-06 cravou apenas estacas inclinadas, enquanto que o BE-02 (Figura4.36) possui os dois casos. 
Tabela 4.20 - Distribuição de ensaios e parâmetros de eficiência por equipamento.

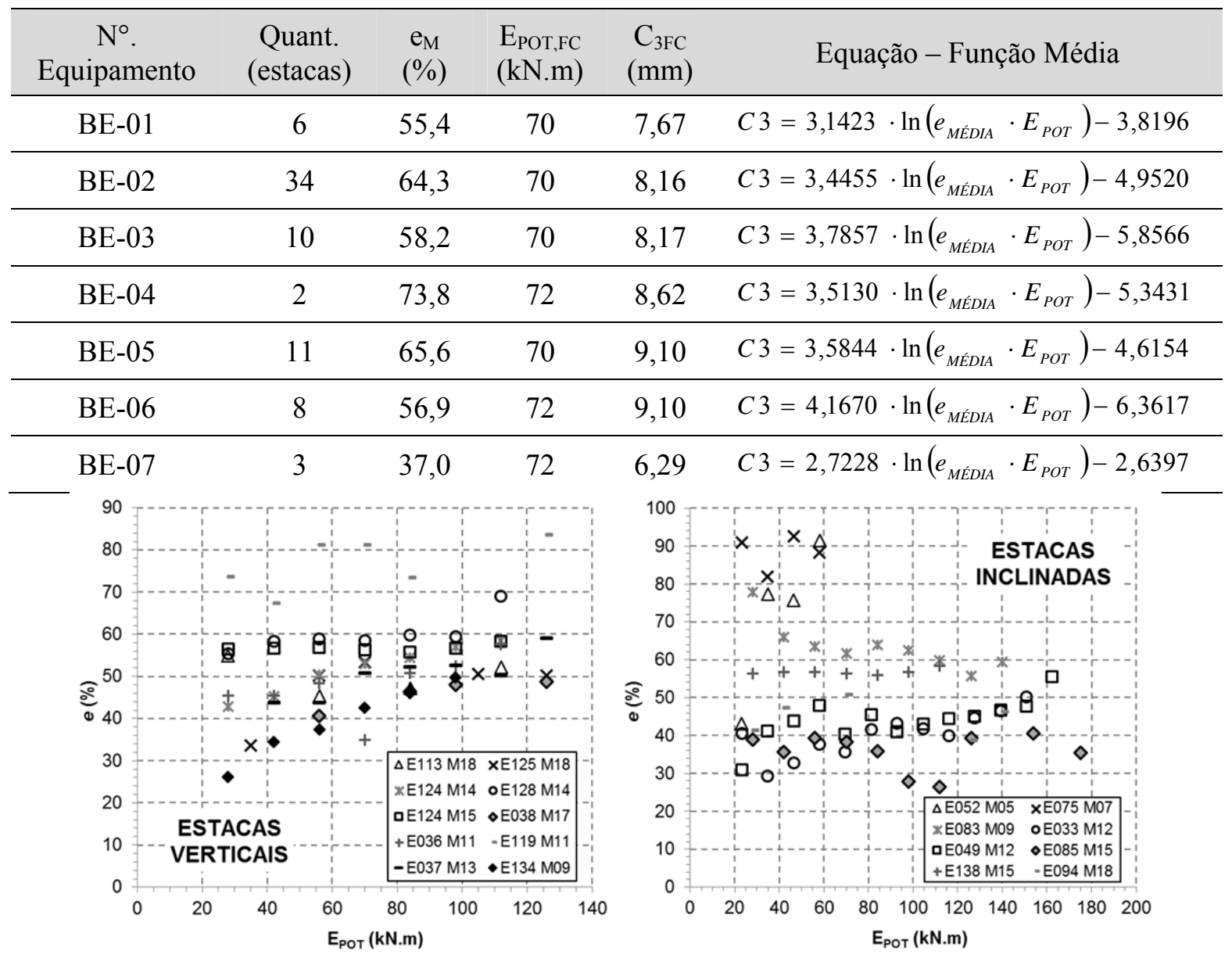

Figura4.35 - Curva de eficiência para diferentes níveis de energia potencial aplicado equipamento BE-02 e BE-06.

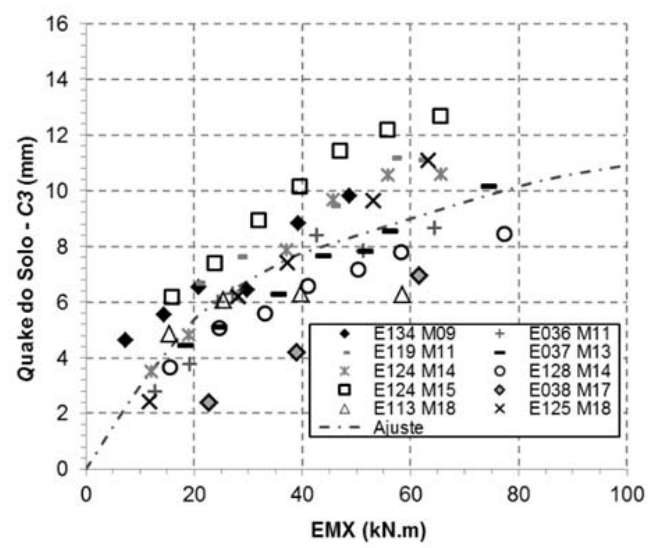

Figura4.36 - Curva de quake do solo ( $C 3$ ) em função dos diferentes níveis de energia liquida aplicado, com ajuste médio - equipamento BE-02. 
Com relação ao formato da curva de $C 3$ pela energia líquida, a tendência de comportamento por um ajuste com curva logarítmica se manteve nos demais casos, apresentando inclinações similares. A Figura4.37 apresenta as curvas médias para cada equipamento.

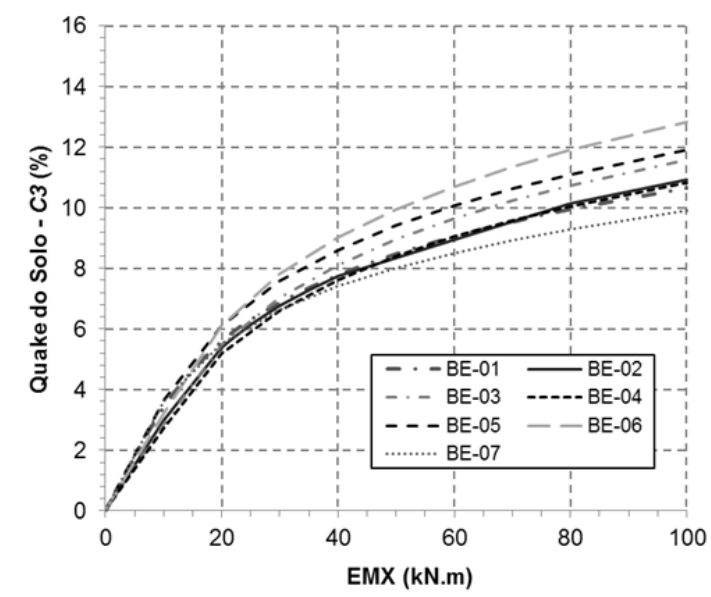

Figura4.37 - Comparativo entre as curvas médias de $C 3$ por EMX para os equipamentos.

\subsubsection{Resistência entre estacas inclinadas e verticais}

$\mathrm{Na}$ avaliação da resistência mobilizada com a utilização de PCD, a base da teoria da equação da onda considera que a propagação da onda de tensão é unidimensional. Normalmente, num projeto em que existam a cravação de estacas verticais e inclinadas, é comum que as estacas inclinadas apresentem resistências mobilizadas inferiores às verticais, para os mesmos níveis de energia empregados.

Esse fato é devido às perdas da energia devido ao martelo de cravação estar inclinado (maior parcela de perdas por atrito entre a guia) e o surgimento de uma força normal ao plano de cravação. Nessa condição a avaliação da resistência é um valor subestimado e necessita da aplicação de um nível superior de energia em comparação a uma estaca vertical.

A Figura 4.38 apresenta a razão entre a energia líquida $(E M X)$ aplicada no último golpe (ponto de maior energia) em relação a máxima energia teórica, definida por ERE expressão [2.58] que pode ser aplicada à estaca sem haver ruptura do elemento estrutural em 
função da resistência mobilizada $(R M X)$.

Para $R M X$ igual a $3000 \mathrm{kN}$, o índice $E M X / E R E_{\text {variou de } 18,8 \% \text { a } 89,5 \% \text { para }}$ estacas verticais, e na faixa de 49,4 \% a 93,9 \% para estacas inclinadas. Portanto, em relação ao limite inferior, o comportamento esperado é coerente com o medido, mas nessa situação, as variabilidades de resistência de ponta podem estar afetando esse comportamento.

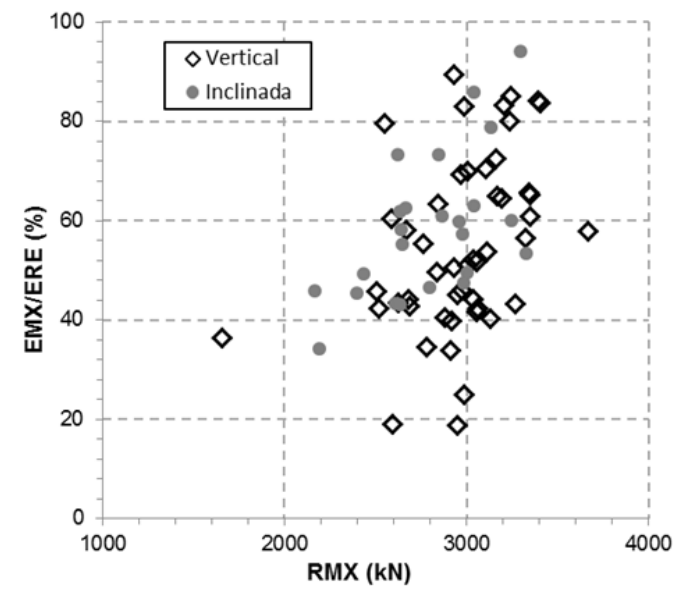

Figura 4.38 - Relação entre $E M X / E R E$ em função de $R M X$ para estacas verticais ( $\mathrm{n}=50$ estacas) e inclinadas $(\mathrm{n}=24$ estacas $)$.
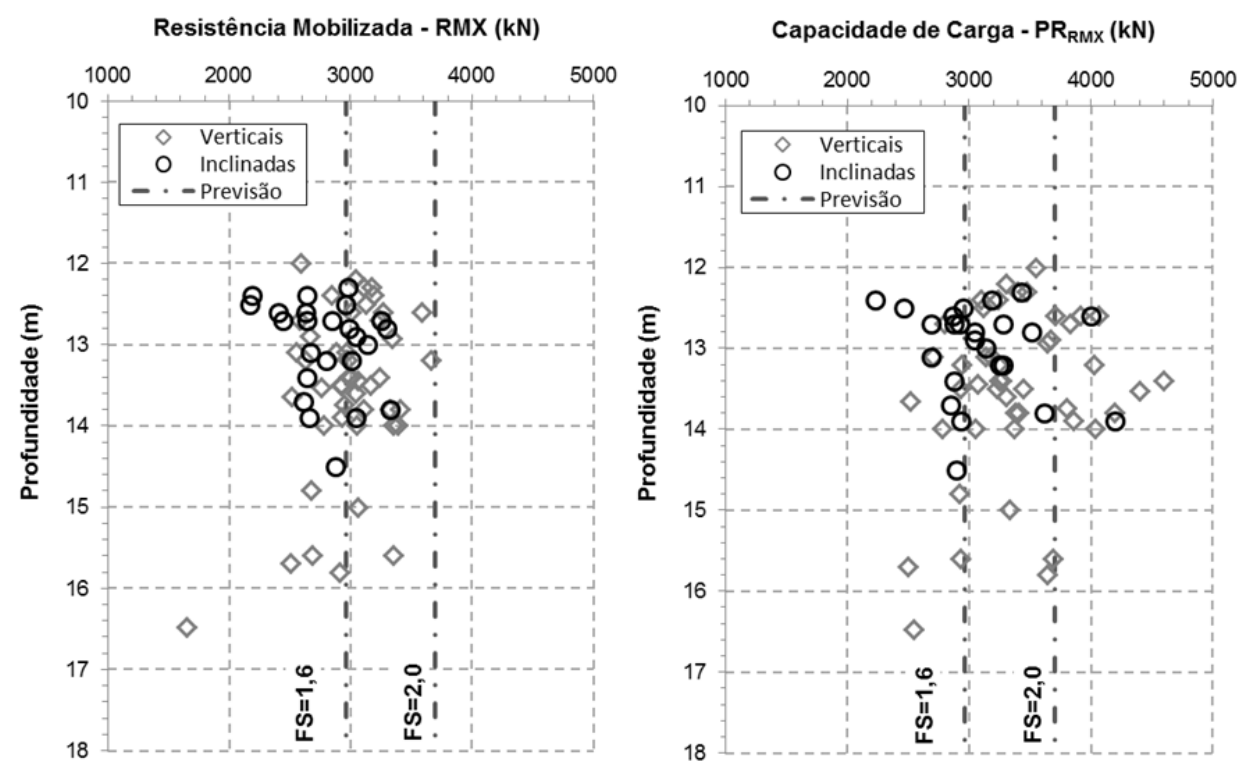

Figura 4.39 - Comparação entre $R M X$ e $P R_{R M X}$ em função da profundidade para estacas verticais e inclinadas. 
Com relação as resistências mobilizadas, e influências na extrapolação das curvas de $R M X$ para $P R_{R M X}$ em função da inclinação das estacas, a Figura 4.39 apresenta uma comparação das duas situações em função de uma relação com carga de trabalho ( $F S$ ).

Para ambas as situações, não existe diferença notável entre os valores de $R M X_{\text {das }}$ estacas verticais e inclinadas. Em termos de $R M X$, os ensaios se pronunciam de forma bastante concentrada e próximo de um fator de segurança global de 1,6 em relação a carga de projeto de $1850 \mathrm{kN}$. Na avaliação por $P R_{R M X}$, há uma tendência de dispersão dos pontos se localizando entre os fatores de carga de 1,6 e 2,0.

\subsubsection{Fator de amortecimento dinâmico}

O fator de amortecimento dinâmico influencia diretamente na resistência mobilizada pela estaca quando utiliza-se o método CASE, para os golpes com níveis de energia intermediários, influenciando a interpretação das curvas de resistência mobilizada por deslocamento.

Os resultados obtidos para algumas PCD são apresentados na Tabela 4.21 para vários valores de $J$ aplicados (inserido o valor final de $R M X$ obtido pela analise CAPWAP). O valor médio de todo o universo ensaiado resulta em 0,61, com mínimo de 0,29 e máximo de 1,0. Pela classificação proposta por Goble et al. (1985), para a camada de areia a areia siltosa a faixa de variação seria entre $0,1-0,2$, e por Rausche (1985) de 0,05-0,30.

Tabela 4.21 - Valores de resistência mobilizada em função do fator de amortecimento ( $J$ ).

\begin{tabular}{lcccccccccccc}
\hline \multirow{2}{*}{$\mathrm{N}^{\circ}$. Estaca } & \multirow{2}{*}{$J_{C P W}$} & \multicolumn{10}{c}{$J_{\text {CASE }}$} \\
\cline { 3 - 13 } & & 0,0 & 0,1 & 0,2 & 0,3 & 0,4 & 0,5 & 0,6 & 0,7 & 0,8 & 0,9 & 1,0 \\
\hline E085M15 & 0,55 & 3965 & 3620 & 3278 & 2950 & 2827 & 2711 & 2601 & 2500 & 2406 & 2378 & 2201 \\
\hline E028M17 & 0,73 & 5092 & 4814 & 4535 & 4256 & 3977 & 3698 & 3419 & 3140 & 2861 & 2583 & 2154 \\
\hline E098M17 & 0,67 & 3992 & 3660 & 3328 & 3158 & 3019 & 2880 & 2741 & 2602 & 2539 & 2501 & 2239 \\
\hline E124M14 & 0,57 & 5250 & 4879 & 4509 & 4141 & 3781 & 3421 & 3069 & 2903 & 2817 & 2739 & 2540 \\
\hline E119M11 & 0,63 & 5532 & 5038 & 4558 & 4232 & 4035 & 3838 & 3646 & 3466 & 3413 & 3367 & 3210 \\
\hline E107M13 & 0,46 & 3899 & 3501 & 3103 & 2712 & 2338 & 2078 & 1973 & 1871 & 1797 & 1772 & 1549 \\
\hline
\end{tabular}


Nesse caso os valores de $J$ foram influenciados pelas condições geológicas do local, pelo nível de energia empregado (Figura 4.40.a). Há uma tendência, para essa situação, que o incremento de energia reduza o fator de amortecimento, isso estaria associado ao mecanismo de interação solo-estaca em que a resistência de ponta é mais exigida.
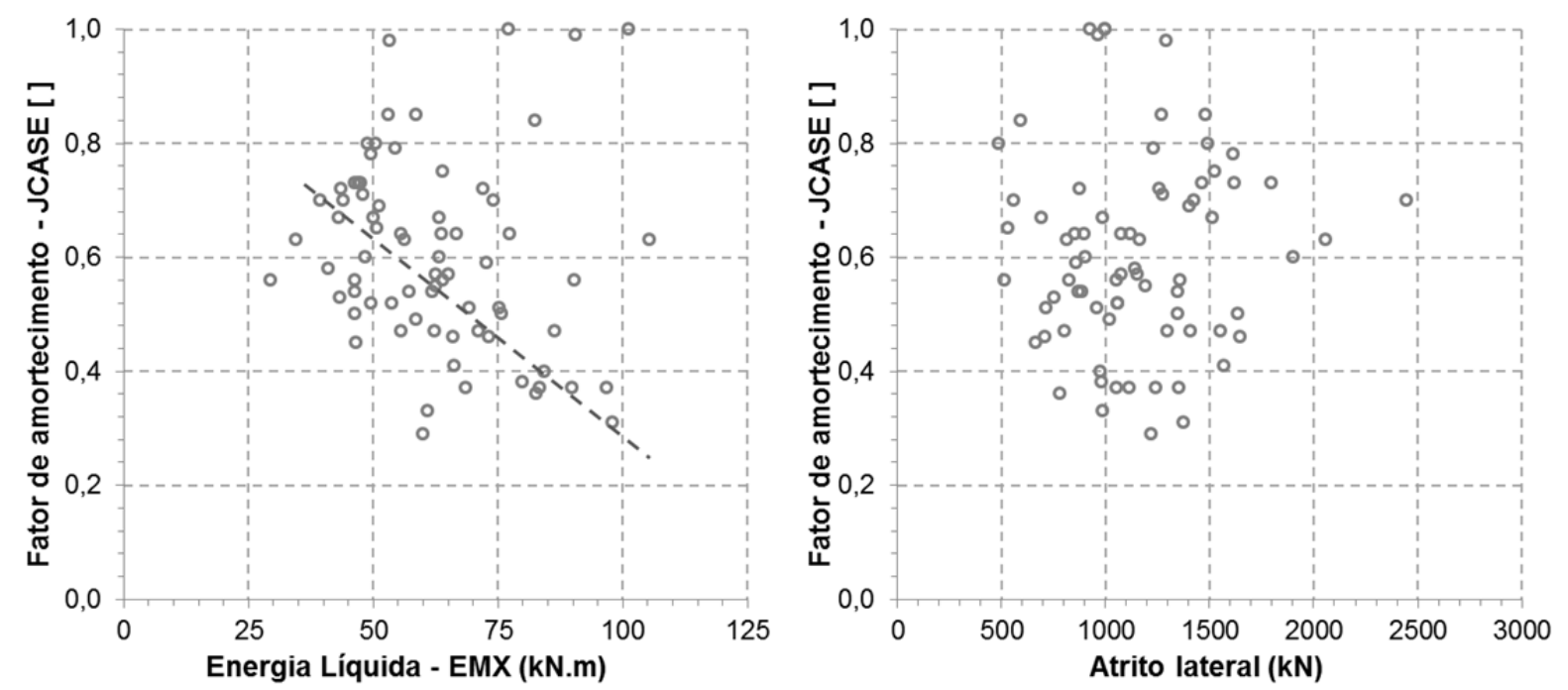

Figura 4.40 - Correlação entre o fator de amortecimento em função da energia líquida.

Gouveia (2003) pela análise das influências do fator de amortecimento na resistência mobilizada, conclui que o fator afeta principalmente o atrito lateral, enquanto que o deslocamento elástico afeta sobretudo a componente de ponta, para o caso analisado. Nos dados dessa dissertação não se observou essa tendência (Figura 4.40.b) por uma má correlação.

\subsubsection{Comparação com as previsões}

Os resultados de $R M X$ obtidas em cada PCD, correspondentes a máxima energia aplicada no ensaio, pode variar em função da eficiência do equipamento, da qualidade do sistema de amortecimento e outros fatores. Portanto, esse ponto não permite uma comparação direta entre os resultados.

Para uniformizar os dados nas comparações, extrapolou-se os resultados das PCD a fim de caracterizar o $P R_{R M X}$, e assim compará-los com os métodos semi-empírico de 
previsão de capacidade de carga (Aoki-Velloso e Décourt-Quaresma), determinou-se para cada estaca os valores previstos para cada método de previsão com base nas sondagens mais próxima (Figura 4.41).

Durante a execução, foi fixado um critério de cravação baseado no registro do conjunto de nega e repique elástico, que proporcionou o comprimento médio das estacas de 13,0 m, com desvio padrão de 1,52 m, com coeficiente de variação igual a 11,7\%.

Pelas provas de carga dinâmica, o valor de $\overline{P R_{R M X}}$ para todo o universo de estacas é de $3294 \mathrm{kN}$ com $C V$ de 14,6\%. Pela previsão com o método Aoki-Velloso, a capacidade de carga máxima e mínima foram $1098 \mathrm{kN}$ e $7141 \mathrm{kN}$ respectivamente, com média de 3596 kN com desvio padrão de 1310 kN e coeficiente de variação de $36,2 \%$. Para o método de Décourt-Quaresma a capacidade de carga máxima e mínima foi de $1106 \mathrm{kN}$ a $5777 \mathrm{kN}$ respectivamente ao intervalo, comvalor médio de $3296 \mathrm{kN}$, com desvio padrão de 997 kN e coeficiente de variação de $30,4 \%$.

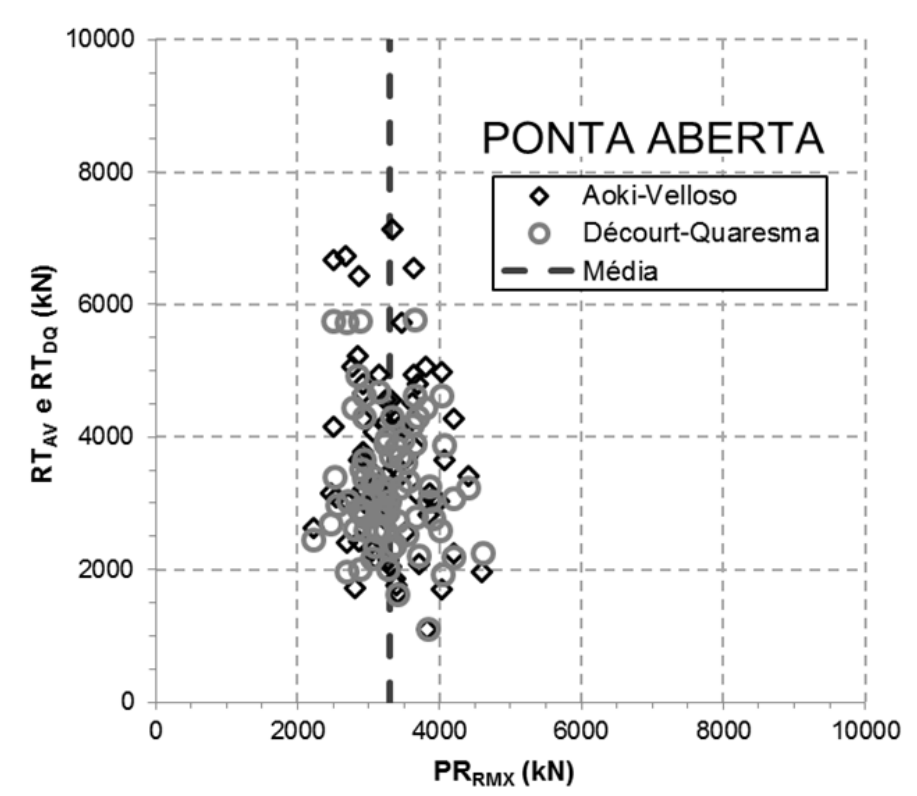

Figura 4.41 - Comparação entre os valores de $P R_{R M X}$ obtidos pelos PCD em relação a previsão pelos métodos semi-empírico $-\mathrm{n}=74$ estacas.

Considerando-se apenas a previsão das parcelas de resistência por atrito lateral, 
existe uma melhor convergência entre grande parte dos resultados com os valores obtidos através das interpretações das provas de carga dinâmica (Figura 4.42). Supõe-se nesse caso, que pelas formas das curvas de $R M X$ por $D M X$ terem caracterizado bem o trecho de ruptura que os valores de resistência por atrito avaliado pelo método CAPWAP nos golpes de maior energia sejam próximos da resistência por atrito na ruptura.

Observando-se a maioria dos resultados de ambos os métodos de previsão, não existe diferenças na avaliação da resistência por atrito lateral ao longo da profundidade (Figura 4.42), os resultados são convergentes com os obtidos a partir das analises CAPWAP.

Pelos resultados de $P R_{R M X}$ e pela premissa adotada para a definição da resistência por atrito lateral, a diferença entre esses valores resulta na parcela de resistência de ponta na ruptura. Comparando-se os resultados obtidos para cada prova de carga dinâmica com a previsão pelos métodos semi-empíricos (Figura4.43).

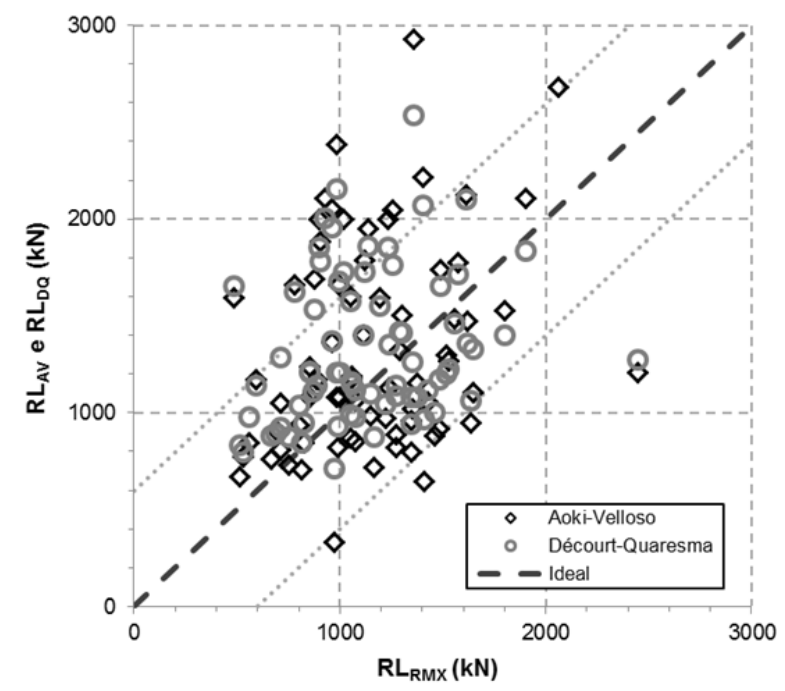

Figura 4.42 - Comparação entre a parcela de atrito lateral (RL) obtida na análise CAPWAP do PCD pelo previsto a partir dos métodos semi-empírico $-\mathrm{n}=74$ estacas.

Na previsão pelo método Aoki-Velloso para a parcela de $R P$ os valores variaram de $154 \mathrm{kN}$ a $7141 \mathrm{kN}$, enquanto que pela parcela de ponta obtida nos PCD a variação foi entre $892 \mathrm{kN}$ a $2451 \mathrm{kN}$, tendo como média $1770 \mathrm{kN}$ e $C V$ de 23,9\%. Pelo método DécourtQuaresma os valores variam na faixa de $153 \mathrm{kN}$ a $4022 \mathrm{kN}$. 
Essa grande discrepância nos valores de resistência de ponta previstos e medidos está diretamente relacionada à variabilidade da camada de areia fina siltosa abaixo da ponta das estacas, avaliada pelos ensaios SPT. Os valores de índice de resistência à penetração ( $N_{S P T}$ ) variaram da ordem de 1 a 60 golpes. Portanto, deve-se ter cautela ao usar um método baseado no ensaio SPT para a estimativa da resistência de ponta, pois para essa situação a variabilidade dos valores de $N_{S P T}$ influenciaram a dispersão nas previsões, o que não ocorreu nos valores obtidos pelas PCD, que apresentam um baixo $C V$.

Na verificação de um valor de $N_{S P T}$ ideal (com base nos resultados das PCD) para aplicar no método Aoki-Velloso, a Figura4.44 apresenta o resultado da retroanálise dos valores de $R P$, para qual foi estimado valores de índice de resistência a penetração $\left(N_{R P}\right)$ esperados e comparados com os valores medidos pelo ensaio SPT na cota da ponta da estaca.

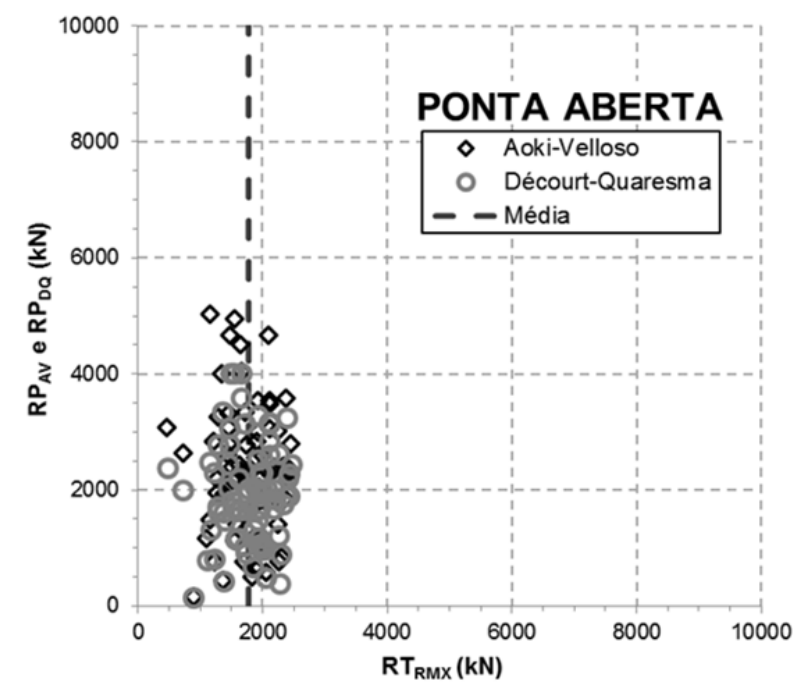

Figura4.43 - Comparação da parcela de ponta (RP) prevista com os resultados obtidos na análise CAPWAP nos $\mathrm{PCD}-\mathrm{n}=74$ estacas.

A faixa de variação obtida na retroanálise mostra que o índice $N_{R P}$ da camada de areia fina siltosa, que deveria ser usado nas previsões, variou entre 7 a 19 golpes $/ 30 \mathrm{~cm}$. 


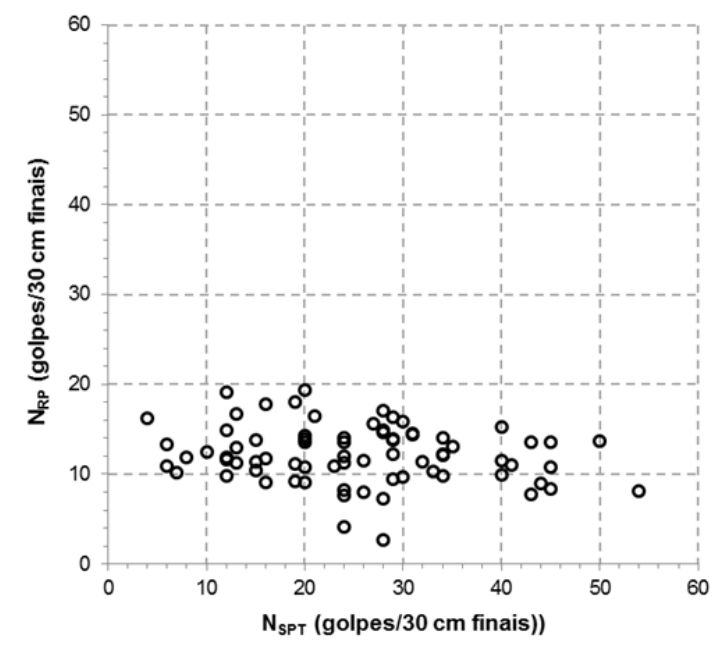

Figura4.44 - Retro análise dos valores de $N_{R P}$ a partir da $R P$ avaliada pelas analises CAPWAP em comparação com os $N_{S P T}$ na ponta das estacas.

\subsection{Avaliação da resistência de ponta - Efeito do Embuchamento}

Para a resistência de ponta prevista das estacas ensaiadas estaticamente neste trabalho (Tabela 4.22), além da questão da variabilidade na compacidade da camada de areia ocasionar uma grande dispersão nos resultados, outro ponto importante é a possibilidade de embuchamento interno da estaca ocorrido durante a cravação.

Nas previsões foi considerada uma hipótese simplificada para cálculo da resistência de ponta, adotando-se a área da ponta igual à da seção anelar de concreto, o que resultou em abaixo dos medidos em campo. No caso especifico da prova de carga da estaca $\mathrm{n}^{\circ}$. E114M02 por haver uma grande diferença entre o resultado da PCE e PCD acredita-se que durante a execução do ensaio estático a bucha se deslocou em relação à estaca ocasionando uma perda de resistência de ponta.

Jardine e Chow (1996) para o caso de estacas com ponta em areia propõe um critério para classificação da possibilidade de embuchamento da estaca em função da densidade relativa da areia (Figura 01).

Na Figura 4.45, considerando - seque no presente estudo os valores ${ }^{N}{ }_{\text {SPT }}$ da camada de areia variaram de 4 a 54 golpes $/ 30 \mathrm{~cm}$ finais, obtendo-se deste modo uma compacidade relativa $\left(D_{R}\right)$ que varia de 55 a $85 \%$, e que o diâmetro interno da estaca é de 46 
cm, de acordo com a proposição de Jardine e Chow (1996), nas estacas deste trabalho ocorreu o embuchamento na cravação.

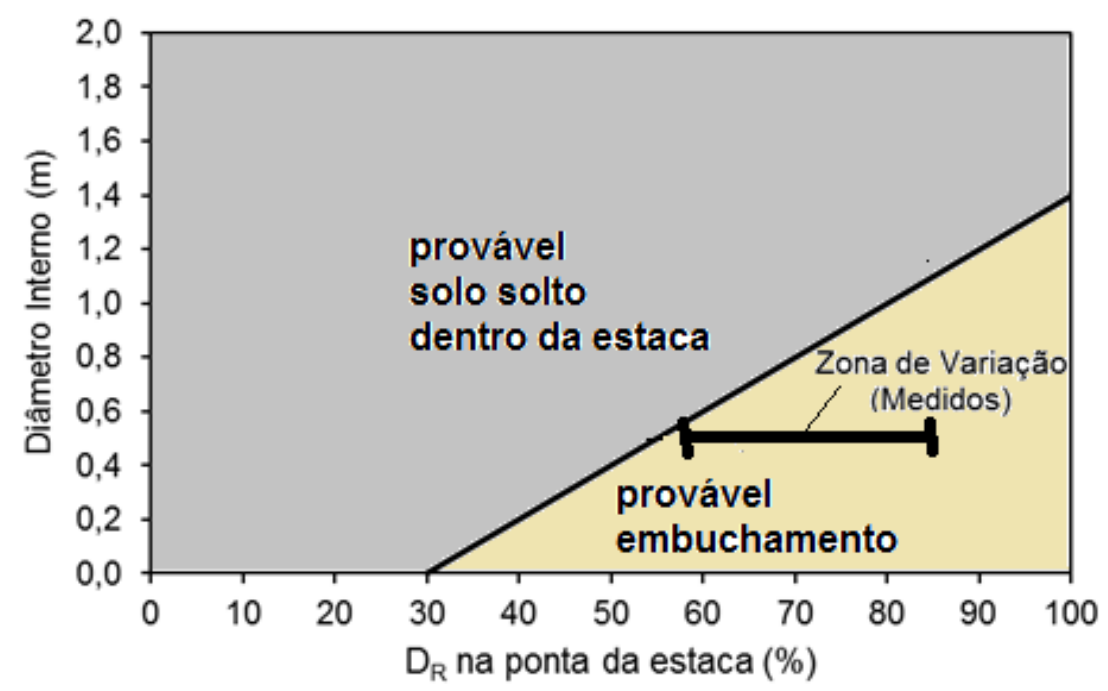

Figura 4.45- Critério de embuchamento de estacas sob areia compacta (Jardine e Chow, 1996).

Para avaliar a resistência de ponta das estacas, buscou-se num primeiro momento verificar o nível de influência da bucha na resistência de ponta, a partir dos métodos semiempíricos de previsão da capacidade de carga, considerando-se duas situações extremas: 1) a situação com a área da ponta igual à da seção de concreto - comportamento de ponta aberta, e 2) com a ponta fechada (área da seção cheia) que como foi apresentado na Tabela 4.22.

Os resultados dessas simulações foram comparados (Figura 4.46) com os dados obtidos a partir das provas de carga dinâmica (extrai diretamente $R F$ das análises CAPWAP) e estática (interpretado pelos métodos de Massad, 1992 e Décourt, 1996 - obtendo-se as parcelas de atrito e por comparação com a carga de ruptura a parcela de ponta).

Para o caso das estacas E114M02, E125M09 e E113M15 os resultados medidos tem uma tendência a se comportarem como uma estaca com a ponta aberta se aproximando dos valores obtidos pelas previsões. A estaca E018M04 já demonstrou uma tendência ao comportamento de estaca de ponta embuchada, ou seja, há uma contribuição da bucha de solo no interior da estaca na resistência de ponta. 

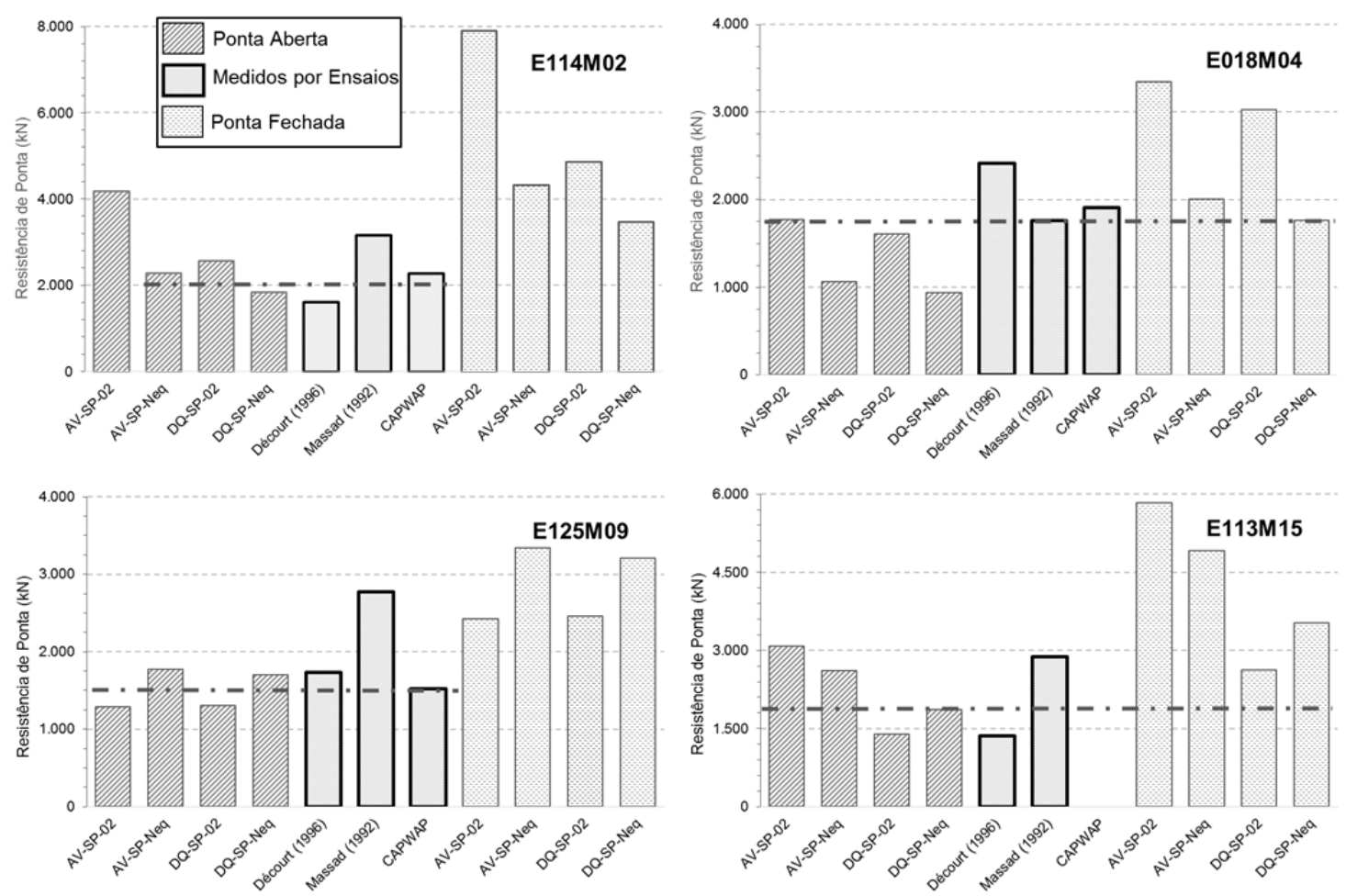

Figura 4.46- Comparação dos valores medidos da resistência de ponta com as previsões considerando-se ponta aberta e fechada.

A partir desse cenário a geometria da seção transversal da estaca foi interpretada para avaliar por alguns métodos a contribuição da bucha de solo na capacidade de carga total da estaca, permitindo-se assim retroanalisar o gráfico da Figura4.43e verificar a influência desse fenômeno nos cálculos.

Na obtenção dos dados de execução, não se deu importância a esse fenômeno, e consequentemente não foram realizadas medições internas à estaca para verificar altura da bucha de solo dentro da estaca. Niyama (1992) verificou através de um estudo experimental, que a altura da coluna da bucha maior que 2 vezes o diâmetro da estaca já é suficiente para absorver por atrito lateral interno a carga atuante na ponta da coluna.

Para a estaca de concreto em estudo com diâmetro externo $(B E)$ de $70 \mathrm{~cm} \mathrm{e}$ espessura da parede $(e)$ de $11 \mathrm{~cm}$ resulta na relação $e / B E_{\text {de }} 15,7 \%$. Plotando-se estes dados nos gráficos -Figura 4.47de Niyama (1992) resulta na relação de $P I / P E=36 \%$ e 55\%. Para a estaca E114M02 com comprimento cravado (L) de 12,2 metros resulta numa altura da 
coluna de solo de 4,6 m a 6,4 $\mathrm{m}$. Em campo há registros da altura da coluna interna de solo da ordem de 5,0 metros, sendo adotado para o cálculo da contribuição da resistência de ponta.
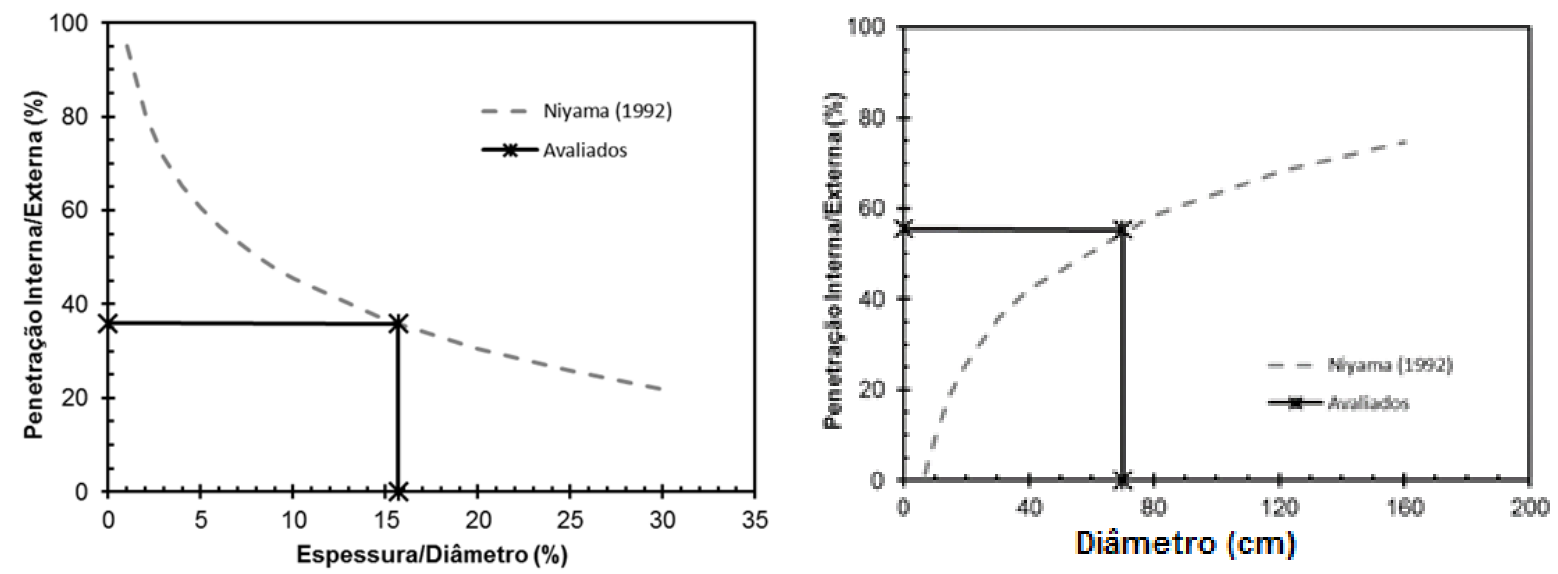

Figura 4.47- Influências da espessura e do diâmetro da estaca na altura da bucha (Niyama, 1992).

A partir da geometria e das considerações da altura interna da coluna da bucha, a Tabela 4.22apresenta para diversas propostas de autores a contribuição do plug de solo na resistência de ponta da estaca. Considerando-se a contribuição do solo embuchado é em média igual a $530 \mathrm{kN}$ de acordo com os métodos da Tabela 4.22, a Figura 4.48deste texto compara-se as 3 hipóteses.

Tabela 4.22- Valores da contribuição do plug na resistência da ponta.

\begin{tabular}{cc}
\hline Proposta & $\begin{array}{c}\text { plug } \\
(\mathrm{kN})\end{array}$ \\
\hline Kishida (1967) & 49 \\
\hline $\begin{array}{c}\text { Soo et al. } \\
(1980)\end{array}$ & 52 \\
\hline $\begin{array}{c}\text { Lehane e } \\
\text { Randolph (2001) }\end{array}$ & $37-542$ \\
\hline Valor médio & 30 \\
\hline
\end{tabular}

A partir das análises efetuada conclui que existe para as estacas analisadas o 
fenômeno de embuchamento que acarreta um incremento de carga na ponta, como demonstrado pelas analises pelo fator $\mu$ (item 4.1.6.2). Para os casos das análises das estacas testes $(n=4$ casos $)$ encontrou-se variações entre a resistência de ponta medida e interpretadas pelos diferentes métodos pela previsão variando da ordem de 0,88 a 2,13 tendo como média 1,31 .
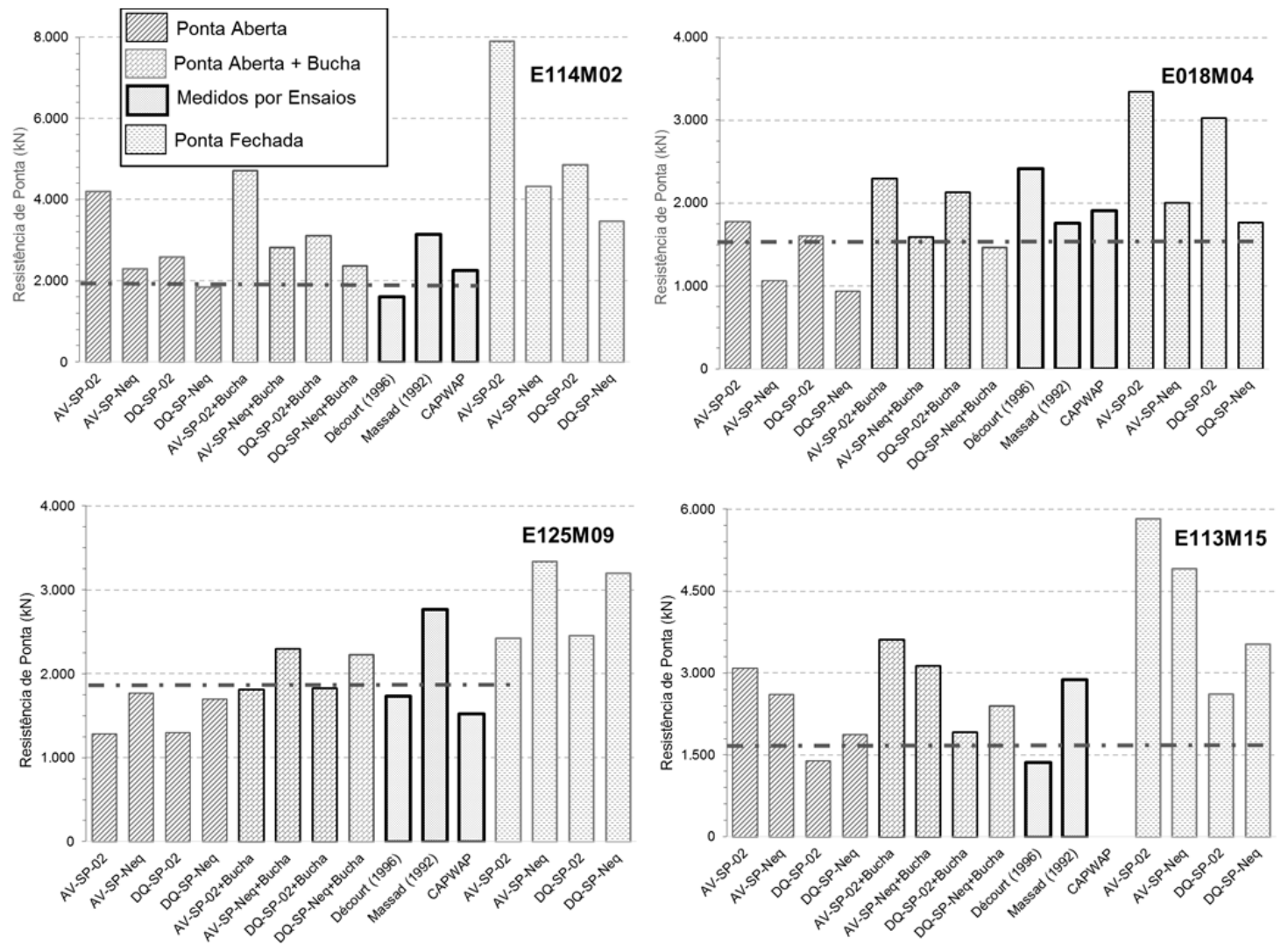

Figura 4.48- Comparação dos valores medidos da resistência de ponta com as previsões considerando-se: 1 - ponta aberta (sem o efeito do embuchamento), 2 - ponta igual à seção do anel mais atrito interno na bucha e 3 - ponta fechada.

Nesse valor apenas uma parcela deve ser atribuída ao fenômeno de embuchamento, pois existe também a questão de variabilidade de resistência da camada de areia na ponta das estacas aliado a sua origem geologia de um deposito sedimentar. 


\subsection{Aplicação das Fórmulas Dinâmicas}

\subsubsection{Fórmulas de Chellis (1951)}

A fórmula (expressão [2.15])considera o solo com comportamento elastoplástico, e na fase elástica há um par de valores de deformação elástica do solo - quake $(C 3)$ e do fator de transferência ( $f$ ) de carga atrito/ponta. Nas análises usuais fixa-se um valor de $C 3$ em função do tipo de solo na ponta da estaca ou pela proposta de Souza e Abreu (1990) e um parâmetro de $f$ em função da previsão do diagrama de transferência do perfil de sondagem.
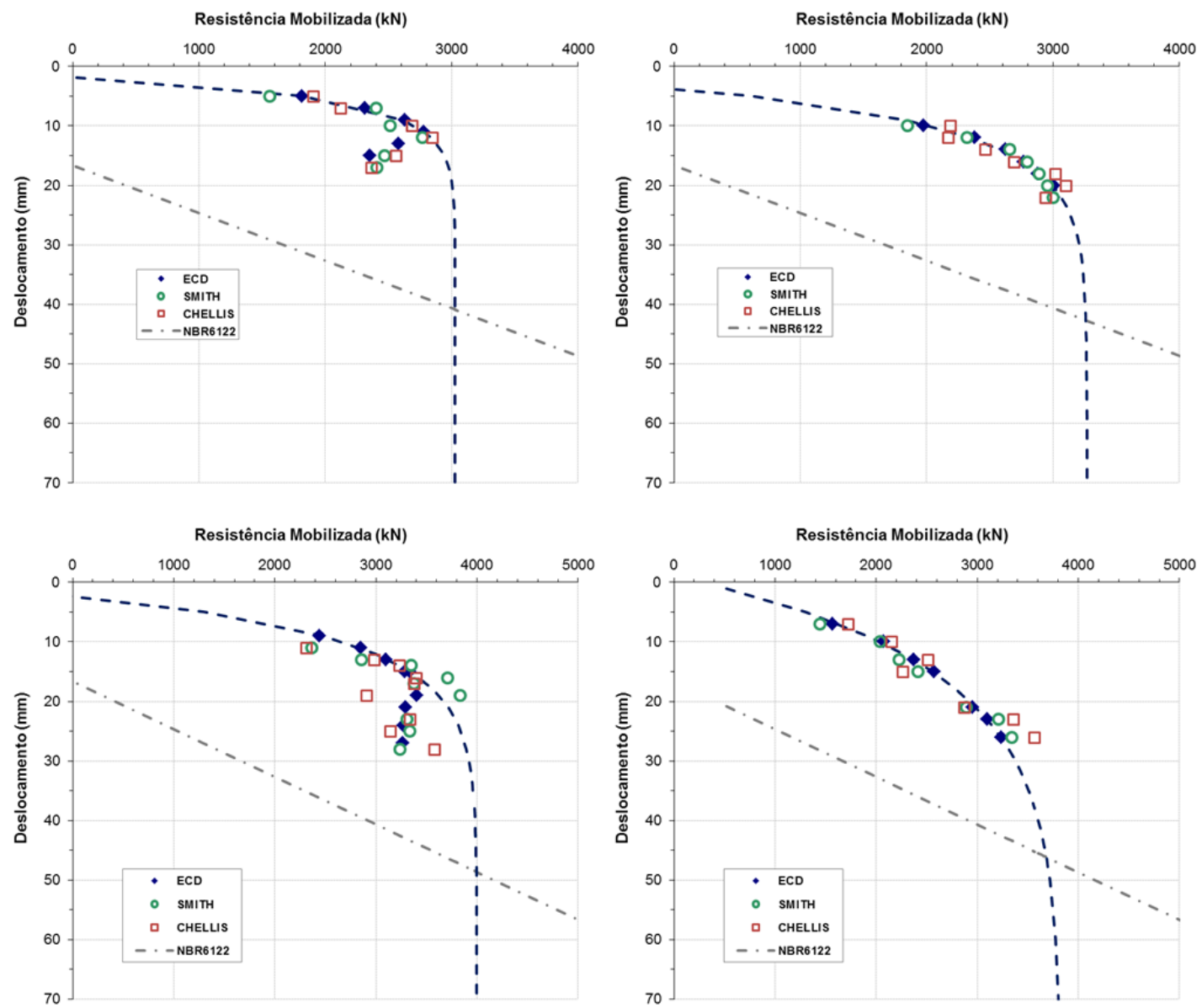

Figura4.49 - Restituição da curva resistência mobilizada por deslocamento a partir dos registros de nega e repique elástico (estacas E132 M18, E124 M15, E122 M07 e E126 M03).

Esses parâmetros são obtidos independentes do nível de energia aplicado pelo 
sistema, devido principalmente a dificuldade de se atribuir um modelo matemático adequado que relacione os diversos intervenientes (Rosa, 2000).

Nesse trabalho os valores de $f$ foram obtidos através da análise CAPWAP pela divisão das parcelas de atrito lateral/ponta, e a partir dessa constante os valores de $C 3$ são analisados através de um estudo de retroanálise considerando a $R M_{C H}$ igual a $R M X$ e posteriormente modelado por uma curva ajustada de $C 3$ por $E M X$ para diferentes níveis de energia.

Adicionalmente para os diferentes níveis de energia aplicados na PCD e com os registros de nega e repique elástico foram correlacionados os valores de resistência mobilizada. A Figura4.49 ilustra alguns casos das restituições de curvas do ensaio obtida a partir dos registros analisados.

\subsubsection{Fator de transferência $(f)$}

O fator $f$ é dependente principalmente da transferência entre as parcelas de atrito lateral/ponta, mas também está em função do quake do solo e do nível de energia aplicado. $\mathrm{O}$ seu valor varia entre 0,5 , quando a estaca trabalha preponderantemente por atrito, a 1,0 totalmente por ponta.

Em função dos dados das estacas ensaiadas, fez-se a previsão de capacidade de carga para cada sistema isolado de fundação, determinou-se um fator de transferência obtida a partir dos ensaios SPT. A Figura4.50 apresenta uma comparação para cada caso entre os valores determinados pela análise CAPWAP com os resultados da previsão.

Pelos dados a faixa de variação que se concentra a maioria dos pontos é de 0,61 a 0,89 representando que a maior transferência é pela ponta existindo uma tendência de que o fator determinado pela análiseCAPWAP ser ligeiramente inferior ao previsto.

Plotando os mesmos pontos de $f$ determinado a partir dos resultados das análises CAPWAP em função do comprimento cravado das estacas (Figura4.51), da seção transversal, do módulo de elasticidade do concreto, dos registros de nega e repique obtido em campo,tendo como única variável o valor do quake, plotou-se num mesmo gráficoas curvas de 
iso-quakes da ponta da estaca (determinados a partir da fórmula dinâmica de Chellis) em função do fator de distribuição de atrito/ponta.

Graficamente é demonstrado que existe uma relação direta entre os a transferência de carga com o encurtamento do solo na ponta da estaca, nessa condição para um fator $f$ entre 0,7 a 0,9 a faixa de variação do quake do solo ( $C 3$ ) na ponta da estaca é de 6,0 a 7,5 $\mathrm{mm}$.

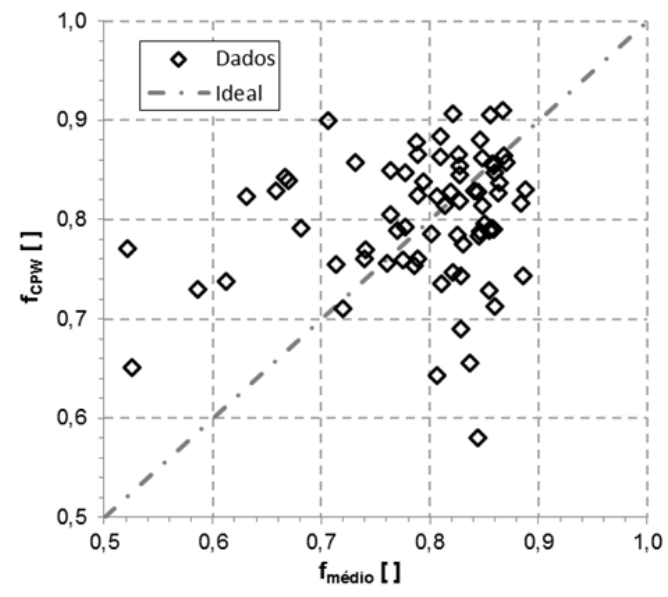

Figura4.50 - Comparação entre o fator $f$ pelos resultados das previsões e analises CAPWAP para os golpes de maior energia.

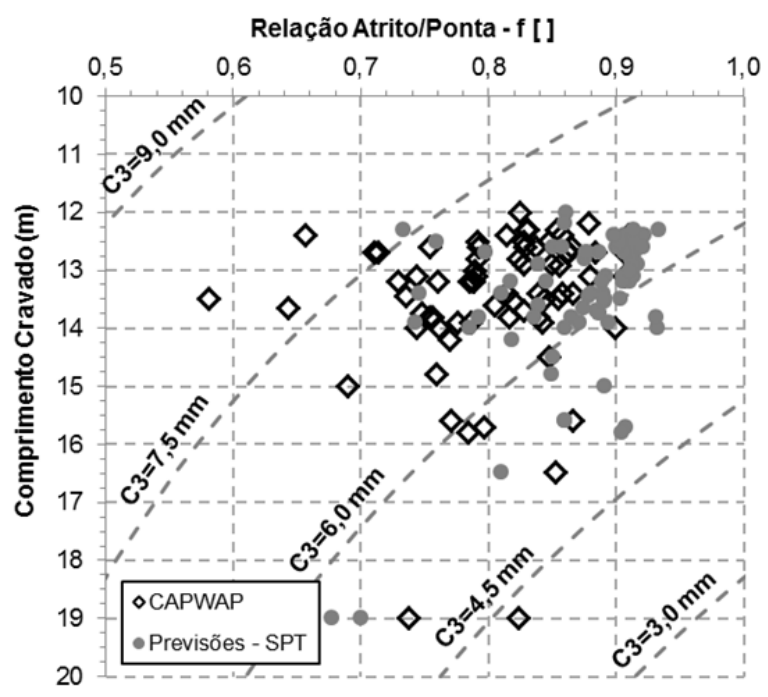

Figura4.51 - Correlação entre o fator $f_{\mathrm{e}} C 3$ em função do comprimento cravado. 
Para a construção das curvas de iso-quakes da ponta da estaca foi admitido que $R M_{C H}$ é igual a 1,6 vezes a carga de projeto $(1850 \mathrm{kN})$, o módulo de elasticidade do concreto de $(29,5 \mathrm{GPa})$, a área da seção transversal igual a $0,2039 \mathrm{~m} 2$ e o repique elástico $\left(K_{\min }\right)$ mínimo de $12,0 \mathrm{~mm}$.

$\mathrm{Na}$ análise dos diversos golpes em função dos diferentes níveis de energia foi assumido o fator $f$ constante, e atribuído o valor obtido pela análise CAPWAP no golpe de maior energia.

\subsubsection{Quake do solo ( $C 3$ )}

Pelos resultados das análises CAPWAP os golpes para cada PCD foi retroanalisado pela fórmula de Chellis num primeiro momento obtendo o valor de ${ }^{C 3_{C H}} \mathrm{e}$ correlaciona-lo com a energia líquida $(E M X)$ para os diferentes golpes de energia crescente.
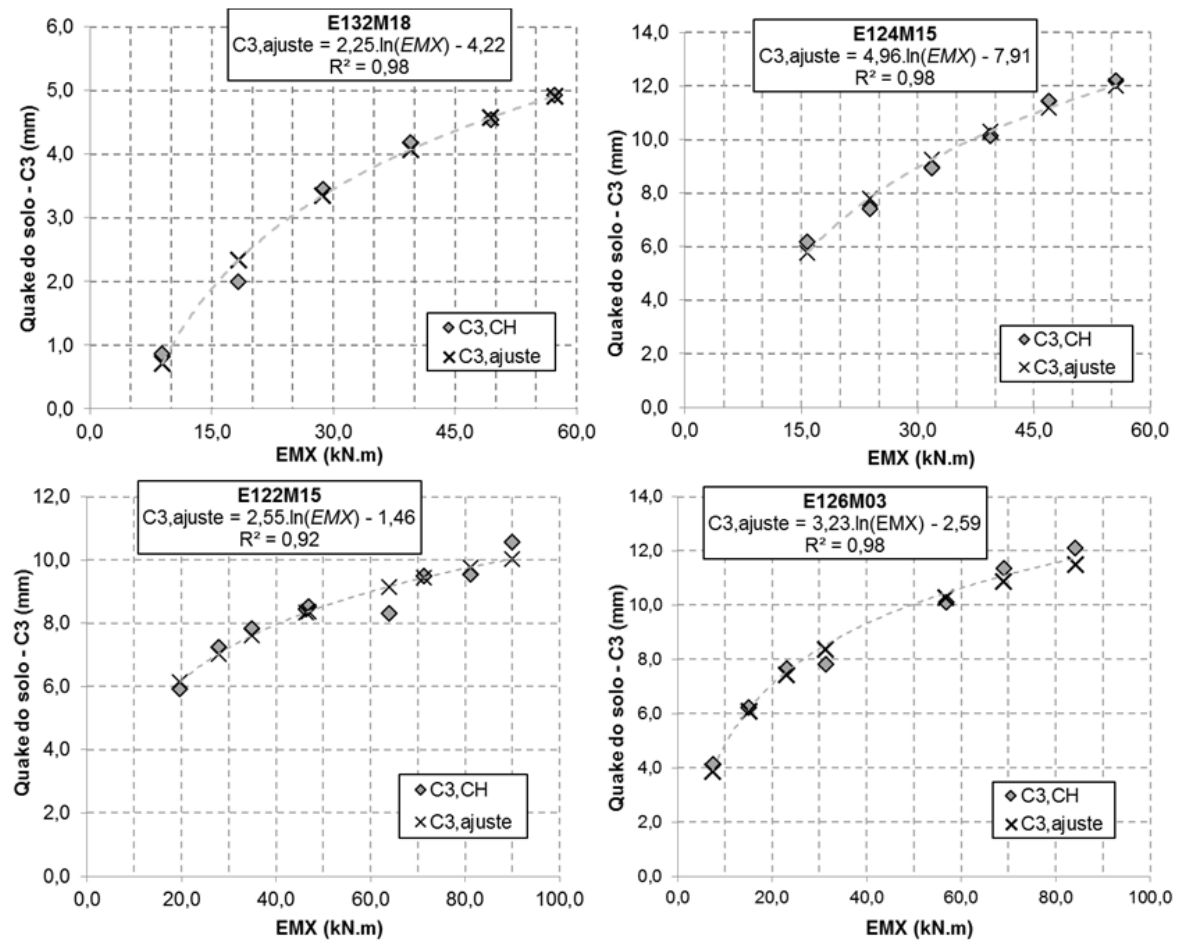
Figura4.52 - Retroanálise a partir dos PCD de $C 3_{C H}$ em função de $E M X$ - estacas E132 M18, E124 M15, E122 M07 e E126 M03.

Para uniformizar os dados, após a execução do ajuste da curva a partir da equação da retroanálise foram recalculados os valores, denominando de $C 3_{C H, R}$.

A Figura4.52 apresenta alguns exemplos dos ajustes realizados em que os pontos demonstraram uma tendência a um ajuste logarítmico, comum a todos os ensaios realizados.

Como resultados das análises CAPWAP é exprimido para o modelo numérico o quake da ponta $\left({ }^{C 3_{C W}}\right)$ adotado. A Figura4.53 apresenta uma comparação entre os valores obtidos pela retroanálise pela fórmula de Chellis $\left({ }^{C 3_{C H, R}}\right)$ e a curva ajustada $\left({ }^{C 3_{C H, U}}\right)$ com o CAPWAP $\left({ }^{C 3_{C P W}}\right)$, demonstrando pequenas diferenças entre as duas formulações e convergência dos resultados. Todas as análises apresentadas a seguir se referem aos golpes de maior energia.

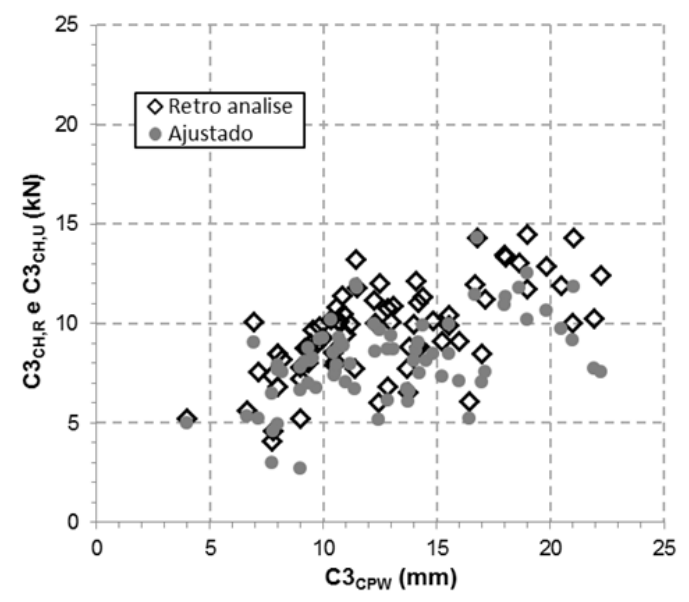

Figura4.53 - Comparação entre os valores de $C 3_{C P W}$ por $C 3_{C H} / C 3_{C H, R}$ obtidos por retro análise da fórmula de Chellis. 

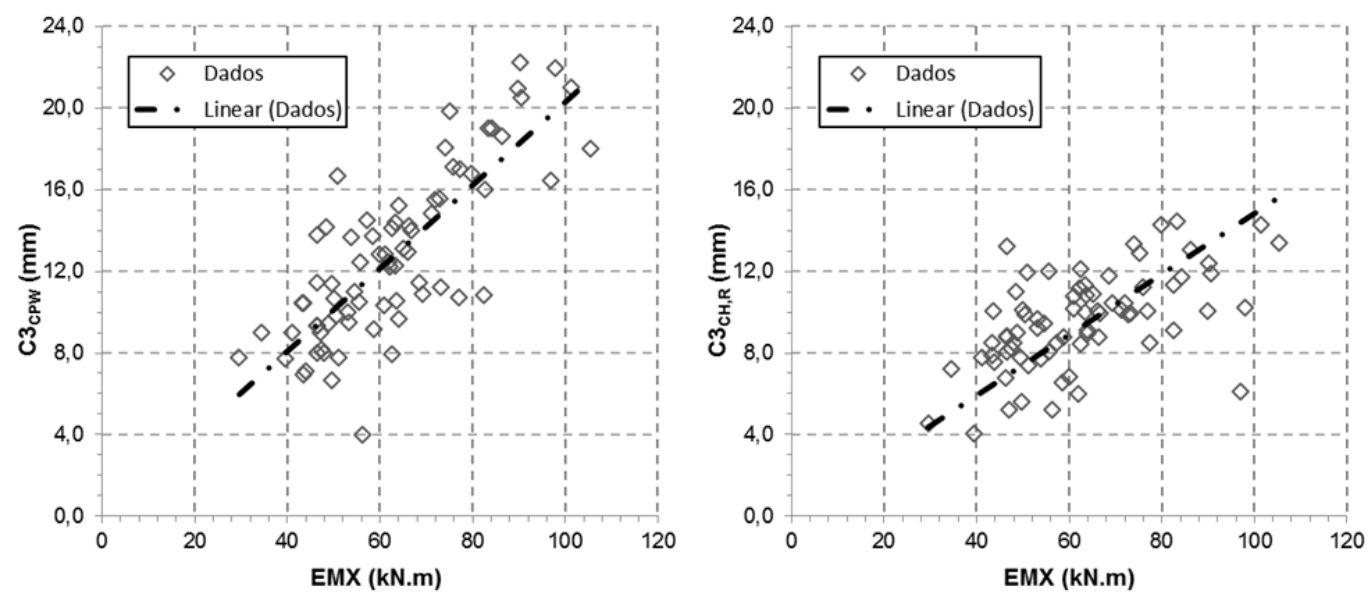

Figura4.54 - Relação entre $E M X$ em função de $C 3_{C P W}$ e retroanalisado $C 3_{C H, R}$.

A Figura4.54 apresenta os valores de $E M X$ por $C 3_{C P W}$ (parte a) e por $C 3_{C H, R}$ (parte b) em que ambos os gráficos apresentam na média um coeficiente angulares próximos, entretanto no ajuste inicial há uma maior dispersão em torno da reta média.

Entretanto para a determinação das resistências mobilizadas das estacas no final de cravação faz-se necessário conhecer a curva de $E M X$ por $C 3_{C H, R}$ uniformizando os resultados em função da energia potencial $\left(E_{P O T}=70 \mathrm{kN} . m\right)$ de cravação levando em considerando as eficiências de cada equipamento/ensaio - Figura 4.55.

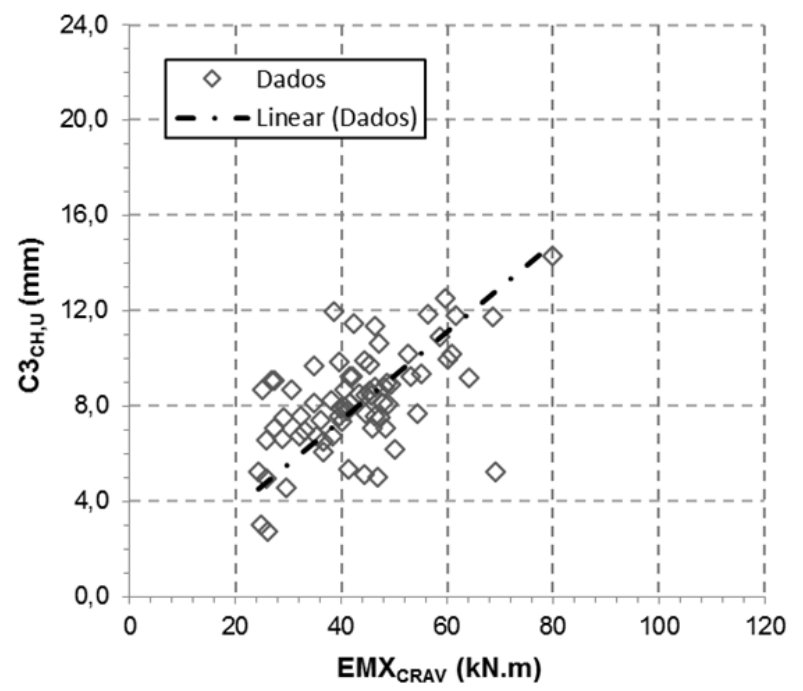


Figura4.55 - Valores de $C 3_{C H, R}$ para energia de cravação $\left(e \cdot E_{P O T}\right)$, no final de cravação.

Para o quake da ponta, Danziger (1990) concluiu que os valores aumentam com o acréscimo da resistência de ponta, e que essa variação pode ser linear, assumindo uma posição contraria ao modelo de Smith (1960) que assume valores de quake lateral e ponta constantes e com valor de $2,5 \mathrm{~mm}$. Plotando os pontos (Figura 4.56) em função da máxima resistência mobilizada, observa-se que o projeto é uma região da curva proposta de Danziger (1990), pois a relação está diretamente condicionada a uma baixa variabilidade do comprimento e o mesmo tipo de material na ponta.

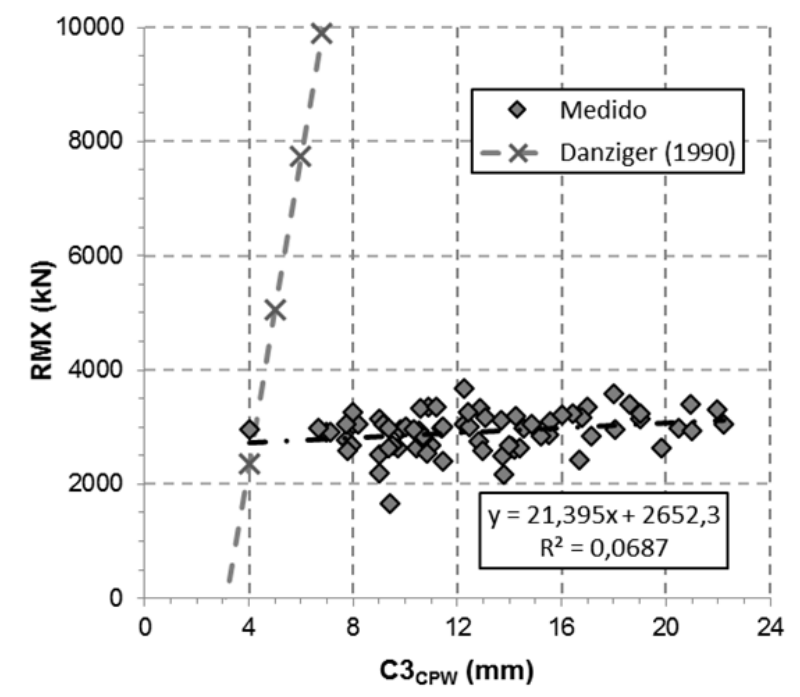

Figura 4.56 - Comparação entre a resistência mobilizada por quake do solo com a observação de Danziger (1990).

\subsubsection{Resistência mobilizada}

Pela variabilidade dos resultados e a fim de obter uma correlação que permita nortear as calibrações, a Figura4.57 apresenta uma correlação entre a resistência de ponta última adimensionalizada ( $\left.R P_{U L T} / P R_{R M X}\right)$ com a influência do quake do solo/deslocamento total $\left(C 3_{C H, U} / D_{K+S}\right)$. 


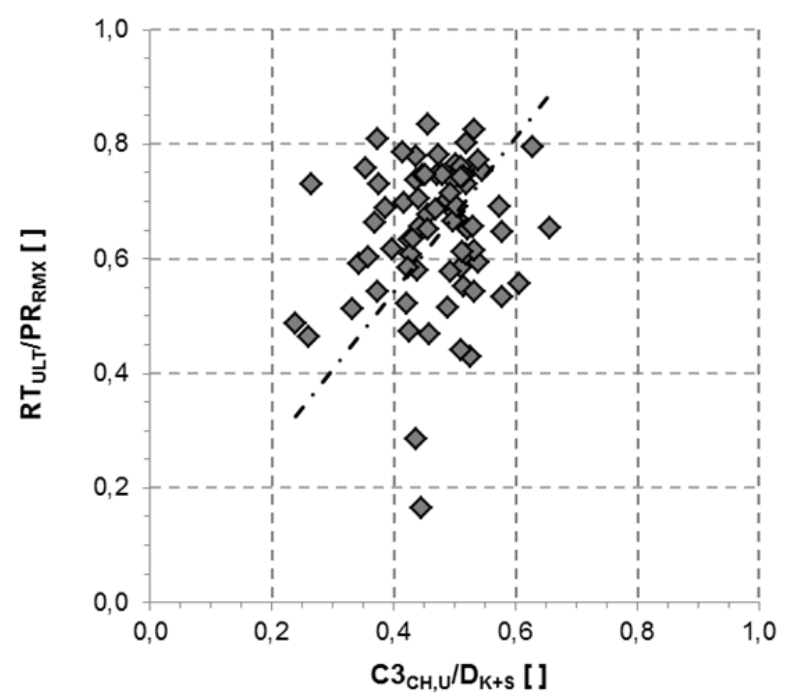

Figura4.57: Adimensionalização entre $R P_{U L T} / P R_{R M X}$ pelos valores de $C 3_{C H, U} / D_{K+S}$.

Apesar da dispersão em relação à linha de tendência média existe uma relação direta entre a resistência da ponta e o quake. Danziger (1990) atribui o aumento do quake de ponta ao aumento/mobilização da resistência de ponta. Para uma variação de $R P_{U L T} / P R_{R M X}$ entre 0,55 a 0,80 a faixa de variação correspondente de $C 3_{C H, U} / D_{K+S}$ é de 0,35 a 0,55.

Após a convergência dos parâmetros e a construção das curvas de variação dos parâmetros, a Figura4.58 apresenta a relação entre os valores da resistência mobilizada obtida a partir da fórmula de Chellis calibrada e ajustada em comparação com as análises CAPWAP dos ECD, em função das três distintas regiões geológica-geotécnicas já caracterizadas. Os pontos se referem aos golpes de maior energia. 


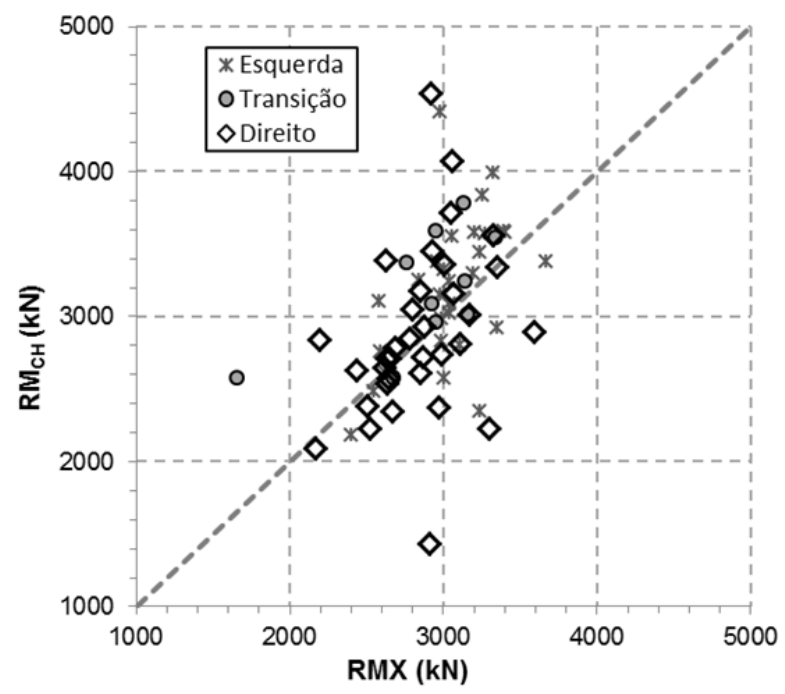

Figura4.58: Comparação entre os resultados entre $R M_{C H}$ e $R M X$.

Realizando o mesmo tratamento matemático para todos os golpes aplicados em todas as provas de carga a Figura4.59 apresenta a comparação entre as resistências mobilizadas pelo ECD com os valores calibrados pela fórmula dinâmica de Chellis para os registros de repique elástico.

A calibração e o ajuste realizado para todos os golpes aplicados resultou numa distribuição dos pontos paralelo a reta considerada ideal, possuindo um coeficiente angular de 0,9982. Na Figura4.59 se aplicou um intervalo de confiança de 15\% entre o valor médio, englobando pelo mais do que $95 \%$ dos dados medidos.

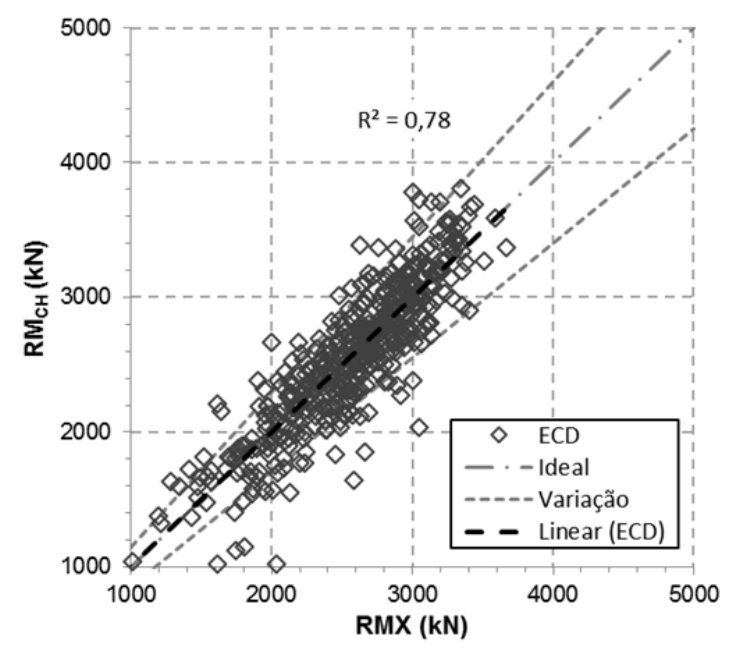


Figura4.59: Comparação entre as resistências mobilizadas obtidas pelo ECD e repique elástico interpretados por Chellis - todos os golpes.

A partir dos mesmos pontos a Figura4.60apresenta a curva de distribuição de frequências e curva de Gauss para a resistência mobilizada calculada a partir da fórmula de Chellis obtendo como valor médio $2565 \mathrm{kN}$, para um desvio padrão de $544 \mathrm{kN}$ e coeficiente de variação de 21,2\%. Para um quantil de 5\% corresponderia a resistência de $1585 \mathrm{kN}$ resistência característica.

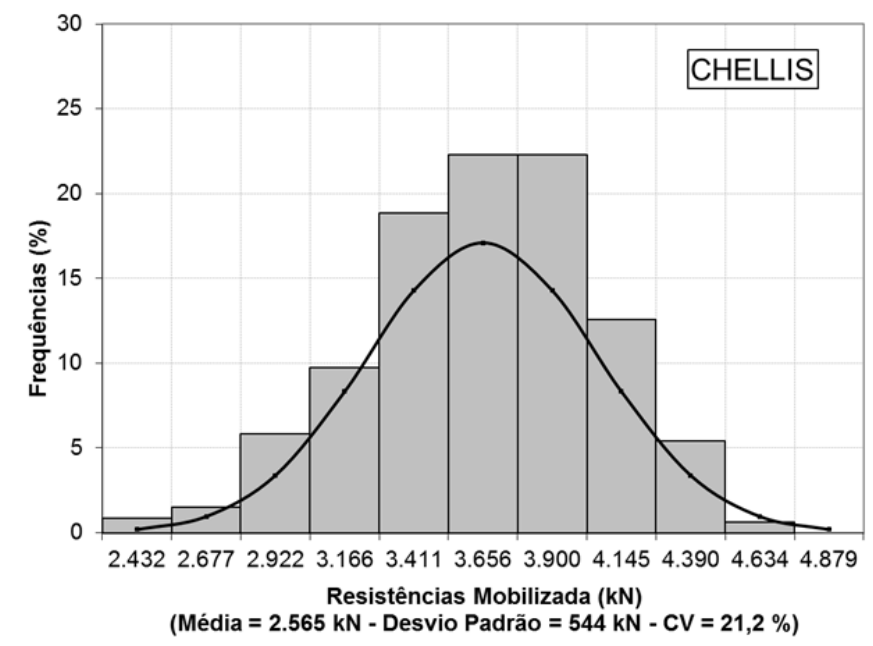

Figura4.60 - Distribuição de frequências para os valores de resistência mobilizada obtida pela fórmula de Chellis.

O histograma corresponde a uma população de 74 ensaios de carregamento dinâmico com 462 golpes medidos na metodologia de energia crescente. Considerar que a distribuição de frequências comtempla todos os golpes com energias variáveis.

\subsubsection{Fórmula de Smith Modificada por Aoki (2011)}

\subsubsection{Parâmetro $\xi$}

A expressão de Smith modificada por Aoki (2011) tem como principal fator de variação o valor de $\xi$ que é único para cada projeto e está associado ao nível de controle empregado e as características da execução. A grande facilidade que esse parâmetro exerce é 
a possibilidade de calibrar todos os golpes do PCD com energia crescente com um único parâmetro.

Adicionalmente uma grande vantagem dessa expressão reside no fato que o parâmetro absorve o efeito de comportamento de solo resiliente ou de elevados valores de quake da ponta ( $C 3$ ).

Pela simplicidade da formulação pouco se sabe ainda a respeito das influências e do balizamento de parâmetros. Dessa forma a princípio todas as medidas dinâmicas foram relacionadas com os ensaios de carregamento dinâmicos a fim de identificar influências e comportamentos na estimativa da resistência mobilizada.

Pelo maior conhecimento da fórmula de Chellis e de expressões baseadas em medidas de nega, tem-se a sensação de que quando menores os valores de nega e maiores os valores de repique elástico há um aumento da resistência mobilizada. Essa premissa não é de toda verdadeira pelo simples fato de que para haver mobilização de resistência é necessário haver deslocamento resultando num aumento (abertura) da nega.

\subsubsection{Resistência mobilizada}

A Figura4.61 apresenta uma curva formada por todos os golpes aplicados nos ensaios de carregamento dinâmico das medidas de $S+D$ em função dos diferentes níveis de energia aplicados. A medida que os níveis de energia são incrementados existe uma relação

direta com o incremento de $S+D$, sendo que na sua composição a nega existe uma tendência de incremento enquanto que o repique elástico tende a estabilizar (Figura4.62). 


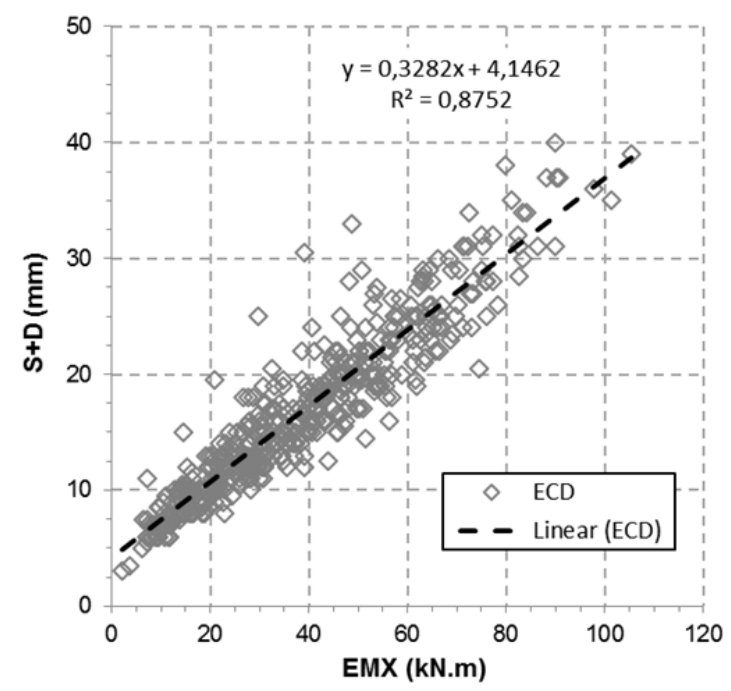

Figura4.61 - Relação entre os registros dinâmicos $(S+D)$ e a energia líquida.

Para os diversos registros de nega e repique elástico (Figura4.62) adimensionalizados em função do diâmetro nominal, em função da energia liquida aplicada/ERE é possível visualizar a tendência que a partir da relação de energia de 30\% existe uma tendência de abertura da nega até um valor da ordem de $1,2 \%$ em relação ao diâmetro nominal.

Para o caso do repique elástico a partir de uma relação de energia na faixa de 60$70 \%$ começa a ter uma tendência de estabilização das medidas. Esse comportamento foi observado por Aoki (1996).

Quanto a calibração dos diversos pontos ajustando com os resultados dos PCD, a Figura4.63 apresenta uma curva de $R M X .(S+D)$ em função de $E M X$ avaliado pela analise CAPWAP, e o coeficiente angular obtido representa diretamente o parâmetro $\xi$, que nesse caso se ajustou em 1,21 para um nível de dispersão R2 igual a 0,67.

Adotando para cada caso o parâmetro de $\xi$ calibrado, a Figura4.65 apresenta uma comparação entre os valores obtidas pela fórmula dinâmica e pelo PCD seguindo a lógica de divisão em função das principais unidades geológicas definidas para a Figura4.58. 


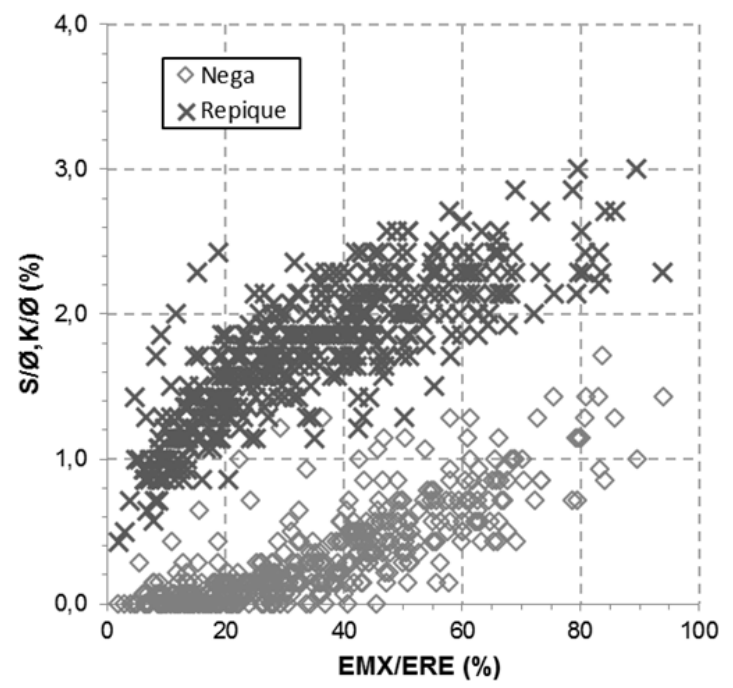

Figura4.62 - Medidas de nega e repique elástico coletados nos diversos níveis de energia aplicados.

Com os parâmetros calibrados para cada ensaio, aplicou-se em todos os pontos resultando numa curva de comparação entre os valores obtidos e a resistência mobilizada do ECD (Figura4.65), obtendo um valor de dispersão R2 de 0,89 e um ajuste muito próximo da condição ideal ( $R M X=R M_{S M}$ ). Nessa curva se aplicou um intervalo de confiança de $\pm_{15 \%}$, em relação a reta de ajuste linear entre os pontos medidos.

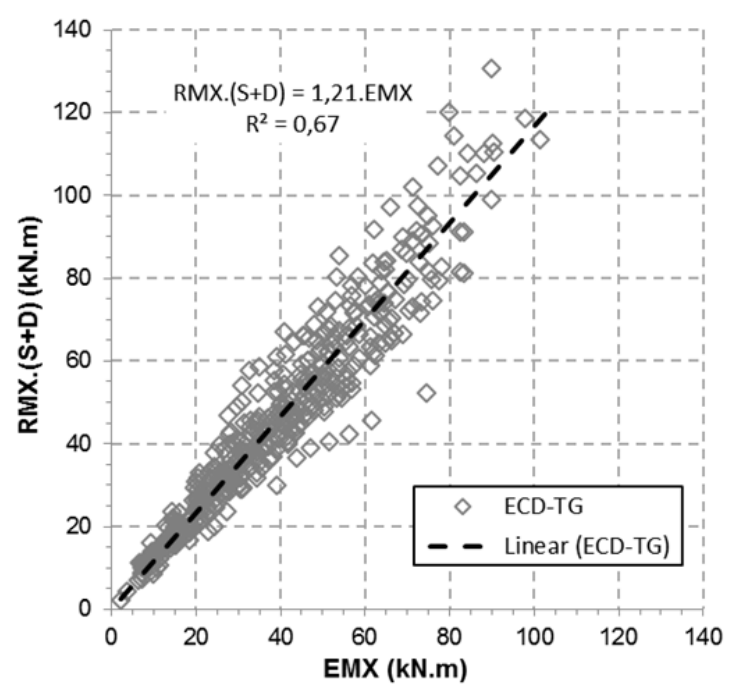

Figura4.63 - Calibração do parâmetro $\xi$ a partir dos golpes aplicados em diversos níveis de energia.

Durante a análise para as diversas curvas dos PCD verificou-se uma influência 
entre o parâmetro $\xi$ com os diferentes setup ensaiados (Figura4.66), em que para ensaios verifica-se um tendência que no final de cravação o parâmetro $\xi$ varia de 1,1 a 1,6 e com o incremento de idade a dispersão reduz, sendo que a partir de 10 dias converge para 1,0, que pode ser representado por menos perdas ao longo do tempo. No entanto, deve-se ressaltar que foram poucas estacas ensaiadas a partir de 10 dias da cravação para confirmar esta pequena dispersão.

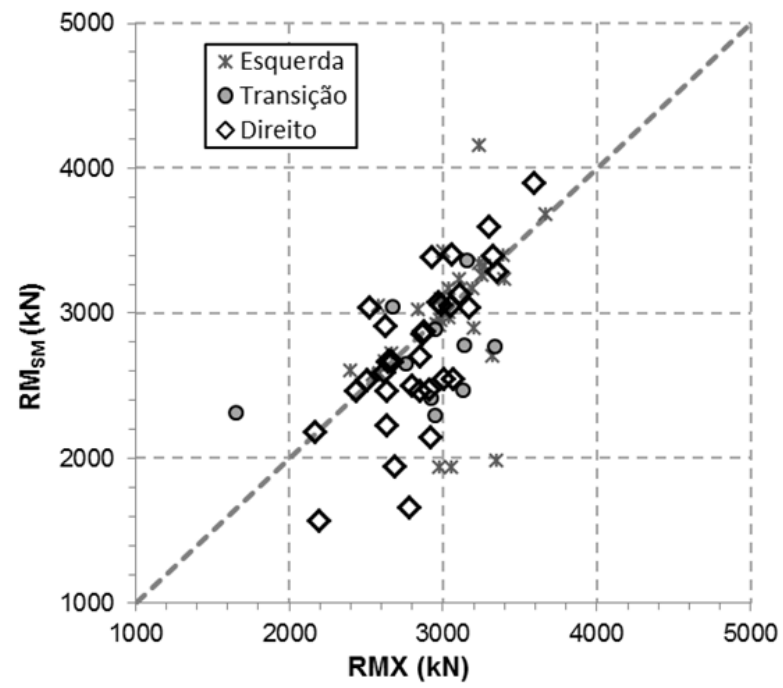

Figura4.64: Comparação entre os resultados entre $R M_{S M M}$ e $R M X$

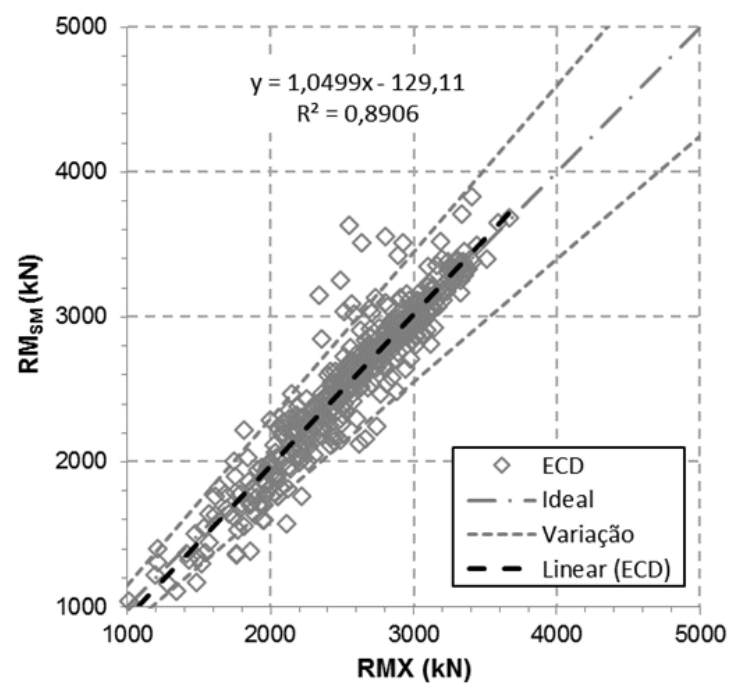

Figura4.65 - Comparação entre os valores de resistência mobilizada pela fórmula dinâmica de Smith com o ECD - análise CASE. 
Pelos pontos de resistência mobilizada (Figura4.65) organizando os dados através de uma curva de distribuição de frequências resultou num valor médio de $2565 \mathrm{kN}$, com desvio padrão de 534 kN e coeficiente de variação de $20,9 \%$.

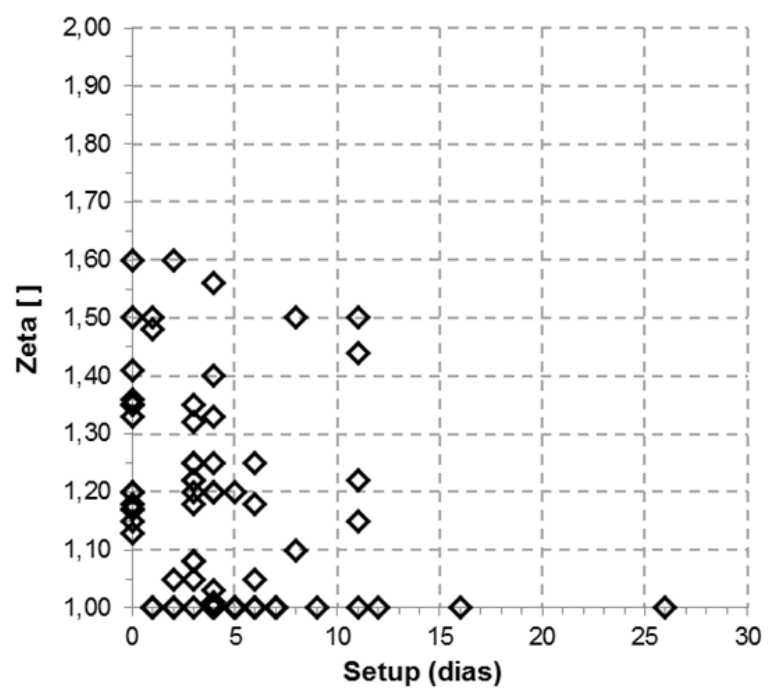

Figura4.66: Variação dos valores de $\xi$ em função do setup.

Em termos de valores médios o resultado obtido é igual à da fórmula de Chellis (Figura4.60), entretanto a diferença reside no fato da curva de distribuição está mais próximo a de uma distribuição normal, enquanto que a de Smith está deslocada para a direita (lognormal).

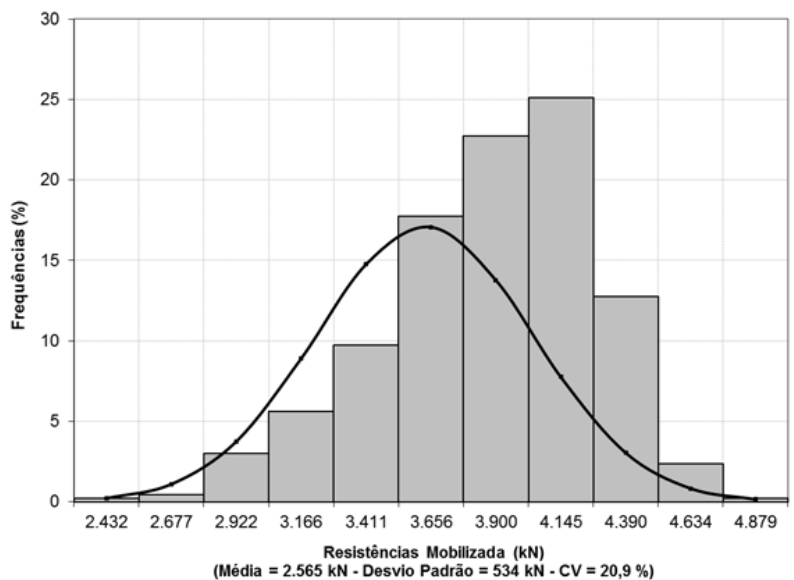

Figura4.67 - Distribuição de frequências para os valores de resistência mobilizada obtida pela fórmula de Smith modificada. 
Este fato mostra que o modo de distribuição de resistência obtido pela fórmula de Smith modificado é mais condizente com os resultados da distribuição dos valores de $R M X$ das provas de carga dinâmica, também deslocada para a direita, como mostra a Figura4.69.

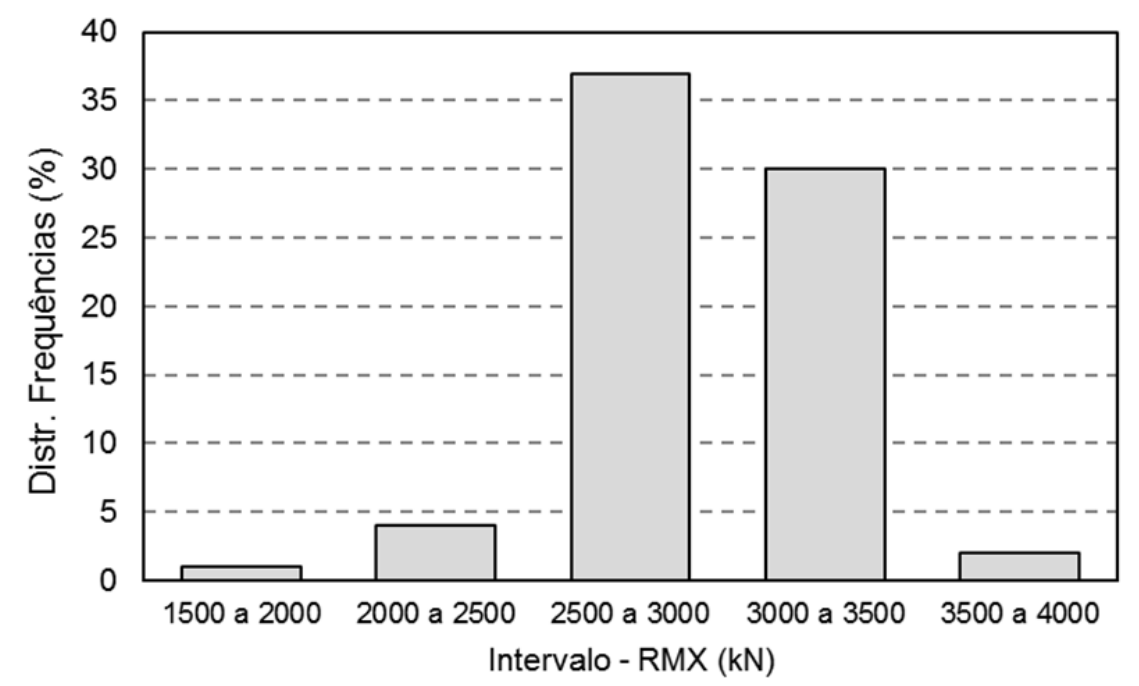

Figura 4.68 - Distribuição de frequências para os valores de $R M X$ obtidos nas PCD.

\subsubsection{Fórmula do Energy Approach}

\subsubsection{Resistência mobilizada}

Paikowsky e Chernauskas (1992) apresentam uma formulação simplificada para a estimativa da resistência mobilizada a partir de medições dinâmicas. A expressão do método é muito similar ao método de $S+D$ apresentado por Aoki (2011) se diferenciando pelo fato de um coeficiente de correção dinâmico $\left(K_{S P}\right)$ aplicado na resistência última (RU) estimada, enquanto que o método $S+D$ calibra um fator ZETA $(\xi)$, que considera tanto a questão entre a resistência dinâmica/estática como outras variáveis como solos resilientes e outros.

A partir da expressão do método aplicou-se em todos os golpes de energia crescente (Figura4.69) para o cálculo da resistência mobilizada em comparação com as resistência estáticas obtidas através da análise CAPWAP/CASE. As linhas pontilhadas representam um limite de variação de $\pm_{15 \%}$. 
Em geral os pontos se mantiveram entre as faixas limites e uma boa aproximação com a condição ideal ( $\left.R M X=R M_{E A}\right)$, apresentando um coeficiente de $R^{2}$ igual a 0,89 . Em comparação com os demais métodos os valores de $R^{2}$ foram de 0,77 e 0,89 para as fórmulas dinâmicas de Chellis (Figura4.59) e Smith modificado por Aoki (Figura4.65).

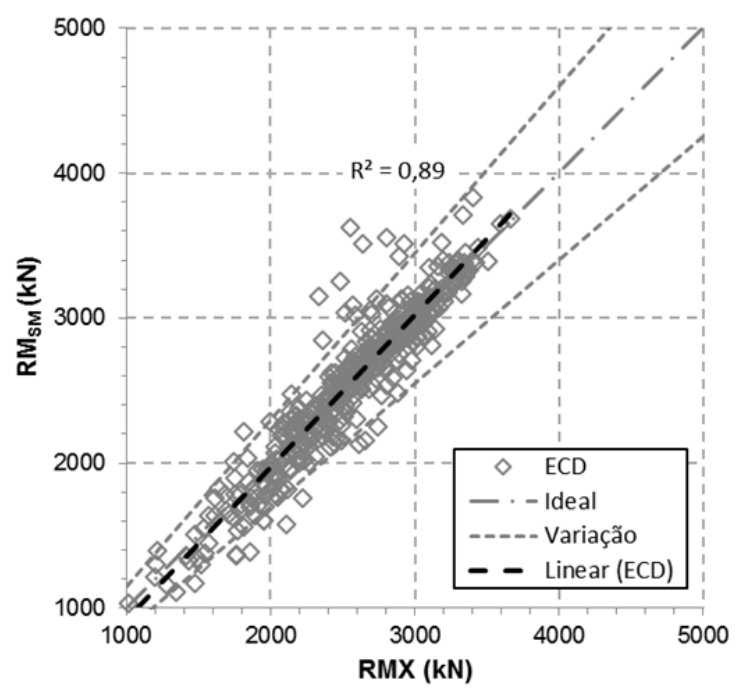

Figura4.69 - Comparação entre a resistência mobiliza obtida pela expressão da Energy Approach com a capacidade estática obtida pela analise CAPWAP/CASE.

\subsubsection{2 $K_{S P}$ - Coeficiente de capacidade estática}

Como uma forma de correlação simples a estimativa da capacidade estática pode ser representada por um simples fator que representa todas as perdas de energia no solo, pelo fator $K_{S P}$.

A Figura4.70 apresenta um gráfico da análise do coeficiente de capacidade estática obtido pela relação $K_{S P}=\frac{R M X}{R_{U}}$ em função da abertura de nega no golpe correspondente. De uma forma geral mesmo ocorrendo um incremento da abertura de nega o valor médio tende a se manter na mesma posição, com valor de $K_{S P}$ igual a 0,6 . Deve ser levado em consideração que todos os PCD foram executados com martelo de queda livre. 
No trabalho dos autores tentou-se verificar influencias do setup na obtenção do parâmetro $K_{S P}$, o que não se confirmou havendo uma grande aleatoriedade dos pontos. Nessa mesma temática os PCD foram classificados em três períodos de setup distintos (Figura4.71), em que tentou considerar uma situação de maior contribuição da resistência dinâmica (final de cravação a menos de 2 dias), um extremo em que não há contribuição do setup ( $>8$ dias) e um situação intermediaria ( 3 dias $<$ setup $<7$ dias).

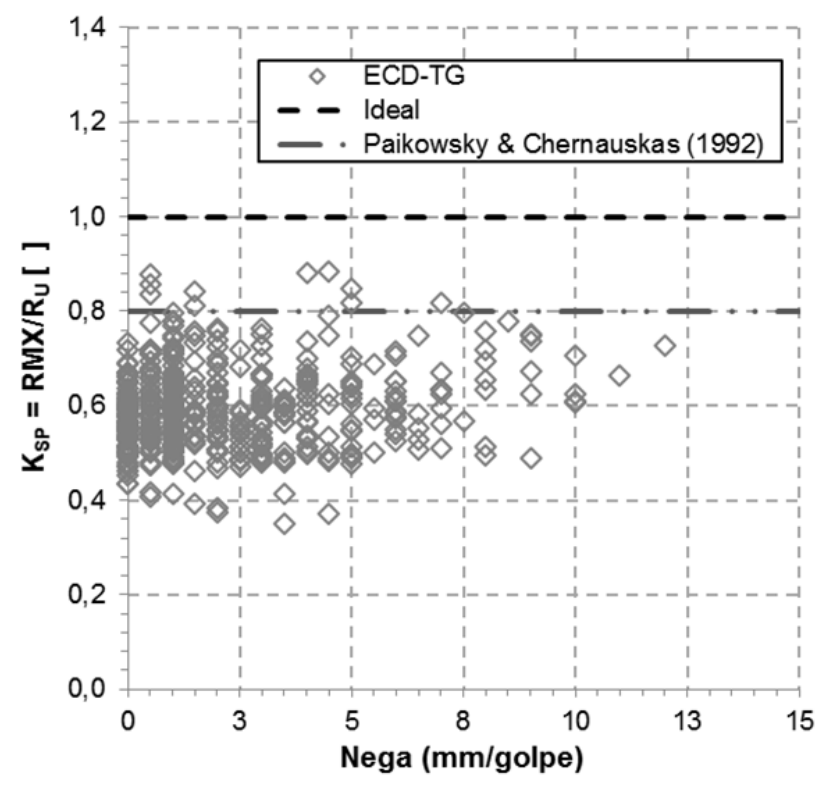

Figura4.70 - Coeficiente de capacidade estática $\left(K_{S P}\right)$ pela da nega obtida pelo ECD em todos os golpes.

Essa análise foi efetuada apenas para os golpes de maior energia.

Para os PCD nas idades iniciais $\left(\mathrm{t}<2\right.$ dias) o valor médio para $K_{S P}$ de 0,63 e existe uma tendência de alguns pontos estarem acima desse valor, e os demais próximos a eixo de 0,60. Nessa condição existem 22 estacas ensaiadas.

A condição intermediária, que é representada por 41 estacas ensaiadas, há uma tendência muito similar a condição de final de cravação e apresentou um valor médio de $K_{S P}$ médio de 0,59 .

No extremo dos resultados em que se espera que todos os efeitos do setup $(\mathrm{t}>8$ 
dias) tenham dissipado e uma menor influência da parcela dinâmica o valor de ${ }^{S P}$ médio foi de 0,65 , para um total de 11 estacas. Observa-se nessa condição em que alguns pontos tiveram os maiores valores de abertura de nega (da ordem de 12 a $15 \mathrm{~mm} / \mathrm{golpe}$ ) e uma tendência de proximidade com o fator $K_{S P}$ igual a 1,0.

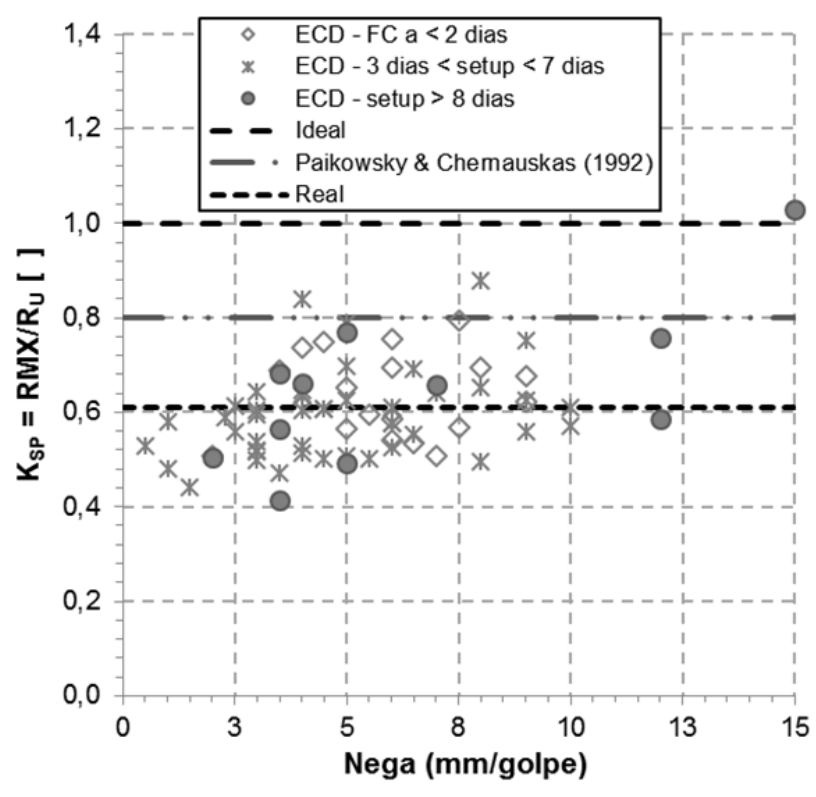

Figura4.71 - Coeficiente de capacidade estática $\left(K_{S P}\right)$ pela nega obtida pelo ECD para os golpes de maior energia em função do setup.

Essa situação pode ter acontecido pelo fato de ocorrer incrementos de energia a fim de mobilizar maiores resistências mobilizada ter rompido a camada resistente da areia na ponta da estaca, e dessa forma ter um comportamento de uma estaca sendo cravada e um estado de final de cravação. Entretanto essa tendência não foi observada nos ECD no final de cravação.

Verificando essa provável a influência do nível de energia aplicado, a Figura4.72 apresenta para os diversos níveis de energia aplicado no ECD ( $E M X)$ os valores do coeficiente $K_{S P}$.

Graficamente não é possível distinguir uma influência da idade na definição do parâmetro, entretanto observa-se que conforme a energia é incrementada existe uma tendência 
de aproximação em torno da média. Para baixos níveis de energia (da ordem de 40 a 60 kN.m) há uma grande dispersão dos valores.

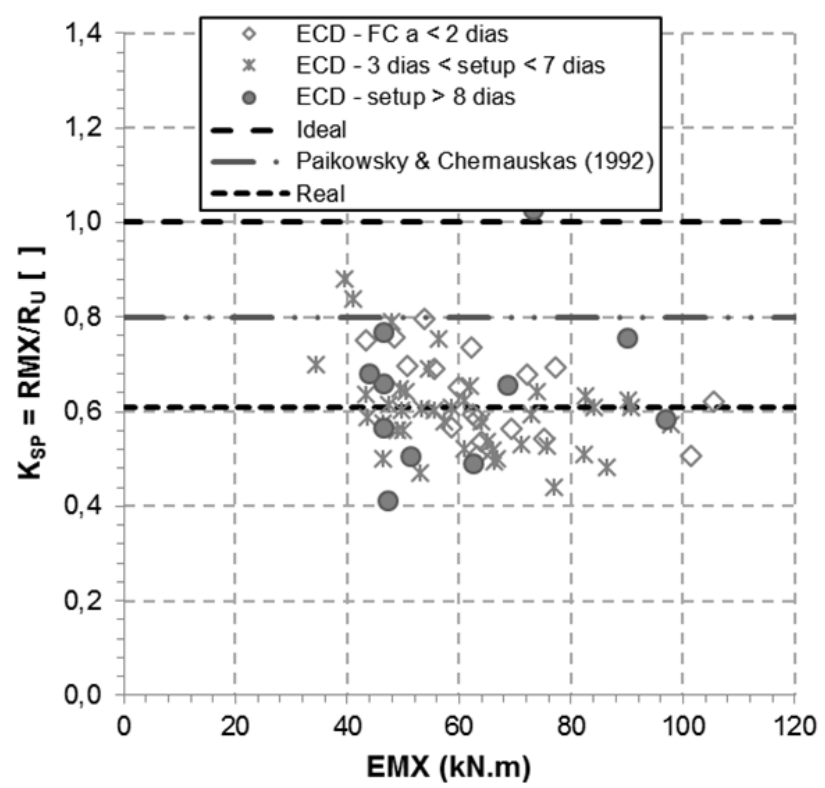

Figura4.72 - Influência do nível de energia aplicado no fator $K_{S P}$.

\subsubsection{Correlação com o Parâmetro $\xi$}

Em termos de desenvolvimento da fórmula matemática a expressão de Smith modificada é a base, a diferença reside na forma de consideração dos parâmetros. Entre a expressão modificada por Aoki (2011) todos os fatores de correção são atribuídos ao parâmetro $\xi$, enquanto que na expressão de Paikowsky e Chernauskas (1992) se determina a princípio a resistência dinâmica mobilizada e se corrige pelo parâmetro $K_{S P}$ para estática.

Em ambas as análises as medidas dinâmica (registro da nega e repique elástico) foram calibrados com os valores de resistência mobilizada da análise CAPWAP/CASE, que a princípio já se considera como o valor estático.

Matematicamente existe uma correlação entre ambos os parâmetros, desde que se considera que a energia liquida $(E M X)$ é igual a $E_{d}$ e que $R M X=K_{S P} \cdot R_{U}$. A partir dessas considerações: 


$$
K_{S P}=\frac{\xi}{2}
$$

Pelos dados disponíveis os valores de $\xi$ foram transformados em $K_{S P}$ e comparados (Figura4.73) com os valores determinados a partir da calibração com os ECD, havendo uma boa convergência entre os parâmetros.

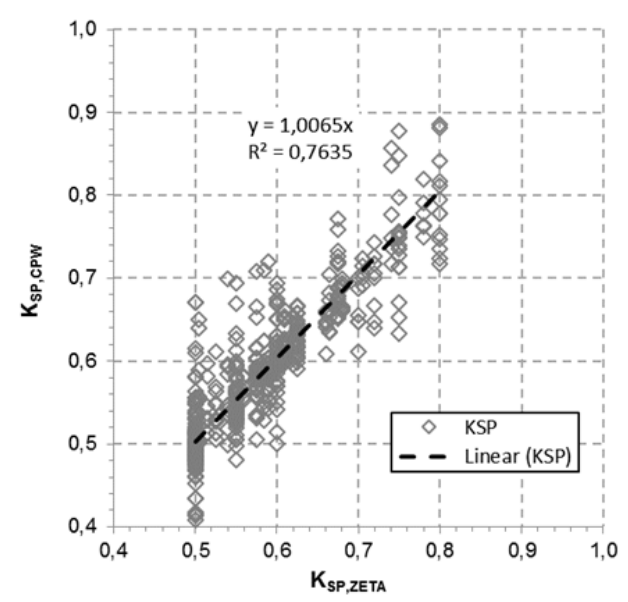

Figura4.73 - Comparação entre a obtenção do coeficiente de capacidade estática $\left({ }^{S P}\right)$ através da análise CAPWAP e fórmula de Smith modificada por Aoki.

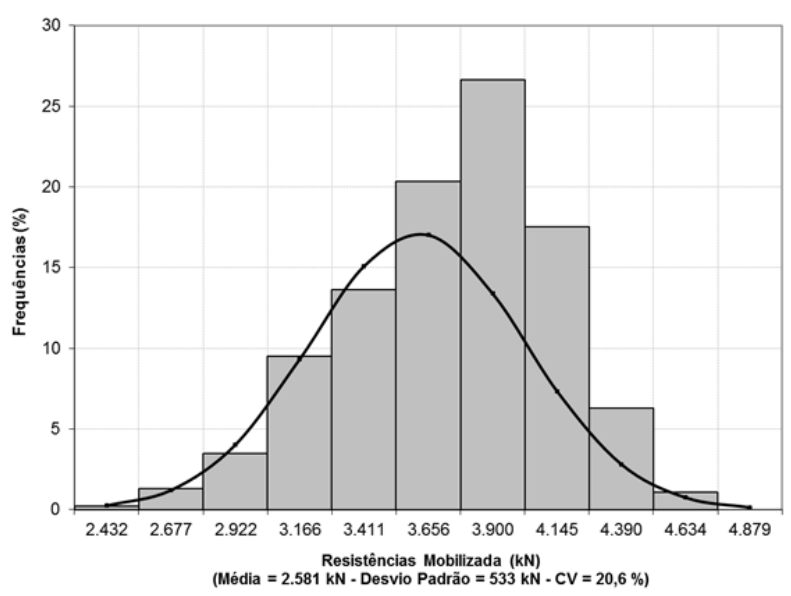

Figura4.74 - Distribuição de frequências para os valores de resistência mobilizada obtida pela fórmula do Energy Approach.

Em resumo, aplicando um único fator de correção para cada ECD as resistências 
mobilizadas para os diversos pontos têm média de $2581 \mathrm{kN}$, para um desvio padrão de $533 \mathrm{kN}$ e coeficiente de variação de $20,6 \%$. Em termos gerais o formato do gráfico é muito similar ao obtido pela fórmula de Smith modificada por Aoki (Figura4.67), estando deslocada para a direita.

\subsection{Universo total das estacas cravadas}

\subsubsection{Comprimento cravado}

A estatística dos comprimentos cravados das estacas encontra-se na Figura4.75, em que todas as estacas foram controladas pelo registro do repique elástico e nega para um total de 10 golpes aplicados, assumindo como valor mínimo de repique elástico de $10,0 \mathrm{~mm}$ (considerando um comprimento médio de 14,0 metros) para uma nega máxima de 30,0 $\mathrm{mm}$.

Em termos de previsão pelos ensaios de sondagem a percussão, para um universo de 103 furos foi previsto um comprimento cravado médio de 13,45 metros, para um desvio padrão de 1,09 metros e coeficiente de variação de $8,17 \%$.

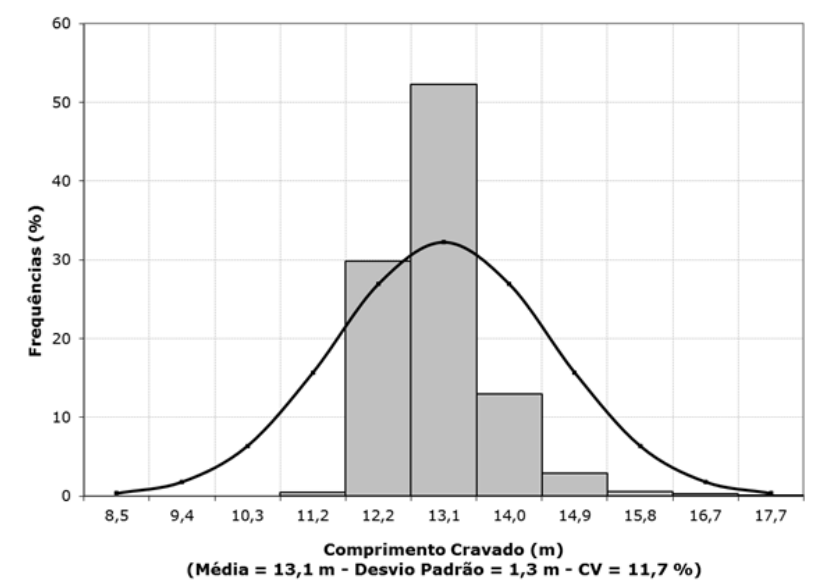

Figura4.75 - Distribuição de frequências e curva de Gauss para os comprimentos cravados ( $\mathrm{n}=$ 2506 estacas).

\subsubsection{Registros de nega e repique elástico}

Com relação aos registros de nega e repique elástico no final de cravação, coletados com o uso do procedimento do lápis e papel (Chellis, 1961), a Figura4.76 apresenta 
as medidas em função do comprimento cravado, admitindo-se um carregamento dinâmico aplicado pelo martelo de cravação para uma energia teórica de 70 kN.m.

Nessa condição pela grande maioria das estacas tiveram os seus comprimentos cravados próximo a média (13,1 metros), nessa profundidade há uma concentração dos registros em que para uma faixa de variação de nega de 2 a $39 \mathrm{~mm} / 10$ golpes aplicados, os registros do repique elástico variaram de 11 a $21 \mathrm{~mm}$.

Ocorreram alguns casos com maiores profundidades, com um caso com comprimento cravado de 50,0 metros, que manteve o mesmo comportamento das estacas curtas, não havendo incremento na medida do repique elástico. Em parte esse comportamento pode ser justificado por após atravessar a profundidade de 20,0 metros o perfil de solo é preponderamente de argila mole, contribuindo para dissipar a onda de propagação de tensões e descarregando à estaca.

Vale destacar que a medida de repique elástico é constituída de duas parcelas, uma devido a deformação elástica do fuste da estaca ( $C 2$ ) e outra devido a deformação do solo na ponta da estaca, ou simplesmente quake ( $C 3$ ). Portanto mesmo a faixa de variação de repique ter uma variabilidade menor que as medidas de nega, isso não representa uma ligação direta com o ganho de resistência uma vez que os valores de $C 3$ podem ser superiores que a parcela de $C 2$.

Rosa (2000) destaca que na aplicação da Lei de Hooke ao fenômeno de cravação de estacas admite-se para o solo um modelo elastoplástico e para a estaca um corpo perfeitamente elástico, livre de qualquer resistência lateral. Quando aplicado um carregamento estático o conjunto (estaca + solo) também apresentará um comportamento elastoplástico. Nessa condição a relação repique elástico/comprimento cravado seria linear e como coeficiente angular da reta a lei de Hooke, sendo que na situação inicial (LCRAV $=0$ ) o valor do repique elástico é igual ao quake da ponta $(K=C 3)$.

Nessa situação deve ser considerando a influência das ondas de tensão na determinação da variação da deformação elástica da estaca em função do comprimento cravado. Como conclusão o autor observa que a relação repique elástico/comprimento cravado é decrescente com o comprimento cravado. 


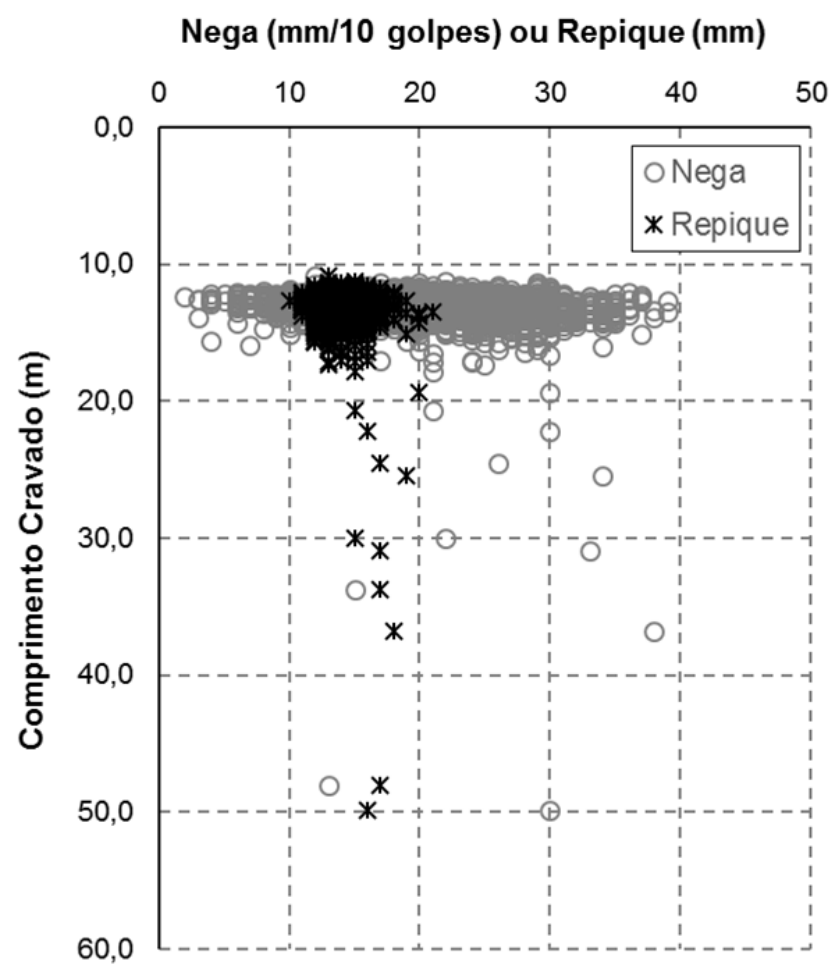

Figura4.76 - Registros de nega e repique elástico em função do comprimento cravado.

A partir dos resultados de campo traçou-se a curva de variação da relação repique elástico/comprimento cravado em função da profundidade (Figura4.77) comparando os resultados específicos dessa geologia/controle a curva de tendência elaborada por Rosa (2000) para diferentes geologias.

Habitualmente em estacas curtas é comum observar elevadas resistências de ponta, entretanto pelo caso em estudo devido aos condicionantes da ponta de estacas ser formada por uma camada intermediaria e ter se fixado um critério de cravação existe uma discrepância com os casos apresentados por Rosa (2000) que foram em um material com elevação resistência.

$\mathrm{Na}$ primeira condição pela camada de areia intermediaria não oferecer uma elevada resistência a penetração (como indicado pelos índices de resistência a penetração) a camada se comporta dissipando parte das tensões da onda propagada, enquanto que na outra situação pelas estacas serem curtas com ponta em solo resistente ocorre uma superposição das ondas de tensão provocando elevados valores de $C 2$, e consequentemente incrementando o 
valor do repique elástico.Para os casos com comprimentos cravados superiores a 20,0 metros a tendência entre as duas curvas é similar.

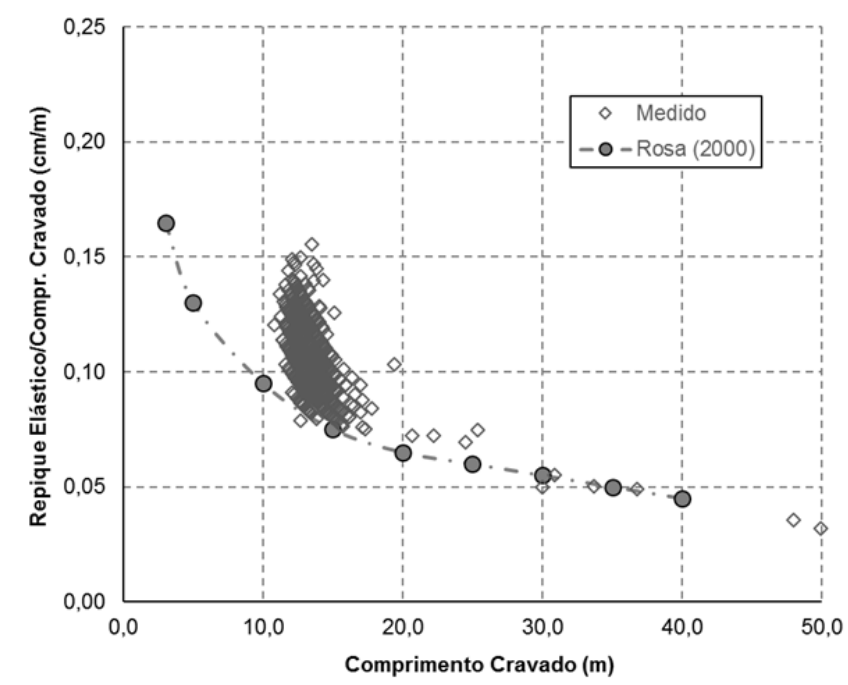

Figura4.77 - Variação da relação de repique elástico/comprimento cravado em função da profundidade em comparação com os resultados de Rosa (2000).

\subsubsection{Resistência mobilizada no final de cravação}

Pelos parâmetros das fórmulas dinâmicas calibrados em 4.4.1 a 4.4.3 obteve-se as principais variáveis em função do equipamento de execução, e ajustando a resistência mobilizada para resistência na ruptura (item 4.4). A partir dos registros de nega e repique elástico obtido em cada estaca, no final de cravação determinaram-se as curvas de frequência, estatística e a curva de distribuição para Chellis (Figura4.78), Smith Modificado (Figura4.79) por Aoki e Energy Approach (Figura4.80).

De acordo com Aoki (1996) o desempenho da fundação e avaliada em função da medida da dispersão da resistência mobilizada em torno do valor médio ao longo da superfície resistente.

No caso do emprego da fórmula de Chellis é observada uma melhor distribuição em torno do valor médio para ambos os lados, enquanto que nos demais métodos existem uma tendência de mais pontos distribuídos para o lado positivo da distribuição. 


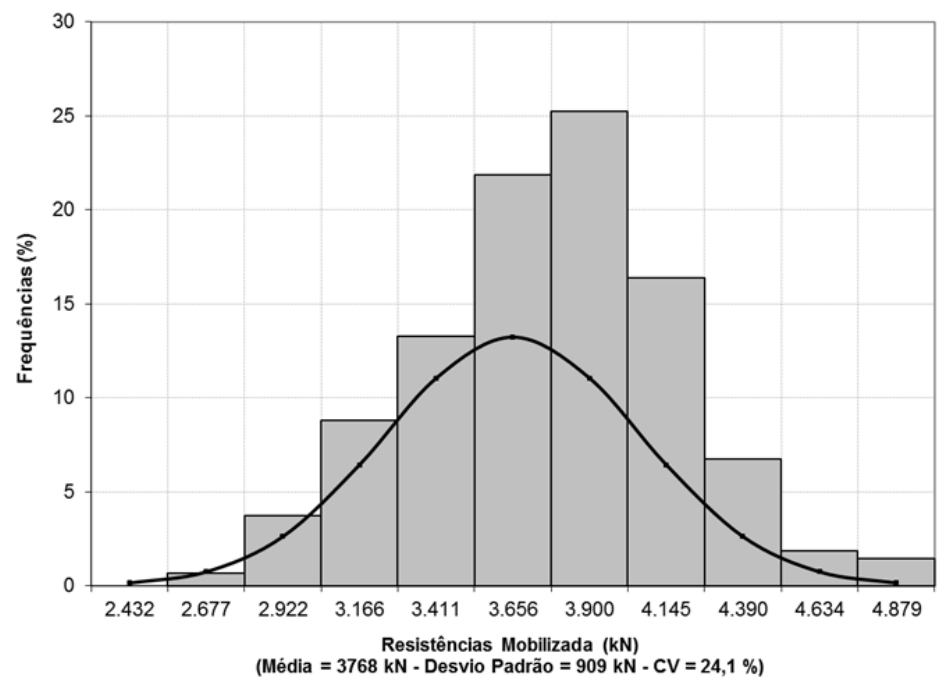

Figura4.78 - Distribuição de frequências e estatística para a resistência mobilizada obtida pela fórmula de Chellis.

Considerando que o método de controle de execução é o mesmo, para as expressões baseadas nas medidas de $\mathrm{S}+\mathrm{D}$ observa-se uma menor dispersão em função da media, com coeficiente de variação da ordem de $16,0 \%$, com desvio padrão $(\sigma$ ) de $513 \mathrm{kN}$ para um valor médio ( ${ }^{\mu}$ ) de 3204 kN. Para a expressão de Chellis o CV é de 24,1\% para um $\sigma$ de $909 \mathrm{kN} \mathrm{e}{ }^{\mu}$ igual a $3768 \mathrm{kN}$.

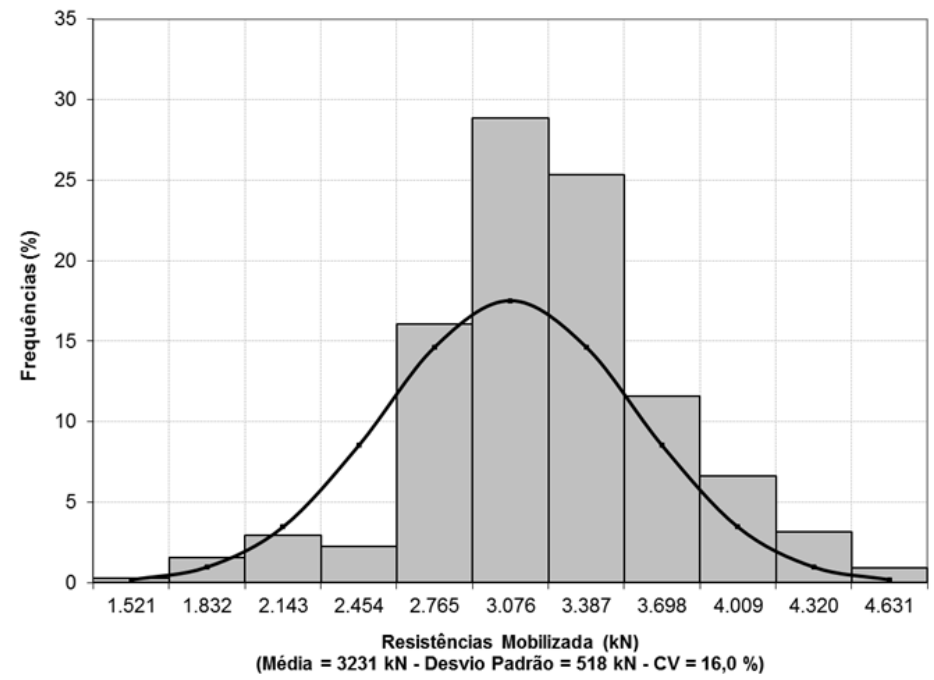

Figura4.79 - Distribuição de frequências e estatística para a resistência mobilizada obtida pela fórmula de Smith Modificada por Aoki (2011). 


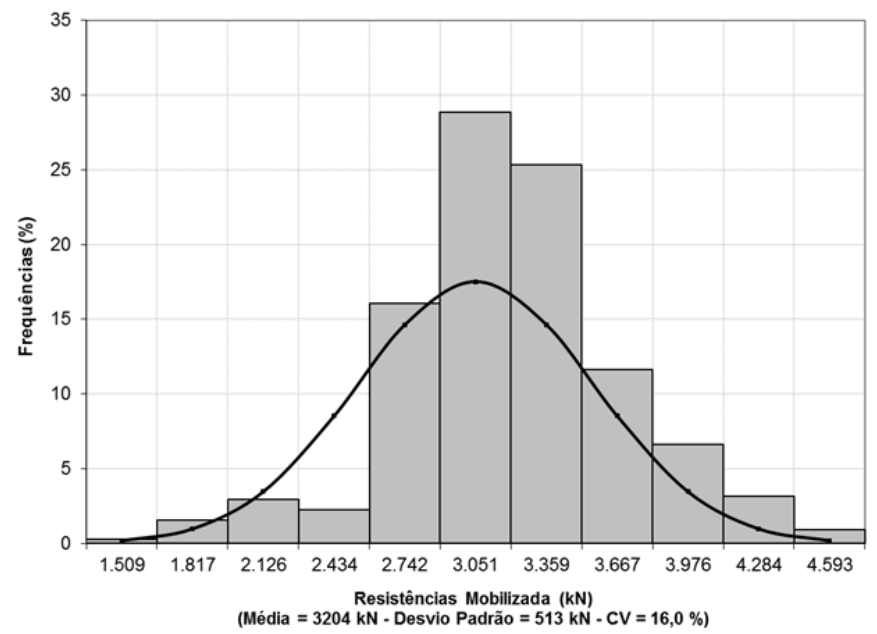

Figura4.80 - Distribuição de frequências e estatística para a resistência mobilizada obtida pela fórmula de Energy Approach.

Comparando os resultados obtidos pelas fórmulas dinâmicas (universo de 2506 estacas) com a análise estatística dos ECD ( $\mathrm{n}=74$ estacas), a Figura4.81 apresenta uma análise da distribuição de frequências acumuladas em relação a resistência mobilizada.

Para os valores apresentados as fórmulas de Smith Modificado e Energy Approach apresentam uma melhor proximidade com a curva do ECD e um nível de dispersão próximo, enquanto que a fórmula de Chellis apresenta uma maior variabilidade e um deslocamento lateral.

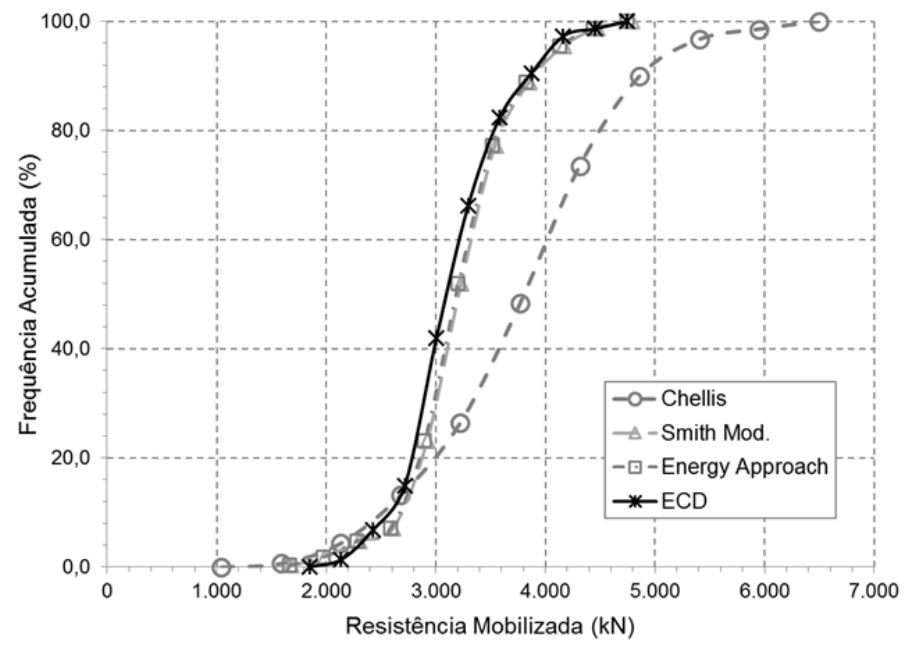

Figura4.81 - Comparação entre as curvas de distribuição de frequências entre as fórmulas dinâmicas e o ECD. 
A Tabela 4.23 apresenta um comparativo estatístico entre os diferentes métodos de avaliação da resistência mobilizada.

Tabela 4.23- Comparação estatística entre os diferentes métodos de avaliação da resistência mobilizada.

\begin{tabular}{ccccc}
\hline Método de Avaliação & $\begin{array}{c}\text { Universo } \\
(\text { estacas) }\end{array}$ & $\begin{array}{c}\mu \\
(\mathrm{kN})\end{array}$ & $\begin{array}{c}\sigma \\
(\mathrm{kN})\end{array}$ & $\begin{array}{c}C V \\
(\%)\end{array}$ \\
\hline Ensaios SPT & 103 & 3275 & 893 & 27,2 \\
\hline Provas de Carga & 4 & 3756 & 461 & 12,3 \\
\hline Ensaios de Carreg. Dinâmico & 74 & 3295 & 483 & 14,7 \\
\hline Chellis (1961) & 2506 & 3768 & 909 & 24,1 \\
\hline Smith Modificado Aoki (2011) & 2506 & 3231 & 518 & 16,0 \\
\hline Energy Approach (1992) & 2506 & 3204 & 513 & 16,0 \\
\hline
\end{tabular}


$-212-$ 


\section{Conclusões}

\subsection{Considerações}

O trabalho mostrou que é possível utilizar os registros de campo (nega e repique elástico) não apenas como um critério de homogeneização, mas como um método de avaliação da resistência mobilizada na estaca ao final da cravação, desde que os parâmetros das fórmulas dinâmicas sejam calibrados por provas de carga dinâmica.

Com o controle por provas de carga dinâmicas, e o uso de curva adimensionalizadas, foi possível homogeneizar os diferentes resultados das estacas da fundação, e ter uma compreensão do comportamento do maciço de solo. Para o caso a relação $R M X / R E$ foi da ordem de 0,45 para DMX / Diâmetro $=3 \%$.

A expressão de Chellis, usada para estimar a resistência mobilizada da estaca no final da cravação, apresenta uma dependência direta com o quake do solo. Estes valores variaram na faixa de 5,0 $\mathrm{mm}$ a $15,0 \mathrm{~mm}$, pela retroanálise da fórmula dinâmica, e de 5,0 $\mathrm{mm}$ a 23,0 mm nas análises CAPWAP. Para essa situação, o parâmetro f variou de 0,8 - 0,9, e os valores da resistência mobilizada se mostraram dependentes da relação $K / C 3$.

No caso da fórmula de Smith modificado por Aoki, existe uma dependência direta com a eficiência empregada e a medida da nega no golpe. Uma das grandes facilidades de se trabalhar com esta fórmula é que a influência de um comportamento resiliente do solo durante a aplicação dos golpes é baixa, não afetando os valores da resistência mobilizada. Para o uso deste método, o único parâmetro a ser calibrado é o zeta $(\xi)$, que variou neste caso de 1,1 a 1,6 .

$\mathrm{Na}$ avaliação da fórmula do Energy Approach, os resultados de resistência mobilizada foram muito semelhantes aos encontrados usando-se a fórmula de Smith modificado. Ambos os métodos dinâmicos para o controle da resistência da estaca no final da cravação, apresentam a facilidade de se ter que calibrar apenas um parâmetro.

Para cada método de controle de campo para determinação dos valores de resistência mobilizada nas estacas da obra, observou-se pequena dispersão nos resultados. Os valores de coeficiente de variação das resistências das estacas, de acordo com o método de 
controle empregado, foram de: $12,3 \%$ para o controle por provas de carga estática; $14,7 \%$ controle por provas de carga dinâmica; e pelo controle usando-se fórmulas dinâmicas os valores variaram de 16,0 a 24,1\% (maior dispersão encontrada na aplicação do método de Chellis). 


\subsection{Sugestões para pesquisas futuras}

Como uma contribuição a futuros estudos, seria apropriado correlacionar uma grande quantidade de provas de carga dinâmica com as medidas de nega e repique, para verificar influencias nos parâmetros de controle em outros tipos de terrenos, diferentes do presente caso.

Um outro ponto a ser melhor investigado é o modelo de Van Weele com as propostas de Massad (1995), de modo a incorporar as tensões residuais no cálculo da resistência mobilizada, e refinar o processo que permite definir a parcela de atrito lateral em função de uma prova de carga dinâmica, que simula uma prova de carga estática cíclica. 
$-216-$ 


\section{Referências}

ABEF - ASSOCIAÇÃO BRASILEIRA DE EMPRESAS DE ENGENHARIA DE FUNDAÇÕES E GEOTECNIA. Research on Foundation Engineering. São Paulo, ABMS, 1989.

ABNT - ASSOCIAÇÃO BRASILEIRA DE NORMAS TÉCNICAS. NBR 6122: Projeto e execução de fundações. Rio de Janeiro, 2010. 91 p.

ABNT - ASSOCIAÇÃO BRASILEIRA DE NORMAS TÉCNICAS. NBR 12131: Estacas prova de carga estática - método de ensaio. Rio de Janeiro, 2003. 15 p.

ABNT - ASSOCIAÇÃO BRASILEIRA DE NORMAS TÉCNICAS. NBR 13208: Estacas ensaio de carregamento dinâmico - método de ensaio. Rio de Janeiro, 2007. 12p.

ALVES, A. Métodos dinâmicos para previsão e controle do comportamento de estacas cravadas. Publicação Teoria e Prática para Engenharia Civil, nº 4. pág. 12-21. 2004.

AOKI, N. Controle "in situ" da capacidade de carga de estacas pré-fabricadas via repique elástico da cravação. In: Palestra realizada no Instituto de Engenharia de São Paulo, ABMS, ABEF. São Paulo, 1986.

AOKI, N. A new dynamic load test concept. In: INTERNACIONAL CONFERENCE ON SOIL MECHANICS AND FOUNDATION ENGINEERING, 12., 1989, Rio de Janeiro. Drivability of piles: proceedings for the Discussion Session 14. Rio de Janeiro: ABMS, 1989. v. 2, p. 55-61.

AOKI, N. Carga Admissível de estacas através de ensaios dinâmicos. SEFE II - $2^{\circ}$ Seminário Engenharia Fundações Especiais. Anais. São Paulo, Vol. 2, pg. 269-292.1991.

AOKI, N. Determinação da Capacidade de Carga Última de Estaca Cravada em Ensaio de Carregamento Dinâmico de Energia Crescente. 1997. São Carlos. Tese (Doutorado). Escola de Engenharia de São Carlos, Universidade de São Paulo.

AOKI, N. Comunicação pessoal, 2011. 
AOKI, N.; CINTRA, J.C.A. Influência da variabilidade do maciço de solos no comprimento de estacas. In: SEMINÁRIO DE ENGENHARIA DE FUNDAÇÕES ESPECIAIS E GEOTECNIA, 3., 1996, São Paulo. Anais...São Paulo, 1996. v. 1. P. 173-184.

AOKI, N., ALONSO, U. R., TRINDADE, O. A. Aplicação de registrador de deslocamento dinâmico (RDD) na avaliação da capacidade de carga mobilizada em estacas cravadas. In: Simpósio sobre Instrumentação Geotécnica de Campo, SINGEO’90, 1990, Rio de Janeiro, Anais .... p. 45-51.

AOKI, N., CINTRA, J. C. A. New Interpretation of the Dynamic Loading Curves for Drive Piles Based on the Energy Approach. In: RECENT DEVELOPMENTS IN SOIL AND PAVEMENT MECHANICS, Rio de Janeiro, 1997. Anais, Rotterdam, 1997.

AOKI, N., NIYAMA, S. Correlação entre Provas de Carga Dinâmica e Estática. In: SEFE II, 2. Seminário de Engenharia de Fundações Especiais, Anais. São Paulo, 1991, Vol. 01, p. 285293.

AOKI, N.; VELLOSO, D.A. Na approximate method to estimate the bearing Capacity of piles. In: PANAMERICAN CONFERENCE ON SOIL MECHANICS AND FOUNDATION ENGINEERING, 5., 1975, Buenos Aires. Proceedings...Buenos Aires, 1975. V.1, p. 367376.

ÁVILA, I. A. Análise do comportamento de estacas metálicas cravadas na Bacia de Taubaté através de provas de carga dinâmica de energia crescente. 2001. São Carlos. Dissertação (Mestrado). Escola de Engenharia de São Carlos, Universidade de São Paulo.

AUTHIER, J., FELLENIUS, B. H. Quake values determined from dynamics measurements. In: Proceedings $1^{\text {st }}$ International Conference on the Application of Stress-Wave Theory on Piles, Stockholm, 1980. A. A. Balkema, Rotterdam, p. 197-216.

BALECH, J. Análise da transferência de carga de estacas cravadas em argila mole a partir de provas de carga dinâmica de energia crescente. 2000. São Carlos. Dissertação (Mestrado). Escola de Engenharia de São Carlos, Universidade de São Paulo.

BERNARDES, G.P. Dynamic and static testing of large model piles in sand. Tese (Doutorado). Norwegian Institute of Technology, Trondheim,1989.

BILFINGER, W. "Set-up” em Estacas Cravadas. In: XV Congresso Brasileiro de Mecânica 
dos Solos e Engenharia Geotécnica, São Paulo: ABMS, 2010.

CAMBEFORT, M. Essai sur Le Comportement em terrain homogéne des Vieux isoles et des groupes de pieux. Annales de $1^{\circ}$ Institut du Batiment et des Travaux Public, $\mathrm{n}^{\circ} 204$, Decémbre, 1964.

CINTRA, J.C.A.; AOKI, N. Fundações por estacas: projeto geotécnico. São Paulo: Oficina de Textos, 2010. $96 \mathrm{p}$.

CINTRA, J.C.A.; Aoki, N.; TSUHA, C.H.C.; GIACHETI, H.L. Fundações: ensaios estáticos e dinâmicos. São Paulo: Oficina de Textos, 2013. 144 p.

CHELLIS, R.D.Pile Foundations - Theory - Design - Practice. Mc Graw-Hill Book Company, Inc. 1951.

CHIN, F.K. Estimation of the ultimate load of piles not carried to failure. In: SOUTHEAST ASIAN CONFERENCE ON SOIL ENGINNERGING, 2. Proceedings.... p.81-90, 1970.

CUMMINGS, A. E. Dynamic Pile Driving Formulas. Journal of the Boston Society of Civil Engineers, Vol. XXVII, N. 01. January, 1940.

DAVISSON, M.T. High capacity piles, Innovations in Foundation Construction, A.S.C.E. Lecture Series. Illinois, 1972.

DANZIGER, B. R. Análise dinâmica da cravação de estacas. Tese (Doutorado) - COPPEUFRJ, Rio de Janeiro, 1991.

DÉCOURT, L.; QUARESMA, A.R. Capacidade de carga de estacas a partir de valores de SPT. In: CONGRESSO BRASILEIRO DE MECÂNICA DOS SOLOS E ENEGENHARIA DE FUNDAÇÕES, 6., 1978, Rio de Janeiro. Anais...Rio de Janeiro, 1978. v. 1. P. 45-54.

DÉCOURT, L. A ruptura de fundações avaliada com base no conceito de rigidez. In: SEFE SEMINÁRIO DE ENEGENHARIA DE FUNDAÇÕES ESPECIAIS E GEOTECNIA, 3., 1996, São Paulo. 1996. v. 1, p. 215-224.

DÉCOURT, L. Relato Geral. Primeira Sessão Técnica: Fundações e Interação Solo-Estrutura. In: X Congreso Brasileiro de Mecânico dos Solos e Engenharia de Fundações. Foz do Iguaçu, 
1994.

FELLENIUS, B. H.; SANTOS, J.A.; FONSECA, A.V. Analysis of piles in a residual soil The ISC' 2 prediction. Published on the NRC Research Press Web Site at http://cgj.nrc.ca, 2004.

FINDLAY, J.D.; BROOKS, N.J.; MURE, J.N.; HERON, W. Design of axially loaded piles United Lingdom Practice. In: Proc. Of the ERTC 3 Seminar Brussels, Edited by F. de Cook e C. Legrand, 1997.

FOÁ, S.B. Análise do ensaio de carregamento dinâmico de energia crescente para o projeto de fundações profundas. Dissertação (Mestrado) - Departamento de Engenharia Civil e Ambiental, Universidade de Brasília, Brasília, 2001.

FLEMMING, W.G.K.; WELTMAN, A.J., RANDOLPH, M.F.; ELSON, W.K. Piling Engineering $-2^{\text {nd }}$ edition. John Wiley \& Sons, Inc., 1992.

FOREHAND, P.W.; RESSE, J.L. Predictions of pile capacity by the wave equation. Journal of the Soil Mechanics and Foundations Engineering. In: Proc. Of American Society of Civil Engineering, p. 1-25, 1964.

GHILARDI, M.P. Comparação entre desempenhos de Estacas metálicas tubadas de ponta aberta e fechada na Baixada Santista. Dissertação (Mestrado), Escola Politécnica da Universidade de São Paulo. São Paulo, 2005.

GOBLE, G.G. ; ABOU-MATAR, H. Determination of wave equation soil constants from the standard penetration test, in "Application of Stress-Wave Theory to Piles". Ed. by Barends, F.B. J., Rotterdam, Balkema, pp. 99-103, 1992.

GOBLE, G. G. Pile driving - an international state of art. Design and Construction of Deep Foundation. Vol. 1, pg. 1-26. 1994.

GOBLE, G.G.; RAUSCHE, F. Wave equation analysis of pile driving: WEAP program. Washington, D.C.: U.S. Department of Transportation, Federal Highway Administration, 1981.

GOBLE, G.G.; LIKINS, G.E. On the application of PDA dynamic pile testing. Stresswave Conference, Orlando, 1996. 
GOBLE, G.G.; LIKINS, G.E.; RAUSCHE, F. Bearing capacity of piles from dynamic measurements. Cleveland: Ohio Department of Transportation, 1975.

HANSEN, J.B. Discussion of Hyperbolic stress-strain response: Cohesive Soils. JSMFD, ASCE, v. 89, n SM4, p. 241-242, 1963.

IPT - INSTITUTO DE PESQUISAS TECNOLOGICAS DO ESTADO DE SÃO PAULO S/A. Desenvolvimento de um Sistema de Aquisição de Instrumentação para Otimização de Dimensionamento de Fundações. Relatório IPT/DCC-ASC nº 25.278, São Paulo, 1987.

JARDINE R.J.; CHOW, F.C. "New Design Methods for Offshore Piles." Marine Technology Directorate Ltd., Publication MTD 96/103, London, 1996. ISBN 1870553314.

KISHIDA, H. The Ultimate Bearing Capacity of Pipe Piles in Sand. Third Asian Regional Conference os Soil Mechanicas and Foundation Engineering, pp. 196-199, 1967.

LEHANE, B.M. e RANDOLPH, M.F. Evaluation of a minimun base resistance for driven pipe piles in siliceous sand. In: Journal of Geotechnical and Geoenvironmental Engineering ASCE, Vol. 128, n. 3, 2002.

LIANG, R.Y.; ZHOU, J. Probability Method Applied to Dynamic Pile-driving Control. In: Journal ASCE, v. 123, n 2, p. 137-144, 1997.

LIKINS, G.; RAUSCHE, F. Correlaction of CAPWAP with Static Load Tests. Stresswave Conference, São Paulo, 2004.

LOWERY JR. L. L., FINLEY JR. J. R., HIRSCH, T. J. A comparison of dynamic pile driving formulas the wave equation. In: Texas Highway Department - Research Report 33-12 Piling Behavior Research Study N. 2-5-62-33, Texas, 1968.

MACHADO, J.R.A. A avaliação da capacidade de carga de Estacas, com base no repique elástico medido no final de cravação. Dissertação (Mestrado) - Escola Politécnica, Universidade de São Paulo, São Paulo, 1995.

MACHADO, J. R. A., DIONISI, A. Repicômetro - Um sistema para medição do Repique Elástico de Estacas. In: SEFE II, São Paulo, 1991. Anais. Vol. 2. 
MAZURKIEWICZ, B.K. Test loading of piles according to Polish regulations, Preliminary Report $n^{\circ}$ 35, Commission on Pile Research, royal Swedish Academy of Engineering Sciences, Stockholm, 1972.

MASSAD, F. Notes on the interpretation of failure load from routine pile load tests. Solos $e$ Rochas, São Paulo, v. 9, n. 1, p. 33-36, 1986.

MASSAD, F. Sobre a Interpretação de Provas de Carga em Estacas considerando as Cargas Residuais na Ponta e a Reversão do Atrito Lateral. Parte I: Solos Relativamente Homogêneos. Revista Solos e Rochas, ABMS, São Paulo, 1992, vol. 15, n² 2, pp. 103-115.

MASSAD, F. Sobre a Interpretação de Provas de Carga em Estacas considerando as Cargas Residuais na Ponta e a Reversão do Atrito Lateral. Parte II: Estaca Embutida em Camada mais Resistente . Revista Solos e Rochas, ABMS, São Paulo, 1993, vol. 16, n² 2, pp. 93-112.

MASSAD, F. Considerações sobre a Forma da Curva Carga-Recalque de Estacas Solicitadas Axialmente. Aula Inaugural do curso de pós-graduação da Escola de Engenharia de São Carlos, São Paulo, 1994.

MASSAD, F. Pile analysis taking into account soil rigidity and residual stresses. Anais: X Congresso Pan Americano de Mecânica dos Solos e Fundações, Guadalajara, México, 1995, II: $1199-1210$.

MASSAD, F.; LAZO, G. Método Gráfico para Interpretar a Curva Carga-Recalque de Provas de Carga Verticais em Estacas Rigídas ou Curtas. XI Congresso Brasileiro de Mecânica dos Solos e Engenharia Geotécnica, Brasilia, 1998, vol. 3, pp. 1407-1414.

MELLO, V.F.B.; SOBRAL, A.C.S. Fundações por estacas: previsões e controles tradicionais reapreciados mediante estatística. In: $6^{\circ}$ Congresso Nacional de Geotecnia, Sociedade Portuguesa de Geotecnia, v. 2, Lisboa, 1997.

MILITITSKY, J. Provas de carga estáticas. Palestra proferida no $2^{\circ}$ Seminário de Engenharia de Fundações Especiais, ABEF/ABMS, São Paulo, 1991. v. 2, p. 203-228.

MINÁ, A. J.Estudo de estacas de madeira para fundações de pontes de madeira. Tese (Doutorado). Escola de Engenharia de São Carlos, Universidade de São Paulo, São Carlos, 2005. 
NAVAJAS, S.; NIYAMA, S. Ensaio de Carregamento Dinâmico em Estacas Moldadas In Loco numa Obra Portuária. Terceiro Seminário de Engenharia de Fundações Especiais e Geotecnica: São Paulo, Vol. 1, pp. 331-342, 1996.

NIYAMA, S. et al. Instrumentação e Monitoração do Teste de Cravação de uma Estaca num Solo Calcário na Bacia de Curimã, Ceará. VII Congresso Brasileiro de Mecânica dos Solos e Engenharia de Fundações. Olinda, Recife, 1982.

NIYAMA, S. Medições dinâmicas na cravação de estacas: fundamentos, instrumentação e aplicações práticas. Dissertação (Mestrado) - Escola Politécnica, Universidade de São Paulo, São Paulo, 1983.

NIYAMA, S. Provas de Carga Dinâmicas em estacas. SEFE II - $2^{\circ}$ Seminário Engenharia Fundações Especiais. Anais. São Paulo, Vol. 2, pg. 229-268. 1991.

NIYAMA, S. Contribuição para o Estudo do Embuchamento em Estacas Cravadas de Ponta Aberta. Tese (Doutorado), Escola Politécnica da Universidade de São Paulo. São Paulo, 1992.

OLIVEIRA, J. R. M. S., NUNES, P. R. R. L., SILVA, M. R. L., CABRAL, D. A., FERREIRA, A. C. G., CARNEIRO, L. A. V., GIRALDI, M. T. M. R. Field Apparatus for Measurement of Elastic Rebound and Final Set for Driven Pile Capacity Estimation. In: Geotechnical Testing Journal, ASTM, Vol. 34, nº. 2, 2011.

PAIKOWSKY, S. G., CHERNAUSKAS, L. R. Energy approach for capacity evaluation of driven piles. In: BARENDS, F. B. J. Application of Stress Wave Theory to Piles. Rotterdam, 1992.

PAIKOWSKY, S.G.; WHITMAN, R.V. The Effects of Plugging on Pile Performance and Design. In: Canadian Geotechnical Journal, 27(3), pp. 429-440, 1990.

PAIKOWSKY, S. G., STENERSEN, K. L. Keynote Lecture: The performance of the dynamics methods, their controlling parameters and deep foundation specifications. In: $6^{\text {th }}$ INTERNATIONAL CONFERENCE OF THE APPLICATION OF STRESS WAVE THEORY TO PILES, São Paulo, 2000. Anais. Rotterdam, 2000. p. 281-304.

PARAÍSO, S.C.; COSTA, C.M.C. A Eficácia do Ensaio de Carregamento Dinâmico na Avaliação do Efeito de "Setup" em Estacas Cravadas. In: XV Congresso Brasileiro de Mecânica dos Solos e Engenharia Geotécnica, São Paulo: ABMS, 2010. 
PEREIRA, J.J.G.Avaliação da capacidade resistente de estacas através do ensaio de carga estático. Dissertação (Mestrado). Instituto Superior Técnico da Universidade Técnica de Lisboa, Lisboa, 2003.

PILE DYNAMICS, INC. Pile Driving Analyser (PDA). Manual. Cleveland, Ohio, 1992.

POULOS, H.G.; DAVIS, E.H. Pile Foundation Analysis and Design. New York: John Willey \& Sons, 1980.

RAUSCHE, F.; GOBLE, G.G.; LIKINS JR, G.E.Dynamic determination of piles capacity. Journal of Geotechnical Engineering. ASCE, Vol. 111, nº. 3, pg. 367-383, March, 1985.

ROSA, R. L. Proposição de modificação das fórmulas dinâmicas de cravação de Chellis e Uto et al. A partir de resultados do método Case.Dissertação (Mestrado), Escola Politécnica da Universidade de São Paulo.São Paulo, 2000.

ROSA, R. L. Comunicação pessoal, 2013.

SAKIMOTO, J., HAGA, T., KONDO, J. The Penetration Behavior of Driven Piles Meassured by Electro-Optical Displacement Meter.In: International Symposium on Penetrability and Drivabilityof Piles, 1985, San Francisco. Proceedings...Vol. 1, p. 193-196.

SCAC. CASE Porto em Santa Catarina. Publicado em http://www.scac.com.br/artigos consulta em 03/07/2014, (2012).

SEIDEL, J. Comunicação pessoal, 2011.

SOO, C.F.; LIN, C.C.; WANG, R.F.; OU, C.D. e MOH, Z.C. Plugging of open-end steel pipe piles. In: 6th Southeast Asian Conference on Soil Engineering, 315-325, Taipei, 1980.

SORENSEN, T.; HANSEN, B. Pile Driving Formulae - An Investigation Based on Dimensional Consideration and Statical Analyses. In: Proc. $4^{\text {th }}$ International Conference Soil Mechanics and Foundation Engineering, vol. 2, p. 61-65, 1957.

SKOV, R.; DENVER, H. Time-Depend of Bearing Capacity of Piles. In: Proc. $3^{\text {rd }}$ Int. Conf. App. Stress Wave Theory to Piles, Otawa, 1988. 
SMITH, E.A.L. Pile Driving Analysis by the Wave Equation. Journal of the Soil Mechanics and Foundation Division, ASCE, Vol. 127, part I, pg. 1145-1193, 1960.

SOARES, F. L. Analise de provas de carga dinâmica em tubulões a céu aberto, no campo experimental de fundações da EESC. São Carlos, 2002. Dissertação (Mestrado). Escola de Engenharia de São Carlos, Universidade de São Paulo. São Carlos.

SOUZA FILHO, J.M.; ABREU, P.S.B. Procedimentos para controle de cravação de estacas pré-moldadas de concreto. Palestra no Congresso Brasileiro de Mecânica dos Solos e Engenharia de Fundações, Salvador, 1990. V.1, p. 309-319.

STEPHAN, A.M. Prova de carga estática em estacas: comparação com os métodos de previsão de capacidade de carga. 1998.Dissertação (Mestrado). Universidade Federal de Viçosa. Viçosa.

TAN ET AL. 2004.

TERZAGHI, K. Pile-driving formulas. Discussion on the Progress Report of the Committee on the Bearing Value of Pile Foundations. Proceedings of the ASCE, v.68, n. 2, p. 311-323, Feb. 1942.

TERZAGHI, K.; PECK, R.B. Soil Mechanics in Engineering Practice. Wiley International Edition. John Wiley \& Sons, p. 176-180, 1967.

TIMOSHENKO, S.; GOODIER, J.M. Theory of elasticity, McGraw-Hill Book Company, Inc, 2nd Ed. 1951.

THOMPSON, R.P.; DEVATA, M. Evaluation of the Ultimate Bearing Capacity of Different Piles. Proceedings of the $1^{\text {st }}$ International Conference on the Application of Stress Wave Theory to Piles: The Hague, Netherlands, p. 163-195, 1980.

YOKOHAMA, Y.; KUSAKABE, O. General Report One Pile Driving in Japan. In: Proc. On Penetrability and Drivability of Piles, San Francisco, v. 1, p. 41-16, 1985.

UTO, K. Dynamic Bearing Capacity Wave Theory, Pile Driving Control. Proc. On Penetrability and Drivability of Piles, San Francisco, v. I, p. 201-204, 1985. 
UTO, K., FUYUKI, M., MIYAJI, A. Measuring Cases of Phenomena of Pile Driving by Using Accelerometer. In: Drivability of Piles, 1989, Rio de Janeiro, Proceedings...Vol. 1, p. 83-86, 1989.

VAN DER VEEN, C. The bearing Capacity of a pile. In: INTERNATIONAL CONFERENCE ON SOIL MECHANICS AND FOUNDATION ENGINEERING, 3., 1953, Zurich. Proceedings...ISSMFE, 1953. v. 2, p. 84-90.

VAN WEELE, A.F. A Method of Separating the Bearing Capacity of a Test Pile into Skinfriction and Point Resistance - 4th. INTERNACIONAL CONFERENCE ON FOUNDATION ENGINEERING, v. 2, London, 1957.

VELloso, P. P. C. Fundações: Aspectos Geotécnicos. Publicação do Departamento de Engenharia Civil da Pontifícia Universidade Católica - Rio de Janeiro, 1987. v. 2/3.

VELLOSO, D. A.; LOPES, F.R. Fundações. Rio de Janeiro:COPPE-UFRJ,2002.v. 2.

VÉSIC, A.S. Bearing Capacity of shallow foundations. In: WINTER-KORN, H.F.; FANG, H.Y. (ed.). Foundation engineering handbook. New York: Van Nostrand Reinhold, 1975. Chap. 3, p. 121-147.

VIEIRA, S.H.A. Controle de cravação de estacas pré-moldadas: avaliação de diagramas de cravação e formulas dinâmicas. Dissertação (Mestrado) - COPPE/UFRJ, Rio de Janeiro, 2006.

ZHANG, L. M. Pile driving process monitoring based on field energy measurements. In: SOILS AND FOUNDATIONS - Japanese Geotechnical Society, vol. 45, n. 6, p. 31-41, 2005.

WHITAKER, T. The Design of Piles Foundation. $2^{\text {nd }}$ edition. Pergamont Internacional Library, p. 26-43, 1976. 
ANEXO

$-227-$ 
$-228-$ 


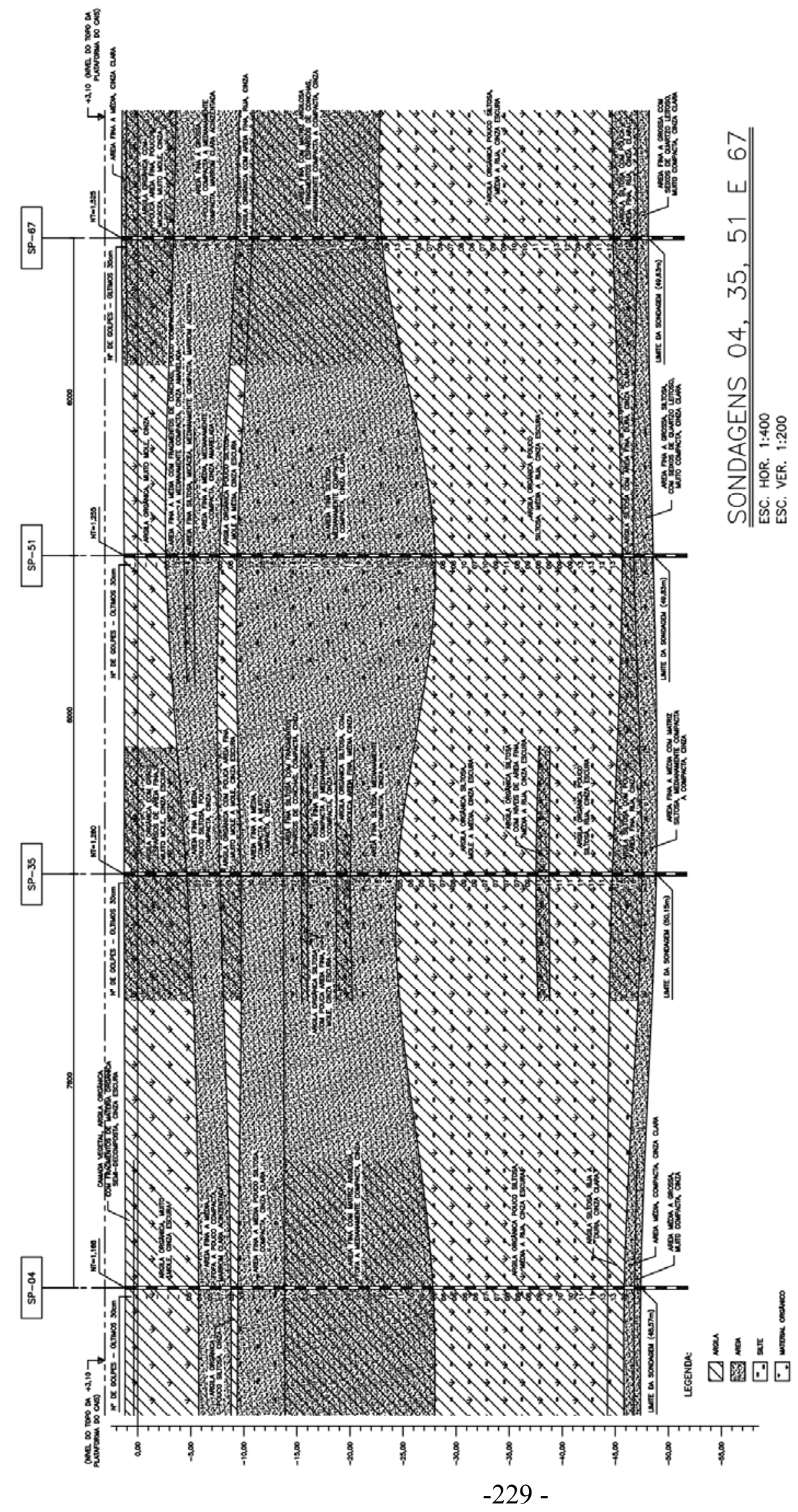




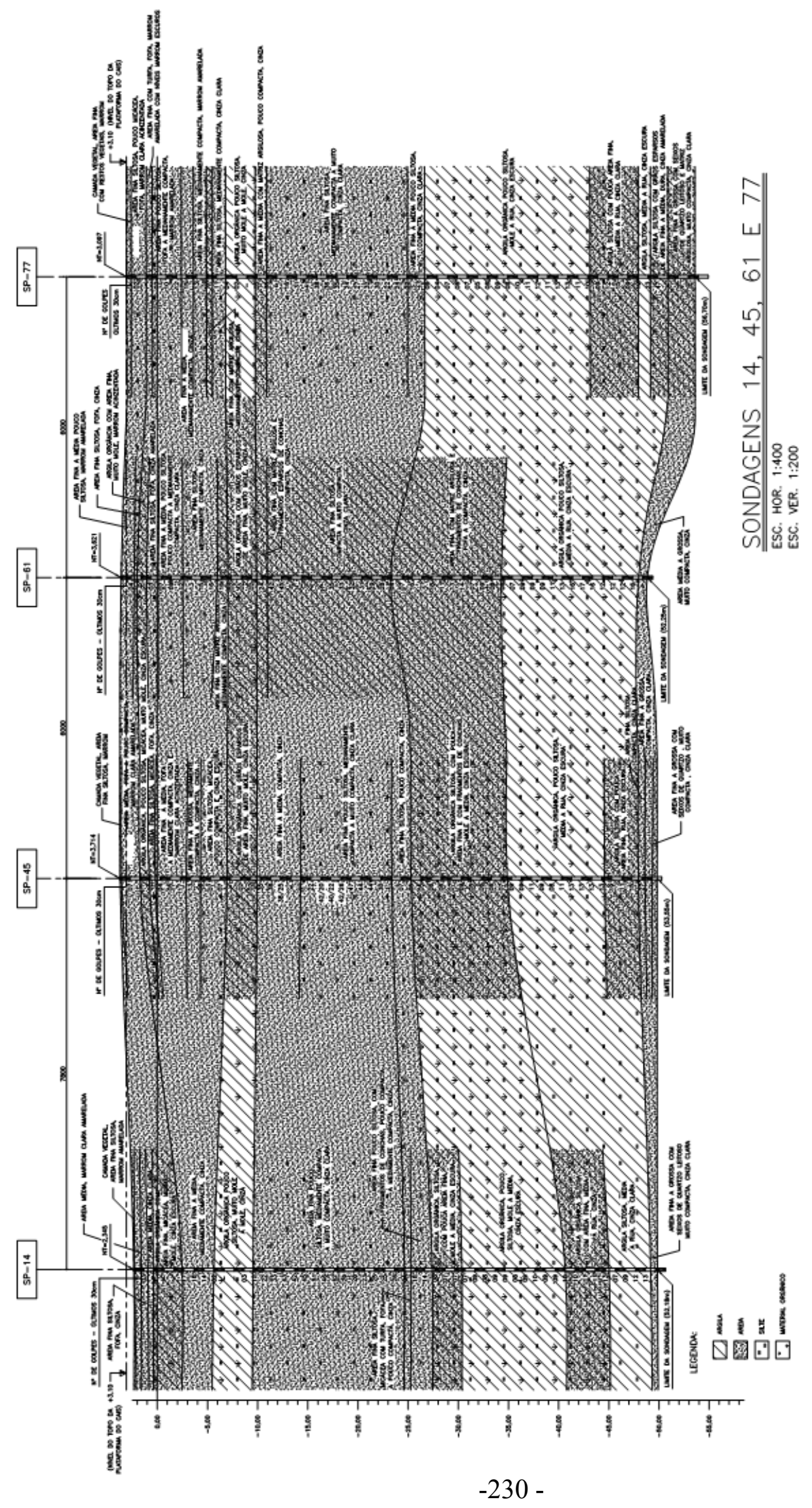

